Portland State University

PDXScholar

Winter 3-8-2013

\title{
Sustainable, Affordable Housing for Older Adults: A Case Study of Factors that Affect Development in Portland, Oregon
}

Alan Kenneth DeLaTorre

Portland State University

Follow this and additional works at: https://pdxscholar.library.pdx.edu/open_access_etds

Part of the Gerontology Commons, Sustainability Commons, and the Urban Studies and Planning Commons

Let us know how access to this document benefits you.

\section{Recommended Citation}

DeLaTorre, Alan Kenneth, "Sustainable, Affordable Housing for Older Adults: A Case Study of Factors that Affect Development in Portland, Oregon" (2013). Dissertations and Theses. Paper 714.

https://doi.org/10.15760/etd.714

This Dissertation is brought to you for free and open access. It has been accepted for inclusion in Dissertations and Theses by an authorized administrator of PDXScholar. Please contact us if we can make this document more accessible: pdxscholar@pdx.edu. 
Sustainable, Affordable Housing for Older Adults:

A Case Study of Factors that Affect Development in Portland, Oregon

by

Alan Kenneth DeLaTorre

A dissertation submitted in partial fulfillment of the requirements for the degree of

Doctor of Philosophy

in

Urban Studies

Dissertation Committee:

Margaret B. Neal, Chair

Nancy J. Chapman

Paula C. Carder

Ellen M. Bassett

Marvin A. Kaiser

Portland State University

2013 
(C) 2013 Alan Kenneth DeLaTorre 


\begin{abstract}
Portland, Oregon, is considered to be a leader in sustainable development. Government agencies, nonprofit organizations, and businesses have been innovators in policymaking and practice that is aimed at creating a more sustainable city. Despite population aging, little is known about how or whether planners and developers consider older persons in terms of sustainable development. Thus, this study examined the case of sustainable, affordable housing developed for low-income adults aged 55 and older.

Interviews with 31 key informants were conducted in order to answer three research questions: What is the meaning of sustainable development in Portland, Oregon, as it pertains to affordable housing for an aging society? How and why has sustainable, affordable housing for older adults been developed in Portland? What are the policies that affect the availability and appropriateness of sustainable, affordable housing for older adults in Portland? The sample included individuals who influenced the creation of senior housing (e.g., urban planners, architects, nonprofit directors) and who were identified either because of their roles within local housing development or through snowball sampling. Six Portland-area developments provided the context for studying how and why sustainable, affordable housing for older adults was planned and created in the city.

The findings suggested that introducing the topic of aging into the discourse of sustainable development will lead to a more robust meaning of the concept, which can aid future research, policy, and practice. Five elements characterizing sustainable housing for older adults were identified: physical accessibility; proximity to community services;
\end{abstract}


infrastructure that connects housing with services; healthy living environments; and highquality social spaces in and near housing developments. The findings also pointed to the need for sustainable development practices to pay attention to social equity and the equitable distribution of affordable housing, including housing for older adults.

Several insights into how sustainable, affordable housing for older adults developed in Portland were gained (e.g., using government subsidies; involving aging experts in integrated design processes; intersectoral partnerships that led to the city becoming an early adopter in greening its affordable housing), as well as why such housing was completed (e.g., there was a collective public-sector response to meet the need for creating sustainable, affordable housing; an emerging culture of sustainable development in Portland; urban and regional planning efforts have begun to address population aging).

However, the amount of sustainable, affordable housing remains insufficient to meet Portland's aging population. Reasons identified include: the absence of specific housing policy attuned to the needs of older adults in Portland; disconnects between housing and health care and supportive services; and lack of integration of older adults in the planning, design, and development processes. Room for innovation and improvement exists in regard to healthy, accessible, green, and affordable housing policies and the development of new models of housing for an aging population. Based on this research, 10 guiding principles of sustainable development for an aging society were proposed to inform future research, as well as planning and development efforts. 


\section{Acknowledgments}

The completion of my graduate studies and this dissertation were made possible by the assistance of many people. I would like to express my deepest gratitude to my committee for their guidance and patience throughout the process. In particular, I would like to thank Dr. Margaret B. Neal, my chairperson and advisor, who has provided me with the instruction and support necessary to grow from a new graduate student into an emerging researcher and professional. I would also like to thank Drs. Nancy Chapman, Paula Carder, Ellen Bassett, Deborah Howe, and Marvin Kaiser who taught me a tremendous amount about research, teaching, and practice in the fields of gerontology, public health, and urban studies and planning. I also wish to thank the faculty and staff of the Institute on Aging, the Schools of Urban Studies and Planning and Community Health, and the College of Urban and Public Affairs, for their support and encouragement. I appreciate the meetings, conversations, phone calls, e-mails, advice, criticisms (both good and bad), and encouragements that have been offered.

To all of the key-informant participants who were involved with this study, I would like to express my gratefulness for the time, suggestions, and expertise that you shared. Portland is a better place due to your contributions and efforts. Also, to my colleagues and collaborators involved with making sustainable, accessible, and agefriendly cities and communities throughout the world; you deserve recognition for your hard work and dedication. 
A very special thank you is due to my family and friends. First and foremost, I would like to thank my wife, Tomoko Kanai DeLaTorre, for your love and support. Even when it meant sacrificing days, nights, and weekends together, you have been my biggest supporter. I would also like to give my sincere appreciation to my grandparents who have been models of wisdom and experience throughout my life. My biggest regret is that my grandmother, Maria Reyes, was not alive to see me complete this journey. And to my sister, Michelle DeLaTorre, who is an inspiration and a fighter; you continue to amaze me. I would like to express my gratitude to my parents, Deborah Tye and Hector DeLaTorre. Without you I would not be here today and I want you to know that I love and respect you both and admire what you have done for our family. I would also like to say thank you to my friends and fellow students. Although communication and time spent together has had its ebbs and flows, you have encouraged and supported me through the good times and bad. Thank you all.

Finally, I would like to acknowledge the older adults in Portland, the United States, and across the world. These men and women fulfill a critically important role in society and should be considered a resource and looked to for opportunities for improving our communities. Moving forward, let me not forget the importance of considering the good for society and serving communities in an attempt to make them better places for the generations to come. 


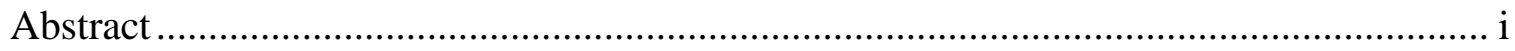

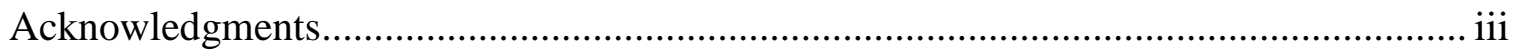

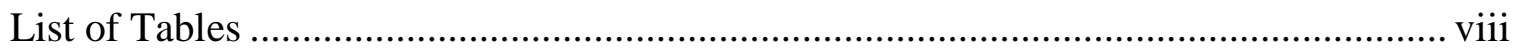

List of Abbreviations ....................................................................................... $\mathrm{xi}$

Chapter 1

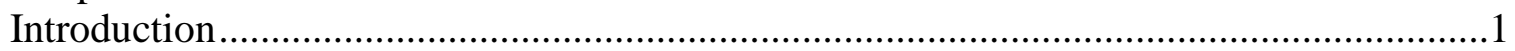

Statement of the Problem ....................................................................................... 1

Purpose of this Study .........................................................................................

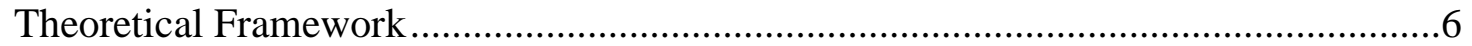

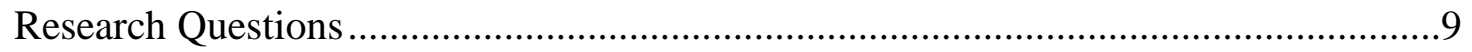

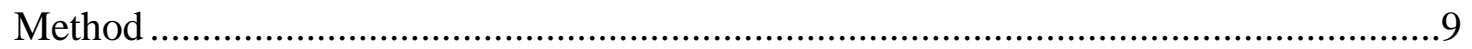

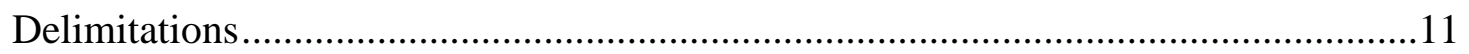

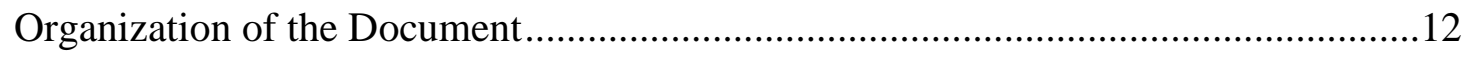

Chapter 2

Review of the Literature ......................................................................................... 14

Our Aging Society: Demographic Trends in the U.S., Oregon, and Portland..............15

Additional Trends within the Aging Population of the U.S. .................................21

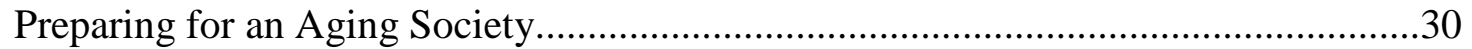

Housing for Older Adults..................................................................................4

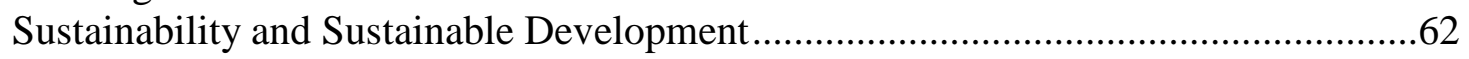

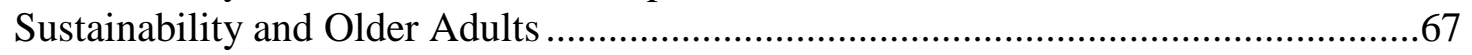

The Policy and Program Landscape for the Planning and Development of

Sustainable, Affordable Housing for Older Adults in Portland ...................................71

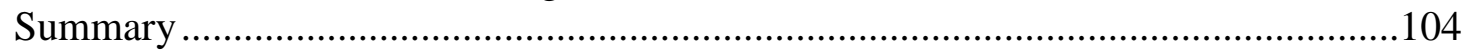

Chapter 3

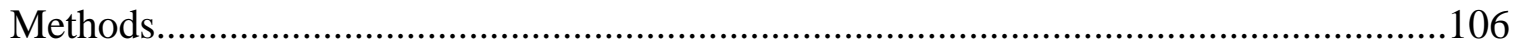

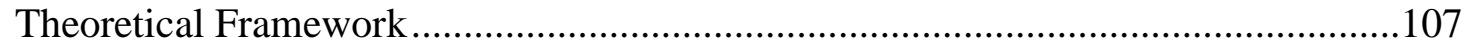

Research Design: Conceptualization ............................................................ 110

Rationale for Using a Qualitative Case Study Approach.......................................113

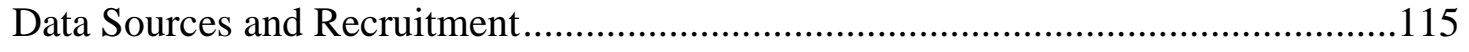

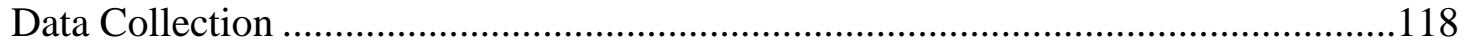

Data Analysis: Development of Codes, Categories, and Themes ...........................119 
Chapter 4

An Overview of Sustainable, Affordable Housing for Older Adults in Portland ............124

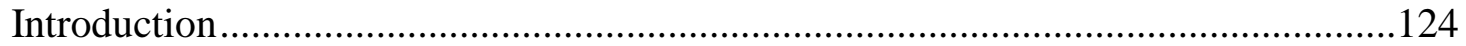

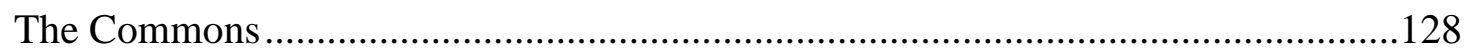

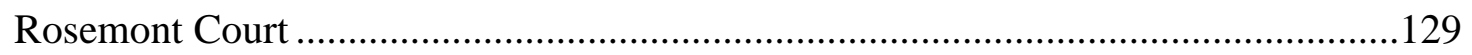

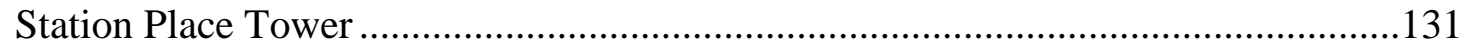

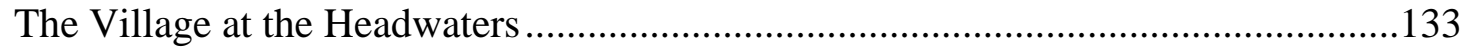

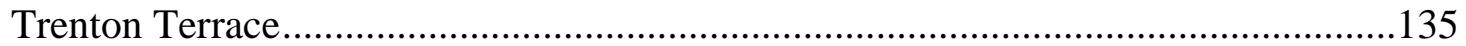

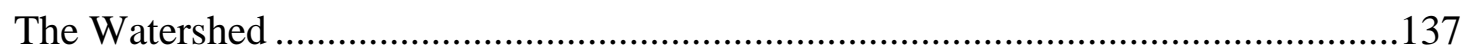

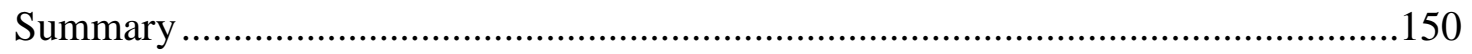

Chapter 5

The Meaning of Sustainable, Affordable Housing for Older Adults .............................153

Descriptions of Sustainable Development ..............................................................155

The Elements of Sustainable Housing and Environments for Older Adults .............159

Further Expansion of the Meaning and Long-term Viability of Sustainable

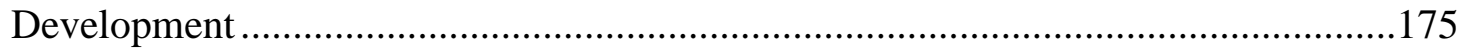

Chapter 6

How and Why Sustainable, Affordable Housing for Older Adults Was Planned for

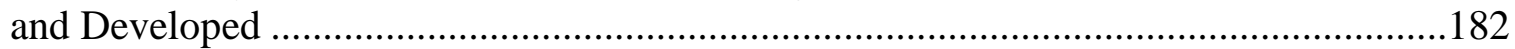

The Roles and Contributions of Actors, Sectors, and Organizations in Projects .......184

Processes and Practices that Contribute to Projects...............................................194

Why Sustainable, Affordable Housing for Older Adults has (and has not) Been

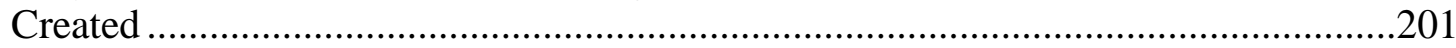

The Social and Cultural Aspects of Sustainable, Affordable Housing for Older

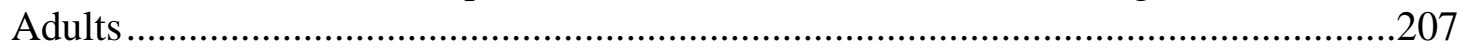

Why More Sustainable, Affordable Housing for Older Adults Has Not Been

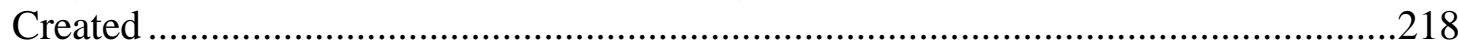

Chapter 7

Understanding Current and Future Policies and Programs Associated with

Sustainable, Affordable Housing for Older Adults.....................................................226

Overview ............................................................................................226

Overview of Data Analysis: Assessment of Policies and Programs that Affect

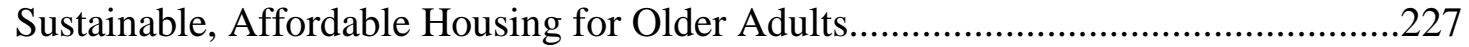

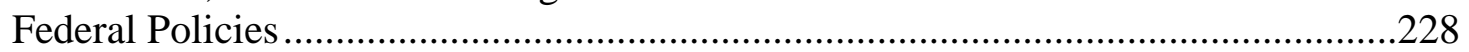

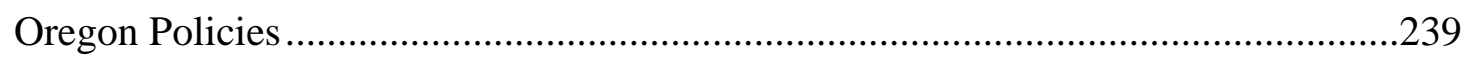

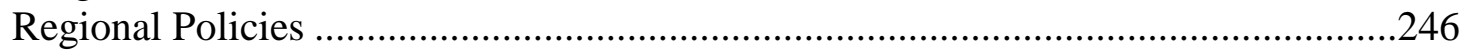

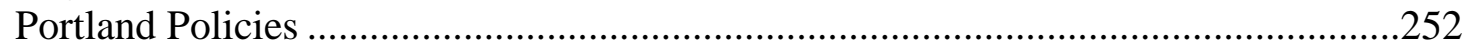

Non-geography-based Polices and Programs to Consider for the Future for Improving Sustainable, Affordable Housing for Older Adults..............................278

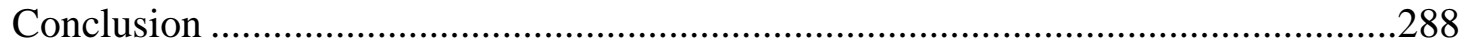




\section{Chapter 8}

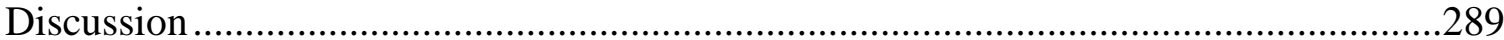

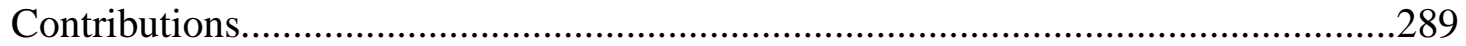

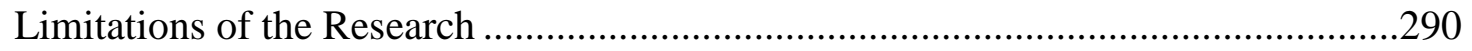

Summary and Implications of Major Findings ......................................................293

The Meaning of Sustainable, Affordable Housing for Older Adults..........................293

How and Why Sustainable, Affordable Housing for Older Adults was Planned

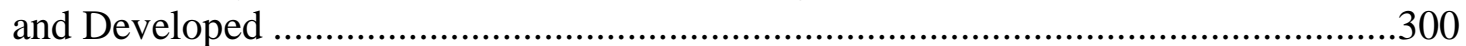

Identified Policies that Have an Impact on Sustainable, Affordable Housing for

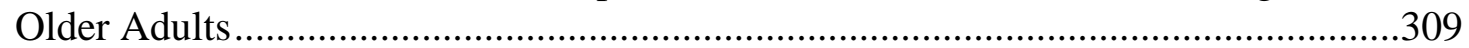

Proposed Guiding Principles of Sustainable Development for an Aging Society.......313

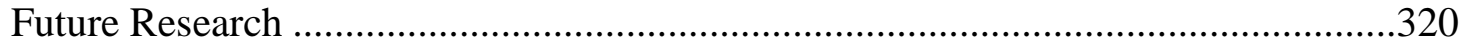

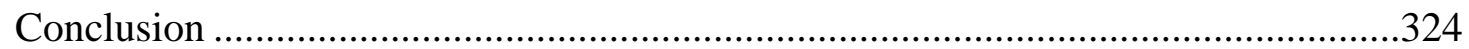

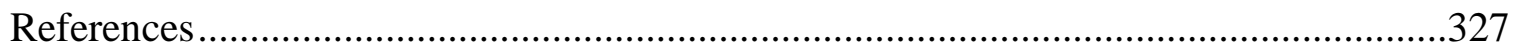

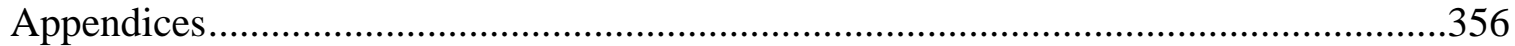

A. Regional Sustainable Development Initiatives Timeline......................................356

B. Human Subjects Research Review Committee Application .....................................360 


\section{List of Tables}

Table 2.1

Overview of the Number, Proportion, and Growth Rates of People Aged 65 and Older in the United States, State of Oregon, and Portland-Vancouver Metropolitan Statistical Area

from 2010-2030

Table 2.2

Median Net Worth by Age of Householder in 1984 and 2009, including the proportional

change over time.

Table 2.3

Six Overlapping Areas of Focus Identified from the World Health Organization's Active Aging Framework and the Eight Domains of the WHO Global Network of Age-friendly

Cities and Communities .46

Table 3.1

Key Informants by Professional Occupation

Table 3.2

Categories Emerging from Data Analysis

Table 4.1

Description of the Six Sustainable, Affordable Housing Developments: Opening Dates,

Number of Units, Minimum Age Requirements, and Affordability Criteria

Table 4.2

Description of the Six Sustainable, Affordable Housing Developments: Sustainable/

Green Building Elements and Funding Sources

Table 4.3

Sources and Uses of Funds for The Watershed

Table 4.4

Summary of Sustainable Elements of The Watershed

Table 7.1

Summary of Federal Policies and Programs Identified as Having a Positive Impact on

Sustainable, Affordable Housing for Older Adults

Table 7.2

Summary of Federal Policies and Programs Identified as Needing Changes to Have a

Positive Impact on Sustainable, Affordable Housing for Older Adults. 
Table 7.3

Summary of Federal Policies and Programs Suggested for Improving Sustainable, Affordable Housing for Older Adults

Table 7.4

Summary of State Policies and Programs Identified as Having a Positive Impact on

Sustainable, Affordable Housing for Older Adults.

Table 7.5

Summary of State Policies and Programs Identified as Needing Changes to Have a

Positive Impact on Sustainable, Affordable Housing for Older Adults....

Table 7.6

Summary of State Policies and Programs Suggested for Improving Sustainable,

Affordable Housing for Older Adults

Table 7.7

Summary of Regional Policies and Programs Identified as Having a Positive Impact on

Sustainable, Affordable Housing for Older Adults.

Table 7.8

Summary of Regional Policies and Programs Identified as Needing Changes to Have a

Positive Impact on Sustainable, Affordable Housing for Older Adults.

Table 7.9

Summary of City Policies and Programs Identified as Having a Positive Impact on Sustainable, Affordable Housing for Older Adults.

Table 7.10

Summary of City Policies and Programs Identified as Needing Changes to Have a Positive Impact on Sustainable, Affordable Housing for Older Adults.

Table 7.11

Summary of City Code Changes Identified as Needing Changes to Have a Positive Impact on Sustainable, Affordable Housing for Older Adults

Table 7.12

Summary of City Policies and Programs Suggested for Improving Sustainable, Affordable Housing for Older Adults

Table 7.13

Summary of Other (Non-geography-based) Innovative Policies and Programs Suggested

for Improving Sustainable, Affordable Housing for Older Adults 
Table 8.1

Proposed Guiding Principles of Sustainable Development for an Aging Society...........319 


\section{List of Abbreviations}

$\begin{array}{ll}\text { ABA } & \text { Architectural Barriers Act } \\ \text { ADA } & \text { Americans with Disabilities Act } \\ \text { ADL } & \text { Activities of Daily Living } \\ \text { ADS } & \text { Multnomah County Aging and Disability Services } \\ \text { ADU } & \text { Accessory Dwelling Units } \\ \text { AMI } & \text { Area Median Income } \\ \text { BCD } & \text { Oregon Building Codes Division } \\ \text { BDS } & \text { Bureau of Development Services } \\ \text { BES } & \text { Bureau of Environmental Services } \\ \text { BEST } & \text { Businesses for an Environmentally Sustainable Tomorrow } \\ \text { BPS } & \text { Bureau of Planning and Sustainability } \\ \text { CAP } & \text { Climate Action Plan } \\ \text { CDBG } & \text { Community Development Block Grant program } \\ \text { CDC } & \text { Community Development Corporations } \\ \text { CPAH } & \text { Community Partners for Affordable Housing } \\ \text { DLCD } & \text { Oregon Department of Land Conservation and Development } \\ \text { DOT } & \text { U.S. Department of Transportation } \\ \text { EPA } & \text { U.S. Environmental Protection Agency } \\ \text { ERV } & \text { Energy Recovery Ventilation } \\ \text { FIFARS } & \text { Federal Interagency Forum on Aging-Related Statistics } \\ \text { HOME } & \text { HOME Investment Partnership Programs } \\ \text { HOPA } & \text { Housing for Older Persons Act } \\ \text { HSRRC } & \text { Human Subjects Research Review Committee } \\ \text { HTF } & \text { National Housing Trust Fund } \\ \text { HUD } & \text { U.S. Department of Housing and Urban Development } \\ \text { HVAC } & \text { Heating, Ventilation, and Air Conditioning } \\ \text { IRB } & \text { Institutional Review Board } \\ \text { LEED } & \text { Leadership in Energy and Environmental Design } \\ \text { LIHTC } & \text { Low Income Housing Tax Credit } \\ \text { MFI } & \text { Median Family Income } \\ \text { MPO } & \text { Metropolitan Planning Organization } \\ \text { MSA } & \text { Metropolitan Statistical Area } \\ \text { NORC } & \text { Naturally Occurring Retirement Community } \\ \text { NSP } & \text { Neighborhood Stabilization Programs } \\ \text { OAHTC } & \text { Oregon Affordable Housing Tax Credits } \\ \text { OHCS } & \text { Oregon Housing and Community Services } \\ \text { OPI } & \text { Oregon Project Independence } \\ \text { OSD } & \text { Portland Office of Sustainable Development } \\ \text { PBOT } & \text { Portland Bureau of Transportation } \\ \text { PDC } & \text { Portland Development Commission } \\ \text { PHB } & \text { Portland Housing Bureau } \\ \text { PI } & \text { Principal Investigator } \\ & \end{array}$




$\begin{array}{ll}\text { PPR } & \text { Portland Parks and Recreation } \\ \text { PSU } & \text { Portland State University } \\ \text { REACH } & \text { REACH Community Development Inc. } \\ \text { RSP } & \text { Research and Strategic Partnerships } \\ \text { SDC } & \text { System Development Charges } \\ \text { TIF } & \text { Tax Increment Financing } \\ \text { TOD } & \text { Transit-oriented Development } \\ \text { TriMet } & \text { Tri-County Metropolitan Transportation District of Oregon } \\ \text { UGB } & \text { Urban Growth Boundary } \\ \text { URA } & \text { Urban Renewal Area } \\ \text { VASH } & \text { Veteran Affairs Supported Housing } \\ \text { VOC } & \text { Volatile Organic Compound } \\ \text { WHO } & \text { World Health Organization }\end{array}$




\section{Chapter 1}

\section{Introduction}

"To be sustainable, cities must provide the structures and services to support their residents' wellbeing...older people in particular require supportive and enabling living environments to compensate for physical and social changes associated with ageing" (World Health Organization (WHO), 2007a, p. 4). This research is a qualitative case study that explores myriad factors that have had an impact on the planning and development of housing in Portland, Oregon, that is considered to be sustainable, affordable, and intended for the use of those aged 55 and older. Those factors include the evolving understanding of the relationship between sustainability, aging, and affordable housing, as well as the confluence of people, processes, and policies that lead to the planning and development of sustainable housing and environments. The findings from this study inform the creation of a set of proposed guiding principles of sustainable development for an aging society that will offer future directions for research, practice, and policy making in Portland and beyond.

\section{Statement of the Problem}

According to the U.S. Census Bureau (2008), in the 20-year span from 2010 to 2030 the U.S. is predicted to witness a 79\% growth in the number of people aged 65 and older. In January, 2011, the first Baby Boomer-those who were born between 1946 and 1964-turned 65, and the aging of this cohort has, and will continue to, dramatically change the U.S. age structure (Federal Interagency Forum on Aging-Related Statistics 
(FIFARS), 2012). Moving forward, Portland, Oregon, the U.S., and the world will face the unprecedented aging of populations and the need to address the challenges and opportunities that will accompany the aging of society (Kinsella \& He, 2009).

Based on a review of literature it is clear that available housing for older adults does not meet their current needs, nor is it expected to meet the increasing needs that will accompany the growing number and proportion of older adults in the U.S. (Commission on Affordable Housing and Health Facility Needs for Seniors in the $21^{\text {st }}$ Century, 2002; Farber, Shinkle, Lynott, Fox-Grage, \& Harrell, 2011; Perl, 2010; Shactman \& Altman, 2002; WHO, 2007a). Furthermore, a call to action has been issued by national policy experts to planners and policy makers specifically highlighting the need to prepare for population aging through urban planning and the development of housing that is affordable, well-designed and close in proximity to essential services and infrastructure, and intended to integrate a diversifying population while fostering social well-being (Farber et al., 2011).

In Planning for an Aging Society (Howe, Chapman, \& Baggett, 1994) it is suggested that a community's ability to effectively respond to the needs of an aging society depends on how well integrated those needs are in planning efforts. The authors explained that "creativity in defining opportunities to make improvements will maximize the use of both public and private resources" (1994, p. 6). Ten years later, Giuliano (2004) detailed the need for research that addresses how the development community responds to aging-specific issues such as accessibility and mobility, and also, how the public sector plans for and encourages age-appropriate development. 
For more than a decade there has been a substantial growth in efforts that are aimed at improving housing and environments (both physical and social) in anticipation of the aging of the population, including AARP's focus on livable communities for an aging society (AARP, 2011; see also AARP, 2000, 2005a, 2005b; Pollack, 2000) and the WHO's focus on age-friendly cities and communities (WHO, 2007a, 2012). Several important findings emerged from the Portland-based age-friendly study that was a part of the larger WHO study (Neal \& DeLaTorre, 2007a, 2007b). First, every category of participant (older adults, caregivers, and providers of service) identified a lack of affordable housing for an aging society. Second, according to respondents, the housing that was available was disconnected from important services and infrastructure needed by older adults to maintain independence and quality of life. Third, housing was not planned for and developed in a way that met the needs of aging individuals. Finally, suggestions for improving housing for an aging society were offered, including changes in planning and development practices and policies that influence housing quantity and quality.

Around the same time that livable community and age-friendly city initiatives were underway, efforts aimed at sustainable development became more prevalent in policy and practice in many jurisdictions. Sustainable development has been broadly detailed as an attempt to meet the needs of the current generation without compromising the ability of future generations to meet their needs (Oregon Sustainability Act, 2001; United Nations, 1987). Policies from the State of Oregon and the City of Portland have focused on requiring sustainable development practices, and Portland, in particular, has been noted to be making a push to become the nation's "sustainability capital" 
(Giegerich, 2008, April 27). At the state level, Oregon's Department of Land

Conservation and Development (2012) specifically aims to foster sustainable, vibrant communities throughout Oregon, and in 2009, the City of Portland integrated its Bureau of Planning and Office of Sustainable Development into the Bureau of Planning and Sustainability to better align the complementary efforts (City of Portland, 2009a).

However, even with the concurrent attempts to plan for and develop housing and environments that are both sustainable and beneficial for an aging population, a disconnect appears to exist between the two efforts. Although both undertakings require forward-looking approaches to policy, planning, and implementation, they have not been looked at together in the academic literature. It seems logical to assume that the rapid aging of society would be integral to sustainable development based solely on the temporal component of sustainability: providing opportunities for current and future generations. However, very little attention has been paid to incorporating population aging into sustainable development research, policies, and practices. More specifically, there has been no research to date that has explored the intersection of the planning and development of affordable housing, housing for older adults, and housing development that is considered to be sustainable.

\section{Purpose of this Study}

This study had three primary purposes: (1) to explore the meaning of sustainable, affordable housing for older adults; (2) to better understand how and why sustainable, affordable housing for older adults was planned for and developed in Portland; and (3) to identify the policies and programs that have had an impact on the availability and 
appropriateness of such housing. As was detailed in the statement of the problem above, there is a growing need for affordable and appropriate housing for older adults in Portland, Oregon, other municipalities throughout the U.S., and indeed the world. Additionally, when decision makers are implementing sustainable development policies and programs they must pay more attention to future demographic shifts such as population aging.

Portland provides an ideal setting for a case study of sustainable development, as six developments were identified within the city limits that are specific to people aged 55 and older, affordable by government standards, and have elements that are considered to be sustainable. Additionally, because of a strong push for sustainable development in Portland, the city is home to many experts who were able to elucidate how and why certain factors affected the planning and development of sustainable, affordable housing for older adults. However, extant developments and the presence of experts still have not resulted in the appropriate quality or quantity of sustainable, affordable housing for an aging Portland, and changes are needed to meet these growing needs.

If sustainable housing development is intended to meet future needs, that development must consider the specific housing needs of an aging society before it is too late. Jon Pynoos, in an interview for National Public Radio (Norris, 2011), explained that most housing in the U.S. can be considered "Peter Pan" housing, as it is designed for people who are never going to grow old. Although there are early adopters who grasp the meaning and needs of housing for an aging society, most municipalities have yet to establish policy, practices, and funding mechanisms that support the rapidly changing 
demographics. In Portland and nearby communities, public responses aimed at developing sustainable, affordable housing have been focused on issues that have taken precedence over an aging population, such as homelessness and workforce housing (Cities of Portland and Gresham, and Multnomah County, 2011). Moving forward, public responses must consider demographic projections if they are to address the growing needs of older adults.

This study makes several important contributions. First, this research contributes to the literature in gerontology, urban planning, public health, and urban studies by improving understanding of sustainable development as it pertains to affordable housing for an aging society. It explores the meanings and definitions associated with sustainable, affordable housing for older adults, and it highlights how and why planning and development of such housing has occurred in Portland. Second, this research seeks to be translational in that it is intended to inform future policy making and program implementation specifically in Portland, particularly in the City's efforts to plan and develop sustainable housing for its aging population. Finally, a third contribution of this study is the development of guiding principles of sustainable development for an aging society which can be used to guide future research, planning and development practices, and policy in Portland and perhaps in communities throughout the world.

\section{Theoretical Framework}

This research has been informed by the ecological perspectives in the fields of gerontology and public health (Altman, 1975; Lawton, 1986; Lawton \& Nahemow, 1973; Moos \& Lemke, 1996; Sallis, 2003). Lawton (1986), a seminal author who led the 
development of the ecology of aging perspective in gerontology, specifically detailed the need to consider multiple contributing factors to the health and well-being of older adults, including aspects of the social and physical environments. In the field of public health, the ecological perspective has been used to guide the building of health interventions and healthy communities by detailing the various factors that contribute to the health and well-being of individuals and society (Satariano, 2006; WHO, 2010). Both ecological perspectives considered how individuals and groups of people interact with various environments, whether they be social environments (e.g., personal interactions, cultural values), physical environments (e.g., sidewalks, housing units), or policy environments (e.g., affordable housing programs, comprehensive planning efforts).

Stokols (1992) highlighted the need to integrate the ecological perspective into research efforts in an attempt to move beyond the scope of individual behavior change and to focus on societal-level interventions (i.e., upstream approaches) that examine policy changes and other interventions along an environmental continuum from microlevel settings (e.g., housing facilities) to macro-level settings (e.g., transportation systems, government programs). An example from the literature clarifies some aspects of the environmental continuum: An architect or planner who is designing a housing facility for older adults needs to consider macro-level issues, such as building and zoning codes, potential biological changes that occur with age, such as vision loss and reduced mobility, and aspects affecting public health, such as healthy building materials and safe and accessible design features (Stokols, 1992). 
Cunningham and Michael (2004) issued a call to action suggesting that it is time to move beyond basic research and individual interventions and toward the creation of policies and strategies that aim to achieve healthier communities for older adults. Satariano and McAuley (2003) posited that translational research, such as that described by Cunningham and Michael, should consider social, biological, behavioral, and environmental factors and should attempt to understand the dynamic interplay over time that occurs between older people and their environments. Greenfield (2012) explained that utilizing an ecological framework to advance research, policy, and practice related to initiatives like livable and age-friendly communities would help to keep the various efforts from becoming fragmented from one another.

The ecological perspectives from gerontology and public health informed the present research in several ways. First, pertinent literature informed the development of research questions that focused on understanding how several aspects of housing environments-physical, social, and cultural-were influenced by various actors, regulations, and societal trends. Second, the genesis of this study was research conducted in Portland that was a part of the WHO's global Age-friendly Cities project (Neal \& DeLaTorre, 2007a, 2007b; WHO, 2007a, 2007b). Those research findings detailed a range of ecological factors that were seen as age-friendly features and barriers for both individuals and the general population of Portland; suggestions were also made as to how barriers could be removed or mitigated (e.g., increasing affordable housing, improving housing options). Finally, the ecological perspective was used in creating guiding principles of sustainable development for an aging society. The principles of the 
ecological perspective were examined in combination with findings from this research, suggestions emerging from the findings of the Portland-specific WHO Age-friendly Cities project, elements of sustainable urban development (Wheeler, 2000), the WHO's active aging framework (WHO, 2002) and its age-friendly domains (WHO, 2007a), and research suggestions from the literature in gerontology (Laws, 1995) and urban planning (Giuliano, 2004; Howe et al., 1994).

\section{Research Questions}

The following research questions were asked in order to determine the factors that had an impact on the planning and development of sustainable, affordable housing for older adults:

(1) What is the meaning of sustainable development in Portland, Oregon, as it pertains to affordable housing for an aging society?

(2) How and why has sustainable, affordable housing for older adults been developed in Portland?

(3) What are the policies that have an impact on the availability and appropriateness of sustainable, affordable housing for older adults in Portland?

\section{Method}

In order to answer the research questions, a qualitative case study approach was taken. Primary data were collected from 31 key informants in public, for-profit, and nonprofit organizations. A snowball sampling technique was used to identify participants, with the initial interviews identified from among the author's professional contacts. The remaining contacts were suggested by participants themselves during or following their interviews. The individuals interviewed represented myriad professional occupations including directors of community development corporations, architects, housing 
developers, consultants and academics in the field of housing for older adults, management professionals, current and past elected officials, and staff from Portland's Bureau of Planning and Sustainability (urban planners and green building experts), the Portland Housing Bureau, the Housing Authority of Portland, regional and county government, and the Portland Development Commission.

A conventional content analysis method was used (rather than a directed or summative approach). According to Hsieh and Shannon (2005) conventional content analysis is generally used with study designs aiming to describe a phenomenon when theory or literature is limited, as is the case with sustainable, affordable housing development for older adults; analysis occurs with repeated reading of all data in an effort to form codes, categories, and meaningful clusters. In this research, several iterations of analysis and interpretation occurred. The initial coding of the interview transcripts led to the identification of over 100 unique codes. Those codes were then used to develop 17 distinct categories that addressed the three main research questions. Those 17 categories were then used to create "codes" (i.e., abbreviated code words which acted as a storage area for all words, terms, and quotations) in the computer program Atlas.ti 6 (Atlas.ti) to facilitate further analysis of the interview transcripts. Overall, 903 informant quotations were sorted into the 17 categories. A final analysis within each of the 17 categories led to a meaningful clustering of findings that answered each of the research questions.

The final stage of the research design was an assessment of policies that had an impact on the planning and development of sustainable, affordable housing for older adults in Portland. In response to questions asked to key informants, relevant housing- 
related policies were identified by respondents at the national, state, regional, and local levels that fell into three categories: policies that worked; policies that needed to be improved; and policies that did not exist but that should be considered in the future. In the concluding chapter, the findings from this study were considered, along with existing literature, to create a set of proposed guiding principles of sustainable development for an aging society.

\section{Delimitations}

This case study was limited to the geographic and political boundaries of the City of Portland, rather than the Portland metropolitan region, so that relevant policies and practices could be examined in the sole municipality. Additionally, although this study focused on housing, it also included elements of the surrounding environment that have a functional relationship to housing; for example, adjoining infrastructure, transportation options, and access to services were considered important aspects of the housing environment that go "beyond the walls" of a housing unit.

Although the findings are specific to the city of Portland, it is likely that some of the results will be applicable to other cities and regions. For example, the policy landscape that is explored in the literature review examines federal, state, regional, and local policies and may have relevance to the planning and development of sustainable, affordable housing for older adults in other communities. Also, having a better understanding of the meaning of sustainable, affordable housing for older adults, as well as the practices and processes that are detailed by respondents, may be relevant in a variety of other communities. 
Finally, the views and experiences of older adults themselves were not directly a part of this research, although this perspective was critical in understanding the successes and failures of housing and communities that have been planned and developed for older adults. In particular, the present research was informed by the views of 55 participants in the Age-friendly Cities project in Portland and the findings detailed the day-to-day experiences of older adults, caregivers acting as a proxy for older adults, and providers of services to older adults with respect to eight domains: outdoor spaces and buildings, transportation, housing, respect and social inclusion, social participation, communication and information, civic participation and employment, and community support and health services (Neal \& DeLaTorre, 2007a, 2007b).

\section{Organization of the Document}

Chapter 2 reviews the relevant literature for this research, including: demographic trends depicting the aging of society; efforts to prepare for an aging society; and an overview of sustainable development policies and practices, which includes a review of the landscape of policies in place at the federal, state, regional, and local levels.

Chapter 3 details the theoretical framework and research methods used for this research. A rationale is given for the use of a case study approach and qualitative methods.

Chapter 4 provides an overview of the six developments that are considered to offer sustainable, affordable housing for older adults. It also provides an in-depth look at one of these developments, The Watershed, based on interviews with several key 
informants involved with the project and materials that were made available to the researcher.

Chapters 5 through 7 report findings addressing the three research questions. Chapter 5 explores the meaning of sustainable, affordable housing for older adults based on the responses of the key informants. In particular it looks at how respondents described sustainable development, the perceived elements of sustainable housing and environments for older adults, and exploring the evolution of the term sustainable.

Chapter 6 details how and why sustainable development for older adults is developed through an exploration of the roles that various sectors play in planning and development, as well as the reasons that developments are produced.

Chapter 7 focuses on the policies that that are connected to the planning and development of the housing being examined in this research. An assessment is conducted to identify policies that have had a positive impact on developments, those that need changes, and policies recommendations to consider in the future.

Chapter 8 summarizes the key findings, discusses contributions and limitations of the dissertation, and details future research needs. Additionally, based on the study's findings, a set of proposed guiding principles of sustainable development for an aging society is offered. 


\section{Chapter 2}

\section{Review of the Literature}

This research approached the topic of sustainable, affordable housing for older adults based on the literature in several fields of study, including social and environmental gerontology, public health, the emerging research on sustainability and sustainable development, urban studies, and urban and regional planning. This review of literature identified a gap in the empirical research. To date, no research exists that has focused on understanding the relationship between sustainability and an aging society, specifically as it pertains to the planning and development of affordable, sustainable housing for older adults. Additionally, there is insufficient literature that explains the policies, programs, processes, and practices that impact the planning and development of sustainable, affordable housing for older adults.

A number of demographic trends highlight the rapid aging of society at the national, state, and local levels. The demographic imperative caused by this unprecedented population aging calls for attention to policies and programs that can improve the well-being and quality of life of older adults. Particular attention in this review is given to the literature in social and environmental gerontology and public health that has focused on active and healthy aging. An overview of ecological models is provided in an attempt to understand the relationship between older adults and their housing and environments, from the micro to the macro level. Literature pertaining to sustainable development is also explored, including the concept's evolution and its 
relationship to older adults. Finally, the policy landscape related to sustainable, affordable housing for older adults is reviewed by focusing on policies and programs that affect housing development in Portland, from federal legislation (e.g., affordable housing allocations) to city and regional policies and programs (e.g., comprehensive planning efforts).

\section{Our Aging Society: Demographic Trends in the U.S., Oregon, and Portland}

The United States. The irreversible rate of population aging will shape national, regional, and local economics and policymaking unlike any other demographic shift that the U.S. has witnessed (Congressional Budget Office, 2005; Kinsella \& He, 2009; Mrsnik, 2010). Based on 2010 population estimates (U.S. Census Bureau, 2012) and 2030 population projections (U.S. Census Bureau, 2008), in the 20-year span from 2010 to 2030, the U.S. will see an increase in the overall number and proportion of those 65 and older, from 40,267,984 in 2010 (approximately $13.0 \%$ of the population) to $72,092,000$ in 2030 (approximately $19.3 \%$ of the population). This represents a $79.0 \%$ growth in the overall number of those aged 65 and older from 2010 to 2030 and a $48.0 \%$ growth in the proportion of those older adults during that same time period (see Table

2.1). For comparison, according to the U.S. Census Bureau estimates (2012) and projections (2008), the total population of the U.S. is expected to increase from approximately $308,745,538$ people in 2010 to $373,504,000$ in 2030 , which represents a $21.0 \%$ growth in the total population, and the population aged $0-64$ is expected to increase from $268,477,554$ in 2010 to $301,412,000$ in 2030 , an expected growth rate of $12.3 \%$ during the 20-year period. This unprecedented and disproportionate aging of the 
U.S. population will be driven largely by the aging of the Baby Boomers. The first members of that age group (those born between the years 1946 and 1964) turned 65 in January, 2011 (FIFARS, 2012).

According to comparisons between 2010 population estimates (U.S. Census Bureau, 2012) and interim state population projections by the U.S. Census Bureau for 2030 (2005), in the 20-year time period between 2010 and 2030 every state will have witnessed an increase in both the number and proportion of those aged 65 and older, except the District of Columbia, which is expected to see a rise in proportion of the 65 and older population from $11.5 \%$ to $13.4 \%$, but an overall decline in the number of that population from 61,036 to 58,238. Based on U.S. Census Bureau (2012) demographic profiles, in 2010, the proportion of those aged 65 and older in individual states in 2010 ranged from a low of $7.7 \%$ in Alaska, to a high of $17.3 \%$ in Florida; in 2030, the projections included a low of $13.2 \%$ in Utah and a high of $27.1 \%$ in Florida (U.S. Census Bureau, 2005).

Comparing 2010 population estimates (U.S. Census Bureau, 2012) and interim state projections for 2030 (U.S. Census Bureau, 2005) several trends should be noted during the 20-year period: The lowest rate of growth in the absolute number of older adults (not including the District of Columbia) was projected to occur in West Virginia, where an increase of $43.4 \%$ is expected to occur, based on the projected rise in the number of those aged 65 and older from 297,404 in 2010 to 426,443 in 2030. On the other end, Arizona is expected to witness a $169.0 \%$ increase is the number of older adults, as the state's population of older adults is projected to rise from 881,831 to $2,371,354$ 
during the same 20-year period. The growth in the proportion of older adults from 2010 to 2030 was projected to range from a low of $31.0 \%$ in Oregon (from $13.9 \%$ in 2010 to $18.2 \%$ in 2030) to a high of $113.1 \%$ in Wyoming (from $12.4 \%$ in 2010 to $26.5 \%$ in 2030).

The State of Oregon. In 2010, Oregon was projected to have $13.9 \%$ of its population aged 65 and older, which is the slightly higher than the U.S. proportion of 13.0\% (U.S. Census Bureau, 2012); Oregon was projected to have 533,533 adults aged 65 and older in 2010, a number that the U.S. Census Bureau (2005) expected to grow to 881,957 in 2030 (approximately $18.2 \%$ of the population). The expected increase in older adults represents a $65.3 \%$ growth in the overall number of those 65 and older (which is lower than the $79.0 \%$ expected in the U.S.), while the projected rate of growth in the proportion of older adults in Oregon from 2010 to 2030 (31.0\%) is lower than the $48.0 \%$ increase in the U.S. (see Table 2.1).

The reason for Oregon's low projected rate of growth in the proportion of older adults is not clearly explained, but a demographic profile of the U.S. (Shrestha \& Heisler, 2011) offered some insight: two major drivers of future growth in the U.S. are identified as fertility and immigration; Oregon's projected immigration patterns differ from those of other states. Oregon's Office of Economic Analysis (2011) showed that minorities in Oregon have been growing at a faster pace than is being witnessed at the national level, including the rapid growth of Hispanics in the state; the report also noted that Hispanics tend to be recent immigrants with large families with a high proportion of children and young adults. 
This demographic shift may contribute to the lower projected proportional growth of Oregon's population aged 65 and older. It is important to note that living arrangements for Hispanics are different from those of other populations. Bicket and Mitra (2009) called for policy makers to focus on the living arrangements of a diversifying and growing elder population in the U.S. and explained that Hispanics aged 65 and older are less likely to live alone than non-Hispanic whites and Blacks and that they are more likely than those groups to live with other relatives and non-relatives. Thus, assumptions about housing configurations for a diversifying population in Oregon may need to be reconsidered.

Overall demographic changes were discussed at a joint Oregon-Washington housing summit that was convened in Portland by the American Planning Association (2004, October 6), including comments made by Richard Bjelland, a representative from the Oregon Housing and Community Services department. Bjelland, who developed models to assist local governments in assessing housing needs, came to several conclusions: Every Oregon county had a "significant affordable housing problem;" aspects of age were correlated with housing trends (e.g., "The older you get the more likely you will be a homeowner, until you hit 75 , and then you are more likely to become a renter."); and natural growth in the Hispanic population will fuel housing demand in single-family, multi-person, and non-family households (p. 4).

The Portland metropolitan region. According to Metro (2009), the PortlandVancouver Metropolitan Statistical Area will witness a growth in the number and proportion of its entire population, as well as the number and proportion of those aged 65 
and older from 2010-2030 (all reported population characteristics in this paragraph are from Metro's 2009 population forecasts). The entire population (i.e., all ages) is expected to grow from $2,265,500$ in 2010 to $3,050,100$ in 2030 , a growth of $34.6 \%$. The expected increases in the 65 and older population includes a rise from approximately 251,000 people in $2010(11.1 \%)$ to approximately 518,100 people in $2030(17.0 \%)$, which represents a 106.4\% growth in the overall number of those aged 65 and older and a $53.3 \%$ growth in the proportion of older people. These numbers can also be compared to the number of those aged 0-64, which will grow from approximately 2,014,500 in 2010 ( $88.9 \%$ of the population) to $2,532,000$ in 2030 ( $83.0 \%$ of the population); this represents an increase in the number of those aged $0-64$ of $25.7 \%$ and a decline in their proportion of $-6.6 \%$ during the 20-year period. Compared to Oregon and the U.S., the PortlandVancouver region is thus expected to see a larger growth in both the number of older adults and the proportion of older adults from 2010 to 2030, but will retain a lower overall proportion of those aged 65 and older in 2030, at 17\% of the population (see Table 2.1). 


\section{Table 2.1}

Overview of the Number, Proportion, and Growth Rates of People Aged 65 and Older in the U.S., State of Oregon, and Portland-Vancouver Metropolitan Statistical Area (MSA) from 2010-2030 (bold values represent the highest value in comparison to other geographies)

\begin{tabular}{lccc}
\hline \multicolumn{1}{c}{ Category } & $\begin{array}{c}\text { United } \\
\text { States }\end{array}$ & $\begin{array}{c}\text { State of } \\
\text { Oregon }\end{array}$ & $\begin{array}{c}\text { Portland- } \\
\text { Vancouver } \\
\text { MSA }\end{array}$ \\
\hline Number of persons aged 65+ in 2010 & $\mathbf{4 0 , 2 6 7 , 9 8 4}$ & 533,533 & 251,000 \\
\hline Proportion of persons aged 65+ in 2010 & $13.0 \%$ & $\mathbf{1 3 . 9 \%}$ & $11.1 \%$ \\
\hline Number of persons aged 65+ in 2030 & $\mathbf{7 2 , 0 9 2 , 0 0 0}$ & 881,957 & 518,100 \\
\hline Proportion of persons aged 65+ in 2030 & $\mathbf{1 9 . 3 \%}$ & $18.2 \%$ & $17.0 \%$ \\
\hline $\begin{array}{l}\text { Growth rate in number of persons aged } \\
\text { 65+ from 2010 to 2030 }\end{array}$ & $79.0 \%$ & $65.3 \%$ & $\mathbf{1 0 6 . 4 \%}$ \\
\hline $\begin{array}{l}\text { Growth rate in proportion of persons } \\
\text { aged 65+ from 2010 to 2030 }\end{array}$ & $48.0 \%$ & $31.0 \%$ & $\mathbf{5 3 . 3 \%}$ \\
\hline
\end{tabular}

Sources: United States: 2010 estimates are from U.S. Census Bureau's (2012) The Statistical Abstract of the United States, and 2030 projections are from U.S. Census Bureau's (2008) 2008 National Population Projections; State of Oregon: 2010 estimates are from U.S. Census Bureau's (2012) The Statistical Abstract of the United States, and 2030 projections are from U.S. Census Bureau's (2005) Interim State Population Projections; and Portland-Vancouver MSA: all forecasts are from Metro's (2009) 20 and 50 Year Regional Population and Employment Range Forecasts.

A report conducted for Metro, Portland's regional government, detailed some of the housing and spatial location patterns related to the aging of the Portland-Vancouver Metropolitan region (Neal, M.B., Chapman, N., Dill, J., Sharkova, I., DeLaTorre, A., Sullivan, K., Kanai, T., \& Martin, S., 2006). In particular, older adults in the region were found to be similar to those in the U.S. as a whole, in that they were less likely to move as they grew older, but when they did, they tended to move into higher-density housing than middle-aged adults. Additionally, Portland ranked highly for severe housing cost burden, which was seen to limit housing options, especially for renters, who typically have lower incomes than owners. It is also important to note that Hispanics aged 65 and 
older were less likely to own homes in the Portland region than similarly-aged white and Asian households (U.S. Census Bureau, 2003).

\section{Additional Trends within the Aging Population of the U.S.}

Several important trends should be noted within the larger population of those 65 and older and should be considered by researchers and policy makers moving forward, including those related to subpopulations that vary by age, health, functional ability, race and ethnicity, and socioeconomic factors.

The growth of the "oldest old." The category of the "oldest old" has generally been considered to consist of those aged 85 and older. The 85 and older population in the U.S. is projected to more than double, from 4.7 million in 2003 to 9.6 million in 2030 , and then more than double again, to 20.9 million in 2050 (He, Sengupta, Velkoff, \& DeBarros, 2005). More recently, He and Muenchrath (2011) noted that the 90-and-older population has grown and will continue to grow faster than those aged 85-89 and that relatively little is known about this age group's characteristics. These authors analyzed American Community Survey data from 2006-2008 and reported that, as compared to younger-older people (i.e., those aged 85-89 and all those under the age of 85), the 90and-older population has a lower gender ratio (i.e., fewer men per 100 women) and much higher rates of widowhood, poverty, and disability.

Increasing diversity. According to FIFARS (2012), as the population of older adults in the U.S. grows older, it will also grow increasingly diverse and will require greater flexibility in programs and services to meet its needs. Six cultural phenomena have been identified that affect health and well-being among different cultures, including 
environmental control (e.g., use of community resources and social supports), biological variations (e.g., physical, genetic, nutritional), social organization (e.g., socialization and ethno-religious patterns), communication (e.g., language, non-verbal cues), space (e.g., personal and shared space, territoriality), and time orientation (e.g., present- versus future-orientation of activities and goals) (Giger \& Davidhizar, 1995; Spector, 2004).

FIFARS (2012) reported that from 2010 to 2050 the proportion of non-Hispanic white persons aged 65 and older will drop from $80 \%$ to $58 \%$, while all other race categories will increase, including Black alone (from 9\% to 12\%), Asian alone (from 3\% to $9 \%$ ), Hispanic of any race (from $7 \%$ to $20 \%$ ), and all other races alone or in combination (from $2 \%$ to $3 \%$ ). This increasing diversity is expected to affect families, businesses, and health care providers in the U.S. (Vincent \& Velkoff, 2010), and Latino health and aging is considered an important challenge and opportunity for policymakers at the national and regional levels (Torres-Gil \& Lam, 2012).

Generational conflict. According to Bengtson and Putney (2006, p.20), “The problem of generations and aging, and the resulting problems of generational succession, support, stability and change, represents one of the most enduring puzzles about social organization and behavior." Binstock (2010, pp. 575-577) detailed the "ideological context" in which aging-related policies and programs have been developed in the U.S. and pointed to several distinct ideologies that have exemplified intergenerational perceptions over time: (1) the rise of collective concern following the Great Depression, which led to the passage of key social policies (e.g., Social Security, Medicare, and Medicaid); (2) the emergence of the neoliberal/conservative focus on "greedy geezers" in 
the media and politics; and (3) the debate on "intergenerational equity" that has paid attention to the overall health of the economy in relation to expenditures on benefits for older people.

In the U.S., intergenerational conflict has influenced policies such as health care and retirement programs and has led to public anxiety about future conflicts that have the potential to undermine the social contract between generations that resulted in old-age entitlements (Binstock, 2010; Walker, 1990). The potential for intergenerational conflict remains as pressures on federal, state, and local budgets continue to grow along with the aging of society; however, some have warned that changing or eliminating policies and programs that support older adults' well-being may have tremendous impacts on the families and communities that will be left with the burden of caring for those no longer supported (Bengtson \& Putney, 2006; Binstock, 2010).

Economic indicators. Prior to the financial crisis of 2008, the economic status for a large segment of older adults in the U.S. had improved as a result of rising social security and pensions (public and private) to create an "economic status of the elderly as a group [that] is now very similar to the rest of the population - a dramatic change from their disadvantaged position in the past" (Schulz, 2001, p. 55). However, as Schulz explained (2001, p. 56), "Economic deprivation and insecurity still exist on a large scale among the elderly" and, although poverty among the aged is lower than in years past, it is still common among the oldest old, ethnic minorities, and older women, and large numbers of "extremely vulnerable" older adults exist who have incomes clustered not far above the poverty level. In 2010, women aged 65 and older were more like to live in 
poverty $^{1}(10.7 \%)$ than older men $(6.7 \%)$, and older black (20.5\%), Hispanic (20.9\%), and Asian $(15.1 \%)$ women were more likely to live in poverty than older non-Hispanic white women (8.3\%); older black (14.2\%), Hispanic (14.2\%), and Asian (14.0\%) men were also more likely to live in poverty than older non-Hispanic white men (5.0\%) (FIFARS, 2012).

In regard to poverty rates, it is also important to note that for people aged 65 and older in 2010 , neither the number in poverty (3.5 million) nor the poverty rate $(9.0 \%)$ was significantly different from 2009, but for those aged 18-64 the poverty rate increased from $12.9 \%$ in 2009 to $13.7 \%$ in 2010 , a jump in the two years from 24.7 million to 26.3 million; children under the age of 18 saw increases from 2009 to 2010 in poverty rate (from $20.7 \%$ to $22.0 \%$ ) and overall number (from 15.5 to 16.4 million) (DeNavas-Walt, Proctor, \& Smith, 2011). These trends reflect steep declines in poverty rates among older adults that began in the 1960s and 1970s-due to the expansion of Social Security benefits-that have been followed by gradual declines since (O'Brien, Wu, \& Baer, 2010). They also show the success and importance of government programs in providing a support system for vulnerable older adults, particularly members of ethnic minority groups as poverty rates remain higher than those for non-Hispanic whites.

Dependency ratios are used to assess the changing relationship among the number of older adults, government expenditures, and total economic output and are defined as measures that seek the "number of persons in the society not engaged in producing output

\footnotetext{
${ }^{1}$ According to the U.S. Department of Health and Human Services (2012), the poverty guidelines for the 48 contiguous states and the District of Columbia were $\$ 11,170$ for one person and $\$ 15,130$ for two people in a family.
} 
relative to those in the labor force who are" (Schulz, 2001, p. 287). Vincent and Velkoff (2010) measured the youth, old-age, and total dependency ratios from 2010 to $2050 .^{2}$

They found that the total dependency ratio for the U.S. is expected to increase from 67 to 85 during the 40-year period between 2010 and 2050 and that the old-age dependency ratio will see a rapid increase between 2010 and 2030 (from 22 to 35), followed by a gradual increase to 37 through 2050. Schulz (2001, p. 291) described the implications of the increases in dependency ratios and the future burden of the elderly as falling on "governments' ability to tax (that is, voters' willingness to pay taxes) and...payments outside the family-both government and employer-sponsored health and pension benefits."

Income trends of older adults compiled by the U.S. Census Bureau (DeVavasWalt et al., 2011) revealed that from 2009 to 2010 , real median household income ${ }^{3}$ for those aged 65 and older declined by $1.5 \%$ (as compared to a 2.3 percent decline in the U.S.); the highest declines were in the several 10-year cohorts under the age of 65: young adults aged 15-24 (-9.3\%), the early Baby Boomers (-4.3\% for those aged 45 to 64$)$, and the older portion of the Baby Boomers (-2.3\% for those aged 55-64). These data highlight that although the decline in income for older adults was less than that of the U.S. as a whole, the Boomer cohort has recently witnessed some of the highest declines in income in the years prior to reaching the age of 65.

\footnotetext{
${ }^{2}$ Total dependency $=(($ Population under age $20+$ Population aged 65 years and over $) /$ (Population aged 20 to 64 years $)) * 100$. Old-age dependency $=($ Population aged 65 years and over $/$ Population aged 20 to 64 years $) * 100$. Youth dependency $=($ Population under age $20 /$ Population aged 20 to 64 years $) * 100$.

${ }^{3}$ According to the U.S. Census Bureau "real" income refers to one's income after adjusting for inflation. All income values are adjusted to reflect 2010 dollars.
} 
Another economic indicator, net household wealth for older adults in the U.S., must be considered from two perspectives. The first is the rising income gap between younger and older people. The second is the disparity that exists between the upper and lower income groups of those aged 65 and older. In regard to the former, households headed by older adults have made dramatic gains in their economic well-being over the last quarter of a century. According to Fry, Cohn, Livingston, and Taylor (2011), the 42\% increase in median net worth from 1984 to 2009 among those aged 65 and older was substantially higher as compared with the entire population in the U.S. (10\% increase), as well as all other subgroups, which ranged from declines of $-68 \%$ (those younger than 35) to increases of $10 \%$ (those aged 55-64) (See Table 2.2). 
Table 2.2.

Median Net Worth by Age of Householder in 1984 and 2009, ${ }^{4}$ Including the Proportional Change Over Time (all estimates are in 2010 dollars)

\begin{tabular}{lccc}
\hline & $\mathbf{1 9 8 4}$ & $\mathbf{2 0 0 9}$ & Change \\
\hline All & $\$ 65,293$ & $\$ 71,635$ & $10 \%$ \\
\hline Younger than 35 & $\$ 11,521$ & $\$ 3,662$ & $-68 \%$ \\
\hline $\mathbf{3 5 - 4 4}$ & $\$ 71,118$ & $\$ 39,601$ & $-44 \%$ \\
\hline $\mathbf{4 5 - 5 4}$ & $\$ 113,511$ & $\$ 101,651$ & $-10 \%$ \\
\hline $\mathbf{5 5 - 6 4}$ & $\$ 147,236$ & $\$ 162,065$ & $10 \%$ \\
\hline $\mathbf{6 5}$ and older & $\$ 120,457$ & $\$ 170,494$ & $42 \%$ \\
\hline
\end{tabular}

Source: Pew Research Center (Fry, Cohn, Livingston, \& Taylor, 2011).

Several additional income trends must also be noted. For instance, FIFARS (2010) reported that from 1974 to 2007 (before the economic downturn), there were increases in the proportions of those aged 65 and older in the middle income (from $32.6 \%$ to $33.3 \%$ ) and high income (from $18.2 \%$ to $30.6 \%$ ) categories, and decreases among those in the low income category (from $34.6 \%$ to $26.3 \%$ ) and those under the poverty threshold (from $14.6 \%$ to $9.8 \%$ ). The FIFARS report also highlighted the potential effects of the 2008 economic downturn, positing that age groups could be disproportionately affected: e.g., those aged 50-64 may have been most affected and those aged 65 and older may have been least affected. This is of particular concern since the 50-64 population represents the cohort that will become the largest proportion of older adults in 2030 .

\footnotetext{
4 "Median" denotes the midpoint of a group_-in this case the point at which $50 \%$ of the households have more wealth and $50 \%$ have less. All worth is reported in 2010 dollars.
} 
According to another report from FIFARS (2009) that specifically looked at the 2008 financial crisis and the economic well-being of older Americans-the crisis was deemed to have begun in December, 2007-the effects of the downturn included a loss in the value of retirement accounts of those aged 50 and older of $31 \%$ (from September, 2007 to May, 2009), rising unemployment, decreased spending, falling housing prices, and increased pressure of foreclosures. Similarly, according to an analysis of Baby Boomer wealth by Rosnik and Baker (2009), younger (45-54) and older (55-65) cohorts of Baby Boomers witnessed a loss of wealth due to the collapse of the housing bubble and the plunge in the stock market (measured from the years 2004 to 2009) that will make them far more dependent on Social Security and Medicare than prior generations. Not only did these cohorts witness a loss of wealth, but they did not save during those years and lost peak years in which they should be saving. An important policy implication noted by the authors is that "Proposals for substantially cutting back Social Security and Medicare for those approaching retirement are unrealistic given the financial situation of those near retirement" (Rosnik \& Baker, 2009, p. 21).

Healthy aging. According to Kinsella and He (2009, p.1), population aging represents "a human success story of increased longevity;" life expectancy has increased since the mid-1800s due to improvements in medicine, sanitation, and public health. However, along with increased life expectancy come changes in health and functional ability. FIFARS (2010) reported that from 2006 to 2008, respondent-assessed health status of those aged 65 and older in the U.S. showed increases in the "fair or poor" health categories and decreases in the "good to excellent" categories across each age category 
(i.e., 65-74, 75-84, and 85 and older), including for all gender and race categories. According to the Administration on Aging (2005), the rate of limitations in activities of daily living (ADLs) (i.e., bathing, dressing, eating, walking, toileting, and getting in and out of bed) showed increases with age: Those aged 85 and older reported more limitations than those aged 75-84, and the latter group had more limitations than the 6574 cohort.

The Centers for Disease Control and Prevention and The Merck Company Foundation (2007) report The State of Aging and Health in America presented the following seven calls to action that are intended to encourage individuals, professionals, and communities to take specific steps to improve the health and well-being of older adults: (1) address health disparities among older adults, particularly in racial and ethnic minority populations; (2) encourage people to communicate their wishes about end-oflife care; (3) improve the oral health of older adults; (4) increase physical activity among older adults by promoting environmental changes; (5) increase adult immunizations, particularly in racial and ethnic minority populations; (6) increase screening for colorectal cancer; and (7) prevent falls, a leading cause of hospitalization and injury deaths among older adults.

There is no single, fundamental cause of healthy aging, "rather a multiplicity of factors working together to facilitate optimal functioning well into later life" (Bengtson, Gans, Putney, \& Silverstein, 2009, p. 8). Ryff and Singer (2009) explained several factors that lead to a biopsychosocial understanding of healthy aging: social structural influences that are indexed by one's location in the social structure (e.g., age, gender, socioeconomic 
status, race/ethnicity, cultural context), individual psychosocial and behavioral influences (e.g., personality, traits, social ties, behavioral practices related to health), and biological influences (e.g., normal aging/senescence, damaging processes caused by internal and external factors, prevention and protection). Glass, De Leon, Bassuk, and Berkman (2006) have also argued that physical and mental decline associated with older age reduces the capacity to engage in physical, social, and community activities outside of one's home environment.

The WHO, in its report, Active Ageing: A Policy Framework (2002), highlights one approach that can be taken that will lead to healthy, or active, aging. The WHO (2002, p. 12) paper defined active aging as the "process of optimizing opportunities for health, participation and security in order to enhance quality of life as people age." The WHO's active aging framework focuses on policy and program development for the individual and for society by attempting to understand the evidence that supports a broad range of determinants, including gender, culture, health and social services, the physical environment, and social, economic, behavioral and personal determinants (see Table 2.3 for an overview of determinants). This approach is a shift away from a needs-based approach and assumes a rights-based approach that recognizes the rights of people to equality of opportunity and treatment as they grow older (WHO, 2002).

\section{Preparing for an Aging Society}

The emergence of the field of gerontology. If we are to successfully prepare for our aging society we must consider the multiplicity of issues that have been identified in the field of gerontology, from demographic changes and economic shifts to trends in 
disease patterns and the promotion of healthy behaviors. Gerontology-the study of the biological, psychological, and social aspects of aging-emerged as a research area in the U.S. in 1939, the Gerontological Society of America was founded in 1945, and graduate schools in the U.S. began offering degree programs in the 1960s (Gerontological Society of America, 2011; Haley \& Zelinski, 2008; Hooyman \& Kiyak, 2011).

The aging of society became an area of growing interest in the field of urban planning following the Baby Boom after World War II, when demographic projections prompted calls for foresight and preparation. Kaufman (1961) relayed the sentiment of the American Society of Planning Officials in a Planning Advisory Service report titled, Planning and an Aging Population. He explained that the approach to the post-war housing boom taken by community development and planning experts had been "childor family-centered" and that the pronounced shift in the age composition will "necessitate some reshuffling - discarding some outmoded theories, recasting tenuous theories, and originating some new theories." Kaufman (1961, p. 32) concluded that "within a relatively short period, our society has moved from a position of disinterest to one of sharp interest in the older generation." However, little evidence of action of this type in the field of planning is evident until the late 1980s when Howe and colleagues received a grant from the U.S. Administration on Aging to develop a program titled Livable Environments for Older People (Howe et al., 1994).

Development of theories in gerontology and related fields. Street (2007) detailed the growth of theory in gerontology, which began with the empirical testing of micro-level theories in the 1960s and 1970s such as disengagement, activity, and 
continuity theories. These micro-level theories provided three distinct contributions to understanding pathways of adjustment in old age: some individuals disengage from their social settings; some individuals remain very active into old age; and some individuals continue to use their foundations of early life to cope with age-related changes. As interest in gerontology grew, so too did theory, adding both "meso-level (or mid-range) theories that explored linkages between individuals and societies" (e.g., subculture and exchange theories), and "macro-level theories that specified the structural relationships between society and individuals in the context of the changing age structure of national populations" (e.g., modernization and feminist theories) (Street, 2007, p. 146).

The connection between micro-, meso-, and macro-level theories in gerontology can be partially attributed to the psychologists Kurt Lewin and Urie Bronfenbrenner and their contributions to early ecological models (Richard, Gauvin, \& Raine, 2011). Lawton (1980, p. 11) explained that Lewin was the first psychologist to try and conceptualize person/environment relations, formulating the ecological equation $\mathrm{B}=f(\mathrm{P}, \mathrm{E})$, which sees behavior as a function of the person and the environment; Lawton considered this "a useful statement, but certainly overly broad," as it was unclear what is included as the "person" and what is the "environment."

Bronfenbrenner (1979, p.3) offered a theoretical perspective for research in human development that conceived of the ecological environment as "set of nested structures, each inside the next, like a set of Russian dolls." These nested structures provide the context for understanding human development as extending beyond individuals' behavior to "encompass functional systems both within and between 
settings" (p. 7). The four described settings, or concentric structures, include microsystems (connections among an individual, objects, and other persons inside an immediate environmental setting), mesosystems (the bond among two or more microsystems or settings that an individual frequents or will frequent), exosystems (interconnections among an individual's settings in which he or she participates and those which may never be entered but still affect the individual's life), and macrosystems (overarching patterns of ideology and the organization of social institutions that are particular to a culture/society) (Bronfenbrenner, 1979; L'Abate, Cusinato, Maino, Clesso, \& Scilletta, 2010).

Person-environment perspective in the field of gerontology. The ability to adapt to biological, psychological, and social changes with age varies among individuals. As described by Lewin and the person-environment perspective, adaptation implies a dual process in which the individual adjusts to the social and physical environment, and the social and physical environments can also be changed (Hooyman \& Kiyak, 2011).

Lewin's ecological equation first described behavior as the outcome of personenvironment factors, or $\mathrm{B}=f(\mathrm{P}, \mathrm{E})$, but it was mainly $\mathrm{M}$. Powell Lawton and his colleagues who first applied the concept to the field of gerontology. Lawton and Simon (1968) were aware of the functional limitations of older persons, which led to their environmental docility hypothesis: "The more competent the organism - in terms of health, intelligence, ego strength, social role performance, or cultural evolution - the less will be the proportion of variance in behavior attributable to physical objects or conditions around him." (p. 108). Conversely, they argued, a person with a lower level of 
individual competence has less capacity to deal with a similar environment and less ability to adapt to that environment than a person with a higher level of individual competence.

Lawton and Nahemow's (1973) Ecology and the Aging Process developed a description of the ecology of aging (i.e., the Adaptation Model), which recognized that adaptation is one of the most important elements of human ecology and the aging process. The ecology of aging was defined as a "system of continual adaptations in which both the organism and the environment change over time in a nonrandom pattern; either the environment or the organism is capable of initiating a cycle of action, or of responding" (Lawton \& Nahemow, 1973, p. 621). This model focused on the behavior of an individual as a function of the person and the environment, measured separately, which is known as a transactional person-environment model.

Lawton (1980) advanced the earlier work on the ecology of aging by identifying the interactive processes between persons and environments, which led to an expansion of Lewin's original model to include the person-environment interaction: $\mathrm{B}=f(\mathrm{P}, \mathrm{E}, \mathrm{P} \mathrm{x}$ E). The person-environment interaction (i.e., $\mathrm{P} \times \mathrm{E}$ ) represents the interface between two elements in which "the combination of subjective experience and external environment may have an effect on behavior that is in addition to and independent of either the person or the objective environment" (Lawton, 1980, p. 17). Weisman, Chaudhury, and Diaz Moore (2000) elaborated, explaining that this interaction may be influenced by processes of socialization and enculturation which contain a shared set of expectations or rules that may affect behavior; individual traits such as personality or environmental cognition 
(e.g., significance of place) can be considered as a part of the person-environment interaction.

The term "environment" was, and still is, a broad term with various meanings and room for interpretation. Lawton (1986) felt that there was a notable absence of a truly functional taxonomy of environments, and he sought to name and define several aspects of the environment. These included: the personal environment (e.g., significant persons in the life of a subject); the group environment (e.g., relationships of an individual to groups, such as pressure and norms, but the absence of a wider social context); the suprapersonal environment (e.g., characteristics of the aggregate of individuals in proximity to an individual, such as average age, income, and/or race); the social environment (e.g., social and political movements, economic cycles, traditions and values); and the physical environment (e.g., the natural or built environment).

Kahana (1982) added to the ability to conceptualize the environmental transactions of the elderly through the concept of person-environment congruence, which theorized that individuals with certain types of needs are most likely to seek, and be found in, environments that are congruent with their needs. Lawton (1986, p. 15) added that congruence is "associated with a positive mental state, incongruence with a negative state" and that congruence may be viewed as "any point where competence and press are in balance."

Congruence can also be understood by thinking in terms of person-environment (P-E) fit, as Kahana (1982) recognized that adaptations can occur either in the environment (e.g., making road signs easier to read) or at the personal level (e.g., no 
longer driving at night). Carp (1987) expanded on the concept to include two levels of "fit:" first, a primary level of life maintenance needs (e.g., food, water, shelter) which are dependent on a person's ability to perform activities of daily living (e.g., bathing, toileting, feeding); second, after the primary-level needs are met, higher-order needs such as social contact, need for privacy, and locational preferences. Achieving both levels of P-E fit depends on an individual's ability to find environments that are congruent with their personal needs, no matter what his or her competence and adaptation levels may be.

\section{Ecological models: The ecology of aging and the social ecological model.}

Lawton and colleagues discussed the ecology of aging as it pertained to individual behavior, but they also conceptualized the micro- and macro-level environments that contributed to the well-being and functioning of older adults. Of particular importance were an individual's home-considered a part of the microenvironment-and his or her community and neighborhood, and the policies and programs that were considered to be part of the macro environment. Lawton (1986) posited that for an older person of marginal competence, the availability of a spectrum of macro-level supportive services may be the difference between a positive or negative outcome, or the difference between being able to age in one's community or becoming institutionalized.

Moos and Lemke (1996) also used a conceptual framework to evaluate the physical and social environments in residential settings for older adults. Their evaluation framework was guided by a model of the relationship between program and personal factors and resident stability and change. The framework builds on the work of Lawton and of Carp by highlighting the fact that a given environmental feature can vary in the 
way that it affects different residents, leading to varying levels of congruence or fit. The framework was designed to assess congregate settings along five areas: (1) objective characteristics of program (aggregate residents and staff characteristics, physical, and policy factors); (2) personal factors (socio-demographic characteristics, health status, functioning factors, and preferences); (3) social climate; (4) residents' coping responses; and (5) resident adaptation (adjustment, activity level, and use of services). The utility of this framework is that it provides practitioners, program evaluators, and researchers with an integrated assessment tool that measures the quality of residential settings for older adults.

In the field of public health, ecological approaches emerged in the 1980s to analyze and understand disease prevention, health promotion, and possible interventions, and, according to Richard et al. (2011), enthusiasm for these approaches remains. The models emerged from the early work of Lewin and Bronfenbrenner and together, they have come to be known as the social ecological model and/or the ecological perspective. The National Institute of Health (2005) provided a clear explanation:

The ecological perspective emphasizes the interaction between, and interdependence of, factors within and across all levels of a health problem. It highlights people's interactions with their physical and social environments. Two key concepts of the ecological perspective help to identify intervention points for promoting health: first, behavior both affects, and is affected by, multiple levels of influence, second, individual behavior both shapes, and is shaped by, the social environment (reciprocal causation). (p. 10)

In order to effectively achieve health promotion, the ecological perspective focused on understanding the multiple levels of influence that affect health. McLeroy, Bibeau, Steckler, and Glanz (1988) critiqued the ecological models by Bronfenbrenner 
and others in the social sciences as lacking sufficient specificity to guide either the conceptualization of a problem or appropriate interventions. In developing an ecological model for health promotion that aims for behavioral outcomes, five levels of influence were defined (McLeroy et al., 1988; National Institutes of Health, 2005): (1) intrapersonal levels; (2) interpersonal levels; (3) institutional factors; (4) community factors; and (5) public policy.

Stokols' (1992) work on establishing and maintaining healthy environments suggested a need to move beyond focusing on behavior change and to begin understanding the advantages of health-promotive environments. Healthfulness, Stokols explained, is a multifaceted phenomenon encompassing physical health, emotional wellbeing, and social cohesion, factors that require moving beyond the emphasis on individual-level interventions and toward the inclusion of policies and interventions along an environmental continuum from micro- (e.g., housing facilities) to macro-level setting (e.g., metropolitan and national settings).

Designing health-promotive environments at the local level thus was seen as being influenced by regulatory and economic policies implemented in local, regional, and national contexts. For example, Stokols (1992, p. 15) noted that an architect or planner designing a residential facility for the elderly will need knowledge across many disciplines, including "environmental law (e.g., the regulations intended to mitigate negative impacts of proposed environmental developments), life span human development, (e.g., the specialized health and safety need of different age groups), and 
ergonomics and public health (e.g., the potential health consequences of poorly designed, toxic or injury-prone environments)."

Both the gerontology and public health ecological models focus on attributes of the individual (e.g., the aging body, disease and disability, individual behavior) and the environment (e.g., accessibility and usability, social connections and interaction, healthy housing). Sallis (2003) considered the ecological models as useful for guiding research, and he focused on the need to consider effective public interventions pertaining to healthy and active aging. However, as Cunningham and Michael (2004) explained, there is a need to move beyond basic research and individual interventions toward the creation of policies and strategies that aim to achieve healthier communities for older adults. Satariano and McAuley (2003) argued for action-based research that would consider the impacts of social, biological, behavioral, and environmental factors while understanding the dynamic interplay over time that occurs between older people and their environments. For example, as one grows older, what opportunities and/or barriers affect one's ability to maintain social connections, choose from a continuum of housing options, or have access to services?

Greenfield (2012) looked at the ecological frameworks and their utility in advancing research, policy, and practice and concluded that theoretically-derived dimensions that characterize aging-in-place initiatives (i.e., environment- and personfocused aspects) should be used to ensure that such initiatives (e.g., WHO's Age-friendly Cities and the Village models, both described in the next section) do not become disparate from one another. Rather, different initiatives can be applied in different 
communities, where appropriate, but will remain tied together theoretically, which may provide an opportunity to explore their similarities, differences, and potential.

Livable communities and age-friendly cities. As discussed above, older adults' well-being and health are affected by their social and built environments, which requires looking at the contributing factors across many levels, from the biological characteristics of an individual, to macro-level public policy. The early work in environmental gerontology developed theoretical underpinnings, conceptual models, and research findings that contributed to understanding the patterns of interactions and relationships that exist between older persons and their environments and point to ways for planning for the aging of the population, including areas of housing and policy (Golant, 1992; Howe et al., 1994; Lawton, 1986; and Pynoos, 1987).

Glass and Balfour (2003) pointed to the fact that systems of social welfare (e.g., health care, neighborhoods, housing development) have failed to keep pace with the needs of an increasingly aging population, and Kochera and Bright (2006) suggested that poorly designed housing, inadequate sidewalks, limited mobility options, and few supportive services can make it difficult for people to remain active and engaged with friends, families, and neighbors. For a little more than a decade, a number of new research agendas, initiatives, projects and programs have focused on making cities and communities better for the older adults who function within those settings on a daily basis.

One of the first such efforts involved researchers in public health, gerontology, and urban planning, who focused on the connections between older adults' levels of 
physical activity and the environment (both built and social). In the Gerontologist, DiPietro (2001) described safety and accessibility factors of the built environment as having an impact upon physical activity (e.g., quality of sidewalks, fear of crime). The Journal of Aging and Physical Activity published a supplemental edition to the regular journal (Chodzo-Zajko, 2001) that focused on increasing physical activity among older adults by addressing various barriers in public policy and home, community, workplace, and health care settings.

Chodzo-Zajko's (2001) Journal of Aging and Physical Activity publication was a result of funding by the Robert Wood Johnson Foundation, which also provided funding for a report titled, National Blueprint: Increasing Physical Activity Among Adults Aged 50 and Older (The Robert Wood Johnson Foundation, 2001) that grew out of the need to develop a framework for planning, collaborative action, and social change among organizations involved in physical activity and aging. In 2002, the American Journal of Preventive Medicine published a supplemental issue (King, Bauman, \& Calfas, 2002) that looked at innovative approaches to understanding and influencing physical activity. This special journal issue included research that sought to bring together multiple disciplines, such as public health and urban planning (Handy, Boarnet, Ewing, \& Killingsworth, 2002) and understand how programs such as Tai Chi classes can have an impact on physical functions among older adults (Li, Fisher, Harmer, \& McAuley, 2002).

Outside of academia, AARP was attempting to assess and shape communities that were appropriate for older adults. The Public Policy Institute published Livable Communities: An Evaluation Guide (Pollack, 2000), which sought to empower local 
older adults to evaluate their environments in order to prepare them to enact communitylevel changes. This initial guide was revised in 2005 and focused on the areas of transportation, walkability, safety and security, shopping, housing, health services, recreational and cultural activities, and caring communities (AARP, 2005a). AARP's work in the area of livable communities has continued to expand, including original research conducted by its Public Policy Institute focusing on livable communitiesBeyond 50.05: A Report to the Nation on Livable Communities: Creating Environments for Successful Aging (AARP, 2005b)-and policies that support aging in place across the U.S. (AARP, 2011), such as those that encourage strengthening the connections between land use, transportation, and housing.

There was also an attempt to focus on influencing practitioners to create environments that would lead to healthier communities for older adults, as is evident from the Planning Advisory Service report from the American Planning Association, Planning for an Aging Society, which was written after the training of urban planners in Oregon in the 1990s on the topic of planning for an aging society (Howe et al., 1994). Howe (2001) proposed that the burgeoning number of older adults in the U.S. would encounter significant obstacles to continued independence in the form of land use and planning regulations, public and private investments, and dominant social values. Smart growth initiatives that emphasized walkable cities, diversity in housing choice, a strong sense of community, and accessible environments were seen as needed for maintaining the health, independence, and self-worth of older adults. The International City/County Management Association (2003) approached active living for older adults by targeting 
management strategies for healthy and livable communities. The report focused on local governments needing to consider policies and practices in land use planning, streetscape and sidewalk design, transportation, and housing to ensure that aging societies would remain healthy and active.

Another research effort that focused on the assessment of communities was the AdvantAge Initiative (Feldman \& Oberlink, 2003), a research model for elder-friendly communities that included indicators to measure and help improve community capacity to promote the health and well-being of older adults. The findings of the project identified four primary aspects of an elder-friendly community. These included addressing basic needs (e.g., housing, services), promoting social and civic engagement (e.g., community connections, meaningful activities), optimizing physical and mental health well-being (e.g., promoting healthy behaviors, preventive health services), and maximizing independence for frail and disabled individuals (e.g., support for caregivers, accessible transportation).

Additional research projects that focus on aging and health have been undertaken in other cities in the U.S. For example, the Atlanta Regional Commission in Atlanta, Georgia, has undertaken a framework for planning called Lifelong Communities that promotes housing and transportation options, encourages healthy lifestyles, and expands information and access to services for older adults (Atlanta Regional Commission, 2009). One outcome of the work in Atlanta was the creation of the Lifelong Communities Handbook (Atlanta Regional Commission, n.d.), which is an element of the Regional Plan and incorporates seven principles: (1) connectivity, (2) pedestrian access and transit, 
(3) neighborhood retail and services, (4) social interaction, (5) diversity of dwelling types, (6) healthy living, and (7) consideration for existing residents.

In Portland, Oregon, researchers from Oregon Health and Science University (Michael, Green, \& Kellogg, 2003) developed a Senior Walking Environmental Assessment Tool to measure built environment characteristics that were associated with walking for older adults. In 2007, the assessment instrument was revised to create an easier-to-use tool for practitioners and community members (Michael, Keast, Chaudhury, Day, Mahmood, \& Sarte, 2008). The revised instrument has been used and/or modified for use in research projects such as the U.S. Environmental Protection Agency-funded project in Portland that looked at the benefits of green street treatments (i.e., natural, landscape-based features to capture stormwater runoff) for active aging (Dill, Neal, Shandas, Luhr, Adkins, \& Lund, 2010).

In 2006, the WHO started the Age-friendly Cities project as part of its Ageing and Life Course program, which was based on the active aging framework described above (also see Table 2.3 below for an overview of the determinants of active aging) which sought to inform research, practice, and policy (WHO, 2007a). The goals of the initial project were twofold: to create a practical guide that could be used to improve cities for those of all ages and abilities and, for participating cities, to learn about their city's age friendliness and to provide a catalyst for positive change.

In developing the Age-friendly Cities project, the WHO used the active aging framework to identify eight domains for research and action: (1) transportation, (2) housing, (3) outdoor spaces and buildings, (4) social participation, (5) respect and social 
inclusion, (6) civic participation and employment, (7) communication and information, and (8) community support and health services. Originally, 33 cities in 22 countries participated in the research (including Portland), and in 2010 the WHO started a related effort, the Global Network of Age-friendly Cities and Communities. The Network grants membership to cities that apply and attest to their commitment to undertake the process of continually assessing and improving their age friendliness, which includes developing an action plan and using indicators to track progress over time (WHO, 2012).

In order to understand the overlap between the WHO's active aging framework (WHO, 2002) and the eight domains that encompass the Global Network of Age-friendly Cities and Communities (WHO, 2007), Table 2.3 describes six shared areas of focus between the two publications from the WHO. 


\section{Table 2.3}

Six Overlapping Areas of Focus Identified from the World Health Organization's (2002) Active Aging Framework and the Eight Domains of the WHO Global Network of Agefriendly Cities and Communities (World Health Organization, 2007)

\begin{tabular}{lll} 
Overlapping areas of focus & $\begin{array}{l}\text { Active aging framework } \\
\text { determinants }\end{array}$ & $\begin{array}{l}\text { Age-friendly cities and } \\
\text { communities domains }\end{array}$ \\
\hline Physical environment & Physical environment & $\begin{array}{l}\text { Housing, transportation, } \\
\text { outdoor spaces and } \\
\text { buildings }\end{array}$ \\
\hline Social environment & Social determinants & $\begin{array}{l}\text { Social participation, } \\
\text { respect and social } \\
\text { inclusion, civic } \\
\text { participation }\end{array}$ \\
\hline Economic resources & Economic determinants & Employment \\
\hline Services & Health and social services & $\begin{array}{l}\text { Community support, health } \\
\text { services, communication } \\
\text { and information }\end{array}$ \\
\hline Population determinants & Culture, gender & \\
\hline Individual determinants & $\begin{array}{l}\text { Personal and behavioral } \\
\text { determinants }\end{array}$ & \\
\hline
\end{tabular}

At the beginning of 2012, it is safe to say that there is a growing awareness of the need to advocate for the creation of age-friendly cities and livable communities. These efforts have built on previous work in the fields of gerontology and public health and appear to have considerable promise. Lehning (2011) found that successful efforts to encourage adoption by cities of innovations that affect the mobility and quality of life of older adults have several characteristics: facilitate the involvement of older adults, target key decision makers within government, emphasize financial benefits to the city, and focus on vulnerable older adults. The age-friendly cities and livable communities efforts have attempted to do just that and specifically aim to improve cities and communities for an aging society. 


\section{Housing for Older Adults}

The demographic imperative that has been identified highlights the urgent need for planners and policy makers to prepare for our rapidly aging society. Included is the need for planning and developing affordable housing for older adults that is well designed, nearby essential services and quality infrastructure, and able to foster social and community integration (Farber et al., 2011).

Housing for older adults can include any type of dwelling where older people may live, from single-family homes, to age-segregated apartment complexes, to long-term care facilities. In 2009, 23.1 million households were headed by an older person aged 65 or older; $80 \%$ were owners, and 20\% were renters (Administration on Aging, 2010). According to the U.S. Census Bureau (2010), in 2008, 68\% of people aged 65 and older lived with relatives, 27\% lived alone, and 5\% lived in group quarters; only 4\% (1.6 million) lived in nursing or skilled care facilities. Housing itself is an important aspect in the lives of older adults, as it contributes to the physical and social aspects of individuals' daily lives. Golant (1992) explained the overarching importance of housing, looking beyond its physical and economics aspects:

[Housing is more than] merely a shelter, a financial holding, or type of land use in a particular neighborhood... [It] must also consider issues such as family ties and relationships; the availability and quality of caregiving assistance; individual beliefs and values about accepting assistance; individual coping styles; the desirability of communal living arrangements; and the cost, availability, and quality of human services and long-term health care. (p. 3)

As detailed in a report by the Commission on Affordable Housing and Health Facility Needs for Seniors in the $21^{\text {st }}$ Century (2002) titled, A Quiet Crisis in America, 
there is a particular need for providing more affordable housing that is healthy and appropriate based on the rapid aging of society. The Commission's report made it clear that federal programs, such as Section 202, Section 8, Low Income Housing Tax Credit (LIHTC) equity, and state and local programs must be used in order to erase shortfalls and meet the expanding needs of an aging population (see the policy and program landscape section later in this chapter for a comprehensive review of policies and programs). According to Cummings and DiPasquale (1998, p. 2), the LIHTC program, ${ }^{5}$ in particular, has been the "de facto federal production program for affordable housing since its inception in 1987." However, due to the recent downturn of the U.S. economy, insufficient funds are being generated by the sale of these tax credits to successfully complete affordable housing projects (Wuest, 2009).

Housing policies and programs pertaining to older adults. Pynoos (1987, p. 27) described housing policy for older adults as a "purposive course of action intended to promote better housing and to deal with general housing problems." Such policies can range from broad, macro-level policies that focus on population trends and funding sources to micro-level policies that deal with specific types of projects and developments (e.g., adaptive reuses of existing buildings and site location issues). Both macro- and micro-level policies are important in addressing the broad need for housing for our aging society and the design and development of appropriate housing for that population.

\footnotetext{
${ }^{5}$ The Low Income Housing Tax Credit program is administered by the Internal Revenue Service and allows private investors to reduce their federal income taxes by $\$ 1$ for every dollar of tax credit received, with the amount of equity generated by the tax credits depending on two factors: the price investors are willing to pay for the credit and various transaction costs connected to the sale or syndication of the tax credits (Schwartz, 2006).
} 
According to Koff and Park (1993), housing policies for older adults have insufficiently considered the quality of life of older adults within housing and have instead focused on housing environments that are only just adequate as shelter. The authors refer to several housing policy objectives detailed by Pynoos (1987) that are particularly important to consider for enhancing the quality of life of an aging society: promoting housing choice; providing an appropriate neighborhood and supportive services; maximizing independence; ensuring housing fit (i.e., housing that matches the needs of its residents); providing adaptable or accommodating housing; and enhancing residential satisfaction and control. Although these objectives were articulated nearly 25 years ago, they are still relevant for creating appropriate, affordable housing for older adults today.

According to Shactman and Altman (2002), the steep rate of aging of the U.S. population occurring after 2010 requires that policies be examined for their current value, as well against the backdrop of the future needs of an aging population. This approach falls in line with the principles of sustainable development (detailed later in this chapter) and is confirmed in a congressional research service report to members of U.S. Congress (Perl, 2010) that stressed the growing need for providing affordable housing for a rapidly aging population. An estimated need for an additional 730,000 units of affordable housing by 2010 was detailed in the report, A Quiet Crisis in America (Commission on Affordable Housing and Health Facility Needs for Seniors in the $21^{\text {st }}$ Century, 2002).

The housing continuum and aging in place. Housing is associated with agerelated changes and the onset of morbidity over the life course and can be understood as 
existing on a continuum that affects an older person's well-being and quality of life. As Newcomer and Weeden (1986, p. 4) explained, that continuum is "characterized both by its physical features and by the attributes of its occupants" and ranges from completely independent households to semi-independent and dependent households. The assumption is that as a person ages, a gradual decline of physical and mental capacities will be accompanied by an increasing need for assistance and the need to move to appropriate care settings (Howe et al., 1994).

Schafer (1999) explained that the desire to "age in place" is recognized as an important objective in the design and implementation of support services for the elderly, in particular housing. Aging in place can slow down the need for older people to move from one household on the continuum to the next. An overwhelming majority of older adults would prefer to age in their current residence, as a national survey on housing and home modification conducted by AARP in 2000 revealed: $89 \%$ of those aged 55 and older agreed that they would like to stay in their current residence for as long as possible. However, as reported in another AARP (2003) publication, These Four Walls...Americans 45+ Talk About Home and Community, many consumers seem to be in denial regarding the possibility of increasing frailty, exhibiting what may be an unrealistic sense of optimism about the future.

When older adults experience functional decline, it is important to consider the options that exist. These may include aging in their home, in a different home in the same community, or in a different home in an entirely different community. Golant (2009) warned that older adults should not automatically assume that aging in their home is the 
best solution to their changing needs. Golant's proposed solution is to make it easier for older homeowners to "occupy more supportive housing arrangements by assisting them with their moving plans and by better informing them and the professionals who serve them about their benefits" (p. 38). Pynoos and Cicero (2009) focused on the need to ensure that older adults who choose to age in place have that option. The authors concluded that there are promising developments and opportunities to foster improvements in physical aspects of housing through policies, building codes, and community-wide efforts.

Design approaches used in housing development that can contribute to aging in place and a continuum of community housing options include accessibility, visitability, and universal design. Accessible design is design that meets standards originally developed in accordance with the Americans with Disabilities Act (ADA) in 1990 that set minimum requirements for newly constructed (and altered) public facilities and accommodations, and commercial buildings that will be used by people with disabilities (U.S. Department of Justice, 2010). Universal design is "the design of products and environments to be usable by all people, to the greatest extent possible, without the need for adaptation or specialized design" (North Carolina State University Center for Universal Design, 2006, p. 2). The general intent of universal design for housing is to make it more usable for everyone, regardless of their abilities, in all aspects possible (e.g., entrances, circulations, appliances, kitchens, bathrooms). Visitable design, as it pertains to housing, targets housing that has fewer requirements for accessibility (e.g., market-rate, single-family housing as compared to housing financed with public 
resources) and has three required criteria: one zero-step entrance, wide doorways with 32 inches of passage, and a half-bathroom on the main floor that can be accessed by a person in a wheelchair (AARP, 2008; Concrete Change, 2008).

Two community-oriented efforts that aim to facilitate aging in place are naturally occurring retirement communities (NORCs) and village models. NORCs originally were defined as housing developments not planned or designed for older adults but that have a large proportion of older adults living within them (Hunt \& Ross, 1990). The size and shape of the housing itself and the age and proportion of its older residents varies. NORCs can be vertical (i.e., multi-story apartment building) or horizontal (i.e., a neighborhood). NORCs do tend to work best in circumstances in which residents have long-standing experience with cooperative activities (e.g., condos, system of governance, homogeneous demographics) (Pine \& Pine, 2002).

The "village" model is defined as a consumer-driven approach that promotes aging in place by combining member support, referrals for services, and engagement with consumers living in the community (Scharlach, Graham, \& Lehning, 2011). The model is considered to be innovative and potentially promising for older adults who are not reliant on public assistance programs. Scharlach et al. (2011, p. 9) detailed the distinctive characteristics shared by most existing villages as including a "service consolidation model of operation, reliance on membership dues and other internal resources, substantial consumer involvement, and relative organizational autonomy."

Age-integrated versus age-segregated housing. One of the debates in the field of gerontology pertains to the positive and negative aspects of age-integrated versus age- 
segregated housing. The argument for age-integrated, intergenerational housing is not new. An article by Louis Mumford in $1956^{6}$ argued for the need to normalize age by "restoring the old to the community" (Mumford, 1987, p. 43). Rosow (1961) noted the problem with segregating older people from other generations is the shrinking of the older generation's primary groups and the older generation's potential to become vulnerable to growing dependency and social needs. More recently, Folts and Muir (2002) explained that intergenerational housing is a normal circumstance for older people and pointed to the example that until children leave the home, most housing is intergenerational. Indeed, many have argued that intergenerational, or age-integrated housing environments, are better for both older adults and society.

On the other hand, Golant (1987) argued that age-segregated housing consists of an extremely diverse array of residential accommodations and that it is exceedingly difficult to make generalizations about the residents living within those developments. He refuted the critics and maintained that not only do older adults in age-segregated housing have links to the "outside world," but they "often belong to clubs and organizations whose members include young and old alike; they eat and shop in establishments patronized by all age groups; they visit with kin, friends, and neighbors-of all ages-on a regular basis; they communicate daily by mail and phone with persons who are considerable distances away; and their spheres of activity often extend beyond their immediate residences" (Golant, 1987, p. 51). Overall, housing preferences are subjective, and arguments can be made for both age-integrated and age-segregated housing for older adults.

\footnotetext{
${ }^{6}$ The original article from May, 1956 was reprinted with permission from Architectural Record.
} 
Affordable housing for older adults. To understanding what constitutes

affordable housing requires a detailed explanation. Bender (1985) noted that attempts to make housing affordable fall into two categories: efforts aimed at reducing the cost of construction and efforts focused on increasing the user's ability to pay for housing. Both categories deal with the cost of the housing in relation to the economic means of the person(s) living in it. This raises the question of the extent to which affordable housing is available to older adults. The supply of affordable housing-mainly public housing for low income people-is mostly focused on the second category of attempts to make housing affordable: increasing the user's ability to pay for housing.

Golant's (1992) examination of the availability of affordable housing for older adults categorizes the older adult population into three groups: the upper-income echelon, who have few problems finding housing that is affordable for them; the lowest-income older adults who are sometime less disadvantaged in finding affordable housing due to government-subsidized programs available to them; and the moderate-income older adults who have incomes above the poverty level and thus are disqualified from receiving most government benefits, yet who cannot afford private housing. According to the National Low Income Housing Coalition (2009), there are more than 1.1 million public housing units in the U.S., and older adults (those aged 62 and older) occupy $31 \%$ of them; another 1.5 million live in homes with project-based assistance (e.g., Sections 8, 202,811 ) and $75 \%$ of those are older adults or persons with disabilities.

The goal of adequately housing older adults has been addressed since the 1937 Housing Act, which sought to provide "safe and decent housing" for all age groups; there 
has also been general acceptance on the part of the public that governmental agencies should bear certain responsibilities for housing older adults (Turner, 1986, p. 42). The question, "Affordable to whom?” must still be addressed to understand what affordable housing is available for older adults in the U.S. and municipalities such as Portland, however.

The U.S. Department of Housing and Urban Development (HUD) is required by law to set income limits that determine the eligibility of applicants for its assisted housing programs, of which the major active programs are the Public Housing program, the Section 8 Housing Choice Voucher program, Section 202 housing for the elderly program, and Section 811 housing for persons with disabilities program (see federal policies described later in this chapter for further details on these programs) (HUD, 2011a). The generally accepted definition of affordable housing was a household paying "No more than 30 percent of its annual income on housing;" also, families paying more than $30 \%$ of their income for housing were considered to be "cost burdened and may have difficulty affording necessities such as food, clothing, transportation and medical care." (HUD, 2012a, para. 2)

According to HUD (2011a), the agency calculates affordability requirements using Median Family Income (MFI) estimates for each metropolitan area, parts of some metropolitan areas, and each nonmetropolitan county (MFI is sometimes referred to as Area Median Income). For example, the Portland Housing Bureau (2012) detailed income thresholds for the Portland-Vancouver-Hillsboro, OR-WA Metropolitan Statistical Area that consisted of Clackamas, Columbia, Multnomah, Skamania, 
Washington, and Yamhill Counties (in Oregon) and Clark County (in Washington State); housing affordability for a single-person household was at the following levels: $30 \%$ of MFI ( $\$ 14,600$ per year or $\$ 365$ per month); 50\% of MFI ( $\$ 24,300$ per year or $\$ 607$ per month); $80 \%$ of MFI ( $\$ 38,850$ per year or $\$ 971$ per month); $100 \%$ of $\operatorname{MFI}(\$ 47,810$ per year or $\$ 1,195$ per month). If an individual makes less than the MFI percentage (e.g., $80 \%$ or $30 \%$ ), and does not have other assets such as savings and investments, he or she becomes eligible to apply for affordable housing. It should be noted that a single person earning less than $30 \%$ of MFI might not be below the federal poverty guideline of $\$ 11,170$ (U.S. Department of Health and Human Services, 2012)

In 2012, a person receiving income of less than $\$ 11,170$ per year was considered to be below the poverty line, while couples below $\$ 15,130$ qualified (HUD, 2012b). According to O'Brien, $\mathrm{Wu}$, and Baer (2010), in 2008 nearly one in six persons aged 65 or older was poor (i.e., under the poverty line) or near poor (i.e., under $125 \%$ of the poverty line). The authors reported that more than $50 \%$ of poor older households spend more than half of their expenditures on housing, and more than $80 \%$ of the same group spends more than $30 \%$. O'Brien et al. (2010) reported that $40.6 \%$ of poor older adults were renters and, in general, older poor renters were more likely to face greater housing costs than older poor homeowners.

According to the Commission on Affordable Housing and Health Facility Needs for Seniors in the $21^{\text {st }}$ Century (2002), 324,000 Section 8-assisted units in senior properties were at risk of "opting out" of the HUD program (i.e., forfeiting their affordability subsidies) and the U.S. was losing more affordable housing units than it 
gained. According to the Commission, this was occurring based on the reduction in funding allocated for new affordable housing construction and the expiration of former affordable housing that was converted to market-rate housing. The Commission also reported that affordable housing in the U.S. is itself aging and in need of renovation and that over the past three decades, U.S. investment in affordable housing has declined.

Abbott (1983) declared that "a displacement of the poor and the elderly and the uneasy teetering of the middle-class housing pyramid add up to a housing crisis that calls for new programs in the city [i.e., Portland, Oregon], metropolis, and nation” (p. 273). In research conducted by the WHO (2007a), there was general agreement among municipalities from 33 cities and 22 countries throughout the world that the cost of housing is a major factor influencing where older people live and their quality of life. In Portland, participants in the local component of the study (older adults, caregivers, and providers of service in the public, for-profit, and nonprofit sectors) reported that affordability of housing is one of the biggest barriers to age-friendliness that older adults in the city face (Neal \& DeLaTorre, 2007a, 2007b).

Howe (2004) pointed out that although housing costs are high in Portland, the City, nonprofit organizations, and for-profit developers have made significant commitments to produce new housing that meets the needs of lower-income households, even though it is more expensive to develop this kind of housing. Howe explained that over time, Portland has developed a strong, multifaceted commitment to housing, as is evidenced in its Comprehensive Plan Goals and Policies (City of Portland, 2011a), and, in particular, the City's housing goal. Within the housing goal is language that indirectly 
addresses affordable housing for older adults, as it details the "needs, preferences, and financial capabilities of current and future households." The full landscape of policies concerning housing development is explored later in this chapter.

Development of housing for older adults. The development of housing for older adults has been a growth industry, and it is expected to expand over the next several decades due to the aging of the population. According to Gordon (1998), in the latter half of the 1980s and during parts of the 1990s, investors and developers began seeing the development of senior housing and communities as a desirable opportunity. To date, however, the development and management of senior housing (i.e., congregate housing with or without services) has been undertaken by relatively few large firms and organizations, unlike the general home building industry, which is carried out by numerous small firms (Gordon, 1998). Gordon explained that the need to understand complexities involved with constructing housing with care options can be seen as a barrier to many smaller and less experienced developers.

Outside of for-profit developers of housing for older adults, housing is often developed through partnerships that exist between for-profit, nonprofit, and public organizations (Porter, Brecht, Cory, Faigin, Gamzon, \& Taber, 1995). In Portland, the nonprofit housing development sector has a strong presence and many affordable housing developments have been completed by these entities. The public sector is also a contributor to the development of housing for older adults, and like the nonprofit sector, is a main contributor of affordable housing for lower-income people, in general. Specialized knowledge is necessary for developing housing units for older adults, 
especially those that provide long-term care, as there are complex government regulations and management requirements that are encountered in senior housing (Porter et al., 1995). Successful development firms have a thorough understanding of options, policies, and laws that are needed in order to complete a development (Gordon, 1998).

However, although the development of senior housing is unique due to its scope, complexity, and emphasis on the management of finished products, the basic process parallels the development of other types of housing in many respects (Porter et al., 1995). Porter specifically pointed to the initial stage of development as perhaps the most important part of the process, specifically when the developer is concerned with establishing basic strategies and approaches for a proposed project (e.g., formulating the basic concept, understanding its community and neighborhood context, determining the constraints and opportunities posed by the site, and structuring the subsequent sequences in the development process, including obtaining zoning approvals).

Gordon (1998) explained that no chronological order can be placed on the development of a senior housing community project, but he agreed that there is a "frontloaded" interdependent process (including team selection, site selection, and formation of the basic concept) wherein members of the development team are all, to varying degrees, called on throughout the process to expand, rethink, and refine their work as the project evolves. Porter et al. (1995) outlined the multidisciplinary project team of experts that a developer must assemble: a sponsor/developer and design team (architect, site planner, other design specialists), a market analyst, a builder or construction manager, an investment adviser, financing sources, a management and marketing firm, and an attorney 
with specialized expertise in senior housing. Additionally, private developers of housing for older adults tend to have created models for development that include specialized design for older persons.

These experts are crucial to the success of the overall project, as each of them possesses unique knowledge and experience. In collaborative projects where there are multiple developers, exploring the roles of different actors and processes necessary to completing a project on time and budget are important. The added dimensions of affordability and sustainable development practices that are specifically geared toward older adults may require additional expertise that may complicate the project further.

The processes and partners in a housing development are complicated. The general outline of processes have been described by Gordon (1998) and Brown and Tremoulet (2006) as having several characteristics: First, the owner/sponsor of a project will often begin a project with a building program that lays out the elements and processes desired in the creation of housing development (e.g., target population, number of units, green elements, steps in the process). The program often responds to a market analysis, a request for proposals from a government agency, and/or a vision for a building that may or may not be sustainable and/or affordable. The building program is then used to begin assembling the team that will be responsible for financing, designing, developing, and potentially managing the eventual housing project. After a development team is assembled several normal processes occur: appropriate sites are explored, feasibility studies are conducted, early design stages are begun, neighbors are notified of proposed activities, city-required reviews are conducted (e.g., environmental, 
transportation, zoning), and permits and fees are arranged. At this stage developers will address public concerns (e.g., neighborhood associations) and can make adjustments and/or change direction based on the input they receive. If the project is still considered feasible, then site control is obtained (i.e., gaining legal right to use land), which leads to the next series of processes, including detailed design, financing, construction, and the eventual occupancy of the building (Brown and Tremoulet, 2006; Gordon, 1998).

Giuliano (2004, pp. 208-9) posed two important questions that she argued should be asked in future research: "How sensitive are developers of senior communities to mobility and accessibility issues? Additionally, what are cities doing to encourage the location of senior communities in appropriate places?" An important component of Giuliano's position was the presentation of a possible research topic: studying urban planning practice related to senior housing development. This suggested research topic highlighted the limited attention that the academic community had placed on the planning and development of senior housing, and it provides part of the rationale for this research.

Howe et al. (1994) explained that as creative options for housing older adults arise, planners who are reviewing these projects will have few precedents to guide their assessment as they make important decisions (e.g., zoning amendments) during hearings and cases at the city level. In Planning for an Aging Society (Howe et al., 1994), creative planning processes were called for in regard to aspects of clustering/dispersal of developments, neighborhood impacts on issues such as parking and nearby businesses, community resistance (especially to low-income/affordable housing), and changes in land use that may be required (e.g., mixed-use, residential, commercial); additionally, site 
planning and the development proposal process were noted as important aspects of developing housing for older adults.

\section{Sustainability and Sustainable Development}

The term sustainability is derived from the word sustain, which means "to endure without giving way or yielding...to keep up or keep going, as an action or process; maintain" (Random House Webster, 1992, p. 1347). Aguirre (2002, p. 102) explained that "the scientific practice of sustainability antedates the recent collective surge centered on the idea of sustainable development." Wheeler (2000, p. 436) noted that "the birth of the sustainability concept in the 1970 s can be seen as the logical outgrowth of a new consciousness about global problems related to the environment and development, fueled in part by 1960s environmentalism.” Aguirre (2002) noted that the term sustainability had always referred to matters of the natural environment and Choguill (2007) suggested that the concept of sustainable development was initially conceived as a term most relevant to economic development. Today, the concepts of sustainability and sustainable development are used in many academic disciplines and professional settings.

An Internet search for the terms sustainability or sustainable development yields hundreds of millions of results, ranging in nature from urban planning and design to food systems and recycling. The terms are applied and represented in many ways; thus, it is crucial to provide ample context when discussing them. For example, the Oregon Sustainability Act (State of Oregon, 2001) defined sustainability to mean "using, developing and protecting resources in a manner that enables people to meet current needs and provides that future generations can also meet future needs, from the joint 
perspective of environmental, economic and community objectives." Oregon's definition has a distinct similarity to the best-known and commonly embraced origins of the concept "sustainable development" (Williams \& Millington, 2004), which comes from the Report of the World Commission on Environment and Development (United Nations, 1987), commonly referred to as the "Brundtland Report," after the commission's chair Gro Harlan Brundtland.

According to Meadowcroft (2000), although the Brundtland Report did not coin the expression "sustainable development," the report helped legitimize the concept, which was then formally endorsed by political leaders in 1992 at the United Nation's Rio Earth Summit in Brazil. In fact, he traced the concepts of "sustainability" and "sustainable society" to the 1970 s literature pertaining to the radical environmental movement. However, Choguill (1999) suggested that it was not until the 1990s that the concept of sustainable development moved beyond environmental and economic applications and into the areas of human settlements, urban areas, and housing. Today, these many variations of sustainability permeate political, academic, professional, and popular culture.

The Brundtland Report (United Nations, 1987) stated that "humanity has the ability to make development sustainable to ensure that it meets the needs of the present without compromising the ability of future generations to meet their own needs" (p. 24). Choguill (2007) noted that although this definition is ubiquitous among those familiar with sustainable development research, policy, and practice, it is a much more complex topic than the simple definition suggests. In a book titled Sustainable Cities in the $21^{\text {st }}$ 
Century (Foo \& Yuen, 1999), Choguill (1999, p. 135) explained that although the Brundtland Report's definition was "wonderfully appealing," it was impossible to operationalize as it did not "readily lend itself to measurement."

In order to clarify sustainable development's components, an overview of its descriptions in the literature is necessary. The United Nation's commission convened by Gro Harlan Brundtland attempted to identify the essential components of a sustainable future and has been summarized as the need to balance "the three E's" of environment, (social) equity, and economy (Berke, 2002, p. 30). McDonough and Braungart (2002) have opted to use the following descriptions to describe sustainability components: ecology (rather than environment), equity, and economy. Elkington (2012, p. 1), who first "coined the term triple bottom line" in 1994 in reference to necessary components of sustainable capitalism, focused on the following three components: people, planet, and profit. McDonough and Braungart (2002, p.154) suggested that businesses should consider the "triple top line" as a strategic design tool before beginning a project, rather than after the fact.

Dillard, Dujon, and King (2009) explained that that although social sustainability issues have been alluded to within the literature, social sustainability is still just emerging into the mainstream concerns of many in practice and in academic research. In Social Sustainability in Urban Areas: Communities, Connectivity and the Urban Fabric (Manzi, Lucas, Lloyd-Jones, \& Allen, 2010) the authors proposed that "principles of social sustainability are inseparable from environmental and economic factors" and that the "concept needs to consider the central question of equity" (p. 24). Manzi and colleagues 
(2010) detailed that a social equity policy agenda must focus on implementation efforts that are based on three specific visions of how a good society should function, namely that it is inclusive (tackling social exclusion), caring (fostering the development of social capital), and well governed (instituting effective government mechanisms). In addition to the focus of social equity, the United Nations Educational, Scientific and Cultural Organization (2001) expanded upon the three core components of sustainability by including culture as a necessary element that should be considered as important as environmental issues and as a necessary partner to both the for-profit sector and civil society.

The resiliency of the term sustainable development can be attributed to the concept's most important strengths, which Meadowcroft (2000) noted as "its focus on global issues, on linking economic and environmental decision making, on inter- and intra-generational equity, and on achieving structural reform while leaving it open to experience to establish the ultimate parameters of the required changes" (p. 384). Meadowcroft added that sustainable development also considers "relevant stakeholders" who are engaged in participatory, process-oriented directions and who perceive sustainable development "as a value to be enhanced rather than as an absolute goal" (p. 439). Leach, Mearns, and Scones (1997) argued that urban scholars-planners in particular-are analyzing sustainability incorrectly as power inequalities and community institutions are largely ignored. Instead, they posited that agendas of specific interest groups with different goals and perspectives on problems and solutions need to be considered. 
Krueger and Gibbs (2007) detailed that the discourse of sustainability is more frequently found in urban and regional development strategy than ever before. They explained that sustainability "exists as a diverse set of policy provisions being rolled out around the world," but that what remains unclear is "how those policies mesh with the social relations that attend our current form of capitalism and raise critical questions about the prospects of sustainability and how it must be engaged if it is to live up to its tripartite concerns of economic stability, social equity, and environmental integrity" (p. 9). Raco (2007) described "implementation deficits" as an area of concern and distinction between discourses of sustainability and implementation practices; he noted a "significant difference between the aspirations of policymakers and the institutional structures and resources that exist, or are created, to bring policy measures to fruition" (p. 225). Taking comments from Krueger and Gibbs and Raco together, the prospects of sustainability depend on the ability to move beyond policy and into implementation stages which requires concerted efforts and resources to be dedicated by policymakers and institutions.

In summary, sustainable development and sustainability have evolved over time from being an outgrowth of the environmental movement and economic principles to becoming an overarching direction in which policymakers, citizens, academics, and practitioners are encouraged to follow. This includes the need for more focus on issue of people and social equity in the future and moving beyond policy formation and into implementation efforts. The application of sustainable development to urban areas and, in particular, housing, has emerged in the recent past. The concepts of sustainable development focus primarily on three principles: (1) short- and long-term perspectives 
need to be integrated in daily actions and planning processes; (2) the environment (physical, cultural, and social) or ecology, economic stability, and social equity are all inextricably connected in balancing for future growth and consumption patterns; and (3) participatory, processes-oriented directions must be followed in planning for future sustainability.

\section{Sustainability and Older Adults}

We must remember to consider that the next generation will be aging differently from any previous generation and also, according to Berke (2002) and Meadowcroft (2000), that a goal of sustainable development is intergenerational equity, which implies fairness to coming generations. This multi-generational perspective is also seen in some Native American approaches to decision-making. For example, the Seventh Generation Fund for Indian Development (2011) considers the impact of decisions seven generations into the future with respect to revitalization, restoration, preservation, planning, and development projects.

As our population ages, intergenerational dilemmas, such as dwindling resources and increasing need, may cause conflict. Wright and Lund (2000) explained that most of the attention to the impact of an aging society has focused on economic issues, especially the aging of the Baby Boom population (e.g., national debt, federal entitlements, and healthcare costs). In reality, as early as 1995, scholars had begun discussing sustainability and an aging population from a different perspective. At a conference convened at the University of North Texas in Denton in 1995 titled, An Aging Population, an Aging Planet, and a Sustainable Future: Thinking Globally, Acting Locally, academics 
examined the relationship between population aging and ecological development in order to explore the ways in which older people can help societies meet the ecological and social challenges facing our world (Ingman, Pei, Ekstrom, Friedsam, \& Bartlett, 2005).

In Chapter 1 of a publication arising from that conference, Elderly People and the Environment, Laws (1995) suggested a number of research possibilities regarding elderly people and the environment prompted largely by the "lack of detailed attention to the interaction of population aging, elderly people, and environmental problems" (p. 17). She detailed four important areas needing attention: (1) planning and policy making that is sensitive to local histories and geographies; (2) vulnerability of older adults to natural hazards and environment change; (3) the contributions of the elderly to environmental problems and solutions; and (4) the distribution of resources according to the needs of competing groups.

From the North Texas conference proceedings, Ekstrom and Pei (1995) explored the relationships between sustainable futures and aging populations in order to identify problems and potentials. In regard to the latter issue of potential, they saw older adults as having been excluded by modern society, even though they have valuable contributions to make to sustainability and sustainable development. Additionally, Ekstrom and Pei noted three potential problems: (1) population aging will be problematic due to limited family and governmental resources that will be needed for many groups of people; (2) as economic well-being of the elderly increases, consumption and demand for goods and services increases; and (3) as demands for specialized services such as long-term care 
increase, resources dedicated to providing new technologies will expand, creating further environmental impact.

Ekstrom and Ingman (1999) took into consideration older adults' available skills, time, and enthusiasm as important contributions that could address public concerns. In particular, senior engagement in environmental affairs was seen to be growing, and the authors felt it should be tapped into for the creation and maintenance of sustainable communities. Laws (1995) noted that elderly people are often underrepresented in conversations about the environment, as young people are often the target audience. Ekstrom and Ingman (1999) also pointed to the need for education at all ages, specifically regarding teaching younger people about the process of aging, teaching older people about being stewards of the environment, and ensuring interaction between the two groups so that synergy is created that moves toward more sustainable knowledge and policy.

In the article Sustainability and Automobility among the Elderly: An International Assessment, Rosenbloom (2001) noted that sustainability has many definitions, and she explained that communities and neighborhoods can support older adults' lives in an environmentally responsible way, including the incorporation of transportation-oriented issues that are environmentally friendly. Rosenbloom also saw many aspects of the environment as good for older adults, including: (1) pedestrian amenities that reduce vehicle-pedestrian conflicts (e.g., traffic islands); (2) mixed land uses so that walking, biking, and mass transit are possible and realistic; (3) enhanced comfort, safety, and security, which should increase mobility (e.g., street furniture, lengthened traffic signals, 
electronic warning signs); (4) walkways free from illegally parked cars, bike riding or rollerblading, food carts, and vendor stalls; and (5) housing where residents are not dependent on the automobile, have access to medical and shopping services, feel safe and comfortable, and can afford to live.

Rosenbloom (2001) briefly mentioned affordable and appropriate housing as important to sustainability among older adults. Although a gap in the literature on sustainable housing and older adults exists, we can borrow from Choguill's (2007) detailing of policies in five areas that must be devised and implemented in order to achieve sustainability in the housing sector: (1) involvement of the community in all steps of planning, development, and maintenance; (2) access to quality building materials at a cost that they can afford; (3) building standards that are not overly cost prohibitive but foster good health and safety; (4) improved housing finance models that allow housing needs to be met; and (5) ensuring the availability of adequate land for residential construction at a price that householders can afford. Choguill (2007) concluded that "without thinking through housing policies and basing them on sustainability criteria...there is no chance at all of success" (p. 147).

Landorf, Brewer, and Sheppard's (2008) work on the urban environment and sustainable aging argued that the "disabling impact of the urban environment on older people should be an essential consideration in the urban sustainability debate” (p. 512). They proposed the following urban aspects as critical for creating a sustainable urban environment that facilitate a healthy later life for an aging society: fostering sustainable aging in place; enabling older adults to be engaged in physical, social, and community 
activity beyond the home environment; creating an urban environment that enables the broadest range of functional limitations; requiring governments to coordinate and financially support an inclusive approach to urban design; cultivating independence and empowerment among older adults in later life; and advancing a political and intellectual challenge to the constructs that currently dictate urban development policy and practice.

\section{The Policy and Program Landscape for the Planning and Development of Sustainable, Affordable Housing for Older Adults in Portland}

Since the 1930's the public sector has assumed major responsibility for housing low-income older adults, and there is a general acceptance among the public that governmental agencies should bear that responsibility (Turner, 1986). Public policies, in general, are critical for shaping the health, well-being, and independence of the U.S. population. As Andrain (1998) explained, public policies shape individual, group, and national health when they reduce environmental risks and expand opportunities that lead to improved health. By reducing the prevalence of substandard housing for low-income older adults and increasing housing that is built with healthy materials and in connected neighborhoods (e.g., with access to transit and services), public policy has the ability to improve the health of older adults in need of such housing.

Policies can be seen as a collective response to a social problem by an agency that assumes a position, and programs are the products of policy that are shaped by legislation or regulation as defined by the policies' goals (Segal, 2010). The implementation of policies occurs after a program is enacted and details the administration of a program and the resulting impacts on people and events (Mazmanian \& Sabatier, 1989). Abbott (1983) explained that in Portland, Oregon, in order for policies to be successful, it has been 
necessary to engage elected official, public sector agencies, and individuals and groups that are recognized as legitimate participants in the public decision making process such as advocates, the private sectors, and citizens.

The planning and development of sustainable, affordable housing in Portland, is affected by a range of policies, legislation, regulations, actors, programs, and implementation efforts from the federal to the local level. Some of these policies and programs are administered by higher levels of government (e.g., statewide allocation of Section 8 housing vouchers), some are influenced by federal and state legislation (e.g., the LIHTC program is administered by the Internal Revenue Service, comprehensive plans in Portland are required by the State of Oregon), and some are uniquely local in creation and implementation (e.g., design review in Portland). This section overviews these policies to set the context for the remainder of this research.

In must be noted that the housing policies discussed in this section are specific to independent housing, including such housing with limited supportive services, but do not extend to licensed long-term care and congregate settings (such housing options are not the focus of this research). The policies and programs affect older adults in varying degrees and are covered with the understanding that this research will explore how they affect an aging society.

\section{Federal policies and programs that have an impact on the development of} sustainable, affordable housing. According to Smith (2006), the U.S. has used federal policies and programs to respond to housing needs since the $1800 \mathrm{~s}$, but there were two major turning points in affordable housing policy: first, the enactment of tenement laws 
to regulate the quality of affordable housing, requiring improved health and safety minimums for housing of poor citizens in slum dwellings toward the end of the $19^{\text {th }}$ century; second, after the Great Depression the enactment of housing acts in 1934 and 1937 that launched the modern public housing system and created a means for the federal government to provide funds and authority to remove substandard private housing and replace it with higher quality public housing.

Today, affordable housing policy is often associated with public housing and lowincome subsidies, even though, as Schwartz argued (2006), federal legislation in the form of tax benefits for homeownership has provided a much larger housing subsidy that benefits the affluent. The focus here is on federal affordable housing policy and programs and the goals and outcomes that are associated with the availability of quality, affordable housing, including the meso- and macro-level contexts that the housing lies within.

In addition to subsidizing housing, federal policies and programs focus on the creation of racial and economic diversity in neighborhoods, household wealth creation, strengthening families, linking housing to supportive services, and promoting balanced metropolitan growth; governments are able to shape such policies through direct subsidies, tax incentives, regulatory policies, and by providing supports to financial institutions (Bratt, 1989; Katz, Turner, Brown, Cunningham, \& Sawyer, 2003; Schwartz, 2006).

Policies and programs that directly affect the sustainability of housing, or promote sustainable development with respect to housing and environments, are more recent in creation. Specifically, in June, 2009, the Partnership for Sustainable Communities was 
formed by HUD, the U.S. Department of Transportation (DOT), and the U.S. Environment Protection Agency (EPA). These three agencies pledged "to ensure that housing and transportation goals are met while simultaneously protecting the environment, promoting equitable development, and helping to address the challenges of climate change" (EPA, 2010, April). The interagency partnership was created to coordinate efforts according to six livability principles that are intended to guide the agencies' work: (1) provide more transportation choices; (2) promote equitable, affordable housing; (3) enhance economic competitiveness; (4) support existing communities; (5) coordinate and leverage federal policies and investment; and (6) value communities and neighborhoods (Partnership for Sustainable Communities, 2009).

Federal public housing. The first major subsidized housing program in the U.S., the Public Housing program, originated as part of the Housing Act of 1937, which was itself part of the New Deal, and at the time of passage, the legislation was considered to be as important to job creation as it was to the creation of low-income housing (Bratt, 1989; Schwartz, 2006). Since the creation of the Public Housing program, it has devolved from a strong federal program to increased authority at the local levels and with responsibilities being taken on by the private sector (Smith, 2006). Today, the policy guiding public housing eligibility varies by state, but eligibility is generally broken into three categories: extremely low income, or $30 \%$ of MFI; very low income, or $50 \%$ of MFI; and low income, or $80 \%$ of MFI (HUD, 2012c). As noted earlier, the Portland Housing Bureau's (2012) established income thresholds for a single-person household was at the following levels: $30 \%$ of the area's MFI was $\$ 14,600$ per year or $\$ 365$ per 
month; $50 \%$ of the area's MFI was $\$ 24,300$ per year or $\$ 607$ per month; $80 \%$ of the area’s MFI was $\$ 38,850$ per year or $\$ 971$ per month.

According to HUD (2011b), there were approximately 3,300 housing authorities throughout the U.S. that provide over 1.2 million households with housing. These programs house some of the nation's poorest and most vulnerable households and, over time, the population has become increasingly impoverished (Schwartz, 2006). According to the Resident Characteristics Report (HUD, 2011c), in 2011, 52\% of the residents had an annual income of $\$ 10,000$ or less, $48 \%$ of the residents had lived in public housing for five years or longer, and $46 \%$ were single-person households.

In addition to the Public Housing program, other HUD-operated programs assist in the provision of public housing for low-income older adults: Section 202, Section 221(d)(3), Section 236, and Section 8 (only Section 202 provides housing exclusively for older adults) (Perl, 2010). The Section 8 program consists of two programs: the Housing Choice Vouchers and Project-Based Vouchers programs. The Housing Choice Voucher program is administered by local public housing agencies that assist very low-income families, older adults, and persons with disabilities. Income may not exceed $50 \%$ of the median income and at least $75 \%$ of the vouchers must go to those at $30 \%$ of the median income or below; recipients are free to find their own housing as long as it meets the minimum health and safety standards and they pay $30 \%$ of their household income as rent, even if they do not have an income, in which case they would not pay rent (HUD, 2011d). 
Although vouchers are less expensive to administer by HUD and provide access to a wider range of options (public and private), wait lists are long, and finding housing once a person has a voucher is considered difficult; residents aged 62 and older were also $14 \%$ less likely to succeed in using their vouchers than those younger than 62 (Schwartz, 2006). HUD also provides 20,000 vouchers to eligible homeless veterans as part of the HUD-VASH (Veteran Affairs Supported Housing) program; this program addresses the needs of the most vulnerable homeless veterans, who must be eligible to receive health care and case management service from Veterans Affairs (U.S. Department of Veterans Affairs, 2011).

The Project-Based Voucher program is also funded federally and administered by state and local governments. Developers of a building can cover the cost of constructing or rehabilitating a building, thereby keeping the building more affordable to residents living in units with subsidized rents; tenants pay $30 \%$ of their income, and the property owner receives subsides when a qualified resident occupies the unit (Smith, 2006). After the Section 202 program, the project-based Section 8 program has provided the second most housing dedicated specifically for low-income older adults (Perl, 2010).

The Section 202 Supportive Housing for the Elderly program provides capital advances for constructing, rehabilitating, or acquiring supportive housing exclusively for those aged 62 and older. The program is similar to the Section 811 Supportive Housing for Persons with Disabilities program, as they both provide capital and limited services such as cleaning, cooking and transportation, albeit to different target populations (i.e., persons aged 62 and older and persons with disabilities) (HUD, 2011e). Section 202 was 
established as part of the Housing Act of 1959 and has evolved to award grants to private nonprofit groups and for-profit general partnerships where the sole general partner is a nonprofit organization (Perl, 2010). About 85\% of HUD's Section 202 funding goes to metropolitan areas, and Section 202 and 811 funding mechanisms are able to be used with LIHTC equity for project development (Perl, 2010).

Section 221(d)(3), the Below Market Interest Rate program, and the Section 236 program (on a moratorium since 1973) have also assisted in the provision of public housing for older adults. The former helps public agencies, cooperatives, limited divided corporations, and nonprofit sponsors secure mortgage insurance for loans for new construction and rehabilitation of housing above low-income levels but below marketrate housing; the latter assisted for-profit and nonprofit owners of rental housing for lowand moderate-income families in securing mortgage insurance for construction and rehabilitation projects, as well as rental assistance (Perl, 2010).

\section{Federal policies and programs related to financing affordable housing for}

older adults. A number of additional policies and programs have contributed to the development of affordable housing in the U.S. According to Schwartz (2006), since 1976, the federal government has shifted its attention from the production of new low-income housing toward the preservation of low-income housing already subsidized (e.g., the renewal and extension of contracts). The Mark-to-Market program, launched in 1997 and coordinated by the Office of Affordable Housing Preservation, focused on reducing rents of existing low-income housing units, and thus preserving its affordability, by working 
with property owners and other housing stakeholders; the program was scheduled to terminate on October 1, 2011 (HUD, 2011f).

The federal government does still subsidize the production of affordable housing. The LIHTC program is the single largest subsidy for low-income rental housing in the U.S; it is not a federal housing program but instead is part of the Internal Revenue Code (Schwartz, 2006). Bratt (1989) explained that without tax incentives such as the LIHTC, the private sector would not have become a major producer of federally subsidized housing and that, overall, the LIHTC program has proven to be successful in the goal of producing low-income housing. According to Enterprise Community Investment, Inc. (2011), which helped write the Tax Reform Act of 1986 (the legislation that enacted the LIHTC program), the LIHTC accounts for nearly $90 \%$ of all affordable housing created in the U.S. today (both new construction and rehabilitation).

The way that LIHTC works is to allow private investors to reduce their federal income taxes by $\$ 1$ for every dollar of tax credit received, with the amount of equity generated by the tax credits depending on two factors: the price investors are willing to pay for the credit and various transaction costs connected to the sale or syndication of the tax credits (Schwartz, 2006). According to a study of the LIHTC program by Kochera (2002), although the program has significantly expanded the supply of affordable housing, there is still considerable unmet demand for very poor renters, since LIHTC tax credits are commonly used for affordable housing above the $30 \%$ of MFI threshold, which is considered to be the group with the highest need for subsidy. 
The Community Development Block Grant program (CDBG), Neighborhood Stabilization Programs (NSP), and HOME Investment Partnership programs (HOME) are important funding mechanisms for affordable housing and their surrounding environments, and all three programs have been used in housing development projects that are specifically intended for older adults. The CDBG program, started in 1974, is a flexible program that funds community development needs; it specifically works to ensure that communities receive decent affordable housing, services, and job creation (HUD, 2011g). According to Kochera (2002), 5.7\% of the LIHTC properties developed for older adults between 1987 and 1998 also received CDBG funding. The NSPs were established in 2008 as part of the Housing and Economic Recovery Act for the purpose of stabilizing communities that had suffered from foreclosures and abandonment; HUD issued three rounds of funding available for beneficiaries at or below $120 \%$ of MFI that were still being utilized throughout 2012 (HUD, 2011p; U.S. Government Printing Office, 2012, November). HOME, enacted in 1990, is the largest federal block grant program designed exclusively for the creation of low-income housing (both rental and ownership); the program provides approximately $\$ 2$ billion in funds to local jurisdictions and requires a match of 25 cents of every dollar of support given (HUD, 2011h).

Another program, the HOPE VI program, grew out of the work of the National Commission on Severely Distressed Housing that was formed in 1989; the Commission concluded that about $6 \%$, or approximately 86,000 , of the public housing units in the U.S. were extremely distressed as indicated by considerable crime, poverty and unemployment levels (Smith, 2006). Since that time, hundreds of public housing projects across the 
nation have been transformed from distressed housing to smaller-scale, mixed-income housing that is considered to be a dramatic improvement over the previous housing (Schwartz, 2006). Only public housing authorities that have severely distressed housing units in its inventory are eligible to apply (HUD, 2011q).

The National Housing Trust Fund (HTF) is a new affordable housing production program that is intended to work in tandem with current federal, state, and local programs focusing on low-income housing, including housing for older adults (HUD, 2011i). Established under the Housing and Economic Recovery Act of 2008, the HTF sought funds for the construction and preservation of decent, safe, and sanitary housing for lowincome and homeless families (HUD, 2011i). On July 12, 2011, the House Committee on Financial Services voted in favor of eliminating the HTF (House of Representatives Bill 2441, 2011), but as recently as February, 2012, President Obama proposed \$1 billion in mandatory spending for the 2013 fiscal year (Crowley, 2012, June 7).

\section{Federal policies and programs associated with sustainable, affordable}

housing. The Fair Housing Act, administered and enforced by HUD, was adopted by the U.S. in 1968 to prohibit discrimination by real estate agents and other actors in the housing market; it has been amended considerably in the years since its adoption (Schwartz, 2006). In 1988, an amendment was passed to prohibit discrimination on the basis of disability and familial status (race was already covered in the original Act). The amendment also clarified that housing designated for older adults was exempt from the familial status portion (i.e., families with children can legally be excluded). Specifically, the Housing for Older Persons Act of 1995 provided that housing for older persons must 
be: (1) specifically designed for and occupied by elderly persons; (2) occupied solely by persons who are 62 or older; or (3) house at least one person who is 55 or older in at least $80 \%$ of the occupied units and adhere to a policy that demonstrates intent to house persons who are 55 or older (HUD, 2011j). According to the Fair Housing Act Design Manual: A Manual to Assist Designers and Builders in Meeting the Accessibility Requirements of the Fair Housing Act (HUD, 1998), multifamily dwellings built after March 13, 1991, are required to adhere to specific accessibility requirements so they are usable for residents with disabilities, including housing built specifically for older persons.

The ADA and the Architectural Barriers Act of 1968 (ABA) were important laws that also have contributed to the development of housing and environments for older adults. ADA was a civil rights law enacted in 1990 (amended as recently as 2009) that was the culmination of a two-decade effort to secure the rights of persons with disabilities under five Titles: (1) employment; (2) public entities; (3) public accommodations; (4) telecommunications; and (5) miscellaneous provisions (Koff \& Park, 1993; U.S. Department of Justice, 2009). Bachelder and Hilton (1994) noted that, based on the prevalence of disability that increases with age, older adults are expected to be the single largest group to benefit from the ADA. The ABA requires that buildings and facilities built by or on behalf of the U.S. government (including those partially financed by the government) are accessible to persons with mobility impairments (HUD, 2011k). According to the federal government's website Disability.gov (U.S. Department of Labor, n.d.), the following six federal agencies oversee that compliance is met according to 
established minimum standards: the Architectural and Transportation Barriers Board, U.S. Access Board, U.S. Department of Defense, HUD, U.S. Postal Service, and the General Services Administration. Both the ADA and the ABA address the physical environment and must be followed by developers, designers, and building trade professionals.

Section 504 of the Rehabilitation Act is a national law that protects qualified individuals from discrimination based on their disability in programs and activities that receive federal assistance; this includes housing projects that receive funding from HUD (HUD, 2011m). The rehabilitation act is seen as one of the policy efforts (along with the Fair Housing Act and the ADA) that enable older adults-with and without disabilities-to be integrated in their communities and to be provided with opportunities similar to other populations (Pynoos, Nishita, Cicero, \& Caraviello, 2008).

Within the past decade, the federal government has begun to look at key partnerships among federal agencies that will lead to more sustainable, affordable housing options. In 2008, a report to Congress titled Better Coordination of Transportation and Housing Programs to Promote Affordable Housing Near Transit (DOT, the Federal Transit Administration, \& HUD, 2008) focused on promoting and coordinating the provision of affordable housing near transit. That report detailed needed actions on three separate but related issues: (1) expanding the availability of affordable housing near transit; (2) developing a more comprehensive approach to address household expenditures on housing and transportation; and (3) preserving existing affordable housing. Based on the recommendations of that report, funding streams were 
dedicated to coordinating and expanding affordable housing near transit; the report was also instrumental in fostering a new partnership at the federal level, as explained below (HUD, 2011n).

The Partnership for Sustainable Communities-formed in June, 2009-is an interagency program considered to be one of the most innovative partnerships that has been implemented among three agencies: HUD, DOT, and EPA (as a reminder, the latter two agencies are responsible for federal transportation and environmental services, respectively); it aims to coordinate and invest in housing, transportation, and the environment (Madrecki, 2012, February 14). Garcia (2011) explained that the partnership among the three agencies, which have usually operated independently, will promote sustainability across the six livability areas: (1) providing more transportation choices; (2) promoting equitable, affordable housing; (3) enhancing economic competitiveness;

(4) supporting existing communities; (5) coordinating and leveraging federal policies and investment; and (6) valuing communities and neighborhoods. Garcia detailed that the promotion of sustainability would occur through increased efforts to focus on reducing resource depletion, increasing cross-jurisdictional planning, and eliminating duplicative requirements across siloed organizations. In 2013, President Obama dedicated $\$ 100$ million toward the Partnership, effectively funding the Sustainable Communities Initiative from CDBG funds which will be split between the Sustainable Communities Regional Planning Grants and Community Challenge Grants (Jordan, 2012, February 14).

Oregon policies and programs that have an impact on the development of sustainable, affordable housing. In Oregon, various policies and programs at different 
levels (i.e., state government, boards and commissions, associations, villages, cities, counties, and regional government) affect the planning and development of sustainable, affordable housing for older adults. The public sector uses legislation, resolutions, planning documents, zoning and building codes, permits, fees, inspections, and financing mechanisms, all of which influence the subsequent planning and development of housing and environments (e.g., transit, pedestrian infrastructure, nearby services).

The Oregon Department of Land Conservation and Development (DLCD) guides state land policy and the statewide land use planning program that was established in 1973; the DLCD seeks to provide a healthy environment, sustain a prosperous economy, ensure a desirable quality of life, and provide fairness and equity to all Oregonians (DLCD, 2012). As a part of its land use planning program, Oregon has maintained a set of planning goals and accompanying guidelines. Goal 10 of Oregon's Statewide Planning Goals and Guidelines (DLCD, 2010a, p.1) focuses on housing and seeks to "provide for the housing needs of citizens of the state." The guidelines specify that local comprehensive plans developed by local governments should include housing and land inventories, housing stock available at various income ranges, a determination of housing vacancies and needs, and an allowance for housing densities and types that are needed within communities.

Another state agency, Oregon Housing and Community Services (OHCS), shares the same goal and responsibility for providing for the "housing needs for the citizens of the state." OHCS specifically provides "financial and program support to create and preserve opportunities for quality, affordable housing and supportive services for 
moderate, low, and very-low income Oregonians" (OHCS, 2010). OHCS affects

regional- and local-level jurisdictions through the following action: financing housing

through loans, grants, and tax credits; administering federal Section 8 program; managing

and reviewing affordable housing loans and contracts; and convening the Oregon State

Housing Council, which sets statewide policy, rules, and standards for housing programs.

Oregon Revised Statute 456.510 (State of Oregon, 2011a), which first appeared in

OHCS's Consolidated Funding Cycle Application in 2004, addresses specific

requirements that make some publicly funded housing easier for people with mobility

impairments to visit. The statute is an attempt to increase the availability of "visitable

housing” by prohibiting OHCS from providing funding for the development of new rental

housing that is subsidized unless it adheres to a list of requirements. ${ }^{7}$ Oregon Revised

Statute 456.513 allows exemption requests to be made based on topography, community

and design standards, undue cost restraints, or conflicting funding requirements (State of

Oregon, 2011b). The visitability statute applies to new subsidized rental housing

construction and rehabilitation projects that receive OHSC funding (e.g., bond financing

and/or non-competitive tax credits) and specifically aims to "encourage the design and

construction of dwellings that enable easy access by individuals with mobility

impairments and that allow continued use by aging occupants" (OHCS, 2011).

\footnotetext{
7 “(a) Each dwelling unit of the housing meets the following requirements: (A) At least one visitable exterior route leading to a dwelling unit entrance that is stepless and has a minimum clearance of 32 inches; (B) One or more visitable routes between the visitable dwelling unit entrance and a visitable common living space; (C) At least one visitable common living space; (D) One or more visitable routes between the dwelling unit entrance and a powder room; (E) A powder room doorway that is stepless and has a minimum clearance of 32 inches; $(F)$ A powder room with walls that are reinforced in a manner suitable for handrail installation; (G) Light switches, electrical outlets, and environmental controls that are at a reachable height; (b) For a development that has a shared community room or that has 20 or more contiguous units, there is at least one powder room available for all tenants and guests that is accessible"
} (State of Oregon, 2011a, para. 2-9). 
Another piece of legislation associated with the creation of affordable housing was House Bill 2436 (the Housing Opportunity Bill), which was passed in the 2009 legislative assembly and led to an assessment of a $\$ 15$ recording fee on real estate transactions (State of Oregon, 2009; The Housing Alliance, 2011). A fund was intended to be created for the purpose of developing affordable housing, but it is unclear whether any funding has been dedicated for that purpose to date.

Oregon's Building Codes Division (BCD) is another important agency that has an impact on the physical accessibility of housing and environments, as it provides code development, administration, inspection, plan review, licensing, and permit services to the construction industry (BCD, n.d.). In addition to ADA and ABA requirements, $\mathrm{BCD}$ adopts and administers guidelines and enforces license, code, and permit requirements. Any potential changes to building code that would affect accessibility (e.g., visitable and universal design) would need to be coordinated through BCD, since it sets the statewide standards.

One important Oregon ballot measure that is important to the state government and tax revenue is Measure 5. Measure 5 passed in 1990 and is considered to be one of the most contentious tax measures in Oregon history, as it capped property and real estate taxes and has had an influence on the reduction of funding for government services (McMahon, 2010).

Finally, policy related to inclusionary zoning must be mentioned; inclusionary zoning is also described as inclusionary housing or as inclusionary land-use regulations (Mallach, 2009). Policy Link (2003, p. 1) described "inclusionary zoning" as the creation 
of affordable housing that requires developers to "make a percentage of housing units in new residential developments available to low- and moderate-income households." Hickey (2013, p. 3) added that inclusionary housing was being used to describe policies that "either require developers to offer lower-priced units...or encourage their inclusion through incentives." According to Policy Link (2003, p. 1), in the past, developers have received "non-monetary compensation" in the form of: "density bonuses, zoning variances, and/or expedited permits that reduce construction costs."

The Center for Housing Policy's report After the Downturn: New Challenges and Opportunities for Inclusionary Housing (Hickey, 2013, p. 3) noted differences between mandatory and voluntary policies as being "thin at times;" some voluntary policies were “acting as requirements" while some mandatory policies were "giving developers a choice of whether to opt in." Since "substantial gray area" was noted as existing between voluntary and mandatory policies, Hickey (2013, p. 3) used the term "inclusionary housing" to "encompass both approaches" in his paper that detailed the challenges and opportunities for inclusionary zoning as the housing market begins to recover.

According to Mallach (2009) inclusionary zoning is related to two ideas that began to capture the attention of planners, housing developers, and local officials in the 1970s: (1) there were good reasons why lower-income families could live in the same housing developments as affluent ones; and (2) more affordable housing could be created if it were made to be a part of market-driven development processes through taking advantage of the considerable energy and resources possessed by builders and developers. 
Provo (2009), explained that Portland's regional government, Metro, passed its Regional Framework Plan in 1997 which detailed the following regulations: local municipalities were to remove barriers to creating affordable housing and take steps to promote housing production (including the enforcement of a numerical fair share target backed up by regulatory tools); if the prior actions failed, region-wide mandatory inclusionary zoning would be required. Metro (1997, as cited in Provo, 2009, p. 376) detailed that the implementation of the inclusionary zoning provision would occur at the end of 1998 "if cooperative programs have not significantly moved the region towards the goals of this policy." Metro created an Affordable Housing Technical Advisory Committee in July of 1998 to shape the debate and build consensus for or against the issue; however, the reaction to the proposed policy was swift and negative, and in only a few months the home builders coalition in Oregon sought and won what may be the only statewide ban on the adoption of inclusionary zoning ordinances in the U.S. (Provo, 2009). In 2011, a repeal of the 1999 legislation was proposed as Oregon House Bill 3531 (State of Oregon, 2011c, p. 1). That bill did not pass.

A final important policy at the state level that must be mentioned is Oregon Project Independence (OPI). OPI is a program that is designed to help older adults stay in their home by offering assistance with basic tasks (Lehman, 2010, June 23). This type of program helps people age in place by bringing services to homes, which supporters of OPI say is a bargain, especially when compared to the alternative: paying for long-term care services in a care facility (Lehman, 2010, June 23). Although funding for OPI has 
shrunk in recent years, it is still considered an important program in Oregon that helps to meet the needs of older adults.

\section{Regional and county policies and programs that have an impact on the}

development of sustainable, affordable housing. The goals and guidelines from the State of Oregon are applied in Portland by Metro, Multnomah County, and the City of Portland. In addition to Goal 10 (Housing; see Oregon's policy and program in the previous section), a critical aspect of determining the quantity and quality of housing is related to Goal 2 (Land Use Planning), as this goal requires local governments to “establish a land use planning process and policy framework as a basis for all decisions and actions related to use of land and to assure an adequate factual base for such decisions and actions" (DLCD, 2010b, p. 1). One of the results of this goal is the development of comprehensive plans that are integral to the planning and development of all housing in the state.

Metro is a unique government agency; beginning operations in 1979, it is the only directly elected regional government for any U.S. metropolitan area since that time (Abbott, 2011). According to Seltzer (2004, p. 38), by law in Oregon "only cities and counties have the responsibility and authority to develop comprehensive land use plans," which are the "primary legal documents guiding all local and planning and development decisions." However, as Seltzer explained, Metro has also been given the "astounding power" to require local entities (e.g., Portland) to make their comprehensive plans "consistent with the regional functional plans" (p. 38). Metro is the official metropolitan planning organization (MPO) of the Portland region; MPOs are responsible for 
transportation planning in metropolitan areas, and most receive the majority of their planning funds from federal sources, but they also receive funds from other sources such as states or localities (U.S. Government Accountability Office, 2009).

Metro manages the region's Urban Growth Boundary (UGB), which is required under Oregon's statewide Goal 14: Urbanization. The Metro UGB encompasses Washington, Multnomah and Clackamas counties, along with 24 cities and more than 60 special service districts. It is defined by the region's growth management policy, known as the 2040 Growth Concept and the related Urban Growth Management Function Plan. Affordable housing, transportation, and regional planning are all components of Metro's charge, and 10 urban design types have been identified as the "building blocks" of the regional strategy for managing growth: central city, main streets, regional centers, town centers, station communities, neighborhoods, corridors, industrial areas and freight terminals, rural reserves/open spaces, and neighboring cities/green corridors (Metro, 2011a, para. 4). These building blocks, and the wider set of land use policies originating from Metro, set the stage for the comprehensive planning efforts of both Multnomah County and the City of Portland.

Multnomah County is also involved in Portland's efforts to develop sustainable, affordable housing for older adults, albeit only slightly. A review of the county's planning guidelines revealed that their direct impact on urban planning in the city of Portland is inconsequential. The City of Portland's (2001a) document, Land Use Changes for City-Zoned Multnomah County Properties, explains the Multnomah County's ceding of authority to the City of Portland on urban land use issues: 
On January 1, 2002 properties within unincorporated Multnomah County but within Portland's Urban Services and Urban Growth Boundaries will be given City zoning and subject to Portland's land use regulations. This was done as part of an intergovernmental agreement between the City and the County to let the County focus on rural land use concerns and the City on urban ones. The changes are needed for county compliance with regional land use laws. (Multnomah County, 2011, para. 1)

Although the County is not involved in urban planning in the City of Portland, it is involved with related public processes (e.g., housing needs assessments), service provision for older adults, and operating senior centers and other programs that are important for the overall well-being of older adults and people with disabilities.

One agency in Multnomah County that contributes directly to the creation and operation of affordable housing for older adults is Home Forward. ${ }^{8}$ Home Forward is the largest producer of affordable housing in Oregon, with more than 6,000 apartments, 8,400 Section 8 vouchers, and over 100 community agency partners that support housing options for low-income individuals and families (Home Forward, 2011). The countybased housing authority is critically important in providing affordable housing for older adults with high needs, as the agency subsidizes rents and develops, redevelops, and preserves affordable housing for older adults, which is considered by researchers to be a clear and immediate need in the county (Carder, Weinstein, \& Kohon, 2012). For 20122013, the agency has prioritized implementing a long-term strategy for populations who are aging and have increasing needs but are not yet ready for long-term care; the agency is also considering developing or renovating housing that allows elderly and disabled

\footnotetext{
${ }^{8}$ As of May 17, 2011, the Board of Commissioners for the Housing Authority of Portland had renamed the agency "Home Forward."
} 
populations to transition from independence to aging in place (Housing Authority of Portland, 2010).

One important policy that Home Forward has initiated is its Public Housing Preservation Initiative (Housing Authority of Portland, 2009), which has four primary objectives: (1) replace public housing units that are inherently inefficient to operate with more efficient public housing; (2) address unmet and unfunded capital needs across the portfolio; (3) bring back unused public housing subsidies to increase the current public housing supply; and (4) pursue a plan to change the type of operating subsidy from the traditional federal Annual Contributions Contract to project-based Section 8 funding while maintaining the same resident protections and Home Forward ownership of properties.

In addition to Home Forward, Multnomah County's Aging and Disability Services (ADS) provides many services that allow older adults to maintain independence in their housing in Portland. In order to receive funds allocated to Multnomah County as part of the Older Americans Act, Multnomah County ADS must produce an Area Plan. The 2008-2012 Area Plan included a description of the service system in the county, focal points for the five-year period, a profile of the population, types of service funded and unmet needs, major changes expected to the next Area Plan, and a description of the planning processes used to determine the service priorities (Multnomah County Aging and Disability Services, 2011). Included in the activities to be carried out as a part of the Plan were: identifying items for legislative action that would increase funding of affordable housing; increasing housing stability for vulnerable, low-income older adults; 
and working with partners to plan for housing, transportation, and public health for the County's growing population of older adults. The 2013-2016 Area Plan has also been released by Multnomah County Aging and Disability Services (2012).

One partnership between Multnomah County and the City of Portland that should be mentioned is the 2009 Climate Action Plan. This joint effort was undertaken as a response to the intertwined problems of climate change, social inequity, rising energy prices, and degraded natural systems and require an integrated response to reducing carbon emissions, creating and maintaining jobs, improving community livability and public health, addressing social equity and fostering strong, resilient natural systems (City of Portland and Multnomah County, 2009). The Climate Action Plan has created measurable objectives and detailed actions that align very closely with principles of sustainable development outlined earlier.

\section{Citywide policies and programs that have an impact on the development of} sustainable, affordable housing. In Portland, a wide range of policies and programs affect the planning and development of sustainable, affordable housing for older adults. Portland's policies and programs are coordinated by a number of bureaus, including the Bureau of Planning and Sustainability (BPS), the Portland Bureau of Transportation (PBOT), the Bureau of Development Services (BDS), the Bureau of Environmental Services (BES), the Portland Housing Bureau (PHB), Portland Parks and Recreation (PPR), and the Portland Development Commission (PDC).

The charge of the housing bureau (PHB) is to "solve the unmet housing needs of the people of Portland" (City of Portland, 2011b). PHB, along with Multnomah County 
and the City of Gresham, are required by HUD to complete a Consolidated Plan that establishes a vision for housing and community development programs and is a requirement to receive federal $\mathrm{CDBG}$ and $\mathrm{HOME}$ funding. The Consolidated Plan that covered 2005-2011 (an extra year was requested from HUD to bring the plan to six years, rather than five), identified the following priorities: (1) increase housing opportunities at or below 50\% of the area's MFI, (2) prevent and end homelessness, and (3) assist adults and youth to improve their economic conditions (Cities of Portland and Gresham, and Multnomah County, Oregon, 2005). The 2011-2016 Consolidated Plan determined five priorities: (1) rental housing; (2) homelessness prevention; (3) homeownership; (4) shortterm shelter; and (5) economic opportunity (Cities of Portland and Gresham, and Multnomah County, Oregon, 2011).

The 2005-2011 Consolidated Plan (Cities of Portland and Gresham, and Multnomah County, 2005) needs assessment included several issues identified for older adults aged 65 and older: older adults were considered a predominant low-income family type ( $28 \%$ of the low-income population); $28 \%$ of older adult households were considered to be at risk of homelessness; over half of Portland's low-income homeowners were 65 and older; and older adult renters who rented units that lacked kitchen facilities, indoor plumbing, or had other problems were considered particularly vulnerable. The Plan also noted that since 1992, approximately 250 subsidized units in Multnomah County for persons aged 62 and older had been lost, and that older adults may wait on public housing waiting lists between one and a half and three years. Overall, it was reported that new subsidized units had not kept pace with need. The 2011-2016 
Consolidated Plan (Cities of Portland and Gresham, and Multnomah County, 2011) also identified Multnomah County's "shortage of affordable accessible housing in good condition [and] the on-going shortage of affordable, accessible housing for low-income people with disabilities, including seniors" and seeks to increase the supply of "safe, decent, and accessible housing for low-to moderate families and people with disabilities" (p. 232).

It should also be noted that the City of Portland has an affordable housing preservation policy (Chapter 30.01 Affordable Housing Preservation) in place that states that "publicly assisted rental housing affordable to low and moderate income persons and households should be preserved as a long-term resource to the maximum extent practicable, and that tenants of such properties should receive protections to facilitate securing new housing should the affordable units be converted to market-rate units or otherwise be lost as a resource for low and moderate income housing" (City of Portland, 2012a, para. 1). This initiative helps to ensure that buildings do not convert to market-rate apartments, as the City will have first chance to preserve their affordability. Additionally, this policy addresses the requirement that affordable housing properties receiving City subsidies are subject to a minimum of 60 years of affordability, rather than being able to become available for market-rate renters (or for purchase).

Portland's dedicated development commission (PDC) also plays an important role in the production of sustainable, affordable housing for older adults in Portland. The PDC operates as a lender in housing development and also plays additional roles in the development of sustainable, affordable housing for older adults, including its 
implementation of a tax increment financing (TIF) strategy for urban renewal areas that captures tax revenues that can be reinvested in community infrastructure (e.g., transportation, sidewalks), and its setting aside of $30 \%$ of all TIF dollars for affordable housing (PDC, n.d.). Additionally, the PDC has focused on increasing features considered to be associated with development that is sustainable, such as green building, transitoriented development, and small business and economic development.

It should be noted that the roles played by the PDC and PHB in housing production have changed within the past several years. Many of the housing components within the PDC were shifted over to PHB in 2009 during the restructuring of the functions of the agencies, as detailed in the City's Resolution No. 6803 (PDC, 2010). PHB assumed the responsibilities of housing rehabilitation, finance and development agreements, but PDC maintained financing components for housing that were funded by the $30 \%$ set aside.

Portland's urban planning in conducted by (BPS), the Bureau of Planning and Sustainability (until 2009, the functions of BPS were operated by two separate organizations: the Bureau of Planning and the Office of Sustainability). BPS specifically aimed to "create and enhance a vibrant city... to advance Portland's diverse and distinct neighborhoods, promote a prosperous and low-carbon economy, provide a forum for community engagement and education and help ensure that people and the natural environment are healthy and integrated into the cityscape" (City of Portland, 2011c, para. 1). The projects and programs within the BPS's planning arm range from broad visions to specific design details to comprehensive planning efforts. The sustainability arm of the 
Bureau focuses, among other things, on climate change, energy, food systems, and green building.

The City's comprehensive plan is intended to guide the future growth and development of Portland and is required by the State of Oregon and Metro. The current comprehensive plan was adopted in 1980 and the staff from the former Bureau of Planning began to strategize how to develop a new plan beginning in 2006. Two public engagement processes, visionPDX and the Portland Plan, have been used to engage Portland citizens in envisioning the future of the city. The visionPDX project-which won the prestigious American Planning Award for Public Outreach (Mayer, 2008, December 16)-was a community-led visioning project that established three values: (1) community connectedness and distinctiveness; (2) equity and accessibility; and (3) sustainability (City of Portland, 2008a). The Portland Plan was a strategic and practical planning effort conducted from 2010-2012 with an eye toward the year 2035; the plan set short- and long-range goals for the city and focused on a core set of priorities: prosperity, education, health, and equity (City of Portland, 2012b).

Of particular importance to creating a better Portland for older adults was a twopage insert in the Portland Plan titled, "Portland is a Place for All Generations"9 (City of Portland, 2012b, pp. 24-25). The visionPDX and Portland Plan efforts have been intended

\footnotetext{
${ }^{9}$ The "Portland is a Place for All Generations" insert defined ten specific five-year policy action items along with the broad goal to "make Portland a more physically accessible and age-friendly city:" (1) enforce Title VI; (2) track the information needed to understand disparities; (3) implement the Disabilities Transition Plan; (4) remove barriers to affordable housing; (5) create physically accessible housing; (6) align housing and transportation investments; (7) develop an age-friendly city action plan; (8) encourage development of quality, affordable housing; (9) promote transit use and active transportation; and (10) enhance pedestrian facilities.
} 
to inform the comprehensive plan, which currently addresses twelve goals ${ }^{10}$ that provide a coordinated set of guidelines for decision-making and guide the future growth of the city, including the methods to implement the guidelines (City of Portland, 2011a).

Revisions to Portland's comprehensive plan have the potential to identify the needs of a burgeoning population of older adults. If this is accomplished, the onus of implementing strategies will then fall on various City bureaus, agencies, and leaders of the city to create appropriate housing and environments that support that rapidly increasing population. The availability, affordability, accessibility, and appropriate siting of housing are detailed in the current Comprehensive Plan, and older adults are specifically mentioned as a population that needs to be a focus moving forward.

Additional bureaus in Portland that have an impact on housing and environments for older adults include those responsible for transportation (PBOT), environmental services (BES), development services (BDS), and parks and recreation (PPR). They all serve important roles in the creation of sustainable, affordable housing and meso- and macro-level environments for older adults. For example, the PBOT is essential for the design and development of pedestrian infrastructure that is necessary for older adults to be able to navigate the city. BES creates healthy environments that affect the well-being of older adults. PPR maintains green spaces that are used by older adults and provides programming that is used by older people. Together, the various arms of government in the City of Portland will continue to shape the environments that aging Portlanders will

\footnotetext{
${ }^{10}$ Current goals of Portland's Comprehensive Plan: Goal 1-metropolitan coordination; Goal 2-urban development; Goal 3-neighborhoods; Goal 4-housing; Goal 5-economic development; Goal 6transportation; Goal 7-energy; Goal 8-environment; Goal 9 citizen involvement; Goal 10-plan review and administration; Goal 11-public facilities; Goal 12-urban design.
} 
encounter every day. Finally, the BDS enforces building codes that require accessibility and adherence to accessibility.

One role of the BDS is facilitating the City's design review process, which is used to "ensure the conservation, enhancement, and continued vitality of the identified scenic, architectural, and cultural values of each design district or area and to promote quality development near transit facilities" (City of Portland, 2011d, para. 1). Design review is required for certain areas in the city within a "Design Overlay Zone" which is identified in zoning maps by a letter "d" symbol. Projects within the identified overlay zones can be reviewed using a set of community standards, depending on the location, scale, and procedures desired by the project applicant. Common elements of design review include: architectural style; structure placement, dimensions, height, and bulk; lot coverage by structures; and exterior elements of the proposal, including building materials, color, offstreet parking areas, open areas, and landscaping (City of Portland, 2011d). Design review applies to affordable housing developments for older adults when they are in design overlays, which is the case in downtown Portland and other transit-rich areas.

Green building in Portland. "Welcome to Portland, the City that gets it" were the words of Rick Fedrizzi, president and CEO of the U.S. Green Building Council as he opened the 2004 Greenbuild International Conference and Expo (Libby, 2005, January 12). The annual conference is a meeting of green building peers, industry experts, and influential leaders in the green building movement and which, as Libby explained, is hosted by cities that are "among the nation's most enthusiastic in embracing sustainable, or 'green,' building methods, materials, and advocacy" (para. 2). Portland is popularly 
regarded as a national leader in urban sustainability and green building (Wise, Fiore, Brockman, \& Brukman, 2007). Appendix A contains a comprehensive list of adopted guidelines, established programs, and endorsed policies that promote and expand sustainable and green building practices in Portland since 1973 (City of Portland, 2008b).

In a release by Portland's Office of Sustainable Development (City of Portland, 2005a), the City's investment in green building is described as performing triple duty: cleaning up Portland's environment, enhancing livability, and stimulating sustainable economic investment. Several mechanisms for the promotion of green building in Portland have included the Green Building Policy (City of Portland, 2009b), the Green Building Policy Program Guidelines (PDC, 2005), and Portland's Green Investment Fund, which, from 2005 to 2009 awarded $\$ 425,000$ per year to a total of 36 innovative residential and commercial projects; no funding has been made available since 2009 (City of Portland, 2012c).

Sustainable development was defined in Portland's original Green Building Policy (City of Portland, 2001b, p. 3) as that which "seeks to balance human development, growth, and equity with ecological stewardship." The Green Building Policy has been updated twice, most recently in 2009, and requires that green building practices (i.e., environmental benefits, local job creation, improved health of building occupants, productivity and the quality of workspace, and the generation of lifecycle financial savings for the City) be incorporated into the "design, construction, remodeling, and operation of all City-owned facilities" (City of Portland, 2009b, para. 1). The updated Green Building Policy, Binding City Policy: BCP-ENB-9.01 (City of Portland, 2012c) 
describes the purpose of the policy and highlights the need for careful use of natural resources, understanding the causes and effects of climate change, complementing existing policies across jurisdictions, fostering economic development, mitigating human impact, using Leadership in Energy and Environmental Design (LEED) standards, and maintaining the City's role as a leader in green building. This policy includes the development of affordable housing and specifically requires that housing which is owned by the City be subject to green building standards.

Portland has articulated three distinct strategies for implementing its green building policy: (1) incorporating green building practices into all building projects; (2) financing projects at a level suitable to meet the Policy requirements; and (3) holding each City bureau responsible for incorporating the Policy into capital improvements, purchasing practices and staff training (City of Portland, 2009b). One requirement is that all new, renovated, and existing buildings strive to adopt appropriate LEED standards for their buildings. An industry standard for green building, LEED Green Building Rating System ${ }^{\mathrm{TM}}$ "provides building owners and operators with a framework for identifying and implementing practical and measurable green building design, construction, operations and maintenance solutions" (U.S. Green Building Council, 2011, para. 1). The U.S. Green Building Council offers LEED certification for new construction, existing buildings, commercial interiors, core and shell construction, homes, schools, retail, and healthcare facilities.

In another attempt to facilitate green building in Portland, the PDC established a set of Green Building Program Guidelines (PDC, 2005) for any funded projects in an 
Urban Renewal Area (URA) within Portland. The PDC, in its 2007 publication, A Green Building Primer and the Business Case for Constructing LEED Certified Buildings, also explained that "LEED buildings promote design and construction practices that increase profitability and reduce negative environmental impacts, and protect the public's public health and environment through air quality, tenant comfort and conservation" (PDC, 2007, p. 5).

Another aspect of Portland's evolving green building policies and programs was a recommendation for the City to update the report Greening Portland's Affordable Housing (City of Portland, 2002). That report has provided affordable housing developers, designers and builders with information about local products, building materials, construction practices, vendors, and services needed to successfully execute a green project. The 66 guidelines were categorized as either threshold or voluntary and included the following six categories: (1) design and site, (2) energy conservation, (3) water conservation, (4) conserving materials and resources, (5) enhanced indoor air quality, and (6) operations and maintenance (City of Portland, 2002).

It must be noted that Portland's green building policies and programs have a strong focus on LEED standards, and the adequacy of those standards has been called into question by public health experts. Fischer (2010, June 7) noted that there is an emerging agreement that LEED is focused primarily on environmental quality and energy savings, and not enough on human health. Although the City posted Fischer's article on the PDC's Sustainability Program webpage, there is still a heavy focus on LEED-specific benchmarks that qualify a building as meeting Portland's policy requirements. Suggested 
actions include broadening experts creating LEED standards to include health experts and, maybe, involving the federal government in certifying what constitutes green design and defining sustainability for housing and public facilities (Fischer, 2010, June 7).

Portland's planning and development community has achieved success in green building outputs and in meeting current standards of sustainable development. Public, nonprofit, and for-profit entities have followed the lead of early trendsetters in the industry, such as the Green Communities Initiative of the Enterprise Foundation, in producing affordable housing that adheres to green building standards (HUD, 2010a). Portland was highlighted in Enterprise's Green Affordable Housing Policy Toolkit for offering development incentives, specifically density bonuses that were given when developers met green building standards (Miller, 2010).

Portland is, however, looking beyond green building and design and focusing more broadly on sustainable housing development. Goal 4 of the City's Comprehensive Plan states specifically that the City will "enhance Portland's vitality...by providing housing of different types, tenures, density, sizes, costs, and locations that accommodate the needs, preferences, and financial capabilities of current and future households" (City of Portland, 2011a, p. 4-1). Within Goal 4, Sustainable Housing is specifically addressed as a policy that aims to "encourage housing that supports sustainable development patterns by promoting the efficient use of land, conservation of natural resources, easy access to public transit and other efficient modes of transportation, easy access to services and parks, resource efficient design and construction, and the use of renewable energy resources" (p. 4-2). 
Missing from the Portland's green building policies and programs is a more intentional focus on health, similar to the critique of LEED levied by Fischer, as described above. Also there appears to be a disconnect between the City's housing goal and the broad definitions of sustainability used by Berke (2002), the Oregon Sustainability Act (2001), the United Nations (1987), and Wheeler (2000). Specifically, there is no focus on preparing for future generations, which will consist of a rapidly growing number of older adults. Portland is striving to create sustainable development, and it is even achieving success in the eyes of some (Girardet, 2003; Libby, 2005, January 12), but it has yet to set its sights on addressing the demographic imperative brought about by the aging of society in the policy and programs aimed at sustainable development, particularly as it pertains to sustainable, affordable housing for older adults.

\section{Summary}

It is clear that the aging of our population requires foresight and direction from planners, policy makers, community leaders, and advocates if the housing needs of older adults are to be adequately addressed. Affordable housing for older adults in Portland has been developed in the recent past but has lacked accessible and enabling features, appropriate site location and neighborhood services, or has been designed in a prescriptive way (e.g., publicly funded housing, LEED standards) that does not take into account our aging population. There remains a great need for improving housing and environments for older adults in a manner that provides opportunities for future generations to age in a more affordable and sustainable fashion. Moreover, a specific call 
for research regarding urban planning efforts and development related to an aging society has emerged from the urban planning and gerontology literature.

A clear gap exists with respect to understanding the factors that have an impact on the planning and development of sustainable, affordable housing for older adults, even though research has been conducted on numerous stand-alone areas (e.g., housing for older adults, certain aspects of sustainable development for older adults, affordable housing for an aging society, etc.). The present research sets out to fill that gap. 


\section{Chapter 3}

\section{Methods}

Housing for older adults that can be considered sustainable and affordable exists in Portland and other cities. However, the factors that influenced the planning and development of that housing have yet to be studied in depth. In order to better understand those factors, this qualitative case study focuses on the phenomenon of sustainable, affordable housing for older adults specifically in Portland, Oregon. The research design used a purposeful sampling approach to data collection that was informed by the social ecological perspective.

The primary data collected and analyzed for the study come from 31 interviews that were conducted with key informants in public, for-profit, and nonprofit organizations identified using a snowball sampling technique. A review of documents pertaining to six developments that were identified as sustainable and affordable for those aged 55 and older was also conducted to provide additional context for the study. Based on these data, the meaning of sustainable, affordable housing for older adults is explored, as well as how and why such developments are produced. Policies affecting the development of this housing type are assessed in order to identify those which have had positive impacts,

those that need changes, and policy recommendations for consideration in the future. The findings are used to create guiding principles for understanding what constitutes sustainable development for an aging society. 


\section{Theoretical Framework}

This research design has been informed by the ecological perspectives based in gerontology and public health. In gerontology, the ecology of aging (Lawton, 1986; Lawton \& Nahemow, 1973) considers the importance of many factors in the health and well-being of older adults, including aspects of the social and built environment. These environmental factors extend beyond an individual's home to include aspects of the neighborhood, as well as the policies and programs that have had an impact on older adults.

The field of public health has also utilized an ecological model in an attempt to guide the building of healthy communities, including application in the fields of gerontology (Satariano, 2006) and urban planning (WHO, 2010). Public health practitioners have applied the ecological model when seeking to achieve health promotion through five areas of influence (McLeroy et al., 1988; National Institutes of Health, 2005): (1) intrapersonal; (2) interpersonal; (3) institutional; (4) community; and (5) public policy.

The ecological models in both gerontology and public health have sought to explain the behavior of individuals and what Altman (1975, p. 206) described as a socialsystems perspective that emphasized the "design of flexible, changing environments that can be manipulated, shaped, and altered." Similarly, the WHO's (2002) active aging policy framework-which utilized ecological principles in shaping its determinants of active aging-identified particular interventions that ultimately have had an impact on the 
housing and environments that have been created for and used by older adults (e.g., policies, programs, and practices).

Moos and Lemke's (1996) evaluation of residential settings, which was informed by Lawton's ecology of aging, sought to understand several areas of impact on residents, including the social climate of housing, services within housing, and macro-level aspects such as policy factors that influenced aspects of completed developments. Stokols (1992) also described environments such as housing for older adults as being influenced by regulatory and economic policies. In order to plan for, design, and develop such housing, he recommended that knowledge be combined from many disciplines, including law and regulations, human life span human development, and public health. Moos and Lemke, as well as Stokols, have provided a framework for exploring the planning and development of sustainable, affordable housing for older adults that can be used in informing the research design for this study.

Sallis (2003) described the ecological model as useful for guiding research, especially when considering how certain factors intervened in fostering healthy and active aging. There has also been encouragement to move beyond basic research and toward the shaping of policies and strategies that aim to achieve healthier living environments for older adults (Cunningham and Michael, 2004; Satariano \& McAuley, 2003). Following the suggestions by the aforementioned authors, this case study uses the ecological perspectives from gerontology and public health to increase understanding of the factors that influence the development of sustainable, affordable housing for older adults. It should be noted that this research does not consider the perspectives of 
individual residents but instead focuses on aspects of the micro-, meso-, and macro-levels environments that are influenced by the practices of environmental change agents, interventions such as policies and programs, and other forces such as societal trends and social institutions.

A case study approach was used based on Yin's (2003) suggestion that it is a preferred methodology for examining contemporary events; such an event was the completion of six housing developments for residents aged 55 and older with elements of sustainability and affordability between 2001 and 2008 in Portland, Oregon. These developments coincided with the growth of sustainability as a concept and sustainable development as a policy approach for creating sustainable communities. For approximately a decade various forces have shaped the social systems (e.g., agents of change, societal trends, and policies) that have led to the creation of these developments, but they have yet to be studied.

The ecological perspective informed this project from conceptualization through data analysis. Specifically, research questions focused on understanding how the environment, both physical (e.g., green building features, design processes) and social (e.g., the cultural of sustainability, creation of social spaces, the meaning of sustainability), has been impacted by various actors, regulations, and societal trends. Data collection purposively focused on key informants who were able to provide insight into the influences on development of the housing in question and allowed for the exploration of supporting documents that provide a more complete understanding of the phenomenon. 


\section{Research Design: Conceptualization}

The concepts for this study emerged from an exploration of published literature, previous research, and involvement in civic activities focused on older adults in Portland. The study was designed to determine the meaning of sustainable housing development for older adults from the perspective of those involved in planning for and developing such housing, as sustainable housing is a relatively new concept in the lexicon of those involved in planning, designing, and developing housing. A second goal was to explicate how and why features of housing were chosen by those involved in the planning and development processes, such as affordability, age-specific housing design, and those aspects of housing associated with sustainable development (e.g., access to services, efficient resource use, use of healthy building materials). The third goal was to understand the impact of policy and programs on such development.

The ecological perspective informed the research design by calling to question various aspects of socio-cultural, institutional, and policy environments. According to Stake (1995), data gathering for qualitative research often begins before there is a commitment to the study, and a considerable proportion of data is impressionistic; "Many of these early impressions will later be refined or replaced, but the pool of data includes the earliest of observations" (p. 46). The impressions that have shaped this research design can be seen as having been influenced by the researcher's engagement in past activities (e.g., research connected to the WHO Age-friendly Cities project in Portland, involvement in pubic participatory processes related to environments for older adults and people with disabilities), collegial interactions, work as a research assistant and project 
manager at the university, and from coursework and comprehensive examinations in the doctoral education process. Overall, these impressions highlight the need for conducting research in a manner that explores multiple levels of influence as is done when applying an ecological perspective.

This research project has emerged during a time in which both the term and the practice of sustainable development has increased substantially compared to the release of the Brundtland Report (United Nations, 1987). A brief history of the researcher's evolution of interests helps in understanding the conceptualization efforts. First, the topic of sustainable development for an aging society has been a part of the researcher's graduate studies and general interest since 2003. Beginning in 2006, the researcher helped to conduct the Portland-based efforts associated with the WHO's Age-friendly Cities project. As a reminder, the WHO's Global Age-friendly Cities: A Guide explained that to be sustainable, "cities must provide the structures and services to support their residents' wellbeing" and that older adults "require supportive and enabling living environments to compensate for physical and social changes associated with ageing" (WHO, 2007a, p. 4).

Emerging from the WHO research were suggestions from participants that Portland should create more age-friendly housing that was connected to transit options, provided access to nearby services, had enhanced physical accessibility features, and satisfied the need for more affordable housing, among many other recommendations. However, it was not known whether such considerations were being made in housing developments, and, if they were, how and why those considerations were carried out. A 
review of the research literature revealed no understanding of the planning and development processes and practices that influence the development of housing for an aging society. Furthermore, there was no evidence that the sustainable development and green building practices had taken into consideration the aging of future housing residents or the aging society, in general.

The present research fills that gap by exploring the creation of such housing, from the early design stages to financing to the time just before people moved into their residences in Portland. To begin the research a set of criteria was developed to determine what constituted sustainable, affordable housing for older adults and to identify the potential sample of developments in Portland. Those criteria included housing developments that were: (1) "sustainable" (i.e., described as sustainable, having identified "green" elements, or having had an approach that was environmentally friendly $\left.{ }^{11}\right) ;(2)$ "affordable" (i.e., the majority of the units were available to residents who had incomes at or below the threshold of $80 \%$ of the area's MFI; (3) specifically for "older adults" (i.e., housing exclusively for adults aged 55 and older); (4) built recently (i.e., completed since 2000); and (5) located within the city limits.

An Internet search was conducted using terms such as: senior housing; green building; LEED; affordable; low income; and sustainable. Additionally, phone calls were placed to public agencies such as Home Forward (formerly the Housing Authority of

\footnotetext{
${ }^{11}$ All units identified had a self-described "green" element and half considered themselves to be "sustainable." The only unit that did not met these criteria was included based on the following "environmentally friendly" elements: redeveloped brownfield site, mixed use and transit-oriented development, and some "green building" elements such as recycling old concrete, preservation of old trees, and open/recreation space.
} 
Portland), Multnomah County ADS, and the nonprofit organization REACH Community Development Inc. (REACH), which has been involved in creating affordable housing since 1982. Based on the defined criteria, six housing development projects were identified, ranging in size from 51 to 176 units. ${ }^{12}$ All six developments had been completed from 2001-2008 through partnerships that involved community development corporations and City of Portland agencies. They also incorporated Portland's for-profit sector design and construction industries.

\section{Rationale for Using a Qualitative Case Study Approach}

As Creswell (1998) explained, qualitative research is a distinct methodological tradition in which the researcher engages in a process of building a complex and holistic picture of a social or human problem based in a natural setting. According to Flick (2002, p. 45), qualitative research "fits the traditional, linear logic of research only in a limited way." Qualitative research allows for the circular interlinking of empirical steps, flowing from data (e.g., text), to interpretation (e.g., how a model relates to data), to additional data and interpretation, and eventually to a new framework or theory (Flick, 2002; Glaser $\&$ Strauss, 2009; Strauss, 1987). Finally, as Sofaer (1999) noted the process of qualitative research assists in the reduction of uncertainty about a particular phenomenon by gradually understanding which questions to ask, how they should be framed, to whom and where they should be addressed, and even what the correct answers might be. In the present research, using qualitative research allowed for flexibility in design and for

\footnotetext{
${ }^{12}$ The Commons (Northeast Portland, completed 2001); Rosemont Court (North Portland, completed 2001); Station Place (Northwest Portland, completed 2004); The Village at the Headwaters (Southwest Portland, completed 2006); Trenton Terrace (North Portland, completed 2007); The Watershed (Southwest Portland, completed 2008).
} 
building a complete picture of the influences affecting the development of sustainable, affordable housing for older adults in Portland. Additionally, it provided an ideal approach for creating guiding principles of sustainable development for an aging society.

A case study framework is the preferred methodology for examining contemporary events that have behaviors that cannot be manipulated (Yin, 2003). Six housing developments that met the criteria set for being sustainable and affordable were identified within the geographic boundaries of the city, and there was a desire to learn how and why that housing was built. The contemporary nature of events is evident in this research due to the relatively recent emergence of the concepts and policies of sustainable development and subsequent housing. The researcher's inability to manipulate the behaviors associated with the creation of such housing met Yin's second criterion. Yin also argued that research questions concerning the "how" and "why" of a contemporary event contribute to the rationale for using a case study approach.

Other reasons for the use of a case study framework included the nature of the data to be collected and the theory being used. Regarding the collection of data, the case study's unique strength is its ability to deal with a variety of evidence (Yin, 2003). This research draws from the previous findings from the WHO age-friendly cities project in Portland and available documents pertaining to the six identified housing developments (e.g., published informational materials, awards, government documents). It also involved the collection of primary data. In regard to the theoretical component of a case study, the ecological models from gerontology and public health have guided the research design by examining a broad range of factors that contribute to the planning and 
development of sustainable, affordable housing for older adults. Additionally, the WHO's active aging framework and domains of age-friendly cities and communities were used in developing a set of proposed guidelines of sustainable development for an aging society.

\section{Data Sources and Recruitment}

The primary data for this study were derived from 31 interviews-conducted from March 10, 2009 to October 22, 2009-with key informants who were knowledgeable about the professional fields involved in the creation of sustainable, affordable housing for older adults. Table 3.1 provides a listing of key informants by occupation. Initial participants were targeted based on their expertise (e.g., architects and nonprofit directors) and their ability to detail how and why sustainable, affordable housing for older adults had been developed in Portland. As the research progressed, new respondents were identified who were from fields not originally included in the project's conceptualization, such as professionals in building management and services to low-income seniors. The flexibility in the research design allowed for interviews to continue until no new themes were identified, a point in qualitative data analysis referred to as "data saturation" (Glaser \& Strauss, 1967, p.59, cited in Flick, 2002). The final sample included individuals who influenced the creation of senior housing (e.g., urban planners, architects, housing authorities) and who were identified either because of their roles within local housing development or through snowball sampling. 


\section{Table 3.1}

Key Informants by Professional Occupation

\section{Occupation Number of \\ Participants (31)}

Directors of

Community

Development

Corporations (CDC)

Architects

Portland's Bureau of

Planning and

Sustainability (BPS)

Housing Developers

Housing Authority of

Portland

Experts on Housing

for Older Adults

Portland Housing

Bureau

Regional/County

Government

Management

Portland Development

Commission
54 executive directors of CDCs focused on housing; 1 director of a CDC focused on regional livability issues

42 of 4 were also faculty at Portland State University

52 planners in BPS; 3 sustainability/green building experts

21 of for-profit, market-rate housing; 1 of affordable housing subsidized by public financing

31 executive director, 1 board member, 1 director of strategic partnerships

42 on long-term care/assisted living, 1 on smallscale residential/incorporating technology into care of older adults, 1 on supportive services for lowerincome older adults

21 policy expert; 1 community outreach expert

21 regionally elected official; 1 director of county office of sustainability

21 long-term care advocate and expert; 1 independent housing manager who had worked with older adults

21 director of housing; 1 construction coordinator/construction manager 
Recruitment began with recommendations from faculty within Portland State University's College of Urban and Public Affairs who were familiar with the actors involved in affordable housing development and housing for older adults; they provided phone numbers and/or email addresses so that suggested participants could be contacted according to the research protocol. The first key informants recommended were those associated with Portland State University (e.g., adjunct and part-time faculty) who had previously worked in the nonprofit, for-profit, and/or government sectors. In addition, the researcher contacted three individuals who were involved with one of the six identified developments considered to be sustainable and affordable for older adults. Two of the three contacts were identified at a public presentation about one of the developments; this provided the researcher with an opportunity to learn about their project, who they considered to be important actors in the planning and development processes, and who, in particular, would be able to provide new and valuable insight for answering the research questions. Since the respondents were asked about additional potential contacts after the interview had concluded, they were knowledgeable about the types of questions and the objectives of the research. The six housing developments (described further in Chapter 4) included one owned by a public housing agency and five owned and developed by nonprofit, community development corporations.

All aspects of participant recruitment and data collection were approved by Portland State University's institutional review board, the Human Subject Research Review Committee (see Appendix B). Overall, the recommendations made by research participants for additional potential interviewees afforded a strong pool of research 
participants. In all, 42 suggestions were received; however, 11 of the individuals recommended were unable to participate, unwilling to be interviewed, non-responsive to phone and email communication, or not contacted due to receipt of their contact information after data collection had been completed.

\section{Data Collection}

Early piloting of the research instrument was performed with colleagues, and additional feedback was obtained as part of a dissertation colloquium offered at Portland State University. Upon completion of the final interview instrument, 31 interviews were conducted that ranged in length from approximately 36 minutes to 147 minutes; only three of the 31 interviews lasted longer than 90 minutes, which was the maximum amount of time requested during recruitment of the research participants.

In the early interviews, several of the participants were involved in one of the six housing properties for older adults identified as being sustainable and affordable. These interviews included the executive director of the nonprofit community development corporation that initiated the development and that now owns the property, the project architect who designed the building, and a design consultant with expertise in designing for an aging society who was contracted to provide recommendations for the project. These early interviews helped in understanding the various actors and processes involved with the planning and development of housing that were central to this research and ultimately who should be interviewed later in the snowball sampling process.

Glaser and Strauss (1967, p. 59, cited in Flick, 2002) defined saturation as occurring when "no additional data are being found whereby the [researcher] can develop 
properties of the category." Guest, Bunce, and Johnson (2006) looked at how many interviews were needed to reach saturation and concluded that as few as six or 12 interviews would suffice. However, the data collected as part of this research did not reach a saturation of categories that early. In fact, it was clear that through 15 interviews, new data were still emerging, which was consistent with Creswell's (1998) estimate of 20-30 interviews being needed in order saturate categories.

After the $15^{\text {th }}$ interview, signs of saturation began emerging within certain categories. For example, interviews 16 and 17 were with urban planners from the City of Portland, and interviewees 20 and 22 were executive directors of nonprofit organizations. After completing these respective interviews it was clear that no new information was emerging in the interviews within those professional fields. Since snowball sampling had led to potential participants outside of those professions (e.g., county and regional government, for-profit developers, and management professionals), additional participants were contacted in an attempt to reach saturation across additional categories. After the $31^{\text {st }}$ interview, saturation had been completed in the policy category-the last category to reach saturation-and the data were deemed by the researcher as sufficient to answer the research questions and begin data analysis.

\section{Data Analysis: Development of Codes, Categories, and Themes}

A detailed in Chapter 1, a conventional content analysis was used to describe the phenomenon of sustainable, affordable housing development for older adults in Portland and answer the research questions. As detailed by Hsieh and Shannon (2005), preconceived categories were not used, but rather, codes, categories, and meaningful 
clusters, or themes, emerged from the data. Analysis began with a review of printed transcriptions of the 31 interviews with the intent of identifying broad concepts that could then be used in developing categories and themes in later stages of the analysis. Flick (2002, pp. 177-178) explained the process of "open coding" as classifying data "by their units of meaning (single words, short sequences of words)" so that the researcher can attach “"concepts' (codes) to them." As anticipated based on the literature (Flick, 2002; Strauss \& Corbin, 1990), over 100 codes were identified in the first round of review, and numerous other notes and thoughts were recorded when reviewing the transcriptions.

The next stage in data analysis focused on classifying the numerous codes into distinct categories that were focused on addressing the research questions. Strauss and Corbin (1990, p. 61) described this classification as occurring "when concepts are compared one against another and appear to pertain to similar phenomena" and the concepts are then grouped together in a "more abstract concept called a category." A total of 17 categories were created, as displayed in Table 3.2. 


\section{Table 3.2}

Categories Emerging from Data Analysis

\section{Analytic Categories by Research Question}

Question 1: Meaning of sustainable, affordable housing for older adults

1. The meaning of the term sustainable development 54

2. The meaning of the term affordable and affordable income ranges 58

3. The relationship between sustainable and affordable in housing 29

4. The long-term viability of the term sustainable development 33

Question 2: How and why sustainable, affordable housing for older adults was completed

5. Roles of actors involved in the planning, design, and development process for creating sustainable, affordable housing for older adults

6. Contributions and roles of various sectors in creating sustainable, affordable housing for older adults

7. Processes and organizations involved in creating sustainable, affordable housing for older adults

8. Age-friendly design and location features of sustainable, affordable housing for older adults

9. Champions for creating sustainable, affordable housing for older adults

10. The recent economic climate and financing of sustainable, affordable housing for older adults

11. Current practices and examples of sustainable development in Portland

12. Failure to include aging into sustainable development activities

13. Past projects that show positive elements of sustainable, affordable housing for older adults

14. Services and housing in sustainable, affordable housing for older adults

15. Social and cultural elements of sustainable, affordable housing for older adults

\section{Question 3: Policy recommendations and future directions}

16. Policies that impact sustainable affordable housing for older adults

Note. The number of quotations that emerged from the Atlas.ti analysis is represented in the column on the right. A total of 903 quotations were separated into the 17 categories, with a range of 29 to 181 quotations and an average of 86 quotations per category. Some quotations were used in multiple categories which is why the sum of the right hand column $(1,468)$ is greater than the total number of quotations $(903)$. 
After the 17 categories were developed, the next stage of the analysis used the computer program Atlas.ti for additional analysis. This stage of the analysis occurred after category creation and consisted of abbreviated code words being created for each of the 17 categories in the software (e.g., Actors, Sectors), which acted as a storage area for all words, terms, and quotations that were associated with a particular category. Subsequently a line-by-line review of the primary documents (i.e., interview transcriptions loaded into Atlas.ti) yielded a total of 903 quotations that were saved in the 17 categories.

It should be noted that multiple categories can be attached to the same quotation, or section of text. For example, the following quotation from an interviewee was placed into two categories [(1) age-friendly design and location features of sustainable, affordable housing for older adults, and (2) failure to include aging in sustainable development activities]: "Green building was sort of ahead of green building for seniors... [The Leadership in Energy and Environmental Design program] looks at energy use for lighting, and they don't differentiate if it's a senior project...Because they're seniors...their eyes need more light."

Following the organization of quotations into categories, an "output file" was created for each of the 17 categories and then saved in a Microsoft Word format for additional analysis. The category files were reviewed in order to develop major themes emerging from the categories associated with each of the research questions. For example, from the two policy categories (numbers 16 and 17 in Table 3.2), three themes of policies emerged with respect to the development of sustainable, affordable housing 
for older adults: (1) policies that supported sustainable, affordable housing for an aging society, (2) policies that needed changes in order to better support sustainable, affordable housing for older adults, and (3) policies that did not yet exist but could offer future support for sustainable, affordable housing for older adults if created.

The next chapter provides an overview of the six developments in Portland that were identified as having characteristics of sustainable, affordable housing for older adults. A review of documents and participant perspectives about these developments is offered in order to provide a useful contextual backdrop for the data analyzed in the remainder of this research. This review of materials is particularly helpful in understanding the micro-, meso-, and macro-level characteristics of the developments, from urban design and planning goals and outcomes to sources of financing and affordability standards. 


\section{Chapter 4}

\section{An Overview of Sustainable, Affordable Housing for Older Adults in Portland}

\section{Introduction}

Six developments were identified within Portland that were completed from 2001 to 2008 and met the criteria of being sustainable and affordable for those aged 55 and older. This chapter provides an overview of these developments, beginning with a brief description of the first five that were completed, including details regarding their size, location, sustainable elements, and affordability. The Watershed, the most recently developed of the six, is then highlighted and described in greater depth based on the availability of documents and information about the design and development of this housing provided by three key informants-Respondents 1, 2, and 3-interviewed for this research. $^{13}$

The six sustainable, affordable housing developments for older adults had varying levels of rental subsidies that affect affordability, including project-based Section 8 units (residents pay $30 \%$ of their income, regardless of their income) and units are available only to residents whose incomes are at or below $80 \%$ of the area's MFI. Many of the developments shared similar characteristics, such as sustainable elements (e.g., energy and water reduction, reuse of materials, proximity to transit) and age restrictions (e.g., 55 and older), among others. Additionally, awards and accolades were given to several of the completed projects, including recognition from government agencies such as the EPA

\footnotetext{
${ }^{13}$ In order to protect confidentiality, the three key informants associated with The Watershed are labeled Respondent 1, Respondent 2, and Respondent 3.
} 
via its National Award for Smart Growth Achievement. There were also differences between the developments with regard to design that was specific to older adults (e.g., accessible), associated within a larger housing development, size, and funding sources. Table 4.1 provides an overview of developments' completion dates, total units available upon completion, and age and affordability requirements. Table 4.2 provides an overview of the developments' sustainable elements and funding sources. 


\section{Table 4.1}

Description of the Six Sustainable, Affordable Housing Developments: Opening Dates, Number of Units, Minimum Age Requirements, and Median Family Income (MFI) Affordability Criteria

\begin{tabular}{|c|c|c|c|c|}
\hline Name & $\begin{array}{c}\text { Year } \\
\text { Opened }\end{array}$ & Units & $\begin{array}{l}\text { Minimum } \\
\text { Age of } \\
\text { Residents } \\
\end{array}$ & Affordability Criteria \\
\hline The Commons & 2001 & 172 & $55+$ & $55 \%$ MFI \\
\hline $\begin{array}{l}\text { Rosemont } \\
\text { Court }\end{array}$ & 2001 & 100 & $55+$ & $30-50 \%$ MFI \\
\hline $\begin{array}{c}\text { Station Place } \\
\text { Tower }\end{array}$ & 2004 & 176 & $55+$ & $\begin{array}{c}\text { Project-based Section 8; } \\
50-80 \% \text { MFI }\end{array}$ \\
\hline $\begin{array}{l}\text { Trenton } \\
\text { Terrace }\end{array}$ & 2007 & 66 & $62+$ & $\begin{array}{c}\text { Project-based Section 8; } \\
50 \% \text { MFI }\end{array}$ \\
\hline $\begin{array}{l}\text { The Village at } \\
\text { the Headwaters }\end{array}$ & 2006 & 56 & $55+$ & $\begin{array}{c}\text { Project-based Section 8; } \\
45-55 \% \text { MFI }\end{array}$ \\
\hline The Watershed & 2008 & $\begin{array}{l}51 \text { (Units: } 42 \text { for } \\
\text { older adults; } 8 \text { for } \\
\text { formerly homeless } \\
\text { veterans; } 1 \text { for } \\
\text { building manager) }\end{array}$ & $\begin{array}{c}55+\text { and } \\
\text { formerly } \\
\text { homeless } \\
\text { veterans }\end{array}$ & $\begin{array}{l}\text { Project-based Section } 8 \\
\text { for those at or below } 30 \% \\
\text { of MFI }\end{array}$ \\
\hline
\end{tabular}

Note. The MFI for these developments are calculated for the Portland-Vancouver-Hillsboro, ORWA Metropolitan Statistical Area that consisted of Clackamas, Columbia, Multnomah, Skamania, Washington, and Yamhill Counties (in Oregon) and Clark County (in Washington State); 2012 housing affordability for a single-person household were at the following levels: $30 \%$ was $\$ 14,600$ per year, $50 \%$ was $\$ 24,300$ per year, $80 \%$ was $\$ 38,850$ per year, and $100 \%$ was $\$ 47,810$ per year (Portland Housing Bureau, 2012). As a reminder, project-based Section 8 is funded federally and administered by state and local governments. The affordability requirement stays with the unit, rather than being transferable to different units, as is the case with a Section 8 Voucher program. 


\section{Table 4.2}

Description of the Six Sustainable, Affordable Housing Developments: Sustainable/Green Building Elements and Funding Sources

\begin{tabular}{|c|c|c|}
\hline Name & Description of Sustainable Elements & Funding Sources \\
\hline $\begin{array}{c}\text { The } \\
\text { Commons }\end{array}$ & $\begin{array}{l}\text { Brownfield site, transit-oriented, intergenerational } \\
\text { aspects, open and recreational space, tree } \\
\text { preservation, reuse of salvaged materials, } \\
\text { "woonerf space"14 for pedestrians, cars, and drop- } \\
\text { off zones, close proximity to transit and a grocery } \\
\text { store }\end{array}$ & $\begin{array}{l}\text { Low Income Housing Tax Credit } \\
\text { (LIHTC) equity, Oregon tax-exempt } \\
\text { bonds, Federal Transportation } \\
\text { Authority grant, Portland } \\
\text { Development Commission (PDC) } \\
\text { loans, Fannie Mae, private equity }\end{array}$ \\
\hline $\begin{array}{l}\text { Rosemont } \\
\text { Court }\end{array}$ & $\begin{array}{l}\text { Adaptive reuse of former convent and school, } \\
\text { stormwater capture and treatment, reuse of } \\
\text { salvaged materials, planned for car sharing, close } \\
\text { proximity to transit }\end{array}$ & $\begin{array}{l}\text { LIHTC equity, Oregon Affordable } \\
\text { Housing Tax Credits (OAHTC), } \\
\text { Enterprise Social Investment } \\
\text { Corporation historic tax credits, } \\
\text { Oregon Housing and Community } \\
\text { Services Housing Development } \\
\text { Grant Program trust funds, various } \\
\text { loans, private equity }\end{array}$ \\
\hline $\begin{array}{l}\text { Station } \\
\text { Place } \\
\text { Tower }\end{array}$ & $\begin{array}{l}\text { Brownfield reclamation, transit oriented, energy } \\
\text { and water-saving features, rooftop garden, low } \\
\text { volatile organic compound (VOC) paints and } \\
\text { adhesives, proximity to transit and a grocery stores }\end{array}$ & $\begin{array}{l}\text { LIHTC equity, Fannie Mae bond } \\
\text { financing, a PDC loan, as well as } \\
\text { other grants, waivers, and fees }\end{array}$ \\
\hline $\begin{array}{l}\text { Trenton } \\
\text { Terrace }\end{array}$ & $\begin{array}{l}\text { Redevelopment of temporary housing, socially- } \\
\text { and environmentally-friendly, independent living } \\
\text { for older adults promoted, previous residents given } \\
\text { first option for residence, "visitable,"15 native } \\
\text { plants, energy and water-saving features, low- } \\
\text { VOC materials, training to use green features, } \\
\text { proximity to transit and services }\end{array}$ & $\begin{array}{l}\text { U.S. Housing and Urban } \\
\text { Development Section } 202 \text { capital } \\
\text { advance, LIHTC equity, grants from } \\
\text { Enterprise Green Communities and } \\
\text { Energy Trust of Oregon }\end{array}$ \\
\hline $\begin{array}{l}\text { The Village } \\
\text { at the } \\
\text { Headwaters }\end{array}$ & $\begin{array}{l}\text { Adaptive reuse of grayfield site, close to transit } \\
\text { and services, creek restoration and development of } \\
\text { green space, green roof, native plants, energy and } \\
\text { water-saving features, use of recycled materials, } \\
\text { low-VOC materials, and close proximity to transit }\end{array}$ & $\begin{array}{l}\text { LIHTC equity, OAHTC funding, } \\
\text { Housing Authority of Portland } \\
\text { Subsidy, a Green Communities } \\
\text { Initiative grant, and private loans }\end{array}$ \\
\hline $\begin{array}{c}\text { The } \\
\text { Watershed }\end{array}$ & $\begin{array}{l}\text { Sliver certification in Leadership in Energy and } \\
\text { Environmental Design, }{ }^{16} \text { brownfield reclamation, } \\
\text { mixed-use development, energy- and water-saving } \\
\text { features, training to use green features, community } \\
\text { space, close proximity to transit and services }\end{array}$ & $\begin{array}{l}\text { LIHTC equity, grants, and private } \\
\text { loans }\end{array}$ \\
\hline
\end{tabular}

Note. LIHTC equity is a result of an Internal Revenue Service program; private investors reduce their tax liability by paying for tax credits used as equity in the affordable housing developments (Schwartz, 2006).

14 "Woonerfs are streets built with high quality urban design where the boundary between people space and car space is intentionally blurred...pedestrian space is extended from the sidewalk, and into the traffic zone. Whereas in a normal street, pedestrians are made to feel like guests in the cars' space when they cross the street, woonerfs reverse this axiom." (Greater Portland Council of Governments, 2008, Appendix E, p. 2).

15 "Visitable" has three requirements: (1) at least one zero-step entrance; (2) doors with 32 inches of clear passage space; (3) a main floor bathroom accessible to someone in a wheelchair (Concrete Change, 2008).

${ }^{16}$ Based on personal communication with sales representative on July $7^{\text {th }}, 2011$. 


\section{The Commons}

The Commons provides 172 units of housing for adults aged 55 and older in Northeast Portland, approximately four miles from the Portland's city center. It is part of a larger mixed-use residential development known as Center Commons that offers, in addition to the rentals for older adults, 60 affordable housing units for families, 56 market-rate apartment units, and 26 townhomes (Metro, 2011b). According to a report published by the Federal Transit Administration (2004), the project site, which existed along the light rail and the I-84 interstate highway, was targeted for transit-oriented development during planning efforts by the City of Portland in 1994. The PDC purchased the site from the Oregon Department of Transportation in 1996 and then sold the property to Metro in 1999, which then subdivided the parcel and sold the properties to three separate entities, including the site that was developed as the senior-specific building.

Metro (2011b) described the overall development of the three parcels to be a successful pioneering effort in transit-oriented development; the resulting development was designed to be intergenerational, as it consisted of housing targeted for older adults and families, as well as an on-site daycare facility and play area for children. However, problems with age-integrated design emerged: seniors indicated that they "dislike living in proximity to families with children;" a pattern of rentals showed a preference for units away from the children's play area; and some felt that the design of adjoining townhomes was not friendly to older adults or children (Federal Transit Administration, 2004, p. $365)$. 
In regard to the sustainable elements of the development, The Commons was built on a decontaminated brownfield site,${ }^{17}$ has open and recreational space for residents, preserved many of the trees on site, reused salvaged materials, and has a woonerf (see Footnote 14 for definition) that is designed to facilitate the interaction of cars and pedestrian thorough the placement of trees, parking, and drop-off zones. It is transitoriented with nearby access to light rail and bus lines within 0.10 of a mile, and it is close to local services, including two full service grocery stores within 0.40 miles (Federal Transit Administration, 2004; Walk Score, 2012).

The income qualification for those living in The Commons is $55 \%$ of the area's MFI. The Commons is owned by the American Pacific Properties Corporation and Glisan Housing Partners LLC and is the only development of the six for which a representative was not interviewed as a part of the present study (no contact information was found by the researcher during participant recruitment). Funding for the project came from several major sources, including: LIHTC equity, Oregon tax-exempt bonds, a Federal Transportation Authority transit-oriented development grant, loans from the PDC and Fannie Mae, and equity contributed by the general partner.

\section{Rosemont Court}

Rosemont Court provides 100 affordable housing units for those aged 55 and older as part of a larger 165-unit development (referred to as Rosemont Commons) that included 65 homes available for purchase by households of various sizes and incomes

\footnotetext{
${ }^{17}$ The U.S. Environmental Protection Agency (2012, para. 2) describes a brownfield as "real property, the expansion, redevelopment, or reuse of which may be complicated by the presence or potential presence of a hazardous substance, pollutant, or contaminant. Cleaning up and reinvesting in these properties protects the environment, reduces blight, and takes development pressures off greenspaces and working lands."
} 
(PDC, 2001). The development is located in North Portland, approximately four to five miles from Portland's city center. HUD gave the development a Community Development Excellence Award in 2004 to honor the use of a CDBG to create better communities for lower-income residents; in addition to the 100 units for older adults, the 65 homes built on the site included 18 town homes for lower-income families, 10 affordable homes that were built through a partnership between Habitat for Humanity and the Portland Community Land Trust, seven affordable homes developed by the nonprofit organization Home Ownership One Street at a Time, and 30 market-rate homes (HUD, 2004, September 13).

In a news release by the PDC (2001), former City Commissioner Erik Sten explained that the project not only paid attention to the historical nature of this site but that the people who lived there had new homes, wonderful parks nearby, and future access to light rail along North Interstate (the light rail project was completed in 2004). This infill development is considered an adaptive reuse of a former Catholic convent and girls' school and includes a pre-school for the families in and around the site. Residents from the surrounding neighborhood were brought into the design process and voiced their desires and recommendations, which was considered to be useful in reaching the final design outcomes made by the design team (Andrews Architects, n.d.). According to the Network for Oregon Affordable Housing (2010) five of the units are fully accessible, thus meeting the minimum standard of $5 \%$ of all units, as required by the Fair Housing Act.

Sustainability features of the project include: the reuse of existing buildings; the deconstruction of some buildings and salvaging of the maximum amount of usable 
materials; rehabilitating existing masonry and interior features; maintaining existing trees, roses bushes and grottos on the site; using stormwater runoff on the site; and planning for car sharing (PDC, 2001; Andrews Architects, n.d.). Rosemont Court is located within 0.13 and 0.19 miles from two respective bus lines, 0.49 miles from a light rail station, and 0.47 miles from the nearest full service grocery store (Walk Score, 2012).

Rents for the 100-unit Rosemont Court are 30-50\% of the area's MFI, and the majority of units are 600 square-foot, one-bedroom units (a small number of studios and two-bedroom units are part of the project). ${ }^{18}$ Northwest Housing Alternatives is a general partner in the Rosemont Senior Housing Associates LLC and one of the original sponsors of the project. Funding for the project consisted of LIHTC equity, Oregon Affordable Housing Tax Credits, Enterprise Social Investment Corporation historic tax credits, OHCS Housing Development Grant Program trust funds, and various loans and private equity (Network for Oregon Affordable Housing, 2010; OHCS, n.d.)

\section{Station Place Tower}

Station Place Tower has 176 units available to those aged 55 and older in a singleuse building in the River District of Portland (also known as the Pearl District), which is located the northern section of downtown (officially in Northwest Portland). According to MetLife Foundation (2009), MetLife granted REACH Community Development Inc. $(\mathrm{REACH})-$ the nonprofit developer and property manager for the building-the Award for Excellence in Affordable Housing in 2009. Station Place Tower was the first affordable senior housing development in the upscale Pearl District. The project was built to fulfill the development goals pertaining to housing affordability targets for the Pearl District

\footnotetext{
${ }^{18}$ Based on personal communication with Rosemont Court staff on July 11, 2011.
} 
and was completed as part of a larger redevelopment project that included an adjacent parking structure and commercial building (REACH, 2004).

The Home Depot Foundation also provided REACH with an Award of Excellence for Affordable Housing Built Responsibly in 2005, based on its green building features and insight into building for the needs of older adults, such as inclusion of an on-site library, computer access, community space, exercise room, and outdoor terrace with rooftop garden (The Home Depot Foundation, n.d.). The MetLife Foundation (2009) noted that Station Place Tower exceeded accessibility requirements, as 20 of the 176 units are designed to be fully accessible and include the following features: wider doorways and halls for barrier-free entrances; low-pile carpeting; natural light; easily maneuverable vertical blinds; vinyl floor coverings; accessible sinks and countertops; low shelving; tubs and showers equipped with grab bars with built-in, fold-out portable tub benches; and hand-held showers.

The sustainable elements for the building included the brownfield reclamation, energy and water efficient features, recycling areas on each floor, a rooftop garden for residents to use, use of low volatile organic compound (VOC) materials, and the development of operation and maintenance manuals for residents and managers to maintain a green community (REACH, n.d.; The Home Depot Foundation, n.d.). The building is located within 0.26 miles from four bus stops, approximately 120 feet from the Portland Streetcar (which runs directly across the street from the project), 0.21 miles from the nearest full service grocery store, and 0.3 and 0.4 miles from the Amtrak train station and Greyhound bus terminals, respectively (Walk Score, 2012). Of the 176 units, 
76 are dedicated for those with incomes at or below $30 \%$ of the area's MFI, 81 units are for those with incomes at or below 50\% of the area's MFI, and 19 units are for those with incomes at or below $80 \%$ or the area's MFI (REACH, 2004). The sources of funding for the project included: LIHTC equity, Fannie Mae bond financing, a PDC loan, and other grants, waivers, and fees (MetLife Foundation, 2009; REACH, 2004).

\section{The Village at the Headwaters}

The Village at the Headwaters is a 56-unit property for those aged 55 and older and is one of three residential developments that comprise The Headwaters at Tryon Creek in Portland, the other two developments consisting of 14 town homes, and 100 market-rate, workforce housing apartments. The property is located in Southwest Portland, between four and five miles from the city center and was formerly a grayfield site $^{19}$ (Green Communities, 2010; MGH Associates, n.d.). The PDC worked with the property owner and master developer from 2000 in an attempt to revitalize the surrounding neighborhood and to potentially serve as a "significant model of environmentally sustainable development due to the integration of watershed and endangered species habitat restoration, green building and green street practices, and the use of transit-oriented development principles" (PDC, 2005, p. 4).

According to the Real Estate \& Construction Review (2008, p. 44), The Headwaters at Tryon Creek was "hailed as one of the most environmentally responsible green projects in the Pacific Northwest," and it won the American Council of

\footnotetext{
${ }^{19}$ According to the Congress for New Urbanism (2005), a grayfield (or greyfield) site is term that describes a property covered by concrete and/or asphalt such as a parking lot; these sites offer infill redevelopment opportunities.
} 
Engineering Companies of Oregon's 2008 Engineering Excellence Award for Land Development. The project's general contractor felt that the most unique aspect of the development was the resurfacing of Dolph Creek, which had formerly been piped through the site; he explained that the construction team built a new stream bed, added native plants, and aimed at restoring the natural habitat for the area (Real Estate \& Construction Review, 2008). The Headwaters was considered to be important to the master site plan, property design, and relationship to the larger community, even though formal opposition was voiced by the neighborhood association with regard to increased density and parking and traffic impacts (PDC, 2004). In regard to features specific to older adults, there are secured ground floor entrances, common rooms available for small gatherings, a private consultation area for meetings with community service providers, and transportation services (The Village at the Headwaters, 2006).

The Village at the Headwaters has a number of sustainable elements beyond the creek restoration and reuse of a grayfield site, including: the installation of an eco roof ${ }^{20}$ on the building for stormwater filtration; native plants that use harvested rainwater; energy and water-saving features; the use of recycled materials for the project; and the use of low-VOC materials. The property is located 0.10 and 0.25 miles from two respective bus lines and 0.66 miles from a full service grocery store (Walk Score, 2012). Of the 56 units, 14 were project-based Section 8 for those with incomes below $30 \%$ of the area's MFI, 15 were for those with incomes at or below $45 \%$ of the area's MFI, and

\footnotetext{
${ }^{20}$ According to the City of Portland (2011, June, para. 3), ecoroofs are "living, breathing, vegetated roof systems that provide a sustainable alternative to conventional roofing. Unlike roof gardens, ecoroofs have shallow soils and use drought tolerant plants that require minimal irrigation. They are light weight, low maintenance, and as self-sustaining as possible."
} 
27 were for those with incomes at or below 55\% of the area's MFI (Green Communities, 2010). Northwest Housing Alternatives owns and manages the property. Sources for financing the project included the following: LIHTC equity, Oregon Affordable Housing Tax Credit funding, a Housing Authority of Portland subsidy, a Green Communities Initiative grant, and private loans (Green Communities, 2010).

\section{Trenton Terrace}

Trenton Terrace is a 66-unit development for residents aged 62 and older ${ }^{21}$ that was part of a federally funded HOPE VI program that aimed to demolish and redevelop the housing project Columbia Villa, which is now known as New Columbia (Green Communities, 2007; New Columbia, 2009). New Columbia is in North Portland approximately seven to eight miles from downtown Portland. The overall development consists of a total of 854 housing units (which replaced the 462 from Columbia Villa) for residents with a variety of income levels and ages. A new street grid pattern and main street serve the surrounding neighborhood. The New Columbia development won numerous local and national awards, including, among others, the Environmental Protection Agency's National Award for Smart Growth Achievement and the OCHC's Excellence in Housing Award for Housing Revitalization (Housing Authority of Portland, 2007).

The goal of the Trenton Terrace development was to create a socially- and environmentally-friendly community that promotes independent living for older adults

\footnotetext{
${ }^{21}$ The age criterion is based on Section 202 funding from HUD; Trenton Terrace is the only one of the six developments to have received this type of funding and is the only development with an age restriction above 55 years of age.
} 
and fosters green living practices (Green Communities, 2007). The Housing Authority of Portland (n.d.) reported the development's green building features, of which several can be seen as good for older residents (albeit not age-specific), including the affordability and accessibility of the units, the newly-developed surrounding community, energyefficient features that keep costs low for residents, and the use of environmentally friendly materials that create a healthier place for residents. The project was also described as accessible for residents and visitors alike, as every unit is visitable, and the level plot on which the building is built provides safe and easy access to the building, nearby park, and other community and commercial areas that are located in the center of the New Columbia development (Green Communities, 2007).

According to Cascadia Region Green Building Council (2007), the project sponsor and owner, Northwest Housing Alternatives, began working with Enterprise Communities Partners-a provider of development capital for affordable housing in the U.S.-and became eligible for a Green Communities grant about halfway through the design process; this partnership pushed the architects to incorporate additional green building features. ${ }^{22}$ Overall, Trenton Terrace has the following elements that are sustainable: energy and water-efficient features; the use of low-VOC materials; the use of composite wood and carpet that met green standards; a design with an emphasis on pedestrians; the redevelopment of property; and the provision of education to residents and management on sustainable and healthy living (Cascadia Region Green Building

\footnotetext{
${ }^{22}$ Enterprise Green Communities provides funds and expertise to enable developers to build housing that is healthy, energy efficient, and environmentally friendly without compromising affordability. A set of criteria attached to a funding stream by Enterprise Green Communities was launched in 2009 and is described in the publication Green Affordable Housing Policy Toolkit (Miller, 2010).
} 
Council, 2007; Green Communities, 2007). The property is located approximately 143 feet and 0.31 miles from two respective bus stops, 1.48 miles from the nearest light rail stop, and 1.09 miles from the nearest full service grocery store (Walk Score, 2012). Residents' incomes must be at or below 50\% of the area's MFI, and qualified residents pay $30 \%$ of their monthly income. Financing sources included: U.S. Housing and Development Section 202 capital advance, LIHTC equity, and grants from Enterprise Green Communities and Energy Trust of Oregon (Green Communities, 2007).

\section{The Watershed}

Completed in 2008, The Watershed development was the most recent and the smallest of the six developments, with 51 units available for rent. In addition to the nonprofit developer and for-profit design and development teams, several public agencies were involved at various stages of the development, including: the PDC, TriMet, the Portland Office of Sustainable Development, and Metro. The building is in Southwest Portland in the Hillsdale community, approximately four to five miles from the city center. Inside the residential space, a 2,000-square-feet community room is available for residents and the community (Metro, 2011c). In addition to the residential component, there is approximately 3,200 square feet of market-rate office/commercial condominium space, which has been divided into two units (Community Partners for Affordable Housing, 2011), one of which comprises 1,796 square feet and is available for sale or lease, with seven of the parking spaces inside the development dedicated for the tenant (Urban Works Real Estate, 2009). 
Compared with the other five developments, this project is unique in several ways: first, this development is the only one that specifically targets both older adults and veterans, the latter being formerly homeless; second, the nonprofit sponsor of the development, Community Partners for Affordable Housing (CPAH) is housed in one of the two commercial spaces in the building; and third, this is the only development of the six that has LEED certification, having achieved a Silver rating in 2009. As noted in Chapter 2, LEED ratings are known as an industry standard for green building practice; the Silver rating for new construction achieved by The Watershed in 2009 received a score of 50-59 points out of 100 in the following categories: sustainable sites, water efficiency, energy and atmosphere, materials and resources, indoor environmental quality, innovation in design, and regional priority (U.S. Green Building Council, 2008).

The property is located in an area that was designated as a "town center" by Portland's regional government and targeted for economic development and urban revitalization (Metro, 2011d). According to Metro, a town center provides localized services to tens of thousands of people within a two- to three-mile radius, has a strong sense of identity, and is well served by transit (Metro, 2000). CPAH (2011) reported that the Hillsdale community was involved in and supportive of the project from its early stages in 2001.

The building has many sustainable elements, including achieving brownfield decontamination and energy and water-saving features. Additionally, the firm hired a consultant with expertise in design for older adults; this person helped in achieving 
appropriate lighting, indoor air quality and comfort, quality social spaces, and appropriate scale for aging residents (e.g., height zones for light switches and outlets).

The property is within 141 feet of five bus lines, and 171 feet of another four bus lines, it is only 0.1 miles from a cooperative grocery store, and 0.62 miles from a larger full service grocery store connected by a bus line (Walk Score, 2012). The Watershed is considered a mixed-income development and is composed of 40 units for people aged 55 and older who live at or below $30 \%$ of the area's MFI, eight units for formerly homeless veterans, two of which are available to older adults with incomes at or below $60 \%$ of the area's MFI, and one unit which is occupied by the building manager (CPAH, 2011; Green Communities, 2008). The funding for the project came from LITHC equity, grants, and private loans (Green Communities, 2008).

The project site. As described earlier, Hillsdale is a designated town center and is a neighborhood that exists within a compact area well served by public transit. It has a cluster of services that include a cooperative grocery store, a post office, a local high school, and several small businesses and restaurants, many of which are located on the same street as the project site. Metro's regional planning vision-the 2040 Growth Concept-specifically encourages development like The Watershed: compact development, generating business opportunities, balancing transportation systems in order to move people and goods, and housing for people of all income levels (Metro, 2000). The neighborhood also provides an interesting setting for older adults based on the wealth of bus lines, nearby businesses, and close proximity to downtown, but the site 
itself was considered difficult to develop in some respects (e.g., brownfield cleanup, zoning allowances, parking issues).

Respondent 2 described the positive aspects of the site location for older adults: "For us, it was all about the location...right in the town center... We saw it as a place that would be ideal for seniors...it was on transit, and it was pedestrian-friendly, and it was near a lot of services, a senior center, medical [facilities]." However, the same respondent also understood that there were potential problems for older residents: "Some people question [the site] because there are busy streets, and it's a little bit hilly."

Several barriers and challenges to site development had to be overcome. One developer felt that mixed-use development was "too complicated" as there was "not enough parking to support it" (Smith, 2007, July 3, para. 20). Also, since the site was considered a brownfield, CPAH, the nonprofit developer, applied for and was the first nonprofit agency to receive an EPA Cleanup Grant in Oregon. The site was also difficult to develop because of the triangle-shaped lot (known as the "Bertha Triangle") and the desire to maintain a safe and attractive pedestrian environment. In order to preserve a pedestrian feel and accommodate parking, an underground parking structure was incorporated into the development, even though the cost for such structures is high.

Additionally, zoning constraints on the site did not originally allow for multiple uses. In order to develop the property, zoning changes had to be sought, but the development team ran into early pushback, as described by Respondent 1: "I remember walking out of that meeting [with City planners and members of the project team] where they basically said 'Find another site.' We [said] 'No, this is a really good location, a 
regional center...we want to do it here." Eventually zoning changes were approved, and a grant was secured that assisted in paying for the brownfield cleanup. Parking is still limited, as there are few on-street parking spaces for visitors, and the building is adjacent to a commercial area with parking reserved for customers only.

Project financing. Funding an affordable housing project like The Watershed is not easy, as Respondent 1 explained: “Affordable housing...It's ridiculously complex... we have six closing binders for every project, and on a given day I couldn't tell you if we're in compliance with everything." Based on respondents' comments, The Watershed proved especially difficult to finance, given the several factors above and beyond the multiple sources of financing that are normally needed to complete an affordable housing development, including: cleaning up site contamination; LEED certification and commissioning; and the heightened risk for lenders associated with the zoning issues that conflicted with the desired project design. Respondent 2 added, "Affordable housing is challenging on its own to make sustainable...it's tight [financially]...there's not big profit margin at all."

In the end, the financial sources came together to create a package that worked. In addition to loans and LIHTC equity, five grant sources were used: the Meyer Memorial Trust, the Collins Foundation, Portland's Office of Sustainable Development, the Enterprise Foundation's Green Communities Initiative, and Metro's transit-oriented development program (see Table 4.3 for the financial sources and uses of the project) (Green Communities, 2008). 


\section{Table 4.3}

Sources and Uses of Funds for The Watershed

Sources (Total \$11,671,721)

Uses (Total \$11,671,721)

- Loans - $\$ 2,739,543$

- Housing grants - $\$ 315,000$

- Brown to green - $\$ 791,177$

- Tax credit equity - $\$ 6,825,000$

- Other Sources - \$1,001,000

- Acquisition - $\$ 366,433$

- Brownfield cleanup - $\$ 240,000$

- Green construction costs $\$ 275,000$

- Parking - $\$ 1,261,001$

- Construction - \$6,343,095

- Green soft costs - $\$ 115,000$

- Other soft costs - \$3,071,191

Note. Soft costs refer to costs that are not direct construction costs, such as architectural, engineering, and other fees.

Design process. The design process for The Watershed involved gathering input from the community (i.e., residents in the Hillsdale neighborhood), end users (e.g., management and potential clientele), and the design and development team. Community meetings were held throughout the design and development processes and, based on community input, the building now acts as a hub for neighborhood meetings and activities (e.g., the Hillsdale Neighborhood Association uses The Watershed to hold general public meetings and other events). Respondent 1 commented on the quality of input: "It's one of those dreams come true...to have actually a really great neighborhood to work with, and probably because a lot of those people were over 55, there's a mature component of the Hillsdale neighborhood...they have a lot of sophistication in things like land use." 
The building was intended to be designed through an integrated design process. $^{23}$ Respondent 1 explained that the process helped in understanding "the contractor's world, the different levels from the site superintendent, the project manager, to the owner, general contractor." Respondent 2 also felt that an integrated design process was beneficial; however, the respondent explained a shortcoming that could have been improved upon: "Integrated design... [adds] to the final product or the final outcome...I wish the user group would have been there sooner." The respondent also felt that as part of a collaborative process, the ultimate tenants should be involved in the collaborative process, as it would have helped them in "understanding who prioritizes where the money goes and who makes [decisions]...I think is very important for all people to know."

Sustainable goals and elements. ${ }^{24}$ Several sustainable goals and elements were identified for the project: to minimize life cycle costs (an overall project goal), ${ }^{25}$ to use a high-efficiency central hot water boiler, to install an innovative heat-recovering ventilation system, and to detain stormwater onsite so that it could be naturally pretreated by bio-swales to help maintain water quality in the Stephens Creek and Fanno Creek watersheds. A number of building design considerations were also seen as

\footnotetext{
${ }^{23}$ An integrated design process differentiates the roles and impacts of a project design team and allows for several improvements over conventional design processes, including: the client/sponsor is able to take a more active role than usual; the architect is able to become a team leader and form-setter for structural, mechanical and electrical engineers to take on active roles at earlier design stages; and additional participants and facilitators are able to be incorporated into the design process as needed (Larsson, 2004).

${ }^{24}$ Goals, features, and design considerations were ascertained through interviews for the study and a review of project documents shared by project staff.

${ }^{25}$ Life cycle costs are "summations of cost estimates from inception to disposal for both equipment and projects as determined by an analytical study and estimate of total costs experienced in annual time increments during the project life with consideration for the time value of money" (Barringer, 2003, p. 2).
} 
important: durable building envelope materials, high-energy-conserving windows, social space that facilitated interaction among residents, the desire to have the building as a "gateway to the Hillsdale community," and a final design that would be good for older residents. A summary of sustainable elements that were reported by the design and development team can be found in Table 4.4. 


\section{Table 4.4}

\section{Summary of Sustainable Elements of The Watershed}

\section{Materials}

- Using materials with $95 \%$ recycled content

- Recycled content materials (e.g., crushed concrete base, fly ash, concrete, steel, gypsum)

- Using local and regional materials (e.g., wood products, windows, doors, cabinets, paint)

\section{Indoor Air Quality}

- Continuous fresh air and exhaust for both kitchen and baths

- Low-VOC paints, adhesives, and sealants

- Green Label Plus certified carpet

- No added urea formaldehyde composite wood for cabinets and countertops

\section{Operations and Management}

- Third-party commissioning

- Non-smoking building

- Resident and management education on green building features

\section{Education}

- Educational signage, tours, and presentations for the community and general public

\section{Energy Conservation}

- Achieving at least 30\% more efficiency than Oregon code

- Energy Recovery Ventilation (ERV) system that recovers heat from the exhaust during cold weather and pre-cools/dehumidifies incoming air during hot, muggy weather

- High-efficiency central furnaces and heat pumps for common areas

- High-efficiency central boiler for water heating

- Energy-efficient lighting

- Energy Star Appliances, windows, and roofing

- Abundant natural lighting

\section{Stormwater}

- Stormwater cascading rain gardens filter stormwater and detain initial surge to maintain water quality in nearby Stephens Creek and Fanno Creek watersheds

\section{Water Conservation}

- Achieving 30\% water-savings with low-flow faucets, showerheads, dishwashers, and dual flush toilets

- Efficient irrigation with moisture sensor controls

\section{Protection from Water}

- 4' roof overhangs to protect building from rain and sun

- Canopies to protect major entrances from weather

\section{Pet-friendly}

- Building allows pets

- Dual water fountain (upper level for humans and lower level for pets)

\section{Designing for Older Adults}

- Consultant with expertise in designing for older adults hired for project

- Appropriate light levels (e.g., day lighting)

- Glare issues mediated

- Appropriate height zones for older adults (e.g., lower cabinetry)

- Quality social spaces

- Appropriate heat gain in units 
Key Actors and their Roles in Developing The Watershed. As with all housing developments, a team of contributors to the design and development process was assembled. However, team members for The Watershed were chosen by the project sponsor for their past work in designing for older adults and included a consultant who was considered to be a national expert in this field. In order to understand the unique aspects of developing housing for older adults, it is important to better understand some of the key contributions that led to The Watershed's design and construction.

CPAH is a nonprofit community development corporation that provides safe and healthy affordable housing along with support and skill-building activities for individuals and families with the greatest need who live or work in the Tigard-Tualatin area and SW Portland, Oregon (CPAH, 2011). Respondent 2 described CPAH's executive director as "a true champion for both sustainability [and] equitability, equitable access...for not only seniors but low income seniors." However, the respondent acknowledged that government decisions were major drivers in achieving completion of the project: "The PDC and the state were integral...[they] voted to allocate funds for The Watershed." In addition to funding the project, the focus on placing older adults in the Hillsdale neighborhood and on that particular property was considered to be a positive outcome for the residents of The Watershed: "The location is definitely not anything like the typical stereotype of senior housing; it is integrated [into the community setting] and that's very important."

The Watershed was CPAH's first senior housing project. Since then, the organization has been working on developing a second. Respondent 1 acknowledged that 
$\mathrm{CPAH}$ is not "focused on senior housing" but understands that "somebody is turning 60 every 10 seconds or so, and so that means it makes sense for us to be thinking more and more about yes, making sure all of our projects can accommodate seniors." It appears that working on a project specifically for older adults has broadened the scope of understanding within the organization in regard to the needs of an aging society. In part, that may have been facilitated by working with an architectural firm that not only had previous experience in designing housing for older adults but also was willing to hire a third-party consultant who was an expert in design for older adults.

Respondent 1 recalled how the architectural firm's decision to bring a design consultant focusing on aging issues to their interview was perceived; "It's definitely impressive when [William Wilson Architects] specifically called out that they would have a senior design consultant...They've done a lot of senior housing...but the fact that William Wilson brought her in, I thought it said something about their concern, that they felt they didn't know it all, and they were getting that discipline from somebody else who really focuses on that." According to Respondent 2, the architectural firm worked with several consultants during the process on aging-specific issues:

[The aging consultant worked on] lighting systems, reach ranges...there's a height zone for seniors [that is impacted by] arthritis and bending down...The mechanical-electrical consultants [assisted with] what happens to [aging] eyes...The engineering consultant [looked] at heat gain; when you look at a younger person, I think the tolerance and temperature range is a wider swing; as we age, depending on our overall health, that gets less, and that informs what type of HVAC system you use.

The aging consultant, in particular, had an impact on CPAH's understanding of housing for older adults. For example, the suggestion of increasing the amount of 
daylight that was available to residents in The Watershed was described by Respondent 1: "Day lighting was such a big issue...we hadn't really thought about day lighting that much...it made us think more about it." Respondent 3 further explained what the consultant and design team accomplished: "We did get more light inside the apartments by using patio doors instead of windows, so it was more filled with light, and [the older residents] could open it up and sit and have sunlight on their skin while they're sitting there." This particular design element was not considered to be expensive; however, the respondent described some site constraints that limited the availability of day lighting: "Given the orientation of the building, that didn't happen on all four sides."

One aspect of The Watershed that was unique in comparison to the other five developments was its achievement of a LEED Silver rating. Both positive and negative feelings were expressed about the LEED accreditation. One the one hand, Respondent 1 felt that the LEED component of the project was helpful, as it resulted in having "a systems manual, a commissioning manual, and the systems training that was done post occupancy with the management staff... it was better than we've had at other projects." After the residents had moved into The Watershed, CPAH worked with a local university student to use the manuals to teach residents about the various building systems so that they could understand what they were using.

However, the LEED accreditation was not something that was valued enough by CPAH to persuade the organization to go through the process again. Respondent 1 explained that with a different project that was being proposed, "We didn't even try to think about LEED ...[the] commissioning costs $\$ 70,000 \ldots$ we just didn't think funders 
would be interested." This was a marked change as the respondent noted one to two years earlier the agency felt that LEED accreditation would "make our project competitive" so they fought hard to say to the funders "[You] don't have to pay for it, but we'll get it in there, and we came up with additional sources to fund it." Moving forward, however, CPAH will build on the lessons learned from The Watershed by using other green building standards that were detailed by Respondent 1: "We're doing Green Communities, and we'll use Earth Advantage as the $3^{\text {rd }}$ party verification, so it's using the less rigorous model." ${ }^{26,27}$

In regard to services, The Watershed has worked with several organizations that are specifically focused on improving the quality of life of older residents. Three organizations were meeting with CPAH staff and property management to serve residents living in The Watershed: the Veteran's Administration, Northwest Pilot Project, and Neighborhood House. The Veteran's Administration is located near The Watershed and provides services to the veterans living in the building (Green Communities, 2008). Northwest Pilot Project works with The Watershed to provide referrals, relocation assistance, and onsite case management (Northwest Pilot Project, 2011). Neighborhood House-located in the adjacent Multnomah neighborhood-is a senior services agency that provides case managers and a variety of nutrition, health, and recreational programming funded by the Older Americans Act (Green Communities, 2008). Service providers are

\footnotetext{
${ }^{26}$ See Footnote 22 for more details about Green Communities.

${ }^{27}$ Earth Advantage Institute offers several programs for homes, communities, and commercial buildings that focus on topics such as energy efficiency, healthy indoor air quality, resource efficiency, environmental responsibility and water conservation (Earth Advantage Institute, 2012).
} 
able to use designed space within the building to provide services with options for privacy and community interaction, depending on the type of services being offered.

\section{Summary}

Housing that is sustainable and affordable for older adults has been produced in Portland since 2001. Variations exist among the developments in regard to location, size, funding sources, and the surrounding contextual elements. Although all the projects are multifamily developments larger than 50 units, some of them are stand-alone, single-use buildings for older people only, and others are part of a larger master plan that have aimed to engage older people with families and opportunities for intergenerational interaction. The projects were built in neighborhoods throughout Portland, with North Portland and Southwest Portland having two developments each. The communities themselves were most often a part of the planning and design process, and overall, the developments seemed to be important to the communities where they have been located.

In regard to sustainable elements, both variations and similarities exist across the six developments. Interestingly, there was not a linear progression of sustainable, or green, features that could be tracked over time. For instance, the woonerf-completed as a part of the larger Center Commons project, the first project among the six to be completed-was not included in any other development. This was also true of the adaptive reuse of the convent and school, which occurred in the Rosemont development. Overall, although awards were won by many of the final developments, no set of best practices was clearly established with respect to size, certification, energy savings and programs, or affordability. Perhaps this had to do with opportunities that varied from site to site, 
rather than the failure of innovation to spread. Nonetheless, the evidence shows that there are many ways of reaching the goal of housing older adults affordably, and in environments that are socially and environmentally friendly, as well as healthy.

It appears that there are certain sustainable elements have become commonplace across all of the developments, such as the reduction of energy and water use. These building elements were described by respondents associated with the Watershed as being an important aspect of affordability for older adults, who can save money on bills. Additionally, low-VOC materials were commonplace and have important health benefits, especially for older residents. Surprisingly, outside of The Watershed, the creation of accessible environments was not as strong a focus as the sustainable elements; this topic will be addressed in the following chapters.

In regard to project funding, it was clear that federal and state programs played a critical role. Every project received LIHTC equity, including Trenton Terrace, which was largely funded by the HUD Section 202 program. All of the developments relied on grants and private loans, and it was evident in the exploration of The Watershed's financing that the myriad sources of financing can be difficult to track, as can be maintaining compliance with all of the funders' requirements. Affordable rent for the units was tied to funding sources such as project-based Section 8 funding (four of the six developments used this as a funding source), which restricts rent to $30 \%$ of an individual's income. In regard to housing that was situated in mixed-income communities, in some instances, the affordable housing was located adjacent to market- 
rate housing, while in others, projects had various ranges of affordability within the buildings themselves.

The in-depth look at The Watershed provided an opportunity to explore some of the challenges of developing sustainable, affordable housing for older adults. Novel, compared to other developments, was the involvement of outside professionals with specific expertise and experience in designing for older adults. However, some shortcomings remained, such as the failure to include a group representing end users throughout the design process, the fact that site constraints limited the ability to create healthy environments (e.g., the presence of day light throughout the units in the development), and the loss of certain aspects of design due to cost considerations. 


\section{Chapter 5}

\section{The Meaning of Sustainable, Affordable Housing for Older Adults}

Understanding what sustainable, affordable housing meant to the key informants in this research required specific approaches that were developed as part of the interview protocol. First, to develop a better understanding of the concept, an exploration of what "sustainable" meant to the experts interviewed was attempted. It then became important to see how the respondents related the meaning of sustainable to older adults, housing elements, and affordability.

Each of the 31 interviews was conducted in the same manner so as to create responses that maintained as much validity and reliability as possible. All interviews started with a statement that the term "sustainable" would be used throughout the interview to describe quality housing and environments for older adults rather than terms such as "livable" and "age-friendly." ${ }^{28}$ Although both alternate terms were assumed to have different connotations to respondents, they are commonly used in gerontology to describe housing and environments that promote quality of life, healthy aging, independence, and in the case of the WHO's (2007a) publication, Global Age-friendly Cities: A Guide, a component of sustainable cities. It should be noted that the terms livable and age-friendly were used by respondents during the interviews, but the researcher attempted to refrain from using those terms in the questions asked as a part of the research protocol.

\footnotetext{
${ }^{28}$ Further discussion of the use of the term "sustainable" in lieu of "livable" and "age-friendly" is discussed in the limitations section in Chapter 8.
} 
The first two questions focused on were part of the first topic-sustainable housing and environments for older adults-that was intended to facilitate a comfortable, conversation-like environment (see Appendix B for the research instrument). These questions included asking participants to explain what two different descriptions of sustainable development meant to them and then asking what the participants considered to be elements of sustainable housing and environments for older adults. Following the first two questions, which represented the first of four main interview topics, the second topic was started-the state of sustainable and affordable housing for older adults in Portland-which began with a request for participants to respond to statements about sustainable development as a "buzz word" and whether sustainable development addressed affordability. Both the first two questions (i.e., the first topic) and the next two items in the research protocol from the second topic were intended to ascertain the meaning of sustainable, affordable housing for older adults.

Four specific categories of responses emerged from the analysis: (1) the meaning of the term sustainable development; (2) the meaning of the term affordable and affordable income ranges; (3) the relationship between sustainable and affordable in housing; and (4) the long-term viability of the term sustainable development. Based on the analysis of the interviews using the Atlas.ti software, a total of 174 quotations were identified as a part of those four categories, with 54 associated with the first area, 58 with the second, 29 with the third, and 33 with the final area. 


\section{Descriptions of Sustainable Development}

A card was handed to participants that included two descriptions of sustainable environments. The first was from Portland's original Green Building Policy (City of Portland, 2001b, p. 3)-“Sustainable development seeks to balance human development, growth, and equity with ecological stewardship." The second was a modified description from the WHO's Age-friendly Cities guide (WHO, 2007a, p. 5) that replaced the term "age-friendly cities" with "sustainable housing and environments for older adults""[Sustainable housing and environments for older adults] encourage active aging by optimizing opportunities for health, participation, and security in order to enhance quality of life as people age." Participants were asked to share whatever thoughts they had regarding the descriptions.

Four main elements emerged from the analysis of the resulting comments. First, according to respondents, the City of Portland's definition was seen to fit closely with the most utilized definitions and descriptions of sustainable development and green building that participants were familiar with, which included well-known phrases regarding sustainability such as the "triple bottom line" and the "three E's." Both terms specifically refer to three interconnected aspects of the term: (1) prosperity/economics, (2) planet/environment, and (3) and people/social equity. As a green building expert explained, the Portland policy description "is really another way of verbalizing the triple bottom line...social piece, people, equity...economy and profit, viable, affordable...environment would be the planet piece." This sentiment was echoed by a director of a nonprofit agency, who felt the description was "pretty similar to the [EPA's 
definition of] sustainability," which described sustainable development as facilitated by policies that "integrate environmental, economic, and social values in decision making" (EPA, n.d., para.4).

Second, participants felt that the Portland description was very specific to physical development and lacked a social feel. A management expert explained that the "development" in the Portland description "translates to bricks and mortar, what kind of insulation you have...harvesting of rain water... what kind of [heating, ventilation, and air conditioning (HVAC)] system you have to minimize energy." However, one respondent did feel that the use of "human development" in the Portland description was positive, as was echoed by an architect, who also teaches a university course on green building: "The fact they list human development as one of the major factors, I think is really important."

Nonetheless, the word "development" was used most often by respondents to refer to green building practices, not human development, even though the Portland description was intended to "balance human development with growth, equity, and ecological stewardship" (City of Portland, 2001b, p. 3). One participant, who had worked in developing and managing housing for older adults for most of her career, expressed a feeling common to many other interviewees when she explained that the Portland description "doesn't have the social feel to it."

Third, respondents frequently noted the difference in focus (or lack thereof) on age and aging between the two descriptions. One developer said, "The [description] from the City of Portland is not age-specific," and an architect and age-friendly design 
consultant noted that in Portland, sustainability is "played out over the global environment without consideration for the health and the needs of older people."

Overall, "human development" did not seem to trigger thoughts of age and/or aging and thus left Portland's description of sustainable development lacking in regard to its effectiveness in addressing the challenges of an aging population. Conversely, there was general consensus that aging was a central component in the WHO description. Much of the reason for this resided in the fact that the description specifically used the terms "older adults," "ageing," and "age," but there was also a feeling that the Portland description could have done more to describe how sustainable development meets the needs of an aging society and, more generally, the needs that will accompany demographic changes in the future.

The fourth and final aspect of the descriptions of sustainable development is related to the three previous elements. In general, respondents felt that the WHO's description expanded the concept of sustainable development. By adding language about a process that is universal-e.g., all people are aging-the meaning of sustainable development was seen as more complete and appropriate. The language of "optimizing opportunities" in the WHO's description was seen by one developer to relate to outcomes needed as we age, such as enhanced mobility that resulted from the creation of accessible environments; he articulated this by asking: "How do we make the physical environment fit the changes they're likely to go through physically?"

Another limitation seen in Portland's description of sustainability was that it fits only with the common understanding of the elements that comprise sustainable 
development directions: economics, environment, and social equity. This shortcoming was also identified by a nonprofit executive director as evident in other sustainability descriptions: "LEED...Enterprise Green Communities...Earth Advantage... all talk about the physical characteristics... It's all very technical, but it talks about bricks and mortar, and it doesn't include necessarily the sensitivity to the experience people are going to have that live there." As was described in Chapter 2, housing for older adults is more than a physical structure and has many important social and cultural aspects. However, definitions of sustainable development often lack human and cultural components, even when highlighting the social equity aspect of the concept.

The WHO's description of sustainable housing and environments for older adults offered an opportunity for expanding the understanding of sustainable development. Respondents felt that, as compared to the Portland description, the WHO's description was more "focused on humans themselves" and "able to improve the environment for health and quality of life, and the experience people have as they age." The categories of age and aging were talked about by some of the respondents as needing to be expanded to include not only older adults but also "integrating with middle age and especially kids." An urban designer specifically detailed his feeling that sustainable development needed to be more inclusive of all ages by "offering more opportunities to more people throughout their life cycle as opposed to [not] just the last part, but the beginning as well."

The WHO description also drew several strong responses. The executive director of a public housing organization was "more drawn to" the WHO's description, and 
another respondent said "I strongly support the definition from the WHO more." Several respondents directly related to the WHO description because of experiences that they had had with their aging parents, which was also seen as a reason why the topic of sustainable development for an aging society may grow in popularity and relevance in the future. Everyone will encounter personal experiences associated with an aging family member, friend, or one's self.

Asking participants to react to the descriptions of sustainable development from Portland and the WHO proved to be an effective way to engage participants early on in the interview. It also provided an understanding of how respondents related the concept of sustainable to older adults.

\section{The Elements of Sustainable Housing and Environments for Older Adults}

The second interview question was intended to further put respondents at ease and to allow the researcher to become familiar with the respondents' knowledge and perception of the "elements" of sustainable housing and environment for older adults, without considering, yet, the extra element of affordability. The elements discussed by respondents varied depending on their familiarity with green building and the needs of older adults. Based on the responses, five broad elements emerged: (1) physical accessibility, (2) proximity to community services, (3) connecting infrastructure to housing, (4) housing that contributes to health, and (5) designing for social spaces.

Physical accessibility. Knowledge of the need for physically accessible environments was strong among respondents. Generally speaking, it was common knowledge that as older adults age, they have changes in their ability to respond to 
challenges presented in the physical environment (e.g., stairs, maintenance of homes). There was also a clear understanding among many respondents that accessible housing was needed as individuals' functional ability declined over time, whether caused by normal or pathological aging (i.e., disease).

When discussing the elements of accessibility that are important in housing design and construction, the responses were focused on requirements, codes, and compliance. For example, a member of Portland's housing bureau (PHB) detailed removing physical barriers to "entry and egress...for someone who is perhaps mobility impaired, whether in a wheelchair or just not able to walk as far as quickly." Additionally, an affordable housing advocate explained her understanding of the phrase physical accessibility as being specific to "ADA kind of accessibility," which focuses on minimum building codes and compliance standards.

Several participants were aware that physical accessibility, as it pertains to minimum standards and requirements, represented only part of the effort needed for creating appropriate housing for an aging society. Respondents articulated concepts that went beyond federal, state, and local guidelines, such as housing that was "adaptable," "visitable," and "usable," as well as environments that incorporated "universal design" principles. Adaptable housing was described as "having units that are readily adaptable so as people age in place they can make them more accessible to them." This included placing blocking inside of walls before they are finished so that future upgrades such as grab bars can be installed. Additionally, several respondents mentioned the need for housing that would be flexible as their needs changed, specifically allowing for one larger 
unit to be turned into a primary dwelling and an accessory unit so that a caregiver or family member could live there.

The idea of "visitable housing" was raised by respondents several times during the interviews. For example, a PHB employee felt that "a lot more [housing] should be built accessible and visitable than it is now." Visitable housing, which is intended to accommodate a visitor with functional limitations, has three minimum requirements: one zero-step entrance, doors with 32 inches of clear passage space, and one bathroom on the main floor that is accessible to someone in wheelchair (Concrete Change, 2008). A nonprofit director, who felt that "visitable design [was] an important move forward," was surprised that it had not caught on as easily as she would have expected, especially since she believed that "well-designed accessible environments shouldn't look much different." Other respondents also mentioned that they felt visitability and visitable design should be more pervasive in housing in the future.

One housing characteristic that makes visitable design easier to accomplish is the presence of a ground-floor unit or an elevator for upper-level units in multi-family housing units or single-family homes that have only one story. One respondent, who has worked with older adults throughout her career, noted that Portland does not have a lot of options for finding accessible single-family housing; she stated that it is "virtually impossible to find a one-story new home now."

"Universal design" was also mentioned by a few participants as an area that should be considered. One participant explained the need for urgent action: "Well, every year that goes by, the probability of universal design is reduced because of the amount of 
[housing] stock that exists that is not [accessible]. If anything, it's gotten less friendly." One nonprofit housing director proposed that we consider building housing to be “adaptable so every bathroom is sized [to meet full accessible standards]...every kitchen...every doorway....all the hallways are sized that way. So it's 100\% visitable, $100 \%$ adaptable." Another respondent had been involved in a recent conversation where it was proposed that "all housing should be visitable, should be universally designed...If somebody is able-bodied, disabled, if everyone can use all the environments that we build from here on forward, what would be the biggest [obstacle]?" She did note, however, that "it does cost a bit more."

Another important consideration regarding physical accessibility is that of creating environments that are appropriately challenging in certain circumstances. This concept was considered by an architect, who noted, "There's an argument to be made that in a park environment people would anticipate a certain level of physical challenge" and that having the "freedom to build slightly steeper grades, even for the wheelchair-bound population" could duplicate "the experience of somebody using their legs." The thought was that perhaps we can "design a little more challenge into some environments than you would more of a day-to-day necessity."

Proximity to community services. The proximity of housing to appropriate community services was another important concept noted by participants. In describing the "important elements of sustainability," a participant stressed the need for first looking at "the context" in which the housing units are situated. Understanding sustainable housing for older adults to include access to nearby services was seen by an elected 
official as "part of the evolution of sustainability...I think about the senior housing project at Hills dale and one of the issues there is clear, to get to the services that are nearby."

Community services were seen as those in close proximity to housing such as commercial and public services. They were described by one person as "kind of like collateral services," which include "supermarkets...clinic[s]...government services... senior centers...multipurpose centers." An urban planner discussed the need to ensure "proximity to services," explaining that housing needs "adequate connectivity" to “commercial clusters, retail sales and service functions, libraries, civic facilities, medical institutions," adding that whatever services they are, they need to have "adequate and direct, convenient, safe connections."

Additional services noted as important included "all sorts of educational opportunities," for older adults to be close to their "hairdressers and their bank," and to be only "a few blocks from a farmer's market." One respondent liked the idea of having access to "cooperatives," such as tool libraries and food co-ops, and another felt that it would be nice to be close to a "childcare center" so that older people can be around people of all ages, due to the fact that "It's hard to be an older person and just be around older people." One participant even noted the importance of indoor shopping malls, explaining, "When I'm there, almost always I see older adults doing laps, getting their exercise, because it's a covered, indoor facility. Especially in a climate like Portland, where there's nowhere else to go." 
Several respondents focused on services that existed in current neighborhoods. One respondent felt that the "resettlement of existing neighborhoods...[is] attractive for seniors because they can have access to services, social interaction, recreation without having to drive...that's something a lot of the neighborhoods already have." Another respondent compared older and newer neighborhoods, asking "What are the vital services and how do you integrate those into these neighborhoods?" He felt that in "older neighborhoods that would be a lot easier. But in the newer neighborhoods it would be very difficult."

Also related to fostering proximity to services was a feeling that older adults would be attracted to places that could reduce vehicle-miles traveled and improve the natural environment. One approach, as explained by a government official, was to find "places within [appropriate] neighborhoods for seniors to live." He went on to explain that "adapting a building...[promoting] green design" would be welcomed by many older adults and that they think about their "contributions to carbon [emissions reduction], avoiding driving." He concluded by explaining his belief that "those places people don't need to drive are naturally attractive to seniors."

Research participants articulated which services they felt were important, and they noted how Portland's city-wide efforts were attempting to link housing and nearby services. Several comments were made about urban planning attempts to create "20minute neighborhoods" as part of Portland's new comprehensive plan, coordinated by the Bureau of Planning and Sustainability. This idea was explained by a for-profit developer as making it "much easier to get to all of the resources that you need... within 20 minutes, 
preferably by walking, whether that's shopping, or where you live, or where you work, where you recreate...automobiles would be the very last option." It should be noted that Portland's urban planning bureau (BPS) is now using the term "healthy connected city strategy" rather than 20-minute neighborhoods (City of Portland, 2012b, p. 73).

Connecting infrastructure to housing. The connection of infrastructure-i.e., public facilities and systems-to housing for older adults was seen as vital by the majority of respondents for enabling access to nearby services, social connections, employment and volunteer opportunities, and recreational activities. Two elements that were agreed upon as important by respondents were (1) sidewalk and pedestrian infrastructure, and (2) transportation infrastructure. As one respondent explained, "You need access to a transportation system that works for someone who is older; maybe that's walking, maybe it's transit." In addition to the agreed-upon elements, some respondents raised important issues pertaining to future locational preferences (e.g., forecasts showing preferences for living close in and near transit) and whether the focus on bicycle infrastructure was beneficial for older adults, or detrimental.

Pedestrian infrastructure, such as "curb cuts and sidewalk widths," was seen to contribute to "pleasurable environments that people want to be in." One participant viewed this type of infrastructure as contributing to quality of life and sustainable communities: "To me, quality of life means good air to breathe, sidewalks to walk on; all those things we would think of as a sustainable community."

Infrastructure elements-curb ramps, sidewalks, street crossings, markings and signage, etc.-were seen to create a pedestrian environment that "not only serves older 
adults but serves a much broader population," according to an urban designer, who also explained that the environment impacts "conductivity and continuity of that walking system." That interviewee also described a major element of the system as "looking for connectivity, making sure there's at least a connection, a public right of way, or some public connection from one area to another. We'd want a series of connections."

Transportation infrastructure was also identified as important by many participants. A green building expert detailed "access to mass transit" as an important "community scale" element of sustainable housing for older adults; and another respondent explained, "Since people are not able to drive after a certain age, or might not want to drive as much as they did when they were younger...[they should] have good public transit service." Recent research supporting the desire to live near transit was detailed by one public-sector employee: "Forecasts by eight income categories and locations on where people will live, whether it's ownership, or rental, or single family, multifamily...one of the things it shows is continuing high demand to live close in, near transit."

One respondent articulated the connection between public transportation, housing, and older adults by proposing that the more Portland can "increase mass transit, the better options we're going to have." She explained that the "mobility piece" is connected to safe transportation and is going to be a "key factor" for an aging society. Furthermore, the respondent felt that "little nodes of housing" that were "adjacent to light rail or bus transportation" might lead to older people being willing to "give up their car if they had access to transportation." 
A BPS employee discussed the requirements of parking infrastructure for private automobiles and housing design. She explained that many Portland residents "don't need an off-street parking space; you can park on the street in most of Portland, or group the parking someplace." If parking requirements were changed, the participant felt that more "open spaces associated with medium, low-density housing" would be available, such as "courtyard housing developments, with a green area in the middle," which were more common "before there were parking requirements in the 60s."

Bicycle infrastructure was discussed by some interviewees who felt that people should have the opportunity to cycle if they desired but that more attention to an aging society was needed in comparison. One respondent posited that Portland needed to "think about how to serve our elders as much as we think "how do we serve bike riders?"” On a similar note, a different respondent felt that "Portland has such an 'able-bodied' image...the bicycler who's going into the Lucky Lab [Brewing Company]." Both respondents felt, in general, that the concentration on cycling in Portland was not geared toward an aging society as much as it was to younger generations, and that the City should shift its energy to be more evenly divided.

Portland was seen by many research participants as having policy that has created good infrastructure in certain areas. A planner with BPS described Portland as having "strong policy in the downtown area, most notably, for infrastructure for sidewalks, for curb ramps, for walking, environments for lots of multi-modal ways to get around, lots of transit access, that kind of stuff. [Near] the river at least, lots of existing parks and open spaces." 
Despite the existence of quality infrastructure in areas such as downtown and inner-Portland, discrepancies were identified in other areas of the city. As one respondent noted, "Outside of downtown, Gateway, east Portland...the infrastructure, the density, the concentration of uses, and development are not quite there; it's a little more spread out." He specifically noted that "walkability" and the "transportation options and connections" were not as robust as the core of the city. Another respondent, also an urban planner, pointed to areas of the city that "have unpaved streets, they don't have sidewalks, they don't have street lights." These discrepancies call to question how planners can further the equitable distribution of infrastructure throughout the city, especially areas that are currently underserved and may need more assistance than others (e.g., those with higher proportions of older adults).

Housing that contributes to health. An effort to simplify the understanding of green and sustainable housing was common among respondents. As one person said, "When we say 'green building,' it is just 'good' building;" her sentiment was that all housing should just be designed "well." This is consistent with green building principles discussed in Chapter 2 that were described as focused on creating environments that cause less harm to both the environment and to the people who are living in and using the resulting housing, buildings, and infrastructure produced. For example, housing that is built to meet green building standards-e.g., LEED certification, Portland's green building requirements-has tried to reduce issues such as "sick building syndrome" and other maladies caused by poor materials and/or conditions that worsen health over time. 
One respondent felt that housing built according to green building standards would be similar for people of all ages: "I don't think housing for older adults would be any different, or have any less [features] than housing for anyone else." A for-profit housing developer went as far as saying that housing for older adults has the "same energy efficiency issues, same indoor quality issues, same resource efficiency, water use...to me, those things are given. You're going to make it as energy efficient as possible, keep it healthy." He went on to say that reducing the "toxicity of the materials" should be considered across the board.

Several other respondents, however, felt that sustainable housing for older adults required going beyond the "same standards" that would be considered for the rest of the population. A nonprofit director who hired a design consultant with expertise in aging issues explained, "It was really helpful...in part I think she did impart new wisdom, knowledge, learning to us and to our team...there are differences for seniors in the way their eyes work, their bodies work, that we might not be thinking about."

A green building specialist who had had several conversations about "age-friendly housing" with interested clientele explained that in designing buildings "for [older] people to live in," it is important to consider that "your flexibility changes, your vision changes, the way you hear changes" and that "the older you get, the more vulnerable you are to... thermal comfort... factors that determine thermal comfort [are] air speed, relative humidity, and radiant surface temperature." An architect added the need for "good lighting environments" and "floor coverings that are durable and visually don't present issues" that would impact aging eyes (e.g., glare). A housing expert also saw 
design to improve "way finding" as important, such as "way finding in the corridors...way finding to the units, way finding at the elevators."

The expert in aging design discussed several additional concerns. She noted that "sustainable housing that is being built [is] always thought of as a large development; therefore, they need a large piece of land, and sometimes it's unsuitable... it may not be the most desirable location." She expressed concern that in Portland "chunks of land that wouldn't be desirable for other uses" have been appropriated for large-scale housing projects that may be unhealthy for older adults. The same respondent pointed to one housing development that borders on a freeway and has to deal with issues of "air pollution, noise, and.... a chasm or breakdown of the neighborhood where you can't cross [the street]." One siting issue that was particularly problematic was "locating the tower that was to be for [low-income] seniors adjacent to the freeway." She posited this decision was "intentional," as the "market-rate apartment" was further away. In fact, according to a report by the Federal Transportation Administration (2004, p. 362), the plan for the site was to use the building intended for older adults-the largest building-"on the edge as a 'town wall' to act as a sound and visual buffer." The major issue with that locational decision was "the freeway noise," as there was a lack of understanding that "older people have sleep problems, that they are easily awakened in the night." She also explained that older people "have a higher incidence of sleep disorders, and also greater sensitivity to air pollution because of preexisting conditions." The resulting problem that the designer articulated was: "How do you get fresh air in your apartment if you're right out there on the freeway?" 
Housing that contributes positively to the health of older adults was seen by several respondents as being important when planning for an aging society. However, many respondents also made comments similar to the following: "The things we would do for seniors we should probably be doing in general...good lighting environments... accessible, universal features throughout the unit...floor coverings that are durable and visually don't present issues.” In designing “infrastructure able to support people throughout the life course," there was a feeling that the outcome would be environments that would "work for toddlers as well as seniors."

A nonprofit director who operated an affordable housing project for low-income older adults and veterans pointed out, "I can't think of that many issues where it seemed that what we were doing wouldn't have worked for other age groups as well [as older adults]." As an architect explained, it is "not just about you, and your decline, [which] we don't want to believe," but it is about being "stewards of our environments and our neighbors" "by trying to "incorporate those standards in case our family or friends want to come over."

Designing for social spaces. Focusing on "bricks and mortar" is only one component of sustainable housing. As one participant explained, "You can have all the healthy, sustainable elements in your building... [but if you] isolate a person [who is] older, I think you have a real problem." Most participants felt that personal space, such as one's residential unit, should provide privacy; however, as one woman who has been involved in housing development specific to older adults noted, "Providing opportunities for interaction both inside and outside of the building" is also important. 
There was a feeling among several respondents that professional designers have a long way to go to get designing social spaces "right" in housing developments. One architect explained, "We're not that good at designing the more social spaces, thinking outside the unit and thinking more about lobbies, corridors, and things like that." He proposed thinking about "designing a living room for the whole building" and felt that each building and its space must be unique. His rationale was that some "[residential] buildings downtown, where there's a nice lobby, places to sit, nobody is sitting in it." Several reasons were posited as to why something like that might occur, including "street noise," a space that "doesn't feel safe," a lack of "the right relationship to the [front] desk," and "sunshine on the other side of the building."

An interviewee from PDC described what his agency expects in housing designed for older adults: "a community room, a library...encouraging active living and getting seniors involved with more social space." All of these issues are factored in when the PDC "plan the budget, plan for the project... [it is part of] our big vision." What was not discussed was how, or if, older adults themselves were involved in conceptualizing those spaces.

An example of incorporating end users into the design of a housing complex was detailed by a member of an organization that provides services to older adults with very low incomes. He explained that "interviews with low-income seniors who were living downtown" helped in creating what would ultimately "really make [the development] sustainable." He noted that the people who were interviewed "thought of a lot of things [he] wouldn't necessarily have thought of." By talking to some of the people who might 
be using that development daily, the architects and developers found out that "Community space was a big deal" and the result is that now, when someone comes to visit the development, "You'll see all this beautiful community space: a library, a community kitchen, a living room with a fireplace, all community space, community bathroom on the first floor...upper courtyard there, which is a community space."

An architect who also teaches green building principles such as participatory design also pointed to the value of involving users in design, stating: "Engaging everyone in those kinds of decisions is an important step...Another real benefit of participatory design is [that]...including [end users] in the design process empowers them. It makes them feel like [it] is their building...They participated in every decision...They're proud of it." He even expressed the belief that "if you do that responsibly with the general population, people take care of a building they feel they helped make...There's some good examples of that for the very low income...they take care of it. You don't see the graffiti and vandalism that you might otherwise in some populations.” By involving older end users, it seems more likely to results in social spaces that are valued and used by older residents.

In regard to designing for specific social activities, cigarette smoking was brought into the conversation several times. Although smoking cigarettes is a health risk and can cause others displeasure, discomfort, and even adverse medical reactions, there is no denying that smoking is often a social activity and will occur in and around a building, particularly when there are limited locations where individuals are allowed to smoke. As one management expert pointed out, many residents are "going to smoke no matter 
what...It's what they do, and I understand it.” An architect and designer explained that she thinks that "smokers are maybe more socialized [than non-smokers]...they're all huddled out there with their cigarettes in their little group; they probably have more vitamin D. They're killing off their lungs but they're out there hanging out." Based on the fact that residents will smoke, some respondents noted that it is important to be intentional about considering where these residents will smoke and how that will impact them, other residents, and other members of the community.

In addition to outside locations for smokers to gather, respondents noted a number of other spaces outside of the walls of a housing development that are important places for social activity and interaction. As one respondent said, "Almost all seniors like to be near parks...near things like the theater and cultural events." Another participant explained that human interaction occurs in "little cafes...parks...a grocery store... whatever it is that satisfies your cultural life," and another respondent detailed the interesting phenomena of the way "private sector spaces" are becoming "gathering places...Internet access is a big thing...the central library."

Another important element of design brought up in multiple interviews was the need for designing specialized space within the common areas of affordable housing to be dedicated as a consultation room. Such a room would allow for a number of functions. This space was described by one respondent as being "a small office...It may have water, and it's used so a visiting social worker or service provider can meet privately with somebody without having to meet in the unit or in a broader, more public community space." The space would also allow for certain "medical procedures," such as a "flu shot 
clinic, or a diabetes check, or cholesterol check, or podiatry check." A key component is “a little bit of privacy." Privacy in this instance facilitates a sense of dignity, as judgment and other social pressures are alleviated.

\section{Further Expansion of the Meaning and Long-term Viability of Sustainable Development}

After the first two questions of the interview were completed (which represented the completion of the first of four interview topics), the second topic was started: the state of sustainable and affordable housing for older adults in Portland. Participants were read the phrase that encapsulated the first topic area of the interview: "the state of sustainable and affordable housing for older adults in Portland." Participants were then told that they would be read two statements and asked to respond to them. One of the statements focused on an area of interest that was intentionally left out of the earlier portion-the relationship between sustainable housing and affordability-as the researcher felt that respondents should be given the opportunity to explore the meaning of sustainable, affordable housing for older adults in parts, rather than as a whole. This statement read to respondents was: "A development cannot be sustainable unless it addresses the issue of affordability."

The relationship between sustainable development housing and affordability.

Responses to the statement that "a development cannot be sustainable unless it addresses the issue of affordability" varied greatly, especially since respondents were not asked to confirm or deny the accuracy of the statement. Although "true" and "false" answers were common, several trends emerged from responses that can assist in better understanding the meaning of sustainable, affordable housing for older adults. 
Based on the exploration of the concept of sustainability and its relationship to housing and aging in the first two questions of the interview, the majority of participants' responses were focused on the relationship between sustainable development and affordability. The chief executive officer of a consulting and management firm specializing in senior living facilities felt that “'Affordability' is just as subjective of a term as 'sustainable." Affordability could mean the cost of rent relative to someone's wages, or, as an employee of the local housing authority explained, affordability could mean the cost to "keep up" your housing, or the fact someone can't pay rent or "afford to pay the light bills anymore." The question of affordability for that respondent came down to "the ability to pay to be there," regardless of the price that the market will bear.

The director of a nonprofit organization providing service to low-income older adults detailed the evolution that she experienced with the term affordability; the term "got so overused when [they] started doing advocacy in the 90s that it became meaningless." After that, she explained, there was a point when she realized that affordable housing "wasn't affordable to the people [her organization was serving]." At that point she came to understand that affordability needed to be defined specifically "for low-income people." The need to define affordability during the interviews was very clear among the participants.

The statement, "All housing is affordable to someone" was repeated by many respondents. Another common comment from participants was that, when trying to understand housing affordability, one must ask the question, "Affordable to whom?" There were also several mentions of a general "rule of thumb" that housing should cost 
no more than $30 \%$ of a household's income, which is the federal guideline for affordable housing.

To better explain the relationship between affordability and low-income households, the director of the nonprofit who had felt "affordability" was overused explained that "Today....really low-income people....we define that as 30\% [of MFI]. 14\% of Portland is at $30 \%$ of median or less." Another respondent explained that "Affordability is defined one way by one government," and another way by a different government agency. Moreover, the term is used differently among various agencies in the public, for-profit, and nonprofit sectors. Other commonly used "tiers of affordability" that were discussed in the interviews included $60 \%$ and $80 \%$ of the MFI, but, as one respondent explained, some units that are labeled as "affordable" have rents that are up to $120 \%$ of MFI.

Four distinct lines of thought emerged from respondents concerning the connection between sustainable housing and affordability: (1) sustainable developments were not always thought of as affordable and definitions of what was "affordable" differed, (2) some features of sustainable development were seen as leading to cost savings, (3) housing that receives public subsidies (often tied to affordability) was often required to have sustainable elements, such as green building features, and (4) some respondents who understood the term sustainability as being composed of the "triple bottom line" or "three E's of sustainability"-planet/environment, profit/economy, and people/social equity-felt that the social equity component required an element of 
affordability in order to be classified as "sustainable." These lines of thought are elaborated below.

Sustainable housing developments, generally understood to be housing that used green building practices (e.g., met LEED standards), were considered to have a "premium" cost for development. At market rate, this often precluded "affordability" or required additional funding (e.g., grants) to subsidize development costs in order to reach the benchmarks to be considered affordable. Lack of affordability, however, generally did not preclude the development from being seen as "sustainable," in the minds of some respondents. As one architect explained, "There are some very, very wonderful green buildings that were very expensive... but I do think there's a possibility of having a community that's designed for people of wealth that can be sustainable."

Second, some features of sustainable housing, such as energy efficiency and proximity to transit, were thought to lead to cost savings for residents and building operators. For residents, the "sustainable" aspect of the development can create additional affordability through energy and transportation savings (as long as those costs are not passed on to the resident from the developer or property owner). One affordable housing owner and operator explained, "Energy efficiency is so critical for our residents," as is "product durability...I want [the carpet] to last [eight years]." Additionally, the health of the residents was seen as important to the building operator, due to the fact that an "unhealthy environment [is] going to create an economic impact on the operation of that building." 
Third, affordable housing developments that receive public subsidy from various government agencies within the City of Portland and/or the State of Oregon are required to have certain green features (e.g., nontoxic materials, energy efficiency). This is based on green building policies in Portland, in particular, and was considered by several respondents to raise the cost of development. Respondents noted that the PDC will sometimes act as a "gap funder" to help in paying for some of these costs, but grants, loans, and many other funding sources are often needed to make a development "pencil out" or end up with enough money to cover the operating expenses. The resulting affordable housing is considered to be healthier and in many respects better than housing that is not required to meet the same policy standards; on the other hand, it is more expensive to develop and requires many subsidies when operating on affordable rents.

Finally, many respondents who had a firm grasp of the three "E's" of sustainability-environment, economy, and equity-were more likely to feel that a development cannot be sustainable unless it is affordable to lower-income groups. As explained by one participant, "This harkens to our analysis of equity being the ignored part of sustainability... affordability seems like a fundamental component to create fair access, equal access to the development." Taking this perspective, social equity and affordable housing can be seen as critical in sustainable development that meets the needs of future generations; as detailed in Chapter 2, the increasing number of older adults in the U.S. already require a higher quality and quantity of affordable housing, a trend that is expected to increase over time. 
The long-term viability of the term "sustainable development." Within the topic area of the interview phrased as "the state of sustainable and affordable housing for older adults in Portland," participants were asked to respond to a second statement: "Sustainable development is a 'buzz word' that will eventually be replaced by the next trend in planning and real estate development." The intent of the question was to understand the long-term viability of the term "sustainable development."

A couple of respondents felt that the term "sustainable development" was already being replaced by the term "green." As one respondent stated, "From a physical energy side, I would say yes...it seems that 'green' has already replaced it." This perspective seemed to emerge in regard to elements of green building, environment, and energy savings, but it did not extend to the social equity component of sustainable development.

Some respondents felt that sustainable development would eventually be replaced by another word or term. One interview participant said he "always thought of that as a buzz word" and felt that "it probably will be replaced by something else...no doubt it will be at some point." To some respondents there were other terms that preceded sustainable development that had similar meanings, such as the terms "environmentalism," "growth management," and "smart growth."

The vast majority of respondents felt that whether or not the term sustainable development was a buzz word was not important; what mattered was that even if the term did "morph into something else," the values would remain. As another person explained, "'Sustainable' is one of the words that has evolved...that's gotten a broader definition over time... but I think 'sustainable' is a diverse word; it means a lot of different things to 
a lot of different people." Another comment compared sustainable development to art: "It's like impressionism-some people like it, some people hate it, but everybody has an opinion on it, and as long as everybody has an opinion and it evokes a conversation, then it stays alive."

The meaning of sustainable, affordable housing for older adults is clearer, including the elements that make up such housing. The following two chapters will focus on findings that explain how and why sustainable, affordable housing for older adults was completed and policies that had an impact on the planning and development of such housing in Portland. 


\section{Chapter 6}

\section{How and Why Sustainable, Affordable Housing for Older Adults Was Planned for and Developed}

In order to answer the questions of how and why sustainable, affordable housing for older adults was planned for and developed, key informants were asked a series of questions intended to provide unique insight into the practices and motivations of those engaged in the planning and development of such housing in Portland. This chapter focuses on the findings that emerged from the 31 interviews, in particular the roles and contributions of individuals, groups and sectors and specific processes and practices that contributed to the completion of projects.

To address the question of "why" developments were completed, both underlying systemic issues and the culture of planning and development that was identified in Portland are discussed. In addition to focusing on why sustainable, affordable housing for older adults was completed in Portland, findings also emerged as to why additional housing was not completed. These findings have important implications for policies and programs (the focus of the following chapter) and for future research (addressed in the final chapter).

A review of the method used in collecting the data in this chapter will help in positioning the findings reported here. After participants responded to the initial four questions of the interview in the previous chapter-focused on increasing understanding of the meaning and elements of sustainable, affordable housing for older adults-an additional 10 questions were asked to interviewees pertaining to two topics: (1) the state 
of sustainable and affordable housing in Portland; and (2) professional roles in the housing development process. ${ }^{29}$

During analysis of the data, 11 categories emerged that addressed the answers to these questions based on 960 quotations that were identified. The analysis categories (see Table 3.2, Chapter 3, Categories 5-15) represent responses that provide unique insight into how developments were completed. Categories 5-8 have been combined in this chapter to focus on the following two sets of findings: first, the roles and contributions of actors, sectors, and organizations; and second, processes and practices that contributed to the types of developments in question. Categories 9-15 have been combined to include the following three sets of findings that will be presented in this chapter: first, why policies and programs have led to sustainable, affordable housing for older adults; second, the culture of sustainable, affordable planning and development in Portland; and third, why more sustainable, affordable housing developments for older adults have not been created.

\footnotetext{
${ }^{29}$ The 10 research questions that led to findings in this chapter were the following: (1) Please describe, in general, any current efforts that you feel are being made to create sustainable housing for older adults in Portland. Do you feel that Portland is making any specific efforts as compared to other cities?; (2) Do you feel that sustainable housing development for older adults is being "championed" by a particular individual, group, or entity in Portland, and if so, by whom? Why do you feel that is occurring?; (3) Thinking broadly about the real estate development industry-such as developers, architects, contractors, and others-please describe, in general, changes in practice that are occurring in response to our aging society.; (4) In your opinion, what are the major differences in the ways in which the private, public, and nonprofit sectors are contributing to the creation of sustainable housing and environments for older adults?; (5) How do you feel the current economic climate is affecting the development of sustainable and/or affordable housing for older adults?; (6) Please add any additional thoughts that you have regarding the state of sustainable and/or affordable housing for older adults in Portland.; (7) In your opinion, what do you feel are the most important professional roles in the planning and development of sustainable and affordable housing for older adults and how do they contribute?; (8) Collaborative and participatory processes such as design charrettes, design review, integrated design, etc., are being used more commonly in building design and development. In your opinion, how do you feel these processes affect the development of housing for older adults?; (9) How are consultants and/or subcontractors important to the development of sustainable and/or affordable housing for older adults?; and (10) What additional thoughts do you have regarding the various professional roles in the planning and development of housing for older adults?
} 


\section{The Roles and Contributions of Actors, Sectors, and Organizations in Projects}

State of Oregon. At the state level, two government agencies were identified as important in the creation of sustainable, affordable housing for older adults. First, some respondents reported that Oregon's statewide department focused on issues of housing and community services (OHCS) was an important agency that influenced affordable housing development, including housing that was considered to have sustainable features and housing that was specific to older adults. However, it was noted by a small number of respondents that OHCS operated too much like a bank and that the agency could and should take on a more visionary leadership role. The executive director of a nonprofit agency focused on serving the needs of vulnerable older adults suggested that a "much more energetic group" was needed at OCHS. The respondent felt that the agency was not only capable of, but should become more "vision-oriented" rather than focusing its efforts in a constrained financial oversight capacity.

A PDC employee who has worked on numerous affordable, sustainable, and accessible housing projects in Portland felt that OHCS played a critical role for developers. He explained that developers building sustainable and affordable housing for older adults are reliant on state support from OHCS, and he believed that some of these developers were, in fact, "seeking sustainable development for seniors." Overall, the respondent felt that the agency played an important role and that, moving forward, OHCS would be integral in financing and guiding the development of sustainable, affordable housing for older adults in Portland. 
The division responsible for statewide buildings codes, licensing, and permitting in Oregon (BCD) was noted as having an important influence on development standards from the state to the local levels. Although BCD was not mentioned often by respondents, two interviewees believed that the agency needed to foster increased accessibility throughout the state. One respondent familiar with green building technology explained that $\mathrm{BCD}$ has access to knowledge regarding where improvements are possible: "We have a very good list of where all the barriers to accessibility are [such as] the codes and regulations." However, this respondent felt that the removal of those barriers was not happening, and he really did not understand why since removing barriers seemed to be the next "logical next step" after the identification of those barriers. Additionally, the need to revisit state building codes to improve accessibility requirements that have an impact on Portland was mentioned in one interview in which the respondent highlighted BCD's oversight role with respect to local municipalities; local jurisdictions are required to be compliant with statewide building codes and therefore need changes to occur at the state level.

Absent from the interviews was any comment regarding Oregon's Visitability statute (discussed in Chapter 2), which was intended to increase accessible housing in new developments that received funding from certain programs in Oregon. The existence and understanding of how the statute has been implemented deserves future exploration.

The greater metropolitan region and Multnomah County. Metro, Portland's regional government, also has a role in planning for housing and environments for an aging society. Recent research that has been funded and completed by the regional 
government agency has included housing and transportation options for older adults. An elected official who was interviewed for this research felt that Metro was, in fact, aware of and interested in addressing the connected issues of housing, transportation, and land use as it pertains to an aging population in the greater Portland region.

The Metro councilor described an ongoing conversation with an expert advisory group on regional development that was focused on centers and corridors development, stating: "They're saying the Boomers aren't going to live at the edge [of the regional growth boundary], and the young people don't want to live at the edge [either]." He went on to add that the region is "going to have a lot of demand for [development in] centers and corridors... maybe this [economic] crisis will lead to some change." On the other hand, even though he noted Metro's regional focus on concentrated development in centers and corridors, the councilperson pointed to an important question that needed to be addressed pertaining to existing age-related challenges: "How do we adapt the suburbs?" Although the suburbs are a part of the region, the elected official highlighted the fact that they posed a particular challenge for future regional development.

In the future, Metro will play an important role in defining the direction for the region which will, in turn, impact Portland and other municipalities that are inextricably linked to the regional government. Metro's Growth Concept and Function Plan were described by a sustainability expert at the Multnomah County office as important, particularly due to the contributions of urban planners focused on the long-range planning efforts: "Within various levels of government...[planners] are shaping our future." The County employee added that "Metro is going to be key, at least for this region." 
The other local, non-city agency identified in the interviews as having an impact on housing for older adults in Portland was the Multnomah County-based public housing authority, Home Forward. Home Forward had just one project in Portland identified as meeting the criteria for this case study: Trenton Terrace, a Section 202 development that was built as part of a larger, federally-backed Hope VI project named New Columbia. Like other housing authorities in the U.S., Home Forward deals with housing for lowand very low-income households and was described by one of its employees as "targeting the poorest of the poor." As discussed in Chapter 2, Home Forward is critically important in providing affordable housing for older adults with high needs. ${ }^{30}$

City of Portland. Within the City of Portland, the consolidation of housing functions of the PDC into PHB in 2009 was generally seen by research participants as a positive step in improving housing development in Portland. Respondents explained that the PHB seemed to be a more appropriate agency for such functions, and that reducing duplication was a logical approach. The PDC did retain a major role in funding affordable housing in Portland through its set aside of $30 \%$ of tax increment financing for affordable housing within urban renewal areas. Several respondents explained that affordable housing advocates had won a victory in getting that policy passed, and one former Portland councilperson described the policy as "Great." A service provider for low-income older adults explained that "advocates worked very hard to get the $30 \%$ set

\footnotetext{
${ }^{30}$ The number of older adults that Home Forward houses was not available; however, it was estimated that there were 735 older adults aged 55 and older seeking housing solely from the public housing agency and were on its waiting list, with over one-fourth hoping to move in within one month from when they completed a survey. (Carder, Weinstein \& Kohon, 2012).
} 
aside [passed]." However, the set aside elicited responses that varied greatly among respondents.

The majority of respondents who commented on the $30 \%$ aside viewed it as being as a positive policy that would serve as a very important funding source for affordable housing in Portland. A current board member of Home Forward relayed her feelings on the policy: "I'm so excited... we're getting the affordable housing money out of [PDC's] hot little hands." One self-described affordable housing advocate explained that "Theoretically, [the set aside] guaranteed $30 \%$ of the money flows to the poorest people" and that it is a funding source "that's going to drive [affordable housing] preservation and future development." He concluded that "There has to be a revenue source" and saw the set aside as critical to creating much needed affordable housing in Portland.

Some respondents still expressed concern with the PDC's commitment to using the set- aside funds for affordable housing. As the director of a nonprofit focusing on the needs of low-income seniors explained, "[A particular city councilor] is saying [urban renewal taxes have] nothing to do with affordable housing." She added, "We [still] haven't used that $30 \%$ set aside to build affordable housing" and suggested a new approach moving forward: "We should be publishing evaluation." She relayed additional reasons for establishing an evaluation: "I don't think the general public knows [the outcomes of the set aside]... Behind closed doors they've had reports back to the [PDC] and certain committees." Her conclusion was that more accountability was needed, and answers to the following questions should be given: "How have we done on the $30 \%$ set 
aside [and] are we meeting those goals?" Her opinion on whether the city was meeting its goals was very clear: "No, we're not."

A PDC employee offered insight into the PDC's perspective, explaining that perhaps the requirements of the set aside were too rigid and needed more flexibility. He described the policy as an "okay requirement" which was based on his feeling that the requirement has meant that "flexibility is taken away" from the PDC in deciding how to allocate its tax revenue. He elaborated by explaining that the another goal of urban renewal is to "remove blight" and that if " $30 \%$ of the dollars are already prescribed," this might get in the way of a community that "needs business loans so people could be employed, or needs a park more." He added that he felt that "affordable housing needs to be higher on the radar," but that using nearly one-third of the tax increment financing on affordable housing came with problems: "The whole idea [of urban renewal areas] is to make investments that generate revenue...you're not going to capture nearly as much in tax revenues [from] affordable housing." Additionally, the PDC employee explained that if the development is subsidized and it is "a nonprofit that's developing it, that property is going to be tax exempt." This sentiment was not offered by any other respondent but it offers an important window into the perspective of PDC, urban renewal, and the $30 \%$ set aside of tax increment financing.

Nonprofit sector. Nonprofit organizations play a critical role in the provision of housing in Portland, including being at the forefront of the push for building housing according to green standards. The national efforts of Enterprise Community Partners contributed to the local focus on "greening affordable housing," which was described by 
the executive director of one nonprofit: "I'd say really Green Communities, through Enterprise [has] forced us, or brought [nonprofits] to think about how to structure the green side of our affordable housing, and they try to connect with city policy." A policy expert with PHB who previously worked for Enterprise Community Partners explained the evolution of the program which was implemented in Portland:

[Enterprise was] at the forefront of bringing green building [practices] into affordable housing development. Enterprise rolled out a program nationally [called] Green Communities... it was a partnership, one of the first partnerships, between a major national environmental organization aimed at sustainability, to bring the notion forward that green building-building efficiently, building in healthy ways-made as much or more sense for low-income communities than [as] a high end perk. [They advocated that] affordable housing [should be] energy efficient and a healthy living environment, as well as [being located] in a walkable community... Enterprise really brought that into the forefront as far as thinking about affordable housing nationally.

The policy expert went on to explain that Enterprise had shifted its focus away from physical development practices, which she described as "sticks and bricks and crunching spreadsheets," moving instead toward policy issues and operating practices that were intended to build the capacity of "nonprofit organizations [that] own and operate a large share of the housing to be sustainable business-source organizations." In particular, the Green Communities program was described as having "provided a lot of learning [and] planning grants up front for affordable housing developers to integrate [sustainable] design processes [that] actually brought some of those measures into the development of affordable housing." In Portland, the Green Communities program was used in two of the six developments described in Chapter 4. The relationship between Enterprise and Portland's planning and development communities was considered to be 
important and to have influenced, to some degree, Portland's green building policies and programs.

Another aspect of nonprofit development that was discussed by the 31 interviewees was the range of affordability that nonprofits provided to residents and the meaning of the term "affordable." There were differing opinions as to which income ranges nonprofit organizations served. Some expressed the opinion that nonprofits were essential to the provision of housing for low-income residents, while others felt that certain nonprofits had focused on affordable housing for residents who did not have the greatest need. In fact, nonprofit organizations were seen by several respondents as operating, in some ways, as for-profit organizations and were viewed as needing to broaden both their approaches to development and the range of residents whom they serve. Additional findings related to this issue are presented later in this chapter.

For-profit sector. The private, for-profit sector plays an important role in the development of affordable housing and often times, as was detailed by one respondent, becomes involved with projects based on "opportunity... which means you can make some money." In the case of sustainable, affordable housing for older adults, an owner or sponsor-often a nonprofit-will enlist a team of people and organizations in order to plan for, design, and develop the housing project.

As described in Chapter 2, a building program turns into a conceptual design and ultimately into detailed plans for building. Once the plans are approved, bidding for the services of a general contractor or various subcontractors occurs until bid agreements are completed. The detailed plans are then used by the construction team in building the 
actual unit and are most often carried out by a general contractor. The general contractor normally has his or her own team to construct the building and/or will work with subcontractors to complete the various stages of construction, depending on the agreement with the owner/sponsor.

Private consultants can also be an important part of a team in developing sustainable, affordable housing for older adults. For example, a consultant who was brought onto the development team in one housing project designed for older adults had expertise in aging-friendly design. As an architect explained, if your firm doesn't have that expertise, "there are consultants that specifically specialize in aging issues out there." However, based on the comments of the architects and nonprofit directors interviewed, it was not common to employ aging-specific consultants, with a decision made, instead, to address the issues "in house" with someone from the owner/developer, architecture, or contractor team.

Cross-sector relationships. The interviews revealed that the public, private, and nonprofit sectors related to housing development in Portland function in a complex and inextricable fashion with one another. Public-private partnerships existed in each of the sustainable, affordable housing developments for older adults identified, even though the sectors, in general, operate with differing values and priorities (e.g., green building, affordability, organizational missions). For instance, nonprofit project sponsors enlist the assistance of private-sector architects and contractors in order to complete the project, as does the Home Forward, the county's public housing authority. Additionally, funding mechanisms from a variety of government agencies and/or tax abatements are integral in 
creating a level of affordability for both the nonprofit and for-profit sectors developing affordable housing in Portland (as discussed in greater detail in the next section).

A planner at BPS provided insight into the city's partnership approaches. He explained the limitations of certain city agencies: "[BPS] isn't going to go out and build buildings; [PDC] partners with developers to build projects." However, he stressed the importance of collaboration: "We bring [the for-profit sector] around the table [to] talk about a vision [and] a way forward." He explained that there was a need to develop an ongoing dialog that can lead to "getting enough housing at enough of an affordability level for enough different household types and sizes to make [partnerships] sustainable and have enough options for [housing a range of] people."

Another BPS planner noted that some project sponsors/developers in the for-profit sector are "interested in partnering with the city a lot on projects" and that they want to "build projects that are somewhat affordable." One private developer, who at one time worked in nonprofit development, fills a niche for developing affordable housing in certain areas of the city and explained how he was involved in affordable housing development: "Because there were developer agreements 31 that a certain amount of affordable housing had to be provided by the private developers." Since these publicprivate development agreements exist between city agencies (e.g., PDC, BPS) and private developers, they allow that a certain developer "goes in and develops the affordable housing to meet [specified] requirements."

\footnotetext{
${ }^{31}$ The Municipal Research and Services Center of Washington (2010) described a developer agreement as "a contract between a local jurisdiction and a person who has ownership or control of property within the jurisdiction. The purpose of the agreement is to specify the standards and conditions that will govern development of the property" (para. 1).
} 
A policy expert working at PHB described how one particular cross-sector partnership brought together national, state, and local organizations by leveraging subsidies and engaging in collaboration:

[Enterprise] had both the infrastructure to build capacity with the primary developers, as well as the tax credit investment arm, [and] there were some really good folks [in Portland's government agencies] who were interested in having affordable housing and the City's investments in affordable housing linked to some of the same kinds of goals...but the majority of policy was getting passed to exempt affordable housing from meeting those same guidelines...It was [said that] 'affordable housing already costs so much to build that we're not going to layer another unfunded mandate.' When we first started talking to industry partners and nonprofit organizations [Enterprise] tried to reframe [green building policy in affordable housing] as an equity issue. Enterprise, as a tax credit investor, put a lot of effort into quality design and quality location, [but] not all tax credit investors were looking for that. Many were looking strictly for a profit. The State of Oregon actually was one of the earliest to have an architect on board to look at issues like the use of materials and the use of good building systems.

\section{Processes and Practices that Contribute to Projects}

Financing barriers. The finance component of affordable housing is complex and often involves various funding sources, including loans from banks and public agencies, grants, equity in the form of tax credits, bonds, and other possible sources. As was described by the sponsor of an affordable housing development, "It's ridiculously complex." She explained jokingly that it can make someone "brain damaged." A management expert similarly opined, "I bet every one of those [six identified housing developments] has five or six layers of financing in them, or more."

There are also additional layers of complexity in financing sustainable, affordable housing as compared to market-rate housing and housing that is not built to green building standards. One of the complexities has to do with the combined expectations that 
long-term affordability will match the durability of materials needed for sustainable/green building. A public-sector housing expert said that the expectations of durability by the public and nonprofit agencies are often much higher that than the expectations of lenders: "PDC would say 60 years... a lot of nonprofits are looking at that 50- or 60 -year program, not just 10 years." A PDC employee explained the problem from a "lender perspective." He said, "Their return on their dollar" was shrinking due to increased material costs and "Lenders don't often understand the value [in financing for] the long term." The perspective of lenders was not captured in this research but is an area that should be considered in future research.

Differing values associated with affordable housing. A disconnect was also noted by respondents regarding the differing "values" attached to affordable housing developments. Although affordable housing addressed an identified need (housing for low-income older adults) and had an inherent "social value," the "market value" of a housing development (and its land) endangered the affordability of that property when the requirement for affordability expired. A public-sector architect explained that PHB and the PDC had tried to mitigate those issues by adopting policies that required "affordable housing for a 60 -year period... it had previously been 10 years." He added that in the past, "Shortly after 10 years, that housing stock was being turned over to market rate." This turnover is a major reason why the preservation initiatives discussed in Chapter 2 were initiated. This difference in values can be can be partially understood due to lenders not having financial investments that extend beyond the initial terms of the 
building, therefore creating a shorter-term approach to the design and characteristics of the building.

Economic climate. The economic downturn that began in 2007-2008 dealt a substantial blow to Portland's ability to meet its citizens' need for affordable housing. There was near unanimous consensus among respondents that the downturn-described as a "recession," "the great recession," and even as a "depression" by one respondentadversely affected the ability to finance "housing of any kind." One participant explained, "Right now the economic climate is quite harsh and is adversely affecting development. It's chilling development." Another participant felt that "lenders have even retrenched further back to not wanting to take any risk." Another stated, "Development is just off the table."

In regard to the specific case of sustainable, affordable housing for older adults, one participant had experienced that "banks are less willing to fund special needs projects or projects that have much more minimal return on the dollar." He explained that since "lending is brought on by bonds and investors...they want a good return on their dollar." When the profit margin shrinks, as is the case for "special needs housing, special lowincome housing, or housing that has sustainable features," the long-term value often times is "not worth the risk" to the lender.

One hurdle seen as particularly difficult for affordable housing development was the perceived inability to use LIHTC as investment equity. A nonprofit director explained, "The bottom has just fallen out of the tax credit market. It's killed some projects." The difficultly with the tax credits is that they are based on businesses buying them to offset 
their tax liabilities, and as one respondent noted, "People aren't paying taxes as much anymore, so why do you need tax credit?"

The importance of the LIHTC cannot be overstated. According to a Home Forward employee, "the way that America builds affordable housing these days is through these tax credits...it's a very indirect way of subsidizing a social goal, but it's the American way." He continued by saying that "No one is getting any money, so the thing has collapsed." When the economy was going strong, he said, "you were getting a really good deal, over one dollar on value for tax credits, which is very competitive. Now you're lucky to get 75 cents. ${ }^{32,}$

Financing for a project most often occurs in three stages: pre-development financing, construction loans, and permanent financing loans. Each type of financing has its own timeframe, financial terms, and risks. During the economic downturn, some projects were left on hold, and investors lost substantial amounts of their money. A respondent explained that, at the time of the interview, "The surest deals I see the lending institutions moving on are ones that are backed by developers that still have fairly solid collateral." Another respondent felt the economic climate had "reduced the number of [nonprofits focused on housing]" and that those remaining were the ones with the most financial strength.

\footnotetext{
${ }^{32}$ According to HUD (2010b), the LIHTC program was enacted in 1986 to provide the private market with an incentive to invest in affordable rental housing. Developers, often nonprofit developers, can sell the credits to investors to raise capital/equity for their projects. Tax credits are different from tax deductions as they are subtracted directly from one's tax liability dollar-for-dollar and are therefore considered to have a much larger impact than tax deductions. If someone is paying over $\$ 1.00$ for a tax credit, they are not getting equal return on their investment. If they are paying less than $\$ 1.00$ on a tax credit, and they have sufficient tax liability, they are able to get a good return on investment.
} 
Design processes. Integrated design approaches were seen as critical to creating appropriate housing for an aging Portland. A policy expert with experience in educational programs that were focused on sustainable development explained how Enterprise's Green Communities program started in the mid-1990s: "Enterprise [formalized] the practice of actually thinking [about the] integrated design process...Early in the project the developer, the architect, and the contractor were looking for ways to bring in measures that were, again, low cost or no-cost." Such a process was referred to earlier by Larsson (2004; see also footnote 23 for definition), who described the integrated design process as providing an opportunity for active, collaborative roles to be shared from a variety of experts at earlier design stages.

Although green building practices today often include integrated approaches, the inclusion of end users of buildings in the design process (e.g., low-income older adults and persons with functional limitations) does not appear to have been fully realized in Portland. Comments regarding design processes that had incorporated the perspectives and suggestions of older residents, neighbors, and/or related populations (e.g., people with disabilities) were infrequent during the interviews. However, according to a small number of interviewees, when older adults had been involved in the process, exemplary outcomes had been achieved. A housing advocate for older adults summarized the integration of seniors into a project in Portland (the project was not one of the six detailed in Chapter 4 based on it not meeting the criteria for being sustainable):

The architect was trying to figure out what to create...The first thing they wanted to do was talk to seniors about what they would want. I had never heard of an architect taking the time, so a lot of the features in that building were based on the interviews the architect had with seniors who were living in other buildings who 
said, 'We wish our building had' [things like] air flow and ventilation... peep holes in the doors that helps seniors feel more secure if they can look out when someone knocks and see who is there. Things you might or might not think about if you're just used to building housing, what might be really important to a senior, [like] a library, a community kitchen, a living room with a fireplace... community bathroom on the first floor... an upper courtyard [with] common space. All this stuff was based on these interviews with low-income seniors who were living downtown.

Another design process that was discussed by research participants was design review. ${ }^{33}$ Many of the respondents who commented on design review did not believe that it was particularly helpful in the final design of sustainable, affordable housing for older adults, and some even felt that it was burdensome in reaching their goals of completing their projects. The director of one nonprofit housing agency explained that "Pretty much everyone, I would think, sees design review as a 'pain in the side'." She went on to explain, “I don't think you can legislate the design... it's such a subjective thing that some people might think something is fabulous, and you could find 10 other people that said it's horrid." Another nonprofit director stated simply: "I'm not a big fan of design review." Both respondents, however, did say they were in favor of codes for functional building issues, as was reported by the latter respondent: "I'm a fan of clear code that expresses what a local government needs or wants." Interestingly, all three nonprofit directors who commented on design review shared the sentiment that design, in general, was difficult to decide by the committee structure that was in place; however, they agreed

\footnotetext{
${ }^{33}$ As discussed in Chapter 2, design review is required for projects in particular areas of the city (e.g., downtown and transit-rich areas). Projects are reviewed using a set of community standards, depending on the location, scale, and procedures desired by the project applicant. Common elements of design review include architectural style; structure placement, dimensions, height, and bulk; lot coverage by structures; and exterior elements of the proposal, including building materials, color, off-street parking areas, open areas, and landscaping (City of Portland, 2011d).
} 
that functional aspects of housing (e.g., setbacks, building envelopes) should be regulated clearly by codes.

An architect with experience in dealing with design review on Portland-based projects added a unique perspective on potential issues that could arise with individuals who sit on design review committees: "In many cases [they are] either not designers, or designers that have a different agenda." Interestingly, he likened design review to free speech (or lack thereof): "I think in some cases design review infringes on a form of speech... any architect in this town can point to cases where the design review process has been too heavy handed and too micromanaged." Later in the interview, the same architect spoke in favor of design review: "I do support the underlying goal of design review: to have a public discourse on design...Design review committees should, by and large [be] able to make strong recommendations, force designers to look at issues differently." He added that this type of dialog could be extended to accessibility and/or age-specific issues by "challenging a designer." For example, he felt that the committee might ask the following type of question: "Couldn't you do this a little bit differently and make this all work on grade [rather than] those 2 steps?"

Two other private-sector developers actually spoke very favorably of design review. A principal at a leading green building firm in Portland explained that his company viewed design review as useful due their "particularly proactive approach." He explained the process as including "a predesign review process you can go through with the design commission [that] we actively engage in... We try to get input from the commission early on." At the end of the process, he explained "You don't get surprised 
when you go in there with your formal submission, and the design commission is very willing and very good about engaging with developers." Another private developer had a similar take on the process: "To get to design review you have to have fairly detailed schematic plans...I've taken [plans to predesign] where we were struggling with something, we knew it wasn't right." By taking the predesign plans into the committee he felt that his team "got great feedback of where the problems were," which led to their ability to step away and say "That is the problem." The developer felt that "sometimes you might get some ideas about the solution" and the committee can assist with that aspect.

\section{Why Sustainable, Affordable Housing for Older Adults has (and has not) been Created}

In order to answer the question of why sustainable, affordable housing for older adults has been created in Portland, it is important to begin by reiterating that policies represent a collective response to an issue. In this study, the issues that are being responded to through policies are threefold: first, providing affordable housing; second, housing older adults with limited financial resources; and third, facilitating sustainable development or green building practices. Aspects of those policy responses will be detailed in this section (an assessment of policies and program will be reserved for the following chapter). Furthermore, policies are influenced by and contribute to a culture and set of values that permeate society and inevitably affect various sectors that function in the sphere of planning and development. Finally, there are several reasons why sustainable, affordable housing for older adults is not created in Portland and why such 
housing has not met the demand that has grown with the aging of Portland's population. These reasons are explored at the end of this chapter.

Public policy as a contributing factor. Numerous factors have led to the creation of sustainable, affordable housing for older adults in Portland. The various policies and programs described in Chapter 2 represent what is perhaps the most important reason why such housing is created: they represent a collective response to the social problem of providing adequate and appropriate housing for older adults with limited resources. Looking back to Segal's (2010) description of a collective policy response, we recall his explanation that policy represents a position that is assumed by an agency and that the policy in question addresses a need and an issue that society both values and benefits from. Eventually programs are shaped by legislation and/or regulation as defined by the policy's goals and then, as described by Mazmanian and Sabatier (1989), policy implementation occurs through program administration which, in turn, affects the people whom the policy is intended to serve.

Based on the existence of six publicly subsidized developments identified as affordable, sustainable, and specific to older adults in Portland, there is reason to explore why public policy has led to the planning and development of those developments. The following subsections offer additional insight into the extant policies and programs that have catalyzed actors in the public, private, and nonprofit sectors to build such housing. It should be noted that no single policy or program has been identified in this research as having led to the creation of those particular housing developments, but rather a series of somewhat related policies and programs. 
Affordable housing policy. In regard to affordable housing, Bratt (1989) offered the explanation that housing policy in the U.S. has had the primary objective of meeting the needs of low-income people due to the fact that the private market would not produce the needed affordable housing without public incentives. An architect considered to be an expert in green building made a similar comment: "The very definition of the public sector is that it takes care of all the issues the private sector [does not]." He went on to explain, "Private partners [take] the lead using public funding, and I think that's been a pretty successful model, because it means [nonprofit housing agencies] have been on the ground [addressing needs] in the community."

A comment from a Multnomah County employee can be used to summarize a statement repeated by many of the 31 respondents. She explained succinctly that the public sector "sets the minimum standards...based on public need." A private sector architect went further, explaining that the needs of the public are translated into funding opportunities that should "leverage [public] values very directly through mandate" and that Portland "should plan to spend public money on public housing...even if we're doing it with a public, [for-profit] or nonprofit partner."

Affordable housing policies and programs target various income levels and are utilized in different ways in different sectors (e.g., public housing agencies, nonprofit organizations). An affordable housing expert and advocate for affordable senior housing explained how different public programs translated into developments: "The main difference I see has been focused on different income groups... with [the public housing agency] targeting the poorest of the poor, the nonprofits targeting the middle income." As 
mentioned earlier, Home Forward, the public housing agency for Portland and Multnomah County, has specifically addressed the needs of the lowest income groups. The respondent went on, however, to explain that public policies and programs have shifted over time: "It used to be the federal government just gave grants to build public housing, and that's been shrinking... it used to be the government was in the business of just building public housing for the poorest of the poor." His conclusion was that the government has "kind of withdrawn from building any new public housing."

With regard to the nonprofit organizations that are involved in affordable housing development, there was variation in how respondents described the populations whom they served. The majority of respondents stated that nonprofit community housing organizations were building and operating affordable housing through assistance from public policies and programs; however, what qualified as "affordable" was subject to debate. For instance, as was described in Chapter 2, the Consolidated Plan identified the need to increase housing opportunities at or below $50 \%$ of the area MFI in the metropolitan region in response to unmet housing needs. However, a housing expert who tracks unmet housing in the region reported, that "There's a vast shortage of housing units for people that are below 30\% MFI, and countywide we're 19,000 units short for that group. I think in the city there's a 13,000 unit shortfall for folks under 30\% median."

A longtime housing advocate in the metropolitan region provided additional insight about one nonprofit in Portland, which was described as "more like a for-profit [organization] now than a nonprofit [but] I wouldn't say that applies to all [nonprofits in

\footnotetext{
${ }^{34}$ One example of this trend can be seen in the federal funding of Section 202 projects (the main source of funding for supportive housing for older adults) which, according to Bloom (2011, December 20), has witnessed the elimination of all new construction funding for the Section 202 program in the 2012 budget.
} 
Portland]." This respondent went on to describe in greater detail the unclear differences between certain sectors in Portland: "Although I think most nonprofits and advocates for affordable housing would like to say that for-profit [agencies are] bad, I don't think you can say that... there's been a real blurring of those lines that nobody has really analyzed." Those "lines" appear to be between balancing the social good or missions of an agency (e.g., providing affordable housing) and business models that require providing housing for a range of incomes, rather than those with the highest need. A housing advocate for low-income seniors in Portland added the following remark about some local nonprofit housing agencies: "They're interested in a middle-income group, a group that's eligible for tax credits; folks who are 60\% [MFI]." He explained that those organizations could serve lower income groups "If they can get public subsidies from the housing authorities," but that "for the most part they're developing [LIHTC] projects for middleincome seniors."

An employee of Home Forward offered the following insight into the public sector's influence in creating affordable housing: "I think the role of the public sector [is] to stimulate investment." He explained that funding from public agencies helps all of the sectors in meeting their agency's needs, whether profit-, mission-, or needs-driven motivations, and this funding comes with contingencies from the public sector: "If you say you want to do this, you must do that [in return]... oftentimes it's the cost of doing business... that's how you get the private sector involved."

One concrete example of a public-sector contingency is Portland's set of tax abatement programs. A planner at BPS with experience working with the programs 
explained, "Tax exemption, like urban renewal, it is kind of a local subsidy to affordable housing, and some of this housing, obviously, particularly in the downtown, is suitable for elderly and disabled people." She also explained that the tax abatement programs responded to policies articulated by the City of Portland and Metro (e.g., Portland's Comprehensive Plan and Metro's Regional Growth Framework) by providing incentives for "higher density, multifamily housing in light rail station areas and city centers." She went on to describe the perceived value of tax abatements to older adults: "Having housing, affordable housing for older people and very close in to areas downtown, is good; it allows them to live a fuller life, an independent life."

Policies focusing on an aging population. Other housing policies pertaining specifically to older adults were also discussed. A policy expert at PHB felt that the planning process was critical to shaping such policies: "It has everything to do with the goals that are set for the planning process... goals that are set to address or to integrate the needs of an aging population... If that goal is left off the table, then it may not be part of the plan." A nonprofit executive director pointed to there being "a lot of political will at the policymaker level, and for seniors specifically." She went on to describe the reasoning for that political will as being based on population shifts and potential markets: "There's somebody turning 60 every 10 seconds or so, and so that means it makes sense for us to be thinking more and more [about] making sure all of our projects can accommodate seniors." Overall, respondents felt that policy focused on housing for older adults were needed, even though they had yet to be developed in many instances. 
Sustainable development policies. Sustainable development and green building policies have been an emerging priority for elected officials and policymakers in the City of Portland, the region, and at the state level. These policies, detailed in Chapter 2, were a focus of several respondents. An affordable housing advocate explained that the push for sustainable development is "a major focus of [Portland's] mayor and a major focus of a couple of city council members... I would definitely say Portland is ahead of the curve, ahead of other cities in terms of basically requiring these green elements incorporated in part of the funding proposal."

Policies were identified at multiple municipal levels that led to sustainable housing development, as was detailed by one nonprofit executive director: "[PDC] has had some initiatives... There are so many different groups influencing policy at the state and local level, and then Green Communities at the national levels.” Overall, sustainable development policies were well known by respondents and, in general, were seen as a collective response by multiple levels of government to create better housing and built environments that contribute to the health and well-being of people and the environment.

\section{The Social and Cultural Aspects of Sustainable, Affordable Housing for Older Adults}

In Chapter 2, literature was reviewed in which Portland was described as a leader in green building and sustainable development practices. A private developer agreed, opining: "[Portland is] clearly a world leader in terms of pushing the envelope for sustainable development." Policy supporting this push has contributed to this unofficial title, as has the commitment of elected officials and staff in various bureaus and offices locally and regionally. In order to adequately address the issue of why sustainable, 
affordable housing for older adults has been developed in Portland, however, it is necessary to look beyond established policies and government programs and explore other possible contributing factors. Based on the interviews conducted for this research, various social and cultural elements were identified as existing in Portland that can be understood as influencing the planning and development of sustainable, affordable housing for older adults.

Emerging culture of sustainable development. Several respondents commented that the nonprofit and public sectors had embraced sustainable development practices and that a voluntary culture had coalesced around the issue of sustainability. A nonprofit executive director described Portland as a "green beacon...for a city of our size" and noted that "a lot of [the sustainability effort] has been voluntary." Although the respondent noted the importance of policy and government programs as influencing the production of green buildings, she felt that "We seem to be highly respected...for the amount that is voluntary." A representative from Home Forward discussed how their agency had embraced the approach to development: "'Sustainable' very quickly became a culture of the housing authority and how we built; as long as we can get the budget to balance, we're going to do it."

A private developer spoke about the changes that had occurred in the private sector: "Every developer wants to claim their building is sustainable...There is a fundamental change going on in the way people think about buildings, and site development, that hasn't been there." This developer, who has affordable housing developments in his portfolio, noted that he returned to the development profession 
around 1995 with an interest in environmentally sustainable development, but he said: "I could hardly find a consultant out there that could help me figure out what that meant... [Architects] had no idea what they were doing... Contractors didn't want to try anything different because it was new and untested." He went on to describe what has happened since as a "sea of change... it's not just a developer pushing it, but you've got engineers... contractors... architects... thinking about [sustainable development] from the day you start working on your site plan."

A nonprofit executive director stated that architects, in particular, have been instrumental in furthering the green building agenda in Portland: "Many of the architecture firms are very keyed into sustainable design and provide a leadership role for teams in terms of helping to guide what you should do and what you should think about." The director viewed architects as a "key member of the team in terms of helping to shape [the sustainability] part of the agenda." An architect employed by a Portland-based firm with a history of working on sustainable projects also noted the importance of the design profession while detailing how other professionals, too, were involved in the emerging culture of sustainable development: "Historically... the design profession has been probably the most out in front." He went on to detail how others adopt trends: "Development professionals catch on pretty quickly... Contractors have often caught up... [Financiers are] just now starting to figure it out, [such as] banks, or foundations...real estate brokers...[the people on] the money side of the project."

Several other professions were also detailed by respondents as being pertinent to perpetuating sustainable development, including affordable housing for older adults. An 
architect and university instructor teaching green building, for example, noted the critical contributions of engineers and landscape architects: "Mechanical engineers play a huge role... they're in the position to weigh in on creative ways to keep people comfortable... having a mechanical engineer that's ahead of the curve is critical." He also noted another important professional role: "Having a good landscape architect is certainly critical, and the participatory process of landscape architecture is very well established...your garden designer [and] open space designer [can] really turn people on and get them excited... you really create a community."

It was clear from respondents, however, that the most important role in perpetuating the culture of sustainable, affordable housing development-putting aside public policy and related programs-was that of the developer. The architect/instructor articulated the impact: "I think the developer will always be the most important [since they] define the project and say what the expectations are." He explained that if the developer establishes that "sustainability needs to be taken seriously...from the very beginning...then everybody else will figure out what that means."

Champions. Respondents were asked to identify a champion of sustainable, affordable housing for older adults in Portland. Comments varied, but no consensus emerged regarding a single champion. Rather, several champions were identified as supporting various aspects of housing and environments for older adults, including specific advocacy groups, nonprofit housing developers and other community development corporations, professionals in the for-profit sector, and elected public officials. 
The agency most often mentioned as a "champion" was Northwest Pilot Project and its executive director. A former Portland City Commissioner called the agency "the obvious one," and a Home Forward employee explained that Northwest Pilot Project is "a huge part of housing; they're a terrific resource for anybody 55 and older; they're very focused on housing." Some respondents did point out that the focus of the agency was on advocacy and service provision, not housing. One respondent explained that the executive director of the organization is "not a houser...but [is] championing the people as opposed to championing the developments." Nonetheless, an employee who worked at Northwest Pilot Project explained the important role of the organization to older adults in Portland: "Folks come into our office seeking housing that they can't find, or they're on a waiting list that's two years old, or they're homeless, so we're seeing a lot of low-income seniors, and we're acutely aware that there's a crisis of low-rent, affordable housing in this city...[We advocate to] all levels of government."

Several respondents also commented that leaders of nonprofit organizations-such as the ones who developed the six projects identified in this study-should be considered champions. The reasoning behind these comments centered on the mission-driven approach that the organizations were taking to housing underserved populations and the housing units that were produced as evidence of their "championing." The three directors of nonprofits interviewed for this research-each nonprofit oversaw projects that met the criteria to be included in this case study-did not see themselves as champions; instead, they explained that they were responding to the opportunities presented to their 
organizations in the form of needs identified by government agencies and calls for development proposals.

Another set of comments from the interviews worth noting pertained to one elected office and the characteristics of a future champion. The current lack of an identifiable champion for sustainable, affordable housing for older adults led one former elected public official to posit that "It takes a political advocate who [can] multitask... I'm optimistic about [City Commissioner] Nick Fish.” Another respondent, who has been a lifelong advocate for improving the quality of housing for older adults, listed several characteristics of a future champion:

You have to have a charismatic leader... a transitional person, one who understands enough of the other roles... a leader [who] can convince people to be part of a team...It has to be somebody who, through their own passion or their own skills, is able to reach out to the other disciplines and get them to want to be involved... the right person who's willing to be very persistent and focused and who could be a 'pied-piper'... someone who can present something that others can say 'Oh, that's interesting,' 'Oh, that makes sense,' and 'Oh, I want to be a part of that.'

Some respondents saw a potential future champion as being a public official, while others noted that the most important qualification is a person's abilities to work across the "silos" that were present between sectors and professions.

\section{Support for housing specific to older adults as compared to other}

populations. Housing intended for older adults was discussed by several respondents with respect to how it compared to housing that was specific to other populations. A PDC administrator expressed the belief that developers and managers specifically liked housing for older adults: "Most developers prefer to do senior housing because, number 
one, seniors are easy on the real estate. They don't kick doors in...we're seeing more of applications for senior housing than most." He added that turnover tends to be lower as well: "Most seniors don't move a lot, especially after $65 .$. They stay for a long time."

In regard to community support, housing dedicated for those aged 55 or 62 and older (age qualifications depend on program funding) was seen as receiving more support than housing for other populations. A public housing official explained that "People fear [the prospect of] putting prisoners in the neighborhood. Next to that is [the] homeless, then special needs...Elderly [housing] is probably the most easy to do." Participants also commented on the positive reception that communities had for senior-specific housing. A PHB employee described the support for the North Portland development, Rosemont Court: "There was a real interest in the community in having some housing for older adults who couldn't keep up with [their] big, old housing." He explained that the result was "A lot of the people who lived in the neighborhood came there [to live]...I see that as part of keeping the community sustainable." A nonprofit executive who led The Watershed project in the Hillsdale neighborhood in Southwest Portland felt the community was incredibly supportive: "[Hillsdale] was the most sophisticated, the most engaged, the most welcoming, in the sense that they wanted the development, and they wanted to influence the development...A lot of those people were over 55."

Perceptions about aging in Portland. Throughout the interviews many comments were made concerning perceptions of aging and older adults in Portland. Looking beyond needs assessments and specific design features detailed elsewhere in this research, several distinct issues emerged. Respondents across many sectors commented 
on need to "reframe" perceptions of older adults and to move away from negative, needsand deficiency-based views of older people and the aging of society and to focus more on the potential and opportunities that exist. The lead architect for one of the affordable and sustainable projects for older adults articulated his perspective as follows: "There are some exciting opportunities to really rewrite the stereotype of what we think older is [and] see our culture change [to] integrate respect... knowledge... what older adults [did] right...I just don't think our society honors that as it could."

An architecture professor added that the human capital that exists among older generations is undervalued: "We are so focused on traditional monetary capital that we haven't looked at personal capital, social capital [which] really makes for healthy communities and creates the kind of flexibility that allows communities to be strong." He explained the particular characteristics that are unique to older adults: "If you chart all the people in a community on that spectrum of capital... you would find [older adults] are huge in the social capital, and they have huge ways of contributing." He added that it is important to consider how society can best utilize the experiences of older adults, since it has the ability to strengthen communities in the long run: "Resilience comes from building this social capital."

A few respondents commented that age-specific thinking in Portland was focused on younger generations rather than older generations. An urban planner and designer for BPS explained that "The only thing we've wrapped our heads around up to now [is] the young professional orientation." He felt that Portland worked "pretty well for the young hipster that is an art person, or a young, creative class person [who] is into riding bikes 
around." In regard to older persons he felt that focus "doesn't necessarily translate really well to the older adult population... [Portland] is generally perceived as a younger place, [but] that could all change."

Two respondents felt that Portland had a divide between younger, able-bodied individuals and less-able-bodied older adults. A PHB employee explained that although accessibility issues have arisen in strategic planning processes at the city level, she did not think it was "really taken on" by the City. She went on to say that Portland has "such an able-bodied [image]... the bicycler who is going [the pub]...We have a ways to go." A university professor and practicing architect described the separation of generations in Portland and elsewhere: "We're increasingly recognizing the impact modern culture has had in allowing us to exist separately from each other...the young in one group; there is isolation [created]."

The shifting landscape of housing for older adults. Respondents provided insight into possible changes related to housing for older adults in Portland in the future. Several potential trends were identified, including the impression that the Baby Boom generation may be a potential driver of change, that there is an increasing interest in multigenerational housing, and that there is a trend that values are returning to past environmental types that are focused on local connectivity and smaller-scale development.

In regard to the Baby Boomer generation, several respondents pointed to that generation as being a driver of change and as a likely key factor in the aging of Portland and elsewhere. The director of a management firm that focuses on housing for older 
adults explained that "Traditional models are no longer going to be as acceptable...Boomers aren't going to be happy with [what] you see in assisted living." An architect with experience in senior housing projects explained that Boomers were going to "redefine environments for older adults [and] the whole cultural archetype... as compared to the WWII generation." Another respondent felt that there was a false assumption that "Boomers would enjoy the income security their parents... That's not the case." In general, respondents commenting on the potential impact of this next generation of older adults felt that the Boomers had already been a catalyst for change throughout their lives and that additional change attributable to them was probable.

Another aspect of change to future housing that was discussed by interviewees was the feeling that new models for intergenerational housing are desired. Several participants articulated their vision that "intergenerational" or "multigenerational" housing environments will be increasingly sought after, including an elected official for Metro: "I can imagine places that are designed to [be] multigenerational... something more structured [than neighborhoods]." One developer discussed some of what he had heard from friends and clients: "I've had a lot of people talk to me about what we're going to do when we're older, when we don't need our big houses anymore... a little co-housing community with 8 or 10 [people where] we'll take care of each [other in an] intergenerational community." An architect also shared his thoughts on the issue: "I'm hopeful we'll figure out the intergenerational piece, [because] it's frustrating to me that building for an aging population is being perceived as building for just that population rather than [for] keeping that population integrated." 
In addition to the development of housing units, an architecture professor added that other buildings, such as schools, should be considered for intergenerational purposes: "If we design and build a school, can we create opportunities for the elderly to meet there, [to] be a community center at night? Can it double as a place for [older adults] to meet and continue to be in the eye of the community?"

One interesting perspective articulated regarding the future of housing for older adults was that the future might represent a return to a type of environment that existed in the past, returning to better connectivity at the local level. Two respondents discussed the promise of environments that were "pre-World War II," and several commented on a return to environments that were less dependent on the automobile as being good for older adults. A BPS planner and urban designer explained what he saw happening in Portland:

Part of it is the infrastructure and the streetcar stuff that has been there about 100 years. It's gone through a few generations of use by different people of different age ranges... [We should be] learning from that [and] thinking sustainably and holistically about all age ranges, what works the best, the sustainable, the 20minute neighborhoods... We're coming full circle right now. A lot of the stuff is from 1900, 1920, 1930 where no one had cars. There are still horse rings in the curbs...We paved over all those streetcar tracks. Now we're considering letting the cars go away again.

The concept of a 20-minute neighborhood-or healthy, connected communitieswas discussed several times. Comments focused on improving local connectivity that would allow older adults more opportunity to age in their home. A green building specialist with an emphasis on aging in place explained that Portland should "help people age in their homes [by] getting back to basics." She saw the following as important to 
realizing opportunities for aging in place: "I think there is going to be a lot more density, a lot more mass transit, [where] you can walk to everything in 20 minutes." She concluded with some additional thoughts on the 20-minute neighborhood concept: "[It] can definitely help sustainable housing, affordable housing and senior housing. I think those kinds[s] of movements and smaller [housing] footprints will definitely help."

Respondents had differing views on the scale of development and what might be most sustainable for older adults, however. The prevailing thoughts were of two general types. On the one hand, a feeling was expressed that larger scale development allowed for more affordable housing options through economies of scale, as certain costs could be spread across the units (e.g., elevators, permitting and system development charges). On

the other hand, several respondents expressed the belief that larger scale development may not be the ideal environment for older adults. For example, one nonprofit director described smaller communities as fostering a "more humane community." These two perspectives certainly clash-one more focused on economics and one more on social connection-and deserve further exploration.

\section{Why More Sustainable, Affordable Housing for Older Adults Has Not Been Created}

During the key informant interviews the following question was asked of each participant: "In general, what do you see as the major barriers to creating housing developments for older adults that are sustainable and affordable?" The answers to this question provided important insight into the planning and development of sustainable, affordable housing for older adults and implications for future policies and programs and future research. Major themes that emerged from the interviews included: the absence of 
public policy specific to housing older adults; limitations in the current processes and practices in planning and developing housing in Portland; and a failure to include aging and older adults in the discourse on sustainable development in Portland.

Absence of Portland-based policy on housing older adults. Most of the interview participants who discussed public policy and affordable housing for older adults noted policies and programs that existed that were used to fund and guide the character of age-specific housing, as discussed earlier in this chapter. These policies and programs were often initiated at the federal and state levels and were used in the six developments identified as sustainable, affordable housing for older adults in Portland. However, a small number of those interviewed pointed out that at the local level (i.e., the City of Portland) there was, in fact, no clear policy detailing the priority of housing older Portlanders.

Two PHB employees interviewed observed that PHB's top priorities did not yet include older adults. When asked about policies that enabled sustainable and affordable housing for seniors, one PHB representative responded, "Well, there are quite a number of [City] policies about affordable housing, but nothing that I know of that directly speaks to age." She added: "I don't think that this is currently a priority; that priority is defined now around greatest need, and at the top of that heap are...chronically homeless individuals, homeless families."

Others respondents representing both public and nonprofit agencies considered the current efforts to be too limited when compared to the escalating needs of Portland's aging population. The PHB employees both felt that housing for older adults should be 
paid close attention and that the issue of housing for older adults in Portland will continue to grow in importance.

\section{Limitations of current processes and practices. Myriad limitations were}

pointed out by respondents in regard to the current processes and practices that are carried out in the planning and development of housing and environments for older adults. These comments ranged from issues surrounding development processes, to the lack of supportive services in independent housing for older adults, to the lack of attention to health and well-being for older adults living in affordable and sustainable housing.

With respect to the scale of housing developments, one developer of supportive housing for older adults felt that the regulations for development "trend toward largeness." His explanation was that common development patterns were driven by "developers [and] architects and the City, because it takes as much work now to get a five-unit project done as a 100-unit project...so you might as well do a 100-unit project." He saw this as problematic, potentially having an adverse impact on older adults. He explained that larger-scaled buildings may prevent people from feeling as if they are "in an environment that resonates with them and says they're home." Although the same could be said about housing for other age groups, it is important to remember that the social environments for older adults require particular environmental adaptations that are congruent with their personal abilities and needs.

On the other hand, several respondents felt that larger-scale buildings could, in fact, be designed in a manner that facilitated social interaction and created an 
environment that felt like their home. Overall, scale was seen as being important, but there was no consensus about a formula that led to the perfect building size. Building smaller-scale buildings was thought to be cost prohibitive while larger scale building was seen as needing to pay better attention to creating socially-connected spaces and comfortable, home-like environments.

The issue of access to services for older adults living in affordable housing emerged, with two dominant themes. First, several respondents commented on the current health care system, noting it needs to be improved in order to strengthen the ability for older adults to live independently in housing. Second, respondents noted that other supportive services offered in sustainable, affordable housing for older adults were too limited or ineffective. Regarding health care, the executive director of a public agency explained the need to better align resources such as housing and healthcare options:

In our society, when you have these multiple needs that are interrelated... we need to do a better [job aligning] resources so there are strings of funding that are designed to help older people, particularly poor older people... whether it's Medicare, [or the] frail elderly, [or] affordable housing, or assisted housing, or deeply subsidized housing... Why not try to align those systems [so] as they get sicker maybe it's a possibility that they [get] more care and prevent people from moving to nursing homes, which are expensive and dehumanizing, so you keep people living longer [because] you have many different options?

One respondent with years of experience running skilled care facilities felt that incremental changes to the current system would not be sufficient for meeting the needs of an aging population. Instead, he offered his opinion that a "disruptive innovation," or what he termed a "black swan," was needed to fix the current health care system in the U.S. He explained: "You can't incrementally improve a system that's broken... All you 
can do is you get improvements but at much more cost than benefit... What you want to do is create systems that are different than the present systems." His rationale was that the current cost of health care is prohibitive and that housing for older adults is not sustainable; he concluded ultimately that "the elders pay the price" for existing in a broken system.

With respect to supportive services that are offered in sustainable, affordable housing for older adults there was a feeling that more services are needed to maintain the independence and well-being of older adults (e.g., counseling, job training, transitional support into housing, assistance with navigating social programs). A retired executive who worked in the assisted living industry explained the current separation of housing and supportive services: "Fairly recently the City has separated housing with any kind of services, [but] housing is just one part of people's problems. They're usually out of housing because they've got all kinds of other problems, and we don't really deal with those, especially for older people." The respondent was speaking about independent housing (rather than long-term care settings), where minimal services are provided by building operators and which are often coordinated with other agencies, such as transportation.

The executive director of an agency that provides services for low-income older adults described how her agency is filling a void in service provision for older adults: "We're willing to bring [in] supportive services to a building without being reimbursed...That's seen as the gap in a lot of underserved populations...[Our clients] need the housing so badly we're willing to offer up services without being paid for them." 
Although this research did not focus on healthcare and service provisions, those issues are vitally important to sustaining quality of life, well-being, and independence among older adults who are interested in aging in their homes and communities. The topics of health care and services provision require attention in future research.

\section{Failure to include aging and older adults in the push for sustainable}

development. Although sustainable development is a concept within the political and social discourse in Portland, it has not yet incorporated specifics pertaining to aging and older adults. Throughout the key informant interviews two barriers were identified that related to the creation of sustainable, affordable housing for older adults. First, aging has been largely missing from the conversation on social equity; and second, actors and organizations involved in the planning and development of sustainable and affordable housing often operate in isolation from other key actors in the planning and development processes.

Social equity is considered in the sustainability literature as one of the "three legs" of sustainable development and has been the topic of recent discussion in Portland. However, compared to issues of the environment and the economy, it has received considerably less attention. The executive director of an agency advocating regional equity discussed Portland's approach to sustainability and social equity: "People in this community are genuine in their interest in the social sustainability/equity side [and] the affordable housing conversation as it relates to sustainable development." She compared Portland to other regions where "everybody else is going to be doing the green thing," while she saw that Portland could "bring the equity piece in [and] really be able to claim 
that brand of sustainability, [since] nobody else is really doing that." In order to enhance the social equity component of sustainability, the respondent suggested that Portland's leaders and policymakers must "keep expanding what [sustainability] means and adding the social equity pieces [which] include, in my opinion, older adults."

One additional reason why sustainable, affordable housing for older adults has not been more prevalent in Portland is that various actors and organizations associated with the planning and development of housing and environments operate in distinct and separated manners from one another. A developer attempted to explain the problem that exists: "Most people don't understand sustainability...Everyone is in their own silo." In offering further explanation, he said: "The world is so busy and so crowded, so fast; experts all develop silos, and the silos cannot intersect with each other...[there are] lots of people working within their own silo [with no] idea how to connect the dots." To elucidate the issue, the developer continued: "An example is [U.S.] health care; good housing dramatically reduces the cost of health care...Government won't pay you for good housing, but they will pay you for unnecessary healthcare.”

The "silos" or "smoke stacks," as they were called by one respondent, exist between and within many sectors and even within specific projects. Respondents described barriers as existing between City of Portland bureaus, the various sectors (public, for-profit, nonprofit), and even within professionals on the same development team. One solution given for addressing this issue was to include people who bridge the various silos, as was described by a PHB employee:

I think that there are roles for people who can be translators. In other words, they speak housing development and they speak service language, and they have a 
good knowledge about what the needs are for older adults...They can help put together projects that will really be responsive, and it will anticipate the needs of older adults. And because in our society money tends to flow in silos or smoke stacks, and knowledge tends to also go in the smoke stacks, it's hard to find people who are conversant and fluent and even creative with all that.

In summary, respondents highlighted a number of barriers with respect to the planning and development of sustainable, affordable housing for older adults, including language, knowledge, and creativity. They noted that the aging of Portland needs to be inserted into the discourse on sustainable development, and translators are needed to bridge the various "silos" that exist between individuals, agencies, and policies and programs. 


\section{Chapter 7}

\section{Understanding Current and Future Policies and Programs Associated with Sustainable, Affordable Housing for Older Adults}

\section{Overview}

As the aging of our population continues, policies and programs that respond to the need for adequate and affordable housing for older adults with limited resources will be essential. Adequate housing includes, but is not limited to, green and sustainable housing. It also includes housing that is accessible and that contributes to the health and well-being of its residents. In response to the question, "Why has such housing been created?" the findings presented in Chapter 6 identified the existence of policies and programs that address housing for older adults, housing for lower income people, and housing that is sustainable and affordable. Also identified was the absence of additional policies that would address the needs of an aging population.

This chapter focuses on the positive and negative features of policies and programs identified throughout the key-informant interviews that are associated with sustainable, affordable housing for older adults. In particular, policies and programs at the federal, state, regional, and city levels have been separated into three categories: (1) those that were identified as positively affecting housing and environments for older adults; (2) those that were identified as needing changes; and (3) policies and programs not yet in existence but suggested for supporting the future planning and development of sustainable, affordable housing for older adults. 


\section{Overview of Data Analysis: Assessment of Policies and Programs that Affect Sustainable, Affordable Housing for Older Adults}

To address the issue of the adequacy of policies and programs, the interview protocol asked a series of questions intended to garner deeper insight into the extant policies and programs and future directions. Three specific questions were asked of respondents: (1) "In general, what do you see as the major barriers to creating housing developments for older adults that are sustainable and affordable?;" (2) "Are there any policies that are particular to Portland that limit or enable the amount and/or quality of sustainable and affordable housing for older adults?;" and (3) "Looking forward over the next 20 years, what do you expect to occur with respect to the development of housing and environments for older adults?"

Two specific categories of responses emerged from the analysis: those related to (1) existing policies and programs that have an impact on sustainable, affordable housing for older adults; and (2) policies and programs that may affect the future of sustainable development for an aging society. Based on the analysis of the interviews using the Atlas.ti software, a total of 334 quotations were identified as a part of those two categories, with 153 associated with the first area, existing policies and programs, and 181 associated with the second, future directions.

Using the 334 quotations from the two categories, specific policies and programs were identified and counted while consolidating duplicate mentions. Performing a word count of all transcripts using Atlas.ti revealed that descriptions of several policies and programs were given more often than others such as the words "code" (58), "zoning" (50), and "ADA" (45). It should be noted that these counts include mentions by the 
interviewer, since all dialogue was transcribed and used in the electronic word count.

Those policies were then separated into the three aforementioned categories, regardless of their level of governmental implementation: (1) those noted as having a positive impact on sustainable, affordable housing for older adults $(\mathrm{n}=21)$; (2) those noted as needing change $(n=18)$; and (3) those noted as not yet developed but to be considered as possible directions in the future $(n=12)$. Some policies were grouped together in the final counts; for example, although two zoning code changes were discussed, zoning code changes were counted as only one set of policies.

The categories were not mutually exclusive; some policies and programs, such as

the ADA, were classified in multiple categories. For example, some respondents felt that the ADA provided adequate civil rights for frail and disabled older adults, while others felt that aspects of the Act could be improved upon to better meet the needs of an aging society. Therefore, the ADA was listed as both a policy that had a positive impact on housing for older adults and a policy that needed change.

Policies within the three categories (positive, needing change, not yet developed) were examined further based the level of government in which they were, or could be, implemented and/or created. The four levels of government included federal (U.S.), state (Oregon), regional (Metro and Multnomah County), and local (City of Portland).

\section{Federal Policies}

Federal policies and programs with a positive impact on sustainable, affordable housing for older adults. Numerous policies and programs were identified by key informants as having a positive impact on the planning and development of 
sustainable, affordable housing for older adults at the federal level (see Table 7.1 at the bottom of this section for a summary of policies and programs). Several forms of federal legislation were reported as having a positive impact on resulting developments and physical accessibility. As one employee from PHB noted, "The Americans with Disabilities Act and Fair Housing Act...require many of the changes that are beneficial for older adults." In the eyes of one architect and green building expert, the ADA, in particular, represented the "the biggest leap forward" in terms of accessibility in the built environment. A second architect, who also served as a construction manager for cityfunded projects, explained that the requirements were met for ADA and Fair Housing in the projects that he was involved with, and that the federal government monitors HUDfunded projects: "When we're using HUD dollars we do have to use the Fair Housing criteria." The respondent reported that HUD representatives "audit our books on a regular basis," to make sure that local projects are "following the protocol for the Fair Housing Act and the [ADA];" this includes City agencies and clients who are receiving allocations from the City.

It is important to note that the Fair Housing Act exempts housing for older adults from the Act's prohibition on discriminating against protected classes. An amendment to this act-the Housing for Older Persons Act of 1995 (HOPA)-was indirectly described by several respondents (i.e., they did not know the exact name of the Act but discussed its details). As a PHB employee explained: “The Fair Housing Act was amended...to prohibit discrimination on the basis of disability and also to prohibit discrimination against families with children." The respondent explained that the law was passed to 
prevent discrimination against families with children "unless you [operate] a bona fide senior community." The exemption for older adults is described by HUD (2007, para. 6):

[HOPA] eliminates the requirement that 55 and older housing have 'significant facilities and services' designed for the elderly....an exempt property will not violate the Fair Housing Act if it excludes families with children...the property must meet the Act's requirements that at least $80 \%$ of its occupied units have at least one occupant who is 55 or older, and that it publish and follow policies and procedures which demonstrate an intent to be 55 and older housing.

Another policy described as having a positive impact on housing for older adults

was Section 504 of the Rehabilitation Act, which one city employee described as "the HUD code within the Uniform Fair Housing [Act] which says how many units need to be fully accessible,${ }^{35}$ how many units need to be adaptable,${ }^{36}$ how many units will have sound and sight controls. ${ }^{37}$ The respondent detailed the types of development in which the code is applied: "If we're funding [five or more] homes in the same funding loan agreement.... a series of triplexes, duplexes, or even a group of [detached] single family homes...that breaks out how many units are required to be adaptable and accessible." In response to the need to comply with Section 504 and the recurring questions about the requirements, the construction manager/architect explained how he dealt with the

\footnotetext{
35 According to a Portland-specific Section 504 compliance checklist provided by this respondent, "accessible" means "the unit is located on an accessible route, and when designed, constructed, or altered or adapted can be approached, entered, and used by individuals with physical handicaps."

${ }^{36}$ According to Portland's Section 504 compliance checklist, "adaptable" means "the ability of certain elements of a dwelling unit, such as kitchen counters, sinks, and grab bars to be added to, raised, lowered, or otherwise altered, to accommodate the needs of persons with or without handicaps, or to accommodate the needs of persons with different types or degrees of disability. In a unit adaptable for a hearing impaired person, the wiring for visible emergency alarms may be installed but the alarms need not be installed until such time as the unit is made ready for occupancy by a hearing impaired person."

${ }^{37}$ From Portland's Section 504 compliance checklist: "sounds and sight controls" refer to the following: " $2 \%$ of all units, but not less than 1 , shall be made to meet hearing and vision impaired [Uniform Federal Accessibility Standards] criteria."
} 
situation: "Because we're supposed to have them meet 504 [regulations] I've created a [checklist]." The checklist provided clearly defined requirements and locations where additional sources of information could be found for those developing housing in Portland and was used by the PDC to assist with navigating federal requirements. When asked how his checklist compared to HUD's list, he responded that HUD does "not have a specific checklist."

Respondents also highlighted the importance of federal affordable housing programs such as LIHTC and Section 202, which were seen as critically important for furthering the supply of affordable housing for low-income older adults. The director of a public-sector organization explained that as a result of the current policy landscape, "America builds affordable housing...through [Low Income Housing] Tax Credits." An advocate for low-income older adults explained that he believed that Home ForwardPortland's public housing authority, which has LIHTC projects in its portfolio-was important in housing low-income older people: "[For those with] the least resources to pay for the housing...their options are [the] housing authority and HUD 202 projects, [even though] folks are waiting for a long time on waiting lists."

An employee for Home Forward, detailed several important aspects of the federal Section 8 program, including the availability of vouchers and the use of project-based Section 8: "The project-based [Section 8] is administered in old, federally-administered projects...Nothing new happens that way. What happens new is through the [Section 8] voucher program." It should be noted that several respondents felt that federal funding administered to local housing authorities and funding from Home Forward was important 
for low-income residents-although limited-and has not led to sufficiently meeting the housing needs of the population at large.

One important distinction was made in regard to how federal programs were used to create a range of affordability in the housing that was developed by different agencies. In particular, an affordable housing advocate explained that nonprofit organizations often used the LIHTC program for creating affordable housing for the "middle-income group," while housing authorities used Sections 8, 202, and 811 to house the "very-low income." A public-sector housing expert noted that at least one nonprofit director was thinking "out of the box [as] the first person pulling resources from a different program, [Section] $202 \ldots$ to overlay [with LIHTC equity] so you were able to provide more enhancements to the bare bones kind of 202 project." This combining of federal funding from programs is possible in certain circumstances and provides an opportunity for adding certain features to housing (e.g., green and accessible features, supportive services) that can enhance the well-being and independence of older adults living in those developments.

Two other federal programs were seen as having the ability to have a positive impact on the planning and development of sustainable and affordable housing for older adults in Portland: CDBG and NSP grants. The director of one nonprofit, advocacy organization focused on low-income older adults described Portland as having done a good job in meeting the requirements to access the CDBG program: "In order to get Block Grants from the government, [the City must] do a needs assessment, and I just think we do a great job of needs assessment." An urban planner with BPS also noted that NSP grants-federal funding for neighborhood revitalization-afforded an opportunity for 
future affordable housing: "If you have properties that are foreclosed on, the local

government can buy them and turn them over to nonprofits...There are some

opportunities there."

\section{Table 7.1}

Summary of Federal Policies and Programs Identified as Having a Positive Impact on Sustainable, Affordable Housing for Older Adults

\begin{tabular}{|c|c|}
\hline Federal Policy & Positive Aspects \\
\hline Fair Housing Act & $\begin{array}{l}\text { Federal policy that prohibits discrimination in housing but } \\
\text { allows senior-specific housing to exclude families }\end{array}$ \\
\hline Section 504 of the & Obligations and guidelines that require projects receiving \\
\hline Rehabilitation Act & $\begin{array}{l}\text { U.S. Department of Housing and Urban Development } \\
\text { funding to be compliant with specific design standards (e.g., } \\
\text { accessibility minimums) }\end{array}$ \\
\hline $\begin{array}{l}\text { Americans with } \\
\text { Disabilities Act }\end{array}$ & $\begin{array}{l}\text { Wide-ranging civil rights law that secured the rights of } \\
\text { persons with disabilities; increases access to opportunities } \\
\text { for well-being among older adults with disabilities }\end{array}$ \\
\hline $\begin{array}{l}\text { Low Income Housing } \\
\text { Tax Credit Program }\end{array}$ & $\begin{array}{l}\text { Major source of financing for low-income housing, } \\
\text { including all identified sustainable, affordable housing } \\
\text { projects for older adults in Portland }\end{array}$ \\
\hline Neighborhood & Program intended to stabilize communities from \\
\hline Stabilization $\mathrm{Pr}$ & $\begin{array}{l}\text { foreclosures and abandonment that has provided funding for } \\
\text { improving communities during the recession/downturn in } \\
\text { the economy }\end{array}$ \\
\hline Section 8 Program & $\begin{array}{l}\text { U.S. Department of Housing and Urban Development } \\
\text { program that provides affordable housing opportunities for } \\
\text { low-income renters, including older adults }\end{array}$ \\
\hline $\begin{array}{l}\text { Community Development } \\
\text { Block Grant and HOME } \\
\text { Investment Partnership } \\
\text { Programs }\end{array}$ & $\begin{array}{l}\text { Federal programs providing communities with financial } \\
\text { resources for community development which can be used } \\
\text { for building housing and surrounding environments that } \\
\text { contribute to the well-being of older adults }\end{array}$ \\
\hline Sections $202,811, \& 236$ & $\begin{array}{l}\text { Various funding programs for affordable housing; Section } \\
202 \text { focuses exclusively for housing older adults, and } \\
\text { Sections } 811 \text { and } 236 \text { result in some housing for older adults }\end{array}$ \\
\hline
\end{tabular}




\section{Federal policies and programs needing changes to have a positive impact on}

sustainable, affordable housing for older adults. Several policies and programs were identified as needing changes at the federal level in order to have an improved impact on the planning and development of sustainable, affordable housing for older adults in the future (see Table 7.2 for summary). ADA guidelines were mentioned by members of the public, for-profit, and nonprofit sectors, being described as "too prescriptive" in certain instances and in need of greater flexibility. A public-sector architect who had experienced a medical disability earlier in his life noted: “[ADA] doesn't always necessarily fit the bill for [a] particular need." He felt that flexibility in design criteria was needed because having a development with "all the same adaptable features...could go against what's really needed." He gave an example regarding lower counter heights that ADA requires for accessibility and stated: “[ADA] isn't going to fit [everyone]... Not all seniors are going to be in wheelchairs."

Another architect focused on the need for ADA to allow for some challenging environments to be built such as parks and recreational spaces located near housing to be designed in a way that provides opportunities similar to those that exist for able-bodied individuals. As discussed in Chapter 5 certain physical challenges (e.g., trails with steeper grades), even when not compliant with ADA codes, may provide desired challenges. This argument is congruent with the argument presented in Chapter 2 that too little "environmental press" can have a negative impact on older adults, as challenges are needed to maintain an individual's level of personal competence (Lawton, 1986; Lawton \& Nahemow, 1973). 
Another critique of the ADA requirements came from a design consultant who specialized in design for an aging society. She stated that more attention is needed on sensory disabilities: "If we could get the ADA to address sensory loss...you don't know what they are hearing, what they aren't seeing." Additionally, she noted the difficult nature of designing guidelines for people with cognitive disabilities, particularly dementia: “The confusion; you can't experience it, or you can't intellectualize it, so it's really hard for people to address that in the same way they can mobility." Finally, the consultant felt that contrast sensitivity between pedestrian areas and roadways could be designed to be more age-friendly:

My other pet peeve is sidewalks, and curbs, and roadways. One of the issues of aging is the loss of contrast sensitivity, and this is very common to aging, although a lot of people won't talk about it...Loss of contrast sensitivity limits independence... Greater contrast between the color of the curb and the sidewalk, or the roadway, or something that people could see, simple things like that. I think that would really improve mobility because of physical impairment.

In regard to improving other federal policies and programs, funding issues were targeted, such as the need for expanding and improving the funding for LIHTC and other HUD programs. The LIHTC program, in particular, was seen as insolvent during the recession and, more generally, in down economic times. A public-sector housing expert detailed the problem: "The economic downturn is causing issues with getting tax credits...Corporations aren't making a lot of money, so they don't have a lot of tax liability, so they don't need the tax credit." This is in contrast to before the recession when, as the interviewee explained, "They were making so much money they couldn't stand it...they needed ways to get out of paying their taxes." A for-profit housing 
consultant put this more simply by stating that the tax credits "aren't even really worth a damn anymore." A nonprofit housing expert expressed displeasure with the system and summed up the LIHTC program as the federal government "[incentivizing] wealthy institutions to finance the development of affordable housing [as] a way to offset their taxes." In summary, the respondent explained that "The private market is very much driving the development and the financing of new affordable housing;" this has taken place for better, or worse.

Some respondents in the public and nonprofit sectors felt that the system simply was not working and that changes were needed. A nonprofit service provider explained that in the past "the government was in the business of just building public housing for the poorest of the poor." However, more recently, the participant saw "a fraction of what used to be done" and only "a trickle of federal grant programs...nowhere near the scale it needs to be to meet the need." This comment pertained to both the LIHTC program and HUD programs that he felt are needed to meet the needs of an aging population, such as Sections 8,202 , and 236 . The interviewee then responded to the question of what was needed over the upcoming 20 years:

I expect the federal government to really take a much more leading role than they're taking now, especially housing for seniors because the demographics are going to drive that. I think programs like [Section] 202 should be expanded fivefold, or 10-fold. All the affordable housing development programs funded by HUD are in need of giant expansions. They've basically been starved for a long, long time, and I think that might be the major development if the federal government gets back into the business of building affordable housing for lowincome seniors [and] makes it easier for local governments and nonprofit developers all over the country to get the money they need to preserve what we have, upgrade what we have, and build new buildings. 
In addition to expanding funding for the programs, there was also a feeling that the design features mandated by the federal government could be improved upon, especially in housing created for older adults. The president of a charitable nonprofit focused on long-term care for older adults explained that "HUD [and] ADA standards actually work against old people in the bathrooms." She stated that "toilets are too high" especially for older adults who "don't have the body strength to use their grab bars." Her suggestions was to change the funding mechanisms to allow for more flexible and less expensive options: "What helps them more are [non-permanent] bars around the toilet." She explained that those types of accessibility aids are paid for from "health funds which cost 10 times more than they ought to...[it is] silly, but that's the way the funding works."

\section{Table 7.2}

Summary of Federal Policies and Programs Identified as Needing Changes to Have a Positive Impact on Sustainable, Affordable Housing for Older Adults

\begin{tabular}{ll} 
Federal Policy & Changes Needed \\
\hline Americans with & $\begin{array}{l}\text { Needs to be more flexible in design considerations, } \\
\text { including allowing for adaptations for non-wheelchair users } \\
\text { and challenging environments; design considerations need to } \\
\text { take into account age-related sensory and cognitive changes }\end{array}$ \\
\hline $\begin{array}{l}\text { Low Income Housing } \\
\text { Tax Credit program }\end{array}$ & $\begin{array}{l}\text { The program is not financially solvent in a weak economy; } \\
\text { funding must be made sustainable through the ebbs and } \\
\text { flows of the economy }\end{array}$ \\
\hline $\begin{array}{l}\text { Expansion and } \\
\text { improvement of U.S. } \\
\text { Department of Housing } \\
\text { and Urban }\end{array}$ & $\begin{array}{l}\text { Funding for federal low-income housing programs should } \\
\text { increase according the growing needs of the populations; } \\
\text { Development programs } \\
\text { additionally, the design and funding guidelines do not match } \\
\text { the needs of older adults who are, or will, live in the } \\
\text { resulting developments }\end{array}$ \\
\hline
\end{tabular}




\section{Federal policies and programs to consider for the future for improving}

sustainable, affordable housing for older adults. Two specific directions were proposed by respondents as possible policy directions that, if implemented, could have a positive impact on the planning and development of sustainable, affordable housing for older adults (see Table 7.3 for a summary). The first was the effective use of a National Housing Trust Fund. Although the Trust Fund was established in 2008, it has yet to be implemented and is running into opposition in the U.S. House of Representatives (Crowley, 2012, June 7). Nonetheless, a public-sector housing expert explained, the Fund would provide for additional federal investment in housing, which he considered important based on the limited funds available for low-income housing. In particular, he noted that it is difficult to find funding to fill the gaps in "[pulling] together affordable housing deals...the bonds, equity, grants.” According to Crowley (2012, June 7), the current opposition in the House results from a concern that the program is duplicating existing efforts and that the federal government cannot afford to fund new housing programs. However, both respondents and Crowley (2012, June 7) pointed to the need to fund additional affordable rental housing and felt that Trust Fund was an option that should be considered in moving forward.

Another direction that was proposed by a private-sector developer of housing for older adults was to consider a radical death and rebirth of the current policies and programs that fund the systems of care for older adults. The solution proposed by this key informant, who is known as an innovator in small-scale housing for older adults, was to "create systems that are different than the present systems," even if that meant being 
"willing to fail." He went on to say that the healthcare system was so expensive that it makes "all the other money we're spending seem like pocket change," and proposed:

"We need to link healthcare and savings [that would come from a new system] to housing." Although the possibility of such a radical changes seem a bit far-fetched, the literature of housing for older adults has highlighted that the federal government has been unable to keep up with the increasing demand for housing for older adults.

\section{Table 7.3}

Summary of Federal Policies and Programs Suggested for Improving Sustainable, Affordable Housing for Older Adults

\begin{tabular}{ll}
$\begin{array}{l}\text { Potential Federal Policy/ } \\
\text { Program }\end{array}$ & Rationale \\
\hline National Housing Trust Fund & $\begin{array}{l}\text { Would create a funding stream for affordable } \\
\text { housing that fills the current gaps in funding for } \\
\text { low-income housing developments; this may assist } \\
\text { public and nonprofit entities in overcoming the } \\
\text { devaluation of Low Income Housing Tax Credit } \\
\text { equity available after the recession }\end{array}$ \\
\hline $\begin{array}{l}\text { Creation of new systems that } \\
\text { move beyond current models and } \\
\text { strategies and promote } \\
\text { innovation and meet growing } \\
\text { needs }\end{array}$ & $\begin{array}{l}\text { Current housing and health care systems need to be } \\
\text { changed if we are to meet the growing needs of an } \\
\text { aging society; opportunities for innovation, } \\
\text { research, and development may assist }\end{array}$ \\
\hline
\end{tabular}

\section{Oregon Policies}

State policies and programs with a positive impact on sustainable, affordable housing for older adults. Two statewide policies, and related programs, were identified in Oregon as having a positive impact on sustainable, affordable housing for older adults (see Table 7.4 for summary). First, DLCD (the Oregon department responsible for land 
conservation and development activities) has created and implemented a set of 19 statewide planning goals and guidelines that has helped shape the state's system of urban and regional planning and has focused its land policy on fostering sustainable and vibrant communities (DLCD, 2012). As was described in Chapter 2, Goal 10 of the Statewide Planning Goals and Guidelines aims to "provide for the housing needs of citizens of the state" within the development of comprehensive plans at the local level; each plan is to address income ranges and types of housing needed in communities (DLCD, 2010a, p. 1). Goal 1 of the Statewide Planning Goals and Guidelines (DLCD, 2010c) also aims to incorporate the input of Oregonians into efforts such as local comprehensive planning. Several respondents mentioned DLCD's planning goals and guidelines as having a positive impact on the planning and development of sustainable, affordable housing for older adults.

The second policy recognized as having a positive impact on housing older adults was described by a PHB staff member: "During the last legislative session the legislature passed a document recording fee that's supposed to bring in something between $\$ 16$ to \$19 million statewide.” The respondent was referring to a document recording fee of $\$ 15.00$ on real estate transactions that was recently implemented and is aimed at increasing funding for the creation of affordable housing in the state. A housing advocate and a board member of the local public housing authority also noted this legislation and saw it as long-needed: "We have never, ever, ever had... an ongoing, sustainable source of revenue for affordable housing [in] Oregon until about one month [ago] when the document recording fee finally passed." When asked if the fee was the source of revenue 
needed, the respondent was careful to note that it was "the foot in the door...It's a start;

it's tiny; it's not a great deal."

\section{Table 7.4}

Summary of State Policies and Programs Identified as Having a Positive Impact on Sustainable, Affordable Housing for Older Adults

\begin{tabular}{ll}
$\begin{array}{l}\text { State Policy/ } \\
\text { Program }\end{array}$ & Positive Aspects \\
\hline $\begin{array}{l}\text { Statewide planning } \\
\text { goals and } \\
\text { guidelines }\end{array}$ & $\begin{array}{l}\text { Statewide emphasis on land use and on the planning and } \\
\text { development of housing focuses on both sustainable directions } \\
\text { and meeting the state's changing demographic characteristics }\end{array}$ \\
\hline $\begin{array}{l}\text { Document } \\
\text { recording fee }\end{array}$ & $\begin{array}{l}\text { \$15.00 fee on real estate transactions that provides funding for } \\
\text { affordable housing developments }\end{array}$ \\
\hline
\end{tabular}

\section{State policies and programs needing changes to have a positive impact on}

sustainable, affordable housing for older adults. Several Oregon-based policies and programs identified as needing changes are identified in this section (See Table 7.5 for a summary). A respondent from the PHB singled out Oregon's Measure 5 (passed in 1990) limiting property taxes as a major barrier to meeting expenditures that are rising as the result of population aging. The bureau staff person described how the tax system had changed since the Measure's passage: “Notably, before Measure 5 passed...resources through [taxes] were not limited...they are now under tax compression.” Although the respondent did not propose any specific changes, it was inferred that flexibility in the tax code was desired that would provide more opportunities to generate tax revenue to fund needed programs. 
According to Provo (2009), when inclusionary zoning ${ }^{38}$ was banned statewide in 1999, Oregon may have been the only state to take such a step. An advocate for affordable housing and former elected official explained the opposition to a proposal for a regional inclusionary zoning policy (for municipalities under Metro's jurisdiction) that was mounted at the state level: “Developers, bankers, home builders said 'No, we can't do it just for Portland, or just for Metro,' but the damn legislature not only wouldn't pass [the regional policy], they put the prohibition against local governments doing them." An advocate for regional equity issues felt similarly that Oregon is hindered because of this ban on inclusionary zoning and went on to say that it is "our fault because we went after it at a regional level and created this big firestorm... and then really didn't have the capacity to be at the legislature [to fight against the ban]."

Respondents' views on inclusionary zoning varied. A PDC employee observed: "It's a very contentious issue. I'm not sold on inclusionary zoning." He explained that inclusionary zoning "takes models of development, not zoning to make it happen. By models, he meant "examples that work, that pay off, that benefit the community as a whole." Another PDC employee responded affirmatively to the question of whether inclusionary zoning could stimulate affordable housing development from the private sector: "It could if you get it passed." Two respondents-both self-described affordable housing advocates-felt that inclusionary zoning was a very important policy that would lead to needed affordable housing. One explained: "I love it... it's a wonderful tool...It

\footnotetext{
${ }^{38}$ According to Policy Link (2003), inclusionary zoning requires developers to make a percentage of housing units in new residential developments available to low- and moderate-income households and, in return, they receive non-monetary compensation-in the form of density bonuses, zoning variances, and/or expedited permits that reduce construction costs.
} 
would have done more for affordable housing in the last 20 years than anything." Overall, restrictive state-level policy on inclusionary zoning was seen by respondents as reactive when it was passed, and as prohibiting local and regional governments from enacting responses (e.g., like Metro's 1997 attempt) to meet the needs of their population.

Health care policy and programs associated with home- and community-based care in Oregon were also seen by several respondents as insufficient and in need of more funding. Two respondents specifically noted the program, Oregon Project Independence, and how cuts to that program had hurt homebound older adults. A PHB staff person talked of the prohibitive costs for certain supportive services: "Nobody can afford [homeand community-based care]...there really aren't the community resources there to let you do it." She also explained the connection between home- and community-based care and health care policy: “I don't see these challenges really as being that distinct from our health care challenges...they're completely integrated." An advocate for vulnerable older adults felt that although there have been efforts to improve home health services, they fell short of meeting the need: "There have been some limited policy forays... service coordinators that try to hook people up with services...homemaker or home-health services...Meals on Wheels." The executive director of a management and development company described the problem: "We're going to have to come up with some creative ways to meet the need, because [we] don't have a robust healthcare system, don't have a lot of budget." 


\section{Table 7.5}

Summary of State Policies and Programs Identified as Needing Changes to Have a Positive Impact on Sustainable, Affordable Housing for Older Adults

\begin{tabular}{ll}
$\begin{array}{l}\text { State Policy/ } \\
\text { Program }\end{array}$ & Changes Needed \\
\hline $\begin{array}{l}\text { Measure 5 (property } \\
\text { tax limitation) }\end{array}$ & $\begin{array}{l}\text { The tax system in Oregon is limited and may not allow for } \\
\text { adequate funding to support the needs of an aging population }\end{array}$ \\
\hline Inclusionary Zoning & $\begin{array}{l}\text { In 1999 Oregon legislation banned the adoption of inclusionary } \\
\text { zoning; the ban limits local and regional governments' ability } \\
\text { to shape their own legislation pertaining to inclusionary zoning } \\
\text { and limits the availability of affordable housing }\end{array}$ \\
\hline $\begin{array}{l}\text { Improve home and } \\
\text { community-based } \\
\text { services }\end{array}$ & $\begin{array}{l}\text { Revised and expanded programs would allow for aging in } \\
\text { community/home and potential cost savings; the current } \\
\text { program, Oregon Project Independence, has seen reduced } \\
\text { funding and cuts to services for homebound and frail older } \\
\text { adults }\end{array}$ \\
\hline
\end{tabular}

State policies to consider for the future for improving sustainable, affordable

housing for older adults. Two statewide policy areas are discussed in this section (see

Table 7.6 for a summary). First, several respondents called for the creation of policies that would enable the State to better integrate health care, public health, and urban planning and development. The president of a charitable nonprofit foundation that is focused on the needs of older adults saw Oregon as having been an innovator in the past with respect to creating a national model for assisted living. The respondent stated: "Sometimes hard times encourage innovation... Assisted living in one respect is living proof of that...[Assisted living in Oregon] took advantage of tax-exempt bonds because other money wasn't available...In that case adversity helped [find the solution]." Health policy and policy related to planning and development were identified as areas that needed attention. A developer and operator of long-term care for older adults described 
the housing-heath care connection: "Good housing dramatically reduces the cost of health care...we need to link health care and savings to housing." The director of a regional nonprofit focused on equity issues explained the components of policy that connected public health and urban planning: "Equitable access to healthy, clean, safe environments...connections with built environment and healthy communities...parks and access to transportation, walkable neighborhoods." Overall, a number of respondents felt the State of Oregon needed to consider innovative policies that link health care and public health with urban planning and development in an effort to improve both financial and health outcomes.

Second, several respondents discussed "visitable housing" as a viable policy for improving the accessibility of accessible housing for an aging society and felt that visitability should be more pervasive in housing moving forward. Surprisingly, none of the respondents commented on the statewide policy coordinated by Oregon's housing agency, OHCS. The Subsidized Development Visitability statute sets a series of accessibility standards for multifamily housing projects (e.g., zero-barrier entryways, wide hallways and doorways, bathroom on the main floor). The statute requires that housing projects receiving state funding (bond funding and non-competitive tax credits) meet set requirements. As discussed in Chapter 2, Oregon Revised Statute 456.513 allows exemption requests to be made based on topography, community and design standards, undue cost restraints, or conflicting funding requirements (State of Oregon, 2011b).

A PHB representative explained that the term visitability "comes up every time we do our consolidated planned process." Some respondents felt that visitability 
standards would be beneficial, such as a planner in Portland who explained that there was a need to begin "planning for an aging population [and] adopting universal and visitability design standards." As detailed in Chapter 2, visitability can contribute to aging in place; it is safe to say that more education is needed about the current policy in place and additional policy considerations may be warranted.

\section{Table 7.6}

Summary of State Policies and Programs Suggested for Improving Sustainable, Affordable Housing for Older Adults

\begin{tabular}{ll} 
State Policy/ Program & Rationale \\
\hline $\begin{array}{l}\text { Polices pertaining to health } \\
\text { care, public health, and } \\
\text { urban planning and } \\
\text { development should be more } \\
\text { integrated }\end{array}$ & $\begin{array}{l}\text { Oregon has the ability to continue its leadership in } \\
\text { innovative health policy; urban planning and public } \\
\text { health are closely connected and should be considered } \\
\text { together }\end{array}$ \\
\hline $\begin{array}{l}\text { Subsidized Development } \\
\text { Visitability (Oregon Revised } \\
\text { Statute) }\end{array}$ & $\begin{array}{l}\text { Although statute is in place and is intended to improve } \\
\text { the ability of residents and visitors to access commonly } \\
\text { used spaces in residential settings, the program is not } \\
\text { well known and four exemptions are allowed to waive } \\
\text { the requirements }\end{array}$ \\
\hline
\end{tabular}

\section{Regional Policies}

\section{Regional policies and programs with a positive impact on sustainable,}

affordable housing for older adults. At the regional level, three agencies are charged with coordinating federal and Oregon-based policies and programs (e.g., Planning Goals and Guideline, transportation planning). This section details the positive aspects of the policies and programs coordinated by those agencies and how they affect sustainable, affordable housing for older adults (see Table 7.7 for a summary). The first, Multnomah 
County, has an Aging and Disability Services division which creates the federally mandated Area Plan focused on aging for Multnomah County residents, among other functions. The second, Tri-County Metropolitan Transportation District of Oregon (TriMet), is the regional transportation system that spans three counties (Multnomah, Clackamas, and Washington) and operates Portland's buses, light rail, heavy rail, streetcars, and paratransit. The third, Metro, is the regionally elected government that serves as Portland's metropolitan planning organization (MPO; see Chapter 2 for an explanation of the role of MPOs).

Two respondents identified Multnomah County's Weatherization program as having positively affected sustainable and affordable housing for older adults. According to Multnomah County (2012), the agency provides income-restricted assistance in the form of insulation, heating, and related services that aim to save energy through conservation; the savings are expected to decrease utility bills so that available income of residents can be used for other needs. A respondent representing the County explained that there was a joint pilot program with the City of Portland about to launched that "gives low-interest loans to residents who want to weatherize their homes....We hope to expand it, and there was state legislation that was just passed that should take it statewide." This program was seen as important to older adults who needed to weatherize their homes.

TriMet is the regional transportation system that serves the tri-county area. Several respondents described the system in a positive manner. A planner from Portland discussed the region's commitment to transit: "We have a lot of transit infrastructure 
[and] a long-standing commitment to [quality] transit." Respondents across the public, for-profit, and nonprofit sectors spoke positively about the TriMet, including an advocate for low-income older adults who said "MAX [light rail] is wonderful." The "Free Rail Zone" and "Honored Citizen" fares were also seen as helping to make traveling in the urban core more affordable. It should be noted, however, that on September 1, 2012, the "Free Rail Zone" was eliminated in Portland (Fetsch, 2012). ${ }^{39}$ Overall, a number of respondents identified Portland as having a transit system that was "friendly" to older adults, including those with functional limitations.

Metro's planning policies and programs were identified by the greatest number of respondents as having had a positive impact on sustainable environments for older adults. A policy expert working with the City described the connection between Metro's 2040 Growth Concept and the aging of society "[Local and regional governments] are engaging more specifically with the aging community to be sure that we're hearing them." The respondent described the Growth Concept's application as it pertains to older adults: "Metro's 2040 goals focus on centers, focus on corridors; all of those are really good for older adults, because those are locational and access [opportunities] that put people in contact with other community members." She continued with a description of regional planning efforts: "[At] the center or corridor area, you're accomplishing your range of goals for family housing, elderly housing, ground-floor commercial."

\footnotetext{
${ }^{39}$ TriMet estimated that eliminating the "Free Fail Zone" and increasing most fares in the system would save nearly $\$ 9$ million and help to close a $\$ 12$ million shortfall in the agency's Fiscal Year 2013 operating budget. The extensive budget process lasted eight months and resulted in an unprecedented 16,000 public comments.
} 
Additionally, a planner from BPS gave further details about the positive outcomes of

Metro's land use and planning policies:

Multifamily housing in light rail station areas and city centers [is] attractive to older people because we' re trying to locate it in places where you can live without a car [or] walk to services [on] complete streets with sidewalks. Metro has also worked to shape a metropolitan area that has concentrated areas of growth that are balancing environmental, economic, and social equity issues.

\section{Table 7.7}

Summary of Regional Policies and Programs Identified as Having a Positive Impact on Sustainable, Affordable Housing for Older Adults

\begin{tabular}{|c|c|}
\hline $\begin{array}{l}\text { Regional Policy/ } \\
\text { Program }\end{array}$ & Positive Aspects \\
\hline $\begin{array}{l}\text { Multnomah County's } \\
\text { Weatherization program }\end{array}$ & $\begin{array}{l}\text { Aims to save energy through conservation; savings can be } \\
\text { used for other needs; city, state, and national programs also } \\
\text { exist for weatherization }\end{array}$ \\
\hline TriMet policies & $\begin{array}{l}\text { Functional transportation system for older adults and } \\
\text { people with disabilities; policies provide savings for } \\
\text { "honored citizens" and within the dedicated "free rail } \\
\text { zone" in the urban core }\end{array}$ \\
\hline $\begin{array}{l}\text { Metro's } 2040 \text { Growth } \\
\text { Concept and Urban } \\
\text { Growth Management } \\
\text { Functional Plan }\end{array}$ & $\begin{array}{l}\text { Regional growth concept and strategy; planning efforts } \\
\text { focus on sustainable urban growth through comprehensive } \\
\text { planning efforts implemented at the city level by various } \\
\text { local governments }\end{array}$ \\
\hline Climate Action Plan & $\begin{array}{l}\text { Joint partnership between the City of Portland and } \\
\text { Multnomah County (addressed in the City Policy section } \\
\text { below) }\end{array}$ \\
\hline
\end{tabular}

Regional policies and programs needing changes to have a positive impact on sustainable, affordable housing for older adults. Policies and programs identified as needing changes at the regional level focused on Metro's 2040 Growth Concept and Functional Plan (see summary in Table 7.8). Although positive impacts on housing were also identified, respondents offered some critiques of the efforts. A PHB employee, when 
commenting on regional planning said, "It's unusual to hear [aging] articulated as the goal of either planning or design efforts." A Multnomah County sustainability expert discussed some shortcomings of the growth management system and possible approaches: "The urban growth boundary is going to come under assault... The best case scenario is we hold our [growth boundary] relatively steady and we density the hell out of the three counties." She went on to explain some challenges: "I think the market will start to respond to the older population... The biggest problem as we move forward [is] the affordability piece." An urban planner and designer from the city highlighted the need for more equitable distribution of development in the future: "Gateway has been primed for development [for] a long time...[It] is one of several of our extended centers that overall haven't bloomed up into, or transformed into their...aspirational form." As a result, this respondent noted that older adults living outside the city center had less access to services and greater distances to travel for certain needs.

Respondents also noted a need to have affordable housing throughout the region, not just concentrated in certain areas such as downtown. The executive director of a nonprofit housing agency, for example, pointed to the need to focus Metro's comprehensive planning efforts to include senior housing throughout the region: "You start to update the comprehensive plan, who is out there and what do they need...it's going to beg the question...We ought to do something about senior housing...at Metro and in the planning world." A PHB policy expert detailed specific steps needed: "It has everything to do with the goals that are set for the planning process...[if a goal is] to integrate the needs of an aging population, then that becomes part of the plan." She 
offered that conversely, if goals pertaining to older adults were "left off the table," then it "may not be part of the plan." Inclusionary zoning -also discussed in the state section above-was seen as a regional policy that could contribute to more equitable distribution of affordable housing for older adults. Oregon law prohibits local jurisdictions such as Metro and Portland from creating inclusionary zoning programs. In 2011, a repeal of the ban was unsuccessful, proving that change to the legislation remains a critical obstacle. Another area identified as needing change was the call for cultivating regional partnerships to advance sustainable planning and development as it pertains to older adults. A Multnomah County employee detailed some of the needed partners: "Start with the 20,000 foot level [i.e., reviewing macro-level policies]... Oregon planning...code changes, code revisions...There's also going to need to be a partnership with government and private industry, private sector over incentives [for developing housing for older adults]." The president of a charitable nonprofit organization identified the need to raise awareness of the need for affordable housing for older adults and she specifically pointed to Portland State University's Institute on Aging as an entity that could elevate this issue: "It's something one would hope that the Institute would do." An example given of a regional partnership was the joint effort between Portland State University and Metro in developing regional performance indicators; recently an age-friendly data story detailing aging patterns in the region was developed by the Institute of Portland Metropolitan Studies at Portland State University (Greater Portland Pulse, 2011). 


\section{Table 7.8}

Summary of Regional Policies and Programs Identified as Needing Changes to Have a Positive Impact on Sustainable, Affordable Housing for Older Adults

\begin{tabular}{ll} 
Regional Policy/ Program & Needed Changes \\
\hline $\begin{array}{l}\text { Metro's 2040 Growth Concept } \\
\text { and Urban Growth Management } \\
\text { Functional Plan }\end{array}$ & $\begin{array}{l}\text { Development has not adequately addressed aging } \\
\text { issues; current growth management systems intend } \\
\text { to increase density and may negatively affect } \\
\text { housing affordability; inequitable growth patterns } \\
\text { have resulted }\end{array}$ \\
\hline $\begin{array}{l}\text { Expand/revised policies and } \\
\text { programs that lead to the } \\
\text { creation of additional affordable } \\
\text { housing and environments that } \\
\begin{array}{l}\text { are equitably distributed across } \\
\text { the region }\end{array}\end{array}$ & $\begin{array}{l}\text { Additional affordable housing is needed throughout } \\
\text { the region, but funding sources are limited; Metro's } \\
\text { process that can lead to meeting the housing needs } \\
\text { of an increasingly aging region; partnerships should } \\
\text { be cultivated in an effort to plan for an aging region }\end{array}$ \\
\hline
\end{tabular}

\section{Additional regional policies and programs to consider for the future. No}

additional policies and programs were identified by respondents specifically at the regional level. Later in the chapter, additional policies and programs that are not specific to one or more municipal governments are examined, including policies and programs that could exist at the regional level and/or the city, state or federal levels.

\section{Portland Policies}

\section{City of Portland policies and programs with a positive impact on}

Sustainable, Affordable Housing for Older Adults. Respondents detailed many aspects of policies and programs in the City of Portland that had positively affected the planning and development of sustainable housing for older adults (see Table 7.9 below for a summary). These policies included those pertaining to green building and the preservation of the current stock of affordable housing. Programs included tax 
exemptions and abatements, which have an impact on facilitating housing development, as well as a dedicated fund that aims to increase investment in green buildings

As was discussed in Chapter 2, the City of Portland formally established its intention to promote a sustainable future in 1994, and it created the Office of Sustainable Development in 2000. In 2000, a Green Building Fund was created through a resolution by City Council to complement the City's first iteration of its Green Building Policy. A private developer of affordable housing recounted the early years of the push for green building, including the public and private efforts:

I'd say the public sector in Portland, back in '97 or so, moved to start to raise the level of awareness of green building issues here...[They] really tried to create this initiative, and nobody really quite knew what it meant, or what were the barriers. They did a really good job of promoting and started to get support...I'd say the biggest support in Portland came from Gerding [Edlen], a private developer...They got a couple projects going, then they started doing a condo building... and part of it was they had done this whole emphasis on sustainability. I think that worked for the developers.

A private developer involved in the early push for sustainable development discussed the relationship between the public and private sectors in Portland: "I would say in Portland there is a great deal of engagement between the public and the private sectors." He went on to explain in more detail: "We have an environment here where there is strong support in the private sector in terms of even pushing the public sector to adopt policies and codes that are supportive of sustainable building practices." A planner for BPS also noted that the PDC, another Portland-based agency, has complementary requirements for green building for projects funded through urban renewal, in addition to 
the City of Portland's policy: "PDC requires the buildings they fund meet green building standards...they have been championing that."

Two city-specific policies were also discussed by a nonprofit housing expert as having an indirect impact on housing for older adults: the plan to end homelessness and a goal to return to the 1978 levels of downtown affordable housing units. These policies were not specifically written to focus on older adults but were still seen as positively affecting that population. One participant, a housing expert with a nonprofit agency working specifically with older adults detailed long waiting lists for affordable housing and a "crisis of low-rent, affordable housing" in Portland. He explained the connection between sustainable, affordable housing for older adults and homelessness: "Sustainable and affordable housing is the key to ending homelessness... We're not doing a good job with the affordable housing supply [and] giving people housing they're proud to live in [and] can afford...for the long term." In addition to the plan to end homelessness, the housing expert described another policy affecting affordable housing:

The City also has a policy, at least in downtown, to get up to the number of affordable housing units that existed in 1978. In 1978 there were 5,183 housing units that were affordable to the poorest of the poor. Now there [are] 3,300...we lost 1,800 units. [But there is] an ordinance to try to get back to that 5,100 unit level...It costs a lot of money to build new housing, even to preserve the housing the currently exists, but if we don't do that, at some point we're not going to have poor people living downtown... I would say for seniors it's the most often requested neighborhood, to live downtown. I'm talking about poor seniors who don't have cars. You're here on the hub of the transit system; you have lots of free cultural events, and your services.

Several respondents from across the public, private, and nonprofit sectors discussed Portland-style development as leading to "smart growth" outcomes and 
"transit-oriented development" (TOD) projects. Specific tax exemption programs were identified by a planner from BPS who helped facilitate this type of development. She stated: "I work on tax exemption programs where we provide incentives for higherdensity, multifamily housing in light rail station areas and city centers." She described that kind of housing as "attractive to older people" because of its location, noting several reasons why such housing would be attractive: "You can live without a car...you can walk to services...you have complete streets with sidewalks." Overall, she felt that the central city was "a place that traditionally a lot of retirees lived because you can just walk to the grocery store, the public library." She detailed that there are "a lot of services, shopping, cultural amenities" that fit with the lifestyles of certain older adults.

In addition to the downtown tax exemptions, two others exemptions emerged in the interview with planner from BPS as having had a positive impact on the development of sustainable, affordable housing for older adults. The first focused on TOD peojects: "the TOD program...that's for multi-family development in the light rail station areas...They were finding there wasn't dense enough housing being built in light rail station areas, but that's another place that's really appropriate for elderly and disabled housing." As discussed in Chapter 5, proximity to services and connections between housing services and transportation are considered sustainable elements for housing older adults. The other relevant tax exemption program, described by the planner, was for nonprofit housing: "We also have a nonprofit tax exemption program, where nonprofit organizations that provide low-income housing can get their taxes exempted...There's a lot of elderly and disabled housing that fits in that category too." She went on to explain 
that the exemptions had been refocused by City Council: "Right now the only projects that can get that tax exemption are ones that are low income...tax exemption, like urban renewal, it is kind of a local subsidy to affordable housing."

In Chapters 2 and 6, the role that the PDC fills in sustainable development was detailed, including the importance of tax increment financing revenue that is generated within dedicated urban renewal areas. Based on policy enacted by Portland's City Council, $30 \%$ of that tax increment financing revenue is earmarked for affordable housing development. In Chapter 6, it was clear that some affordable housing advocates saw the set aside as having a positive impact on affordable housing development (criticisms and proposed changes will be discussed in the next section). Together with the PDC's green building requirements discussed earlier and the funding provided for housing projects dedicated to older adults (see Chapter 4 overview of developments), it is clear that the PDC has had a supportive role in the development of sustainable, affordable housing for older adults.

The City of Portland and Home Forward-the public housing authority that serves the City of Portland and other local municipalities-both have affordable housing preservation initiatives that were seen by respondents from the public and nonprofits sectors as good policy in relation to increasing the quantity of affordable housing in Portland. One nonprofit employee opined that the preservation initiative was one of the "three big policies that I think could affect the senior housing, in some cases affordable housing in general" (the other two were the $30 \%$ set aside and the goal to return to 1978 levels of affordable housing downtown). He detailed why the policy "has been good in 
terms of sustaining affordable senior housing" through an explanation of what occurs when a development's affordability requirements expire:

The City has a plan to make sure the [subsidized] buildings don't convert to market-rate apartments. There's an ordinance that basically puts the City in the notification loop, so if an owner is going to do something where the affordability of the building could be lost because the federal subsidy has expired, after 30 years, then the City is going to have first chance to preserve the affordability. That's a real important local ordinance that makes these buildings sustainable as affordable housing. Otherwise what would happen is they would convert to upperincome housing.

A PHB employee discussed how nonprofits, in particular, were using the preservation initiatives in a way that benefitted older adults: "Many of the [nonprofits] are involved with preservation of existing subsidized affordable housing." The respondent explained that aging in place was occurring: "Many of these properties have been going for 20 and 30 years, many of the residents are seniors now...The owners have, in a way, inherited, or now find themselves responsible for, a frail elderly population." The executive director of a nonprofit focusing on affordable housing development explained how her agency worked within the guidelines of the preservation initiatives: "Expiring Section 8 [buildings] that were owned by for profits, [after] their affordability period has expired, 20 or 30 years...they're selling them rather than converting them to market...Then we step in and buy them."

Another aspect of the City of Portland's Preservation Policy discussed by respondents was the section titled Long-Term Affordability Requirements (Chapter 30.01.090). The policy pertains to properties receiving subsidies from the City, including the PDC, and was approved beginning with the 1998 Consolidated Plan (City of Portland, 
2012a). A PDC employee described the policy's origins: "The Bureau of Housing and PDC had adopted a new policy that they were going to fund affordable housing for a 60year period. It had previously been 10 years." This policy responded to the following phenomenon, described by the PDC employee: "What was being discovered was that shortly after 10 years that housing stock was being turned over to market rate, [and] the affordability was being lost." The respondent also expressed his feeling that extended affordability had ramifications for the quality of materials in the project: "With 60-year affordability [there is a] need to have durable design methods and materials."

The City of Portland has put in place what one respondent termed "development agreements" 40 that have led to additional affordable housing "in addition to the $30 \%$ [set aside].” In a report from the City Auditor (City of Portland, 2008c, p. 1) the use of "disposition and developer agreements" was described as aiming to "spur development related to economic growth, affordable housing, and urban renewal plans. PDC enters into these Agreements with developers and partner agencies to fulfill City goals." Although the report concluded that the "PDC is not monitoring the Agreements' goals sufficiently once projects are completed," a planner for the City of Portland saw the agreements as having a positive impact on affordable housing development. The respondent explained how two newer areas of development in Portland had agreements to foster more affordable housing: "South Waterfront has [a] development agreement that is administered by the PDC with the developers there for a certain percentage of affordable housing [to be built]." He also noted that "the Pearl District...I don't think people envision this as an affordable neighborhood, [has] a number of affordable units within

\footnotetext{
${ }^{40}$ See Footnote 31 for an explanation of developers agreements.
} 
that." Overall, the City can use these agreements to further the development of sustainable, affordable housing for older adults, as long as it successfully monitors the agreements in place.

The final two policy efforts identified by respondents as having a positive impact on housing and environments for older adults were the Climate Action Plan (CAP; City of Portland and Multnomah County, 2009) and the Portland Plan (City of Portland, 2012b). The CAP was a joint effort between the county and city that responded to global climate challenges; it focused on an integrated set of actions related to livability, public health, social equity, resilient communities, and economics. A sustainability expert with Multnomah County explained that the CAP was important as it would "inform the Portland Plan" and would address "the three realities we're going to be facing... an aging population...a carbon constrained society... a resource constrained society." She expounded on her comments, explaining that "Those three [issues] are going to shape probably most of the land use and transportation planning for the next 100 years." A green building expert from the Office of Sustainability explained (later an employee of BPS) that the CAP would result in major changes: "[The CAP has] an official goal for the city for reducing energy and carbon emissions by $20 \%$ by $2050 \ldots$...that [would require] a complete restructuring of everything in the city if we're actually going to achieve that goal."

In regard to the Portland Plan, there were only two comments from respondents. However, the Portland Plan process had just begun during the study's data collection, so this was not surprising. A planner with BPS recognized the need to incorporate older 
adults into the planning process: "We need to be talking about planning for an aging population, adopting universal and visitability design standards...We're just trying to scope out the things that aren't in the current comprehensive plan [or] are not dealt with in the current codes." A nonprofit executive director also commented on an area that the Portland Plan could address: "We don't have a lot of housing stock that is naturally designed and suitable for seniors." She proposed that the Portland Plan could lead to increased density, which, in turn, would lead to "building more multifamily [housing]... that's good news because multifamily development is easier to make accessible because it's got elevators." 


\section{Table 7.9}

Summary of City Policies and Programs Identified as Having a Positive Impact on Sustainable, Affordable Housing for Older Adults and Their Positive Aspects

\begin{tabular}{|c|c|}
\hline City Policy/ Program & Positive Aspects \\
\hline $\begin{array}{l}\text { City of Portland and } \\
\text { Portland Development } \\
\text { Commission green building } \\
\text { policies and practices }\end{array}$ & $\begin{array}{l}\text { Portland has focused on sustainable development and green } \\
\text { building since the 1990s; relationships between public policy } \\
\text { and private development have helped facilitate projects and } \\
\text { innovation; specific Green Building policy has been refined } \\
\text { since } 2001 \text { that requires all City-owned facilities to adhere to } \\
\text { green building standards }\end{array}$ \\
\hline $\begin{array}{l}\text { City of Portland housing } \\
\text { policies and programs that } \\
\text { indirectly affect older } \\
\text { adults }\end{array}$ & $\begin{array}{l}\text { Citywide policy and programs have focused on increasing } \\
\text { the number and quality of affordable housing units to meet } \\
\text { identified needs, although not specifically targeting older } \\
\text { adults; concentrated efforts focused on reducing } \\
\text { homelessness have an impact on older homeless people; the } \\
\text { City's goal is to return to previous levels of affordable } \\
\text { housing in Portland (i.e., 5,100 units) }\end{array}$ \\
\hline Tax exemption programs & $\begin{array}{l}\text { Portland-specific programs facilitate the creation of } \\
\text { affordable housing in targeted areas of the city (e.g., transit- } \\
\text { oriented development, within the downtown core) }\end{array}$ \\
\hline $\begin{array}{l}\text { Urban renewal/ tax } \\
\text { increment financing }\end{array}$ & $\begin{array}{l}\text { Provides funding for housing and infrastructure } \\
\text { development, including housing and infrastructure used by } \\
\text { older adults; requirement for a } 30 \text { percent set-aside dedicates } \\
\text { a funding stream for the creation of new affordable housing } \\
\text { in urban renewal areas }\end{array}$ \\
\hline $\begin{array}{l}\text { City of Portland and Home } \\
\text { Forward affordable housing } \\
\text { preservation initiatives and } \\
\text { long-term affordability } \\
\text { requirements }\end{array}$ & $\begin{array}{l}\text { Initiatives help to maintain affordable housing stock and } \\
\text { preserve affordable housing when requirements for } \\
\text { affordability expire; initiatives facilitate the creation of } \\
\text { affordable housing with long-term affordability requirements } \\
\text { (i.e., } 60 \text { years) }\end{array}$ \\
\hline Development agreements & $\begin{array}{l}\text { Agreements between Portland government agencies and } \\
\text { developers contribute to increased affordable housing }\end{array}$ \\
\hline $\begin{array}{l}\text { Climate Action Plan and } \\
\text { Portland Plan }\end{array}$ & $\begin{array}{l}\text { Portland and Multnomah County's response to global } \\
\text { climate challenges has focused on an integrated set of } \\
\text { actions designed to enhance livability, public health, social } \\
\text { equity, resilient communities, and economics; the Portland } \\
\text { Plan focused on Portland's future with respect to equity, } \\
\text { thriving and educated youth, economic prosperity and } \\
\text { affordability, and healthy, connected communities }\end{array}$ \\
\hline
\end{tabular}




\section{City policies and programs needing changes to have a positive impact on}

sustainable, affordable housing for older adults. Numerous City policies and programs

were identified as needing improvement in order to have a positive impact on the planning and development of sustainable, affordable housing for older adults (see Table 7.10 for a summary). Receiving the most comments from respondents was the City's comprehensive planning process. Interviewees from the public and nonprofit sectors, in particular, discussed the process and final plan. As described in Chapter 2, the comprehensive plan is crucial to urban planning in Portland, and it has the potential to address the needs of a burgeoning aging population. As discussed in the previous section, a planner with the City noted the need to address "planning for an aging population," in part by identifying "the things that aren't in the current comprehensive plan." A nonprofit executive director who has embraced designing housing for older adults in her organization's projects saw the comprehensive plan as a logical step for preparing for an aging Portland: "You start to update the comprehensive plan [and] they'll start to get to; it's going to beg the question, 'Who is out there and what do they need?' [Then planning] may be a little more accommodating [for older adults].” A senior advocate with experience working with local government on comprehensive planning also supported that assessment, explaining that once the City "[did] some comprehensive planning...it became clear we needed a more citywide planning effort to say what's going to happen."

The consolidated planning process focuses on meeting the housing needs of the Cities of Portland and Gresham, as well as Multnomah County. The plan establishes a vision for housing and community development programs as a requirement to receive 
federal funding. This plan was discussed only by members of PHB, likely because they were the people familiar with the process. A policy expert with PHB described how aging was (and was not) integrated into the process: "We haven't done the demographics and said, 'We have $\mathrm{X}$ number of people in an aging trajectory who would be low income and in need of our thinking."” The housing bureau staff person explained that "Every five years the City and County do a consolidated plan, which is kind of our work plan that we turn into HUD for all of the federal dollars." Another PHB employee explained that the Bureau would be opening up the "[aging] conversation in our next consolidated planning process." She added "I'm excited that we're opening the door."

As discussed previously, the PDC's urban renewal program and revenue generated from tax increment financing are used for the development of housing and infrastructure within dedicated urban renewal areas. Recent mandates from the City of Portland have set aside $30 \%$ of urban renewal funding for affordable housing development, resulting from policy that was seen as having the ability to have a positive impact on the creation of affordable housing, in general, not just housing dedicated to housing older adults. However, two aspects of the policy were discussed as having a potential negative impact on sustainable, affordable housing for older adults: first, the lack of flexibility for the PDC in using funding where it would most appropriately foster sustainable development; and second, concern that more oversight of the $30 \%$ set aside is needed.

With respect to the former issue-PDC's lack of flexibility-a PDC employee noted that "Affordable housing needs to be higher on the radar," but then added that the 
"purpose of urban renewal is to remove blight." In response to the interviewer's question, "Do you think [urban renewal] is a policy that contributes to sustainable development practices?," the PDC employee replied: "Flexibility is taken away," but also that, "Affordable housing is a central piece of the balance." In summary, he explained, "If you could do that with flexibility... it's more sustainable." He then offered examples of other neighborhood needs that could be met with a more flexible approach, such as "business loans so people could be employed" or the creation of a park instead of affordable housing. Opposing sentiment was expressed from respondents in the nonprofit and public sectors, however, who pointed to the lack of adequate funding available to meet the current and future needs for affordable housing in the city.

Three housing advocates who supported the $30 \%$ set aside legislation-two from a nonprofit agency, the other serving in the public sector-felt strongly that the implementation of the set aside needed to be improved. A nonprofit executive director stated, "We haven't used that 30\% set aside to build affordable housing," and a housing expert within the same nonprofit agency also felt that it "has not happened there, yet." As a reminder, housing advocates in Chapter 6 also detailed the desire for more transparency from the PDC, specifically in the form of published evaluation that showed progress toward affordable housing goals.

Moving to the topic of tax exemption programs, we can expand on the comments originally discussed in the affordable housing policy section in Chapter 6 and the previous section on positive citywide policies. A planner with BPS reported that City Council had "called into question" aspects of the programs by asking "Is that the right 
tool to use?" and "Shouldn't we be more specific about what parts of town we're going to implement that tool?" These comments highlight the important of social equity in sustainable development and the need for equitable distribution of affordable housing throughout the city. Another planner at BPS described shortcomings of the tax exemption program: “The rental rehab program isn't used much anymore [and] the new multiple unit housing program is on a moratorium." The reason for the moratorium was due to "a lot of housing construction in the downtown [including] some rather high end rental housing projects in the River District that came in and asked for the tax exemption." The planner explained that "Council and [the] Planning Commission [asked] 'Do they really need this?"”

Overall, both planners quoted above felt that some of the tax exemption programs that were being underused or misused should be reconsidered. However, some lesser used programs should be maintained based on their ability to facilitate quality environments for older adults; as one of the planners explained, "If [the low-income abatement] went away these people would need to live in a more institutional setting." She also commented that inaccessible housing "would be an example" of a barrier to "housing for older adults." She remarked on the possibility of incentivizing a visitability program, noting that, to date, "Portland hasn't developed standards like that, or provided any incentives for development that has standards like that."

The final area of citywide policies to be identified as needing changes in order to have a positive impact on sustainable, affordable housing for older adults were zoning 
and building codes housed in the BPS and BDS (Portland's development services agency). These codes will be described after Table 7.10 below.

\section{Table 7.10}

Summary of City Policies and Programs Identified as Needing Changes to Have a Positive Impact on Sustainable, Affordable Housing for Older Adults

\begin{tabular}{|c|c|}
\hline $\begin{array}{l}\text { City Policy/ } \\
\text { Program }\end{array}$ & Needed Changes \\
\hline $\begin{array}{l}\text { Comprehensive } \\
\text { planning }\end{array}$ & $\begin{array}{l}\text { Planning process and resulting plan influence urban planning } \\
\text { practices; potential to address the aging of society; currently, } \\
\text { however, there is no focus on the needs of older adults }\end{array}$ \\
\hline $\begin{array}{l}\text { Consolidated } \\
\text { planning }\end{array}$ & $\begin{array}{l}\text { Plan focuses on meeting the housing needs of Portland (and } \\
\text { adjacent municipalities); required for federal funding provided } \\
\text { for housing and community development; a greater focus on the } \\
\text { growing needs of an aging population is needed }\end{array}$ \\
\hline $\begin{array}{l}\text { Urban renewal/ } \\
\text { tax increment } \\
\text { financing }\end{array}$ & $\begin{array}{l}\text { Portland's urban renewal areas are home to active development } \\
\text { of housing and infrastructure that is funded by tax increment } \\
\text { financing; oversight is needed for dedicated funding streams for } \\
\text { affordable housing (i.e., } 30 \% \text { set aside); flexibility in how funds } \\
\text { are spent is needed }\end{array}$ \\
\hline $\begin{array}{l}\text { Tax exemption } \\
\text { programs }\end{array}$ & $\begin{array}{l}\text { Certain tax exemption programs in Portland are not used often } \\
\text { (e.g., rental rehabilitation) or have been suspended (e.g., multiple } \\
\text { family housing); consideration should be given to maintaining } \\
\text { low-income abatements, as they provide important housing for } \\
\text { populations that may otherwise be institutionalized; future } \\
\text { improvements that improve accessibility should be considered }\end{array}$ \\
\hline $\begin{array}{l}\text { Revisions to } \\
\text { zoning and } \\
\text { building codes }\end{array}$ & $\begin{array}{l}\text { Zoning and building codes dictate the form and function of } \\
\text { housing and surrounding environments in Portland; specific } \\
\text { changes suggested for the Bureaus of Planning and Sustainability } \\
\text { and Development Services include zoning code changes (zoning } \\
\text { would leads to appropriate housing for older adults, lots sizes, } \\
\text { parking requirements); building code changes (design review); } \\
\text { compliance and enforcement; system development charges. See } \\
\text { table } 7.11 \text { for additional information about suggested changes for } \\
\text { City of Portland codes. }\end{array}$ \\
\hline
\end{tabular}




\section{City zoning and building codes needing changes to have a positive impact on}

sustainable, affordable housing for older adults. As was mentioned earlier in the chapter, the words "code" and "zoning" appeared the in interview transcripts 58 and 50 times, respectively. This represents more mentions than any other policy or program identified during data analysis. Some of the mentions were made by the interviewer; although the words "code" or "zoning" were not part of the interview script, they were used to prompt responses from interviewees when needed for purposes of clarification or elaboration. The discussion of codes fell into two areas: zoning codes and building codes (see Table 7.11 for a summary of needed code changes).

The topic of zoning codes was discussed in depth during the key informant interviews by six respondents, including comments about changes that would be beneficial to sustainable housing development for older adults. Those respondents included the chief executive officer of a private management and consultancy firm, two executive directors of nonprofit housing agencies, and three public sector employees working for BPS (one planner and two sustainability experts who moved from the Office of Sustainability to BPS when the two agencies were merged). With respect to initiating zoning code changes, one nonprofit executive noted that achieving change was difficult and that "Some planners are more willing than others to get into the big picture mode." She also explained the difficulty in navigating the system for making code changes: "You could go to the City Council first, and you'd have a better shot than when you start with a planner, but you can't do that [as] it would violate all the principles." 
A BPS staff member who has worked on issues associated with sustainability explained that change was needed in the manner which the City supports development projects. He explained that Portland is "really slow to get the rules to change and get the support [developers] need." He felt that Portland needs to be more proactive by helping to create the "models of affordable housing that we want to have in our city," elaborating further, he explained, "[The City cannot] "sit back and wait for somebody to say: 'Your zoning is keeping me from doing this."” Instead, he argued, the City should be "helping people build units...make it happen quickly...support this with regulations, and financing." He explained, however, that in Portland, "That's not the way it is. We make [developers] come in here and advocate for changes."

In regard to specific zoning issues, another nonprofit director questioned how zoning affects housing development: "There are some zoning issues around that would be interesting to have people experiment and look at...new housing types that are better [and] aren't really anticipated in housing codes right now." She pointed to several trends and suggested changes to codes that would improve housing for an aging Portland:

There's a move toward smaller footprints...more accessory dwelling units, people looking for land where they can also build a granny flat, either for themselves or an aging family member. Co-housing is definitely developing [and] could be applied to integrate elders and keep them in a community...We' re probably going to have more co-housing models in development for older adults [and] more infill and smaller units, and I think there's going to have to be some zoning changes [in order] to increase density and maximize land use. On a single-family residential scale, a lot of people will be doing additions and building granny flats next to single dwelling units...Efficiencies of scale for services [are needed] while still retaining a sense of [independence and] autonomy and personal space without moving everybody into elevator buildings... an efficient use of land in a singlefamily unit, some kind of hybrid of individual owner and collective space in a single story. 
A private sector executive also discussed housing scale, reporting that he felt smaller-scale housing opportunities for older adults could be "a lot more appealing" for older Portlanders, adding: "I do see the benefit of these sort of cottage-type developments...That might be something that's easier to happen because it doesn't require as much financing as getting a 50- or 100-unit building developed....Zoning and site selection will be the challenge."

A planner and urban designer at BPS explained that the bureau was interested in facilitating "aging in place" and that enabling older adults to "[Age] in their community is something [BPS would] like to do." The BPS staff member pointed to opportunity areas for development as being in mixed-use areas (e.g., centers, corridors, main streets): "If you look at the inner streetcar [areas], zoning is set up to have a lot of elevator buildings, four-story, five, maybe six...Along that corridor...you can have grocery stores, retail, and services, the bus service, sidewalks." He explained that kind of development pattern-e.g., in centers and along corridors and main streets-is what BPS envisions is "going to go through everyone's neighborhood." He also noted that although concentrated development was happening in those types of areas, "We have a lot of limitations once you get off those streets into the more established single family [zones]." Overall, the respondent explained that mixed-use areas held promise for facilitating aging in place, but that it would also be important to connect those areas with nearby residential areas that would not have needed services and infrastructure.

To summarize needed changes to Portland's zoning code in Portland, several areas emerged. First, respondents saw a need for the City to be more flexible and responsive to 
new concepts that were proposed from developers. Second, respondents noted the need for the City to be proactive in providing clearer guidance for their desired development outcomes in areas such as affordable and accessible housing. Third, with respect to the types of housing that should be reflected in future zoning codes, respondents felt that several residential types of development should be improved upon: accessory dwelling units (e.g., appropriately designed for aging in place, new owner/rental financial models), cottage housing (e.g., small clusters of infill housing), smaller-scale co-housing (e.g., not 50 units), and housing that provided for independence and privacy while also providing proximity to a caregiver and/or supportive neighbors. Finally, mixed-uses areas were seen as promising if they had features (e.g., accessibility, proximity to neighborhood housing) that would make them desirable for older adults.

Parking requirements were also an area of concern that emerged in the interviews. A nonprofit executive director with senior housing in her organization's portfolio felt that in the parking code "There could be some subtleties...that would be interesting to [refine]." She detailed opposition to a development that proposed lower numbers of parking spots in an affordable housing project for older adults in one particular neighborhood, noting: “[Current residents] don't believe that very poor, very old people [have fewer] cars as they do." A development expert with a management firm that works with many housing developments for older adults also pointed to difficulties with parking requirements and housing for older adults: "It's really tough to find a feasible way to get the density you're looking for [and] deal with the parking...it would work really well for senior housing if you never had to have parking." 
A planner with BPS also mentioned that parking requirements should be reconsidered, including giving more consideration to reductions in parking requirements and the need for parking with access. She noted: “There's a lot of talk about local governments removing barriers to housing," including "affordable housing for older adults," and then suggested that the City "might want to look at reducing parking requirements, to make developments more affordable." In addition to increasing affordability, she identified other uses for the land that would otherwise be dedicated to parking: "There are courtyard housing developments with a green area in the middle...Those were developed before there were parking requirements... [It is a] really nice open space surrounded by apartments, garden court apartments.” She continued, explaining: "If you had fewer parking requirements, or people that got used to grouping the parking...that could improve the quality of the development, because maybe you could have some open space that wasn't concrete."

An architect and university instructor who teaches a course on green building suggested looking into other cities' zoning and parking codes for examples and then described efforts by another municipality that had allowed for the replacement of "a single-family lot with something that can fit two or three times as many homes...the conditions stated are that the homes usually have to be small, they need to have shared parking, they need to have a shared open space, and they need to have a level of design that's appropriate [for older adults]."

Although allowing for the reduction of parking was supported by several respondents, one urban planner for BPS explained that there was still a need for the 
provision of accessible parking: "Portland hasn't adopted any visibility standards...constructing homes in such a way that someone that is disabled, in a wheelchair, is able to visit you [and] reach the front door." This included parking within close proximity to an accessible entrance of a home.

Several comments made by respondents pertained to design review (Chapter 6 also detailed the responses concerning this issue in the section on design processes). In brief: (1) several nonprofit developers supported clear building codes but felt that design review was too subjective; (2) one respondent felt that many architects saw design review as "too heavy handed and too micromanaged" but felt that public discourse on design was a positive thing and should be encouraged in regard to accessibility and age-specific design; and (3) two private developers felt that design review was useful, as it can help in guiding the design process and garnering ideas about potential solutions.

The final two areas of code that were identified as needing changes in order to have a positive impact on housing for older adults were code compliance issues and system development charges. Although neither area received much attention, those comments made were associated with accessibility, affordability, and quality. Building code, in particular, was discussed by a BPS staff person who explained that building code is "set by the state [and] upheld by local governance." He worried, however, "whether there's enough leeway in there for the City to be making sure things in the code [are] 
friendly to aging populations or not." Additionally, a City staff person expressed a "concern" that there were not enough BDS inspectors. ${ }^{41}$

The topic of system development charges (SDCs)-i.e., one-time, fees-based charges on proposed new or increased uses of a property (new construction and residential redevelopment projects) which increase impact to city infrastructure (City of Portland, 2012e)-was also discussed by two public sector employees. A member of PHB described the current model in Portland: "As new developments are built, systems have to be developed" such as water, electrical, sidewalk and school systems. She explained the "Very low system development charges [in certain areas of the city] are not sufficient to cover the costs [for] the needs of the growing community." She saw SDCs and housing for older adults as also "having an interplay" due to insufficient infrastructure being developed to support older adults living within Portland communities. Looking at SDCs from a housing development (rather than a system development) perspective, a BPS staff person specifically pointed to SDCs as prohibitively expensive in regard to developing accessory dwelling units (ADU) that might serve older adults well: "They have to make it easier...It's a pain...to do an ADU...Once you put a sink in there...the fees are crazy...They really need to ease up on that."

In March, 2010, Portland's City Council adopted City Resolution Number 36766 (City of Portland, 2010, p.1) which suspended SDCs for "Parks and Recreation, Environmental Services, Transportation, and Water for the construction of accessory dwelling units or the conversion of structures to accessory dwelling units until June 30,

\footnotetext{
${ }^{41}$ An article written in the Daily Journal of Commerce (Bjork, 2010, July, p. 1) during data collection detailed that in the previous year "Portland's Bureau of Development Services laid off more than half of its building inspectors."
} 
2013." This brings to light a potential problem between funding necessary systems, as discussed by the PHB employee, and reducing barriers to developing appropriate housing, as discussed by the BPS representative. Perhaps a viable alternative is to suspend SDCs for housing that meets of the needs of an aging population (e.g., accessible, universal, or visitable design). 


\section{Table 7.11}

Summary of City Code Changes Identified as Needing Changes to Have a Positive Impact on Sustainable, Affordable Housing for Older Adults

\begin{tabular}{|c|c|c|}
\hline Code & Bureau & Needed Code Changes \\
\hline $\begin{array}{l}\text { Zoning codes } \\
\text { that facilitate } \\
\text { better housing } \\
\text { environments } \\
\text { for older } \\
\text { adults }\end{array}$ & $\begin{array}{l}\text { Bureau of } \\
\text { Planning and } \\
\text { Sustainability } \\
\text { (BPS) }\end{array}$ & $\begin{array}{l}\text { Improve the current system of zoning codes } \\
\text { and development requirements in Portland in } \\
\text { an attempt to be more flexible and responsive } \\
\text { to new concepts, as well as being proactive in } \\
\text { providing desired models for development; } \\
\text { initiate zoning code changes that would } \\
\text { facilitate residential development that is } \\
\text { appropriate for older adults (e.g., accessory } \\
\text { dwelling units, cottage housing, co-housing, } \\
\text { shared housing); create mixed-use areas that } \\
\text { are vibrant and accessible for older adults }\end{array}$ \\
\hline $\begin{array}{l}\text { Parking } \\
\text { requirements }\end{array}$ & BPS & $\begin{array}{l}\text { Consider reducing parking requirements when } \\
\text { they affect affordability; housing for older } \\
\text { adults may require less parking, but } \\
\text { accessibility remains important for older } \\
\text { adults with cars and special needs; some } \\
\text { space currently dedicated for parking could be } \\
\text { used for green spaces or other uses }\end{array}$ \\
\hline Design review & $\begin{array}{l}\text { Bureau of } \\
\text { Development } \\
\text { Services } \\
\text { (BDS) }\end{array}$ & $\begin{array}{l}\text { Design review is too subjective and } \\
\text { problematic; improve the process of public } \\
\text { dialog pertaining to design review to include } \\
\text { accessibility and age-related design issues; } \\
\text { design review should be useful, guide the } \\
\text { design process, and facilitate appropriate } \\
\text { design solutions }\end{array}$ \\
\hline $\begin{array}{l}\text { Building code } \\
\text { compliance }\end{array}$ & $\mathrm{BDS}$ & $\begin{array}{l}\text { Building code compliance must be improved } \\
\text { and tracking initiated to determine whether } \\
\text { code is friendly to aging populations; Portland } \\
\text { lacks a sufficient number of inspectors to } \\
\text { enforce code compliance }\end{array}$ \\
\hline $\begin{array}{l}\text { System } \\
\text { development } \\
\text { charges }\end{array}$ & BDS & $\begin{array}{l}\text { System development charges should be } \\
\text { reviewed to balance sufficient infrastructure } \\
\text { development in communities while also } \\
\text { considering barriers to development, } \\
\text { especially residential developments that are } \\
\text { age appropriate }\end{array}$ \\
\hline
\end{tabular}




\section{City policies and programs to consider for the future for improving}

sustainable, affordable housing for older adults. Three areas of citywide policy were highlighted for consideration in relation to improving sustainable, affordable housing for older adults (see Table 7.12 for a summary). As noted earlier, Portland, to date, has no specific housing policy in place that, in the words of a PHB staff member, "directly speaks to age." this is due at least partially, according to this respondent, to the belief that aging is not "currently a priority [as compared to] chronically homeless individuals, homeless families." Current planning efforts have identified the needs of low-income older adults, but more attention is needed that directly focuses on the aging of Portland. Respondents from public and nonprofit agencies, in particular, felt that housing for older adults should be a higher priority for the City and seen as an important aspect of local and regional planning efforts (e.g., Portland's comprehensive and consolidated planning efforts). More concerted efforts at creating specific policy language that addresses housing for an aging Portland was identified as needed.

One policy discussed by a policy expert with PHB was the possibility of requiring a certain proportion of housing developed in Portland to have features that would be beneficial to older adults. The PHB expert expressed reservation in creating dedicated geographic areas that would have unique zoning codes pertaining to older adults (e.g., requiring visitable, accessible, universally-designed housing) as she felt that setting geographic goals would be akin to saying "older people should live here in this certain place [rather than knowing] that a choice is out there.” Rather, her suggestion was to consider whether policy could "do it by percentages," which she described as having a 
proportion of "senior housing [developments] designed appropriately for older folks." She noted, however, that it would be difficult to monitor a policy requiring a set percentage of age-appropriate housing and that policy of that kind is "more stick than carrot." She added that the difficult aspect would be getting the "Planning Commission [to start] reviewing project by project."

The final suggestion offered by respondents was for the City to better coordinate the development of housing-related policies with organizations serving the needs of older adults and people with disabilities. A nonprofit executive director from an advocacy group focused on regional equity mentioned the recently formed Portland Commission on Disability: "This new commission...could be a really important addition that would certainly be consistent with what [other organizations] want to see.” The president of a charitable nonprofit that focused on vulnerable older adults felt that nobody was "pounding the drums publicly" for affordable housing, but noted that Portland State University's Institute on Aging might be a good organization to voice that need. A green building expert working for the City identified two Portland-based organizations, Northwest Pilot Project and Elders in Action, as some of the "groups out there...doing good work...specifically for older adults." Overall, several respondents in the public and nonprofit sectors felt that advocacy, education, and service groups focused on the quality of life and well-being of older adults and people with disabilities should be involved in the development of housing-related policies and programs for those groups. A coordinated effort may be beneficial to an aging Portland and others in need of affordable and accessible housing. 


\section{Table 7.12}

Summary of City Policies and Programs Suggested for Improving Sustainable, Affordable Housing for Older Adults

\begin{tabular}{ll}
$\begin{array}{l}\text { City Policy/ } \\
\text { Program }\end{array}$ & Rationale \\
\hline $\begin{array}{l}\text { Create a policy on } \\
\text { housing an aging } \\
\text { Portland }\end{array}$ & $\begin{array}{l}\text { Create policies that directly address the housing needs of } \\
\text { Portland's aging population; City must go beyond needs } \\
\text { assessment to further the availability of affordable and } \\
\text { appropriate housing for older adults }\end{array}$ \\
\hline $\begin{array}{l}\text { Require a set } \\
\text { percentage of age- } \\
\text { appropriate } \\
\text { housing }\end{array}$ & $\begin{array}{l}\text { Create a policy that would require a certain proportion of housing } \\
\text { developed in Portland to have features that would be beneficial to } \\
\text { older adults }\end{array}$ \\
\hline $\begin{array}{l}\text { Coordinate with } \\
\text { aging and } \\
\text { disability } \\
\text { organizations to } \\
\text { create better } \\
\text { policies and } \\
\text { programs }\end{array}$ & $\begin{array}{l}\text { Several organizations dedicated to improving the quality of life } \\
\text { and well-being of older adults and people with disabilities were } \\
\text { identified as having important contributions; coordinating with } \\
\text { these groups in the development of policies and programs was } \\
\text { suggested }\end{array}$ \\
\hline
\end{tabular}

\section{Non-geography-based Policies and Programs to Consider for the Future for Improving Sustainable, Affordable Housing for Older Adults.}

Throughout the key informant interviews possible innovative policies and programs not tied to a particular geography-local, regional, state, or federal-were also identified as having the potential to enhance the development of sustainable, affordable housing for older adults. This section reviews those proposed policies and programs and provides an assessment of their future utility (see Table 7.13 for a summary of the policies and programs).

New models of housing. Many key informants alluded to the need for policies and programs that were not associated with a specific level of government. Chief among 
these were new models of housing that would address sustainable practices for older adults, affordability, innovation, and a sense of community that would benefit an aging society. In all, 11 respondents discussed the topic, including two from the nonprofit sector, three from the for-profit sector, and six from the public sector. As a nonprofit executive director proposed "The age wave, Baby Boom [is] going to slam us, [but] it's not necessarily the same population we've seen... They don't all want to be in senior projects." She was unsure as to whether the various sectors had it "figured out" and whether "the models we're using now are just going to proceed." Her conclusion was that future models would emerge as a "learning process in the market."

A private developer of affordable housing also believed that new models would emerge and that consumers were, in fact, already looking for something new: "I've had a lot of people talk to me about what we're going to do when we're older." He asked the question, "Who is going to decide that?" and followed up with another question asking whether it would emerge from "people thinking ahead for themselves [or] will it be more of a mass production model that says 'Here is what seniors want; we know that because this is what they're choosing to live in?" He added, "There's a tremendous role for people doing research," and described a need for "age-appropriate models, innovative models for senior housing [to] shape the way people start to think about development and spur their creativity."

Various models were described by different respondents. One private developer described a "little co-housing community," and a nonprofit developer envisioned "small, more co-housing environments." Three City of Portland employees described a new 
model of "social housing," while a nonprofit developer called for a "sense of community" as integral. The scale of housing varied from "two households" to "eight or 10 [residents]" to "12 cottages and community living spaces." It was clear that several respondents felt that the co-housing model may work for some older adults, but that the model they imagined was different from co-housing as it exists today. A planner with BPS explained some of co-housing's shortcomings: "Co-housing [requires] a lot of people who want to do it together, 20 to 30 households, and it's going to be a 6-, 7-, 8year process of figuring out what you want to do, finding a site, acquiring a site, designing the structures, site layout, architecture, different types of units." An elected official also discussed development timelines, noting any new model would need to be refined so that it would not take a "five-year journey to figure out."

Other elements were also described, sometimes in relation to where respondents wanted to live, sometimes in relation to what they envisioned when looking forward 20 years. A sustainability expert at BPS believed "Folks are going to want more of that community....inter-generational...cooperative...giving people a purpose and a reason as part of their living community." Several respondents highlighted the importance of a model that would work for people of all ages. For example, a planner at BPS saw the future model as one that "works across the spectrum of age; it works very well at the beginning, young family, to kids, school age children...to older adults." A public official felt proximity to different age groups would be beneficial: "I can imagine places where you have a senior facility next to a school...to connect seniors with kids...places that are designed to have multigenerational [aspects] where people see the benefits of living with 
people of other generations" Another BPS staff member envisioned "a move toward smaller footprints...more accessory dwelling units...more infill and smaller units..., people looking for land [for] a granny flat...for singles as well, single older adults."

Regarding the financial aspects of new models for age-appropriate development, two important aspects emerged: finding a way to make the housing affordable; and pooling resources to purchase needed services. Regarding the first area, reducing housing cost, a planner and urban designer at BPS felt that "co-housing is not affordable" but that "the co-housing prototype" was a starting point for a new model. A developer and management professional felt that some developers were making headway and were already "out there on the cutting edge figuring this out." He believed that, eventually, they were "going to find a way to get it done economically." The elected official stated: "We have to find a niche where the developers can come in and say 'Here's the [required] form'... 'Here's your cut,' 'Here's my cut.' One planner for the City of Portland also thought that "It is possible that local governments might fund projects... not necessarily the co-housing model [but] some sort of model...like that in the future."

Regarding services, a nonprofit developer posited that what was needed was "cooperative purchasing of services to sustain independence [in housing]." She explained that approximately six to eight household may be able to pool resources to "start buying services." This cooperative purchasing would be used to pay for needed services from providers. Explained another way, the respondent detailed what was needed as "FTE" in

\footnotetext{
${ }^{42}$ In was inferred that the respondent used FTE to describe the term "full-time equivalent," or the money that was necessary to hire service providers that would provide an adequate level of service to make the housing model work.
} 
chunks that are big enough" to acquire necessary services that enable aging in one's community.

A final aspect of a new model of housing that was discussed was the "cultural side." This comment came from the executive of a for-profit management firm that oversaw assisted living and long-term care facilities for older adults. He explained that "Traditional models [are] no longer going to be as acceptable to people" and that "The dominant housing models have...primarily been designed for middle class, white population...We don't really know that much about... supportive housing and affordable, sustainable housing models that will work for older people of color." He added, "We have sort of tried to make these dominant housing [models] incorporate some cultural symbols...but they weren't necessarily designed for that population; they were adapted for that population."

Performance- and form-based code. Moving to the topic of codes, the possibility of using performance-based codes was discussed by six respondents: two from the private sector and four from the public sector, which included two university instructors. Adoption and implementation of a performance-based code was not discussed but it may be worthy of discussion by local, regional, or state governments. A private developer explained how performance-based codes may lead to innovation: "Code [is] mandated because it works...you may not say 'I can use this type of piping, or this type of joist in my development,' but if you just give me the chance to show it works, well, maybe it will become a new model that we can use in the future." A university professor 
discussed his thoughts on performance-based codes, including how they might be related to sustainable housing for older adults:

I have been advocating a shift towards a performance-based code. I think it's the single biggest hurdle... If we went to performance-based [code], we might actually find there [are] ways to achieve the same net carbon footprint while fostering the innovation. It would open a thousand different ways to achieve housing for the elderly. Then we might actually get large social spaces which are less air-conditioned and meet a different code with smaller spaces where we sleep that are highly air conditioned; a different kind of equation of balancing all the things out. I think it's that kind of ability to move to a broader reading of how the built environment is created that is really the challenge.

The professor also detailed how Portland, even as a leader in the green building

field, was slow to move to performance-based code and may fall behind other cities.

Also, he saw processes associated with performance based-codes as more participatory:

In Portland, because it has been sitting on its laurels as the greenest city in the country, I think it will get left behind in the next few years...Places like Austin, Charlottesville, all over the country are beginning to write performance-based codes. They're going to run past [Portland], because that's not only going to create a better range of opportunities to house and address the social and housing needs in healthy communities, but it's going to create economic opportunities that are going to pass us by...Performance-based code actually opens the door for more people who are part of the community to actively get involved in the design process.

A green building expert in the private sector noted that "Some people say in order for [Portland] to grow as a leader in the green building community, we should allow for innovation to happen through new ideas coming in, performance-based ideas." $\quad$ A private developer from Portland explained that his firm is trying this, "trying to aim for a level of building performance and not necessarily a point system, which at the end of the day might not give you the best performing building." An architect and project manager 
for the City of Portland explained that with performance-based codes "There's a lot of opportunity" but that in order for that system to succeed "People need to get off their, 'This is the way we've always done it,' mentality." Another area of code that was discussed, although by only one respondent, was the concept of form-based code. ${ }^{43} \mathrm{~A}$ policy expert in PHB discussed this as a way to achieve good design: "It has everything to do with the goals that are set for the planning process. If goals that are set are to address or to integrate the needs of an aging population, then that becomes part of the plan." She suggested that "form-based design, or form-based planning" would allow for “certain elements to occur within a couple of blocks." This type of design, she explained, leaves the opportunity for there to be a development that is "more appropriately designed on the inside for older adults and aging in place that occurs next to something that's more appropriately designed for families." She provided an example: "[In] the center or corridor area, you're accomplishing your range of goals for family housing, elderly housing, ground-floor commercial, and all the other things."

\section{Improving housing affordability by creating savings in development costs.}

The possibility of enhancing affordability in housing by using the principle of economies of scale was discussed by two respondents, one from the private sector and the other an elected official serving the region. The private-sector informant, who worked in the field of management and property development, stated that Portland has "got to find a way to

\footnotetext{
${ }^{43}$ Rouse and Zobl (2004, pp. 2-3) in the American Planning Association publication Zoning Practice define form-based codes as "a regulatory approach designed to shape the physical form of development while setting only broad parameters for use." According to a proponent quoted in the publication "form-based codes focus on what is desirable rather than what is forbidden, the underlying principles having their foundation in a vision or plan developed through community workshops and charrettes."
} 
build things less expensively for the same quality." He suggested that perhaps the City should look into "doing a lot more modular housing... having it built somewhere else, not too far away, but in a really efficient way and bringing it in and assembling it, and getting it built a lot more quickly." He felt that by doing this, it would "save development costs...save architecture costs, and [get] the per-unit cost a lot lower.” An elected official posited that the region was "going to have more infill and redevelopment" and that regional government needed to consider "economies of scale that would keep the prices down from construction." In conclusion, both respondents saw the possibility of affordability of housing being influenced by regional efforts to reduce development costs by building in a more efficient manner, but on a larger, better coordinated scale.

Healthy housing. The final area of new policies not connected to any particular level of government pertained to the need for healthy housing. In particular, three respondents commented on the need to expand the concept of green and sustainable buildings to include a greater focus on health. A nonprofit executive developer who has several green buildings in her company's portfolio explained that the discourse surrounding green building was "a little frustrating as an affordable housing provider." This was based on her perception that any "nonprofit, community-based housing developer" should care about the "health of their clients and their communities [and] save the planet...[provide for ]good air quality so they don't have so many health problems." She felt that healthy housing should be considered in all buildings considered to be sustainable or green, not something that was added on in addition to those features. 
An architect and green building expert added the following challenges that needed to be addressed by policy in order to creating healthier housing: "Tackle the toxicity issue in a way that we haven't yet...indoor air quality...Get more serious about banning the most egregious chemicals from our building industry, the so called 'dirty dozen' [persistent organic pollutants]. ${ }^{44,}$ Finally, a public-sector architect working for the City of Portland opined that in the affordable housing market it is extremely important to focus on green building "because you have a greater proportion of the population that has special needs...their disparity is heightened by some of those sick building syndromes." 45 He felt that an incentive is needed "to find a budget that could accommodate that little incremental increase in cost [which tends to] last longer...[and to improve] the health of the tenant...the key ingredient in the design."

\footnotetext{
${ }^{44}$ According to Alex Wilson (2009, June, p.1) the "dirty dozen" persistent organic pollutants have been restricted since 2001 through the Stockholm Convention on Persistent Organic Pollutants, and additions to the list were made in 2009.

${ }^{45}$ The National Safety Council (2009) defines sick building syndrome as a situation in which occupants of a building experience acute health effects that seem to be linked to time spent in a building, but no specific illness or cause can be identified. The complaints may be localized in a particular room or zone, or may be widespread throughout the building. Frequently, problems result when a building is operated or maintained in a manner that is inconsistent with its original design or prescribed operating procedures. Sometimes indoor air problems are a result of poor building design or occupant activities.
} 


\section{Table 7.13}

Summary of Other (Non-geography-based) Innovative Policies and Programs Suggested for Improving Sustainable, Affordable Housing for Older Adults

\section{Additional Policy/ Program}

Establish new housing models that better meet the needs of an aging society

\section{Rational}

A new model of social housing focused on fostering a sense community; it would be similar to cohousing without the large scale and lengthy development timeline; it would include intergenerational living environments, cooperation among residents and would include lower-income residents and older people of color; economies of scale were discussed, including savings in development and service provision

Performance-based codes

Building codes that are based on building performance rather than pre-determined standards were considered to be needed in Portland; such codes were considered to foster innovation and integrate users into the design process; Portland was seen as falling behind other cities that were moving toward performance-based codes

Form-based code and formbased planning
Zoning codes that result from planning processes that set broad goals focused on what is desirable, rather than what is forbidden; this planning approach is considered to be more inclusive and has the ability to better integrate housing for older adults.

Modular housing and/or building at a larger scale could be a way to achieve savings during the development process that may be translated into affordability

Affordable housing should also be healthy housing; efforts are needed to decrease building toxicity (e.g., indoor air quality) and to eliminate sick building syndrome 


\section{Conclusion}

Myriad policies and programs affect the planning and development of sustainable, affordable housing for older adults. Currently, federal, state, regional, and city governments have distinct policies and programs that lead to important funding streams and regulations. Some policies and programs are connected throughout the levels of government such as funding for affordable housing and regulations that provide development minimum standards (e.g., ADA or building codes). However, the systems are far from perfect, as they lack sufficiently coordinated policy and programs that reach successful implementation. Not only did respondents recommend changes to policies at each level, but they also proposed new policies and programs. Some of the recommendations represent potential models that should be explored in future research in addition to being integrated into discussions with and by elected officials and government staff at all levels of government. 


\section{Chapter 8}

\section{Discussion}

\section{Contributions}

The primary purposes of this qualitative case study were (a) to explore the meaning of sustainable development for an aging society, (b) to better understand how and why sustainable, affordable housing for older adults was planned for and developed, using Portland, Oregon, as a case example, and (c) to identify the policies and programs that have had an impact on the availability and appropriateness of such housing. This study contributes to the literature in gerontology, urban planning, public health, and urban studies by improving understanding of sustainable development as it pertains to affordable housing for an aging society. Existing literature has highlighted the growing need for housing that is appropriate for older adults (e.g., accessible, affordable, healthy) and for research and practice related to urban planning and sustainable development, driven by the unprecedented aging of the population of the United States.

Sustainable development has been understood in the literature as an attempt to meet the needs of the current generation without compromising the ability of future generations to meet their needs. Based on a review of literature it is clear that available housing for older adults does not meet the current need, nor is it expected to meet the future need, which is poised to increase substantially due to the rapid aging of the population. As documented both in this study and in previous research, the City of Portland has policies in place that promote sustainable development, including policies 
that affect the development of affordable housing, such as the City's Green Building Policy and its affordable housing Preservation Initiative. However, Portland-based policies and programs have not sufficiently addressed the affordable housing needs of an aging population and are therefore in need of improvement in order to move toward sustainable development practices.

Although this research has focused on Portland, the findings have applicability beyond the city, with findings concerning policies and programs at the regional, state, and federal levels. Based on the findings, which ascertained the processes, practices, policies, and programs that affect the creation of sustainable, affordable housing for older adults, a set of guiding principles of sustainable development for an aging society have been developed and is presented at the end of this chapter. These guiding principles expand the social ecological perspectives in gerontology and public health to include key aspects of sustainable development as identified in both the literature and the findings of this study.

\section{Limitations of the Research}

The ability to make generalizations based on this qualitative case study is constrained by several aspects of the research design. First, some of the findings are limited geographically and temporally based on the unique set of policies, practices, and developments that exists in the City of Portland, the greater metropolitan region, and the State of Oregon. As was detailed previously, Portland is striving to become a leader in the field of sustainable development and has shaped policy and subsequent action to focus on sustainable development processes and outcomes. Additionally, the specific public, private, and nonprofit sectors involved in the planning, design, and development 
of sustainable, affordable housing for older adults in Portland may not exist in other cities-or may operate in markedly different ways. Additionally, this research was carried out during a time of evolving policies and programs and required limiting emerging phenomena (e.g., comprehensive planning efforts underway during the publication of this research). As a result, some findings and recommendations may not be generalizable to other cities and municipal areas and may be pertinent up to 2012, approximately.

Second, the findings are not triangulated, as they are based on two sources: existing literature and key-informant interviews. Although six housing developments were identified and reviewed to provide additional context for this study, these findings are more vulnerable to errors that are linked to that particular method (i.e., interviews) than are studies that use multiple methods to triangulate their findings (Patton, 1999). As a result, these findings are limited to expanding theoretical understanding-in this study, the set of guiding principles of sustainable development for an aging society that builds on the social ecological perspectives-rather than generalizing to populations (Yin, 2003).

Third, the nature of qualitative research is such that these findings may be questioned by those who may not value or understand this line of inquiry. Although every methodological precaution has been taken to ensure both the reliability and the validity of the data, there is still room for error. The 31 key informants who were interviewed as part of this qualitative case study represent the unique perspective of planners, design and building professionals, developers, managers, policy experts, and directors of public and nonprofit agencies in Portland. The findings from this research, which are based on the primary data resulting from these interviews, may not be generalizable if measured by 
standards of quantitative statistical measurement, nor can they be said to be representative of any broad set of actors, sectors, agencies, or collective groups in Portland or beyond.

Fourth, throughout the interviews, the term "sustainable" was used to describe quality housing and environments for older adults rather than terms such as "livable" and "age-friendly." This was intended to focus responses on particular aspects of sustainability and sustainable development. Although the researcher attempted to refrain from using the terms "livable" and "age-friendly" respondents did use those terms in their descriptions; these responses were considered to be references to sustainable housing for older adults, the main focus of this study. It could be argued that the terms are not equivalent and that too much room for interpretation was taken; however, the researcher attempted to only use such responses when deemed appropriate and in a manner that would lead to reliable and valid findings.

Finally, the researcher has attempted to conduct a valid and reliable study while also undertaking myriad social, civic, and academic activities with the aim of studying and creating better environments for both older adults and people with disabilities in Portland and elsewhere. These activities have heightened the researcher's understanding of what constitutes sustainable, affordable housing for older adults, but could be seen as leading to bias and/or a loss of objectivity. However, as Christians (2003, p. 234) posited, a historic overview of theory and practice in qualitative research has pointed to the need for "an entirely new model of research ethics in which human action and conceptions of the good are interactive." This study is an example of that type of research as it involved, 
simultaneously, ongoing human action (e.g., civic and social activities), recalculations of what was considered good housing and environments for older adults (e.g., policy suggestions to local government and the development of guidelines for future development), and data collection and analysis.

\section{Summary and Implications of Major Findings}

\section{The Meaning of Sustainable, Affordable Housing for Older Adults \\ The relationship between sustainable development and an aging society.} Sustainable development and sustainability have become ubiquitous concepts often understood by variations of a commonly used definition of sustainable development, which is: development that meets the needs of the present generation without compromising the ability of future generations to meet their own needs (United Nations, 1987). The three areas often discussed in conjunction with this definition are distinct yet interconnected: the environment (or planet), the economy (or profit), and social equity (or people), also known as the three E's (Berke, 2002; Elkington, 2012).

It was clear that respondents, in general, did not clearly associate the meaning of sustainable development with the phenomenon of population aging. Introducing the topic of aging into the discourse of sustainable development has ultimately led to a more robust understanding of its meaning; this was originally evident based on responses from some research participants (it should also be the case in future research and practice). At the beginning of each key-informant interview, respondents were asked to react to two 
descriptions that were provided by the researcher. The first was the City of Portland's definition of sustainable development. The second was a modified description of the WHO's definition of an age-friendly city. This allowed the researcher to uncover important perceptions that interviewees held with regard to the language used in current research and practice.

The findings revealed several insights: first, the social (or social equity) component of sustainable development was often minimized with respect to both the environmental and economic components; this reinforces the findings in previous research (Dillard et al., 2009; Manzi et al., 2010). Second, even though the terms "future generations" and "human development" were articulated in descriptions of sustainable housing and environments for older adults, respondents felt that little, if any, attention was paid to an aging demographic. Finally, respondents felt that the prevailing concept of sustainable development should better address the future needs of society-especially population aging-and to go beyond the identification of needs toward opportunities that society should be striving to maximize (e.g., optimizing health, enhancing quality of life).

Taken together, these findings indicated that it is possible to shape a more robust, hybrid description of sustainable development that maintains the commonly used and understood definition and also addresses the dynamic changes that humans face throughout the life course, including those encountered by older adults. The researcher proposes that the description of sustainable development offered in the next paragraphdeveloped from the findings-is more appropriate in describing the challenges and opportunities of future generations. 
Sustainable development seeks to meet human needs while cultivating opportunities for human development across the life course, cultures, and geographies. Such development must address the current generations' ability to sustain their quality of life and well-being while maintaining the ability for future generations to do the same. Furthermore, human development must be integrated into evolving ecological systems by balancing aspects of the natural, built, and social environments. Growth patterns, services, and underlying economic systems must foster social equity in a manner that leads to the health of people, places and systems, both now and in the future.

Five elements of sustainable housing for an aging society. Housing and environments for older adults have long been of interest in the field of gerontology. Research has demonstrated that the physical environments that older adults use on a dayto-day basis are critical to their independence and are a key component of the ability of individuals to function. Recently, sustainable development and green building principles have become commonplace in affordable housing developments, including affordable housing developed for older adults, and have led to buildings that save energy-and expenses for the resident-and contribute to better environmental outcomes (e.g., greater air quality, fewer pollutants). During this study, respondents identified five aspects of sustainable housing and environments that were specific to older adults.

The first element, physical accessibility, was described by respondents as being critical for meeting the functional needs of older adults. Interviewees described the importance of going beyond the minimum requirements currently in place (e.g., ADA guidelines, building codes) in an attempt to create environments that not only comply 
with accessibility standards, but more importantly, are able to be used by the widest possible set of individuals in society. Universal design and visitable housing-both discussed in Chapter 2-were identified as approaches to physical environments that should be incorporated into the planning and development of sustainable housing for older adults. The design features detailed in universally designed and visitable housing were seen by respondents as being able to foster opportunities for people of all ages and abilities (e.g., frail older adults, people using wheelchairs and walkers, parents with baby strollers, able-bodied people) to be more independent and to be better integrated into dayto-day activities in the community.

The second and third elements identified by respondents were closely related: the first was proximity to community services and the second was infrastructure that connected housing with services. Regarding the first area, proximity of housing for older adults to commercial and public services was seen as vitally important, especially as people's functional mobility declines. Certain patterns of development (e.g., automobileoriented urban sprawl, separation of land uses) were seen as leading to social isolation, and suggestions were made concerning bringing housing and services closer together. Furthermore, some key informants reported that bringing housing and critical services (e.g., supermarkets, government services, public transit) together is especially important with respect to affordable housing options. Regarding infrastructure connections, quality pedestrian facilities and transportation services were noted as important if housing was to be considered sustainable. If a person lived near important services but could not overcome barriers to mobility (e.g., lack of contiguous sidewalks or streets, no 
transportation options), proximity was rendered irrelevant. If transportation and pedestrian infrastructure afforded housing residents direct access to community services, this was seen as enabling older adults to better address their needs, maintaining integration within their communities, and aging in place, if they desired.

The fourth element of sustainable housing for older adults that was identified concerned healthy living environments. In particular, the adoption of green building principles was noted as moving in the direction of healthier housing (e.g., reducing the use of toxic materials, better thermal comfort). Respondents also noted that healthy housing for an aging society should be designed to take into account changes in human function that occur with age (e.g., reduced vision, greater risk of falls). Examples of sustainable, healthy housing included that which has good air quality, is well-lit, and has residential units with individually-controlled thermostats to assure comfortable indoor temperature. Additionally, some respondents felt that current green building principles do not encompass adequate design features that are of particular benefit to older adults.

The fifth element of sustainable housing for older adults identified was the inclusion of social spaces in and near housing developments. Participants explained that a balance was needed between personal privacy and access to social activity. Finding the right balance of privacy and access to opportunities for social participation was felt to be vital in facilitating both independence and interdependence as people age. One suggestion for achieving such design outcomes was through the inclusion of future residents and/or knowledgeable older adults in the housing design processes. Specific attention to social spaces within a housing development (e.g., community rooms and libraries, seating 
spaces, smoking areas, consultation rooms) was seen as important. Also seen as important for inclusion in sustainable housing for older adults was access to social spaces located outside of the walls of the housing unit-considered to be an external feature available to the residents of the development-(e.g., parks, plazas, street furniture), as well as private spaces that serve public functions (e.g., cafés, businesses with seating).

The relationship between sustainable housing and affordability. Research participants explained that affordable housing development in Portland has been required to include green building features. Portland's Green Building Resolution (City of Portland, 2005b) and the PDC's guidelines for green building (PDC, 2005) have ensured that affordable housing subsidized by local government is built in a manner that preserves environmental resources and creates better living environments for its residents. These policies have been influenced by the Enterprise Foundation, an early national trendsetter, and have led to changes in development practices in the public, nonprofit, and for-profit sectors (HUD, 2010a)

Affordability was seen by respondents as difficult to define. Although many respondents felt that a housing development could be environmentally sustainable without necessarily being affordable for a wide range of potential residents, many respondents made comments that seemed to recognize that the social equity component of sustainable development called for addressing the needs of populations with lower incomes, including the provision of affordable housing. This is consistent with past calls for policies and programs that lead to additional affordable housing for older adults if society is to meet the growing need in a sustainable manner (Commission on Affordable 
Housing and Health Facility Needs for Seniors in the $21^{\text {st }}$ Century, 2002; Perl, 2010; Shactman \& Altman, 2002).

Even though many respondents felt that sustainable development-driven by its social equity component-needed to address the provision of affordable housing, there was no clear determination of affordability criteria that could be considered equitable or sustainable. It should be noted that several respondents who worked in public and nonprofit organizations serving the needs of lower-income older adults, suggested that paying $30 \%$ of one's income toward rent was the most appropriate housing affordability criterion. However, as described in Chapters 2 and 4, different housing programs use different criteria for affordability, based partially on their funding streams and organizational missions. Looking collectively at the responses offered in this study it was clear that the varied understanding and usage of affordability criteria obscured the relationship between sustainable housing and affordability; nonetheless, a clear need for appropriately-designed and affordable housing for older adults was confirmed.

\section{Advancing the meaning of sustainable, affordable housing for older adults.}

Based on the findings from this study it is clear that the meaning of sustainable development must continue to cultivate aspects of social equity, including the growing needs and assets that are inherent in an aging society. The growing number and proportion of older adults and the population's increasing diversity require considerations of cultural, economic, environmental, and social impacts as we plan for the future. The development of housing and environments must be broadened to improve the well-being of future generations which will require a concerted effort to create enabling, affordable, 
healthy, and interdependent cities and communities. Regardless of whether the concept is labeled sustainable development, sustainability, or another iteration of the term, the core components of the concept should continue to survive and evolve in an effort to plan for and meet the needs of current and future generations.

\section{How and why sustainable, affordable housing for older adults was planned and developed}

\section{How sustainable, affordable housing for older adults was planned and}

developed. This case study sought to understand both how and why sustainable and affordable housing for older adults has been developed in Portland. In order to understand this phenomenon, a review of existing literature provided a foundation for how various processes, practices, policies and programs affected the development (see Chapter 2). In addition, a review of documents pertaining to the six identified housing projects considered to be sustainable, affordable, and specifically built for older adults, provided additional details that improved the understanding of how these six projects were developed (see Chapter 4).

The review of the literature highlighted the rapid aging of society and the demographic imperative to plan for and develop housing and environments to enhance the well-being of older adults and enable them to function as independently. The literature also revealed that there is an absence of knowledge pertaining to sustainable, affordable housing for older adults and a gap exists with respect to understanding the factors that have an impact on the planning and development of this housing type of housing. In particular, Giuliano (2004) and Howe et al. (1994) called for research to examine how development professionals view housing development for older adults, 
what had been done within municipals governments to encourage the appropriate location of housing for older adults, and how creative processes are used in planning and development practices. The present research addressed that call.

Chapter 4 reviewed six existing developments in an attempt to clarify how they were created and what characteristics they displayed. The developments varied considerably with respect to affordability both within each project and between projects. Four of the six projects provided some housing for very low-income populations such as those with Section 8 vouchers who pay $30 \%$ of their income. Overall, the developments provided affordable housing for residents with incomes that ranged from $30 \%$ to $80 \%$ of the area's MFI. The variation in levels of affordability was influenced by financing that was secured from a number of different sources; all of the developments included government subsidies and grants. The equity created by LIHTC funding was critical for achieving affordability, as every development used this federal program; only one project used funding from the federal Section 202 program that specifically aims to provide affordable housing for those aged 62 and older who have very low incomes (the other five developments were for those aged 55 and older).

In regard to the sustainability features of the developments, variations existed in language used to describe the projects, as well as certain green building features that existed in the final developments. Each of the six housing projects-completed from 2001 through 2008-displayed a number of principles associated with green building: earlier developments focused on aspects such as the reuse of existing materials (when sites were redeveloped), improving sites that were previously underutilized or needed 
environmental cleanup, and locating the developments near public transportation; later developments had some similarities to earlier efforts, but also focused on using non-toxic materials, developing mixed uses (e.g., commercial on the ground floor), and following objective green building standards such as LEED. Variations were evident in regard to location (two developments were in North Portland, one in Northeast, one in Northwest, and two in Southwest), size (developments varied from 51-176 units), and whether they were part of a larger development that catered to residents across the age spectrum (two were specific to older adults and four were part of larger, multigenerational developments). It was also clear that accessibility was highlighted in some developments more than others but, in general, the materials reviewed about the projects (including award announcements) did not mention accessibility often, but rather, focused on the existing green building elements.

The data collected provided additional insight into in the manner in which these developments were completed. Key informants noted the distinct roles of the public, forprofit, and nonprofit sectors, the interconnectedness of the sectors, and additional practices and processes that were considered important in completing a project. Although the motivations of various actors differed from one another (e.g., make a profit versus meet a social need), intersectoral partnerships were identified as existing in every affordable housing development. At the same time, the various sectors and actors were often referred to as operating within "silos," which were seen to create disconnections between the different groups and their goals. One respondent expressed the growing need for "translators" who would be capable of bridging the different sectors and roles. Such 
individuals were considered important for connecting policy and practice across the different sectors, and might include public or private consultants facilitating participatory processes or in-house employees of a developer or design firm.

It should be noted that the various actors and entities involved in the planning, designing, building, and developing of housing were not seen as having a particular focus on sustainable, affordable housing for older adults. However, as evidenced by the existence of the six housing developments studied, some government, for-profit, and nonprofit efforts have addressed that population, albeit in a non-systematic way.

The role of the for-profit sector in sustainable and affordable housing development was seen as important in several ways. Architects, engineers, contractors, developers, and consultants were described as being responsible for designing and building housing; they were also seen as driving innovation in Portland as part of a citywide effort to be a global leader in green building practices. In fact, a small number of Portland-based professionals were seen to have started the process of establishing themselves as experts in the design of housing for older adults; some of the housing developments that were considered sustainable and affordable for older adults had hired experts to assist in the creation of this housing.

Also considered to be integral in the development of sustainable, affordable housing for older adults were the funders of projects; however, funding housing of any kind, affordable or not, was seen as having slowed considerably in the recent past (2007/2008). Without adequate financing for development projects, public, for-profit, and nonprofit developers have been left to fund projects in other ways, which has not proved 
feasible in most instances. Respondents reported that the downturn of the U.S. economy specifically affected the development of affordable housing as it reduced direct lending that led to the completion of projects. The economic downturn was also reported to have led to the decrease in the value and availability of tax credits (i.e., LIHTC) which led to a decline in available equity, considered to be an important component in financing affordable housing for public and nonprofit sponsors and developers.

The nonprofit sector was also seen as playing a critical role in the development of sustainable, affordable housing for older adults and was instrumental in five of the six housing developments that were identified earlier (the public sector was the sponsor of the sixth). The nonprofit organizations identified in Chapter 4 have focused on affordable housing development. Although they now have experience in developing affordable housing specifically for older adults, none of those organizations are focused solely on housing for an aging society. Increasingly, based on government requirements for funding and, to varying degrees, their internal organizational values, the resulting developments are being built according to green standards and have sustainable elements. The nonprofit sector was seen as part of a successful effort in advocating for affordable housing legislation at the local (e.g., the 30\% set aside) and state levels (e.g., the document recording fee), along with other advocates. Additionally, nonprofit organizations that provided supportive services for older adults living in affordable housing were described as critical to maintaining independence and quality of life for residents. 
Three particular processes and practices were determined to influence how sustainable, affordable housing for older adults was developed: financing barriers, economic climate, and design processes. First, financing barriers were noted concerning the difficulty of assembling the funds needed to make a proposed development becomes a reality. Many funding sources are needed to allow a development to move throughout the various required stages and the numerous funders often have competing requirements. Second, the downturn in the economy that began in 2007 negatively affected the value of LIHTC credits which, in turn, led to the need for additional funding sources. This halted some projects before they were completed, and created financial losses for investors and developers. Finally, particular design processes were noted to be an important aspect in assuring that completed developments resulted in quality environments for older adults. Specifically, integrated design processes have become commonplace in the green building industry. Many professionals across all sectors were familiar with and had participated in such a process at some moment in the recent past. Integrated design was seen as contributing to the creation of quality housing for older adults, including the incorporation of older adults and aging experts directly into the design process in order to better understand end-user experiences and outcomes (e.g., energy savings, quality social spaces).

\section{Why sustainable, affordable housing for older adults was planned and}

developed. The answer to the question of why sustainable, affordable housing for older adults was planned and developed at all, given the challenges involved, is an important contribution resulting from this research. Perhaps the most obvious factor was the role of 
public policy which addressed the areas of affordable housing, older adults, and sustainable development. Although the policies and programs are detailed in the next section, it is important to recognize that they represent a collective response from governments at the federal, state, regional, and local levels aimed at addressing societal needs. The intersection of those policies and programs led to the creation of the six housing developments examined in this study, and while these housing projects are insufficient in number to adequately meet the needs of the aging population, they do show that public policy can generate viable solutions to social issues such as the need for affordable, sustainable housing.

Another factor was the social and cultural aspects of sustainable, affordable housing for older adults. Informants consistently mentioned an emerging culture of sustainable development in Portland which permeates all sectors. Portland was seen as an early adopter, a city that embraces the principles and practices associated with sustainable development, including the infusion of green building into affordable housing developments. Developers, in particular, were seen as important facilitators of sustainable development practices. Design professionals were also seen as integral in shaping innovative and award winning housing and environments. Additionally, both the public and nonprofit sectors have been seen as leaders in greening affordable housing.

When asked to identify a "champion" of sustainable, affordable housing for older adults in Portland, respondents did not mention one single person or agency. Instead, several champions were identified, either individual leaders of nonprofit agencies or the agencies themselves. Some respondents felt that a future champion might emerge from 
the ranks of elected leaders, but to date, such a person had yet to establish that position. Portland State University's Institute on Aging was also identified as a potential leader, but not a champion, per se.

A final set of findings emerged concerning why sustainable, affordable housing for older adults was planned for and developed. First, support for housing for older adults from communities-not policymakers-appeared to be higher than that for other populations, such as the homeless. Second, the perceptions of aging revealed among respondents showed that there was awareness of the need to move beyond a needs-based view of aging and embrace the opportunities and assets represented by older adults. Third, Portland was seen by some key informants as focused primarily on younger people; they felt that perhaps too much attention in the planning and development communities was given to active, able-bodied individuals. At the same time, respondents did see aging Baby Boomers as a group that could be a catalyst for change in the approaches to planning and development in Portland. Fourth, planning efforts in Portland were identified as beginning to address the aging of Portland, although respondents felt that there was room for improvement in this area. Suggestions for future housing and environments included exploring multigenerational housing opportunities and considering a return to past forms of the built environment that fostered local connectivity.

Why sustainable, affordable housing for older adults has not been planned and developed. During this study, several explanations emerged as to why more sustainable, affordable housing for older adults has not been developed. According to 
several public sector respondents, the major reason was the absence of local policy on housing older adults. Policies were in place for addressing other priorities-such as the growing needs of the homeless population-but the City had yet to establish specific policies for housing aging Portlanders. Moving forward, this is an issue that will need to be addressed by the City, and perhaps with Metro, Portland's regional government. Without an effective policy response, Portland will fall further behind in its ability to adequately house its burgeoning aging population.

Two specific barriers in the current processes and practices undertaken in planning and developing sustainable, affordable housing for older adults were also identified, including: (a) a system of development that favors large-scale housing developments rather than a range of sizes; and (b) a disconnect between housing, on one hand, and access to health care and supportive services (e.g., transportation, counseling, job training) on the other.

Finally, the failure to include older adults in the urban planning and development processes was identified as a reason why sufficient sustainable, affordable housing for older adults had not been developed. In general, there was a feeling that social equity issues had been underrepresented in sustainable development efforts, and that planning for the aging of the population, in particular, had not been viewed as an important element of sustainable development. In the future, more communication between planning and development professionals and end users of housing developments is required if the needs of an aging society are to be addressed. 


\section{Identified Policies that Have an Impact on Sustainable, Affordable Housing for Older Adults.}

\section{The importance of public sector policy in the planning and creation of}

sustainable, affordable housing for older adults. As was described by the respondents, the public sector has focused on addressing the needs of the population it serves through the development of policies and standards that must be adhered to by all actors and sectors carrying out activities in their jurisdiction (e.g., determination of housing needs, visitability requirements for affordable housing). Respondents saw housing development in Portland as being influenced by many levels of policymaking, including federal funding guidelines, national acts such as the ADA, and state-level government that administers those federal requirements and funding opportunities and also sets its own goals and guidelines.

Oregon was identified as requiring local jurisdictions to create comprehensive plans that guide growth and development. In Portland, the regional government, Metro, sets the planning vision for the three counties of the Portland metropolitan area, and this regional planning leads to local comprehensive plans such as the one that exists in the City of Portland. These citywide comprehensive plans work within the constraints of larger efforts (e.g., 2040 Growth Concept, Urban Growth Boundary) to plan for housing, transportation, and land uses that affect the housing and environments used by older adults and all others who live within a given jurisdiction.

Portland's government was described as consisting of many bureaus, offices, and commissions that carry out the City's day-to-day governing and affect housing development opportunities for both the for-profit and nonprofit sectors. PHB, BPS, and 
PDC were all viewed as critical agencies in the identification of the needs of the City's population-e.g., an aging population-as well as carrying out the processes that lead to the funding, planning for, and building of housing for older adults. Respondents felt that, at present, housing for an aging society has not been seen by the City as a top priority, but that it appears to be growing in importance as new efforts, such as the current comprehensive plan, are created.

\section{Identified policies that have a positive impact on sustainable, affordable}

housing for older adults. Policies at every level of government were seen as having a positive impact on the planning and development of housing that is considered sustainable and affordable for older adults. These policies have been implemented in a variety of ways and over several years and have had differing impacts.

On the federal level, a number of acts (i.e., Fair Housing, ADA, and ABA), programs (i.e., Sections 8, 202, 811, 236, and 232), grants (i.e., NSP grants and CDBG funding), and requirements (i.e., Section 504 compliance) were identified as fostering the funding, design, and development of needed housing for an aging society. At the state level, Oregon's planning goals and guidelines for housing development, a document recording fee supporting the development of affordable housing, and visitability standards were all seen as positively affecting such housing. Regionally, the county's weatherization program, regional transportation efforts, and regional planning efforts were felt to have had positive outcomes. In Portland, respondents detailed a number of policies and programs that contributed to a better all-around environment for older adults, including: the Climate Action Plan; specific policies pertaining to homelessness, 
workforce housing, and green building; housing policy requirements (i.e., long-term affordability, building material durability); goals (i.e., meeting targeted levels of affordable housing); practices (i.e., green building, integrated design); specific development agreements between public and for-profit sectors; and public initiatives (i.e., affordable housing preservation).

Identified policies that need changes in order to promote the planning and development of sustainable, affordable housing for older adults. Respondents felt that several changes were needed in policy at the federal level to improve the outcome of housing development, including broadening the scope of the ADA, expanding HUD program funding and scope, improving health-related policies (e.g., Medicaid, Medicare), and attempting to improve the funding of affordable housing (e.g., the LIHTC program). In Oregon, respondents identified the need for the tax system to be changed to allow for better revenue streams for government; additionally, home- and community-based services were seen as needing improvement. Regionally, planning efforts were identified as needing to be enhanced (e.g., to better incorporate social equity issues), benchmarking progress was mentioned as needed, and a more even geographic distribution of affordable housing was noted. At the local level, recommendations were made for improving mandated processes (i.e., design review), revising building and zoning codes, expanding policy scope to include older adults (i.e., workforce housing), and altering urban planning strategies and requirements (i.e., parking, system development charges).

Future policies that should be considered in order to enhance the planning and development of sustainable, affordable housing for older adults. A number of 
policies were recommended that do not yet exist but were thought to have the potential to positively affect the planning and development of sustainable, affordable housing for older adults. In addition to federal, state, regional, and local policies, respondents made recommendations that were applicable at multiple levels of government.

At the federal level, several recommendations emerged for new policy directions, including: the development of a national trust fund that would increase the availability of funding for affordable housing, creating national green building standards, and promoting innovative approaches to producing affordable housing. At the state level, health care and public health policies were seen as needing to be aligned with urban planning and development practices. Allowing inclusionary zoning was also identified as a state policy that might lead to additionally affordable housing. Regionally, it was suggested that attention to older adults should be included in efforts focusing on social equity and environmental justice. In Portland, policy directions suggested included: the creation of new tax incentives and/or abatement programs (i.e., accessory dwelling units, accessibility/usability retrofits, and locating accessible housing close to transit and services), enhancing Portland's bureau coordination and partnerships, and creating the first municipal policy aimed specifically at developing housing for an aging society.

Several additional recommendations were made for policies not associated with a particular geography. These included exploring the viability of innovations in code structures (i.e., performance- and form-based codes); setting healthy housing requirements that would benefit older adults; allowing for licensing that would benefit cooperative living arrangements (e.g., medical services for shared, non-medical housing); 
land acquisition by public sector agencies that would lead to the increased availability of desired site locations; developing policy to ensure better inclusion of older persons in planning and development; and the development of better housing models that would lead to additional housing that was considered sustainable and affordable.

Toward policy that meets the needs of an aging society. Policies and programs that have an impact on the quantity and quality of sustainable, affordable housing for an aging society exist at every level of government, even if they do not explicitly address older adults. Based on the interviews in this study, it is clear that some of this policy is good, some can be improved, and opportunities exist for new policies and programs to be created. The assessment of policies that was conducted in this study provides insight into myriad issues that should be considered in the future. Of utmost importance is the lack of concerted City of Portland policy on housing for an aging population; the absence of such policy leaves Portland vulnerable to the rapidly changing demographics that will increase demands on local governments. Without proactively addressing this issue, Portland may not be able to adequately address the needs of future generations, a key component of sustainable development. In order to create such policies that will help to meet the needs of future generations, guiding principles of sustainable development for an aging society will be useful to policy makers and practice.

\section{Proposed Guiding Principles of Sustainable Development for an Aging Society}

Many of the principles of sustainable development have been integrated into Portland's development-related policies, practices, and culture. The concept is also widely used across the world and can be traced back to the environmental movement. 
More recently, researchers and practitioners have expanded the concept of sustainable development to include social equity, including the emergence of attention paid to agerelated equity. As our population ages and our window for preparing for the demographic imperative continues to shrink, a set of guiding principles of sustainable development for an aging society that can inform future policy, research, and practice will be useful. Based on previous research by others and the findings from the present study, it is clear that better understanding of what constitutes sustainable, affordable housing for older adults is needed.

To begin, the ecological models from environmental gerontology and public health research are helpful in understanding factors that contribute to health and wellbeing of odler adults. As detailed in Chapter 2, the ecological model in the field of public health suggests that five levels of influence (McLeroy et al, 1988; National Institutes of Health, 2005) should be considered: (1) intrapersonal level; (2) interpersonal level; (3) institutional factors; (4) community factors; and (5) public policy. The ecology of aging model (Lawton, 1980; Lawton \& Nahemow, 1973) points to the importance of considering the following environments to better understand which factors influence the functioning of older adults in society: (1) personal environments; (2) group environments; (3) suprapersonal environments (e.g., characteristics of the aggregate of individuals in proximity to an individual such as average age, income, and/or race); (4) social environments (e.g., social and political movements, economic cycles, traditions and values); and (5) physical environments. 
Beyond these two social ecological models, the WHO developed the active aging framework (2002) which sought to inform research, practice, and policy; based on this framework, the WHO then identified eight domains that encompass the aspects of agefriendly cities and communities (2007a). As was detailed in Chapter 2, the following six overlapping areas of focus exist when comparing the WHO's determinants of active aging and its domains of age-friendly cities and communities: (1) physical environments; (2) social environments; (3) economic resources; (4) services; (5) population determinants; and (6) individuals determinants.

By combining the core aspects of the social ecological models in public health and gerontology with the WHO's active aging framework and domains of age-friendly cities and communities, the following seven factors have been identified in this research as contributing to the health and well-being of older adults in cities and communities: (1) individual factors; (2) social factors; (3) aggregated population characteristics; (4) physical environments; (5) institutional and service environments; (6) economic factors; and (7) public policy.

The findings in this study have addressed the majority of the seven factors identified above. In Chapter 4, details of six developments were offered which included descriptions of the populations that were housed in those developments, aspects of the physical environments, and economic and affordability criteria that were based on existing policies and programs. In Chapter 5, the meaning and definition of sustainable, affordable housing for older adults was explored which led to a better understanding of social, physical, and economic aspects of concept. Chapter 6 explored how and why 
sustainable, affordable housing for older adult was completed in Portland, as well as why more was not created. This chapter highlighted the fact that public policy represented a collective response to the issue housing for older adults, that social and cultural factors existed in Portland that affect planning and development efforts, that sustainable development and green building practices did not specially address population aging, and that economic factors (e.g., the recession) had an impact on available financing for affordable housing. Chapter 7 focused specifically on policies and programs pertaining to housing and environments for older adults and how those policies and programs influenced resulting social and physical environments, as well as systems of support for certain income groups. It is now important to look at the literature pertaining to sustainable development and urban planning in an attempt to shape guiding principles of sustainable development for an aging society.

Wheeler (2000) described nine main elements of sustainable urban development: (1) compact, efficient land use; (2) less automobile use, better access; (3) efficient resource use, less pollution and waste; (4) restoration of natural systems; (5) good housing and living environments; (6) a healthy social ecology; (7) sustainable economics; (8) community participation and involvement; and (9) preservation of local culture and wisdom. These elements will be incorporated into the guiding principles of sustainable development for an aging society (see Table 8.1. below).

In addition to ecological models, factors contributing to health and well-being of older adults, and elements of sustainable urban development, this study has sought to answer a call for needed research from the literature. Giuliano (2004) and Howe et al. 
(1994) detailed the need for investigation into the following areas: (1) developers' level of focus on older adults; (2) city-led efforts to locate housing for older adults in appropriate locations; (3) new initiatives/early models connected to planning for an aging society; and (4) best practices and innovative solutions used in planning for older adults. Furthermore, Laws (1995) called for "attention to the interaction of population aging, elderly people, and environmental problems" (p. 17) and stated the need for (1) planning and policy making that is sensitive to local histories and geographies; (2) research on the vulnerability of older adults to natural hazards and environment change; (3) research on the contributions of older adults to environmental problems and solutions; and (4) research concerning the distribution of resources according to the needs of competing groups. She also noted that older adults are often underrepresented in conversations about the environment.

Overall, the calls for research noted above should be considered in research pertaining to sustainable development of older adults. Although this study did not address all of the aforementioned areas of research, it has provided insight into several areas that contribute to the creation of guiding principles of sustainable development for an aging society. First, there was evidence that developers have incorporated design details into housing developments that cater to the needs of older adults; however, more concerted efforts should be made to incorporate end users and/or experts in housing design. Second, the City of Portland has made efforts to locate housing for older adults in appropriate locations but specific policies and programs are needed to improve how and where housing is located in the future. Third, the creation of housing and environments for an 
aging society is gaining momentum in Portland and around the world. Portland and the greater metropolitan region have shown early signs of considering these best practices and innovative approaches, but substantial room for growth exists. Fourth, this research has shown that sustainability and older adults have been relatively disconnected from one another in both existing policies and practices, such as those surrounding green building. This research has not focused on aging and the natural environment but it is an important area for future research and practice. Finally, based on the findings from these studies, it is clear that the resources dedicated to older adults are competing against other issues in Portland. In the future, the rapid aging of society will require reevaluating the distribution of resources in order to ascertain whether additional resources are needed for developing sustainable, affordable housing.

Ten guiding principles of sustainable development for an aging society have been developed by the researcher by taking into account: the findings from this study; aspects of the ecological models from public health and gerontology; factors that contribute to the health and well-being of older adults; elements of sustainable urban development; and calls for needed research pertaining to aging, planning, and urban development. Table 8.1 details the proposed guiding principles, which should have utility for research, practitioners, and policy makers who are concerned with creating quality communities for older adults. 


\section{Table 8.1}

\section{Proposed Guiding Principles of Sustainable Development for an Aging Society}

1. Enable meaningful processes, participation, and partnerships across sectors, organizations, and community stakeholders in an attempt to achieve informed decision making and to bolster community development efforts.

2. Value culture, wisdom, and other assets that exist throughout the life course.

3. Consider social equity implications when creating and/or refining policies and programs in order to provide an appropriate collective response that addresses the identified needs of vulnerable populations and protected classes of people.

4. Create viable and sustainable economic resources that utilize the assets of people of all ages and abilities.

5. Provide appropriate community and health services that focus on enhancing independence and well-being in an affordable and efficient manner.

6. Expand environmental sustainability and green building principles to better address the planning and development of healthy housing and communities that are appropriately and accessibly designed.

7. Refine codes, regulations, plans, and strategies to better align the proximity of and connections between accessible housing, transportation, and land uses in order to create efficient infrastructure systems and appropriate levels of density for an aging society.

8. Foster the creation of accessible and useful places for social interaction and civic activities within and in close proximity to housing for older adults.

9. Integrate research efforts in gerontology, urban planning, public health, and related fields in an attempt to inform practice and improve the implementation of housing and community development policies and programs.

10. Share best practices among municipalities that pertain to sustainable housing and communities for an aging society and adopt or adapt those in an effort to best serve local and regional needs and abilities. 
In order to envision how these guiding principles can be used, it is possible to think about future efforts in Portland that would involve various city and regional organizations (e.g., planning, development services, regional government). Based on the findings from this study, it is evident that policy is needed that addresses the housing needs of an aging society. In the development of such housing policies and programs, we can look to the guiding principles to understand a number of considerations that should be made, including: involvement of older adults in decision making and goal setting; engagement of stakeholders and advocacy groups that represent communities of color, low-income groups, and other vulnerable populations; establishment of policies that protect against the ebbs and flows of the economy, including sustained funding sources for affordable housing; better alignment of housing and services, including access to health care; expanded criteria for green building principles that specifically addressed healthy housing for older adults; refined zoning and building codes that address the need for accessible and affordable environments and proximity of housing to transportation and services; creation of social spaces that promote engagement with other people; and concerted efforts to advance practice through continued translational research efforts and the incorporation of best practices.

\section{Future Research}

Several areas for future research have emerged from this study. First, this study was intentionally bounded to include examination of the factors that influenced the planning and development of sustainable, affordable housing for older adults. Even though it was informed indirectly by the day-to-day experiences of older adults through 
previous research conducted, those views were not directly represented in the present study. A clear next step would involve an exploration of experiences of residents within the sustainable, affordable housing developments in order to better understand how housing has had an impact on their experiences and thus better inform both the creation of policy and the design and development of such housing.

Second, the assessment of policies in this study was not an analysis of policies. According to Vining and Weimer (2009, p. 5) policy analysis is "usually conducted in response to some undesirable condition [and] seeks to construct concrete policy alternatives and assess all of their possible impacts." In this research, policies were identified that had a positive impact, that needed changes, and that could be considered in the future. Respondents offered insight into those policies that helped in understanding how they were applied in Portland; also, respondents offered recommendations for policy changes or new policies to be considered in the future. Future policy analysis should focus on constructing concrete alternatives in housing policy that pertains to affordable, sustainable housing for older adults. Future research should identify all possible impacts of the policies, as suggested to Vining and Weimer (2009), and consider the policies that are unique to federal, state, regional, and local levels, while also considering how the policies are interrelated.

Third, further empirical data is needed regarding the barriers that exist in developing additional sustainable, affordable housing for older adults. Several approaches may be needed, including a survey of housing preferences that focuses on innovative models specific to the aging population (e.g., What housing elements are 
desired that are not possible under current zoning and building codes? What neighborhood features are preferred in areas primed for future growth? What physical infrastructure is ideal for improving connections between housing, transportation, and services? What technology and communication options are people interested in having in their homes and communities as they age?). After housing and community preferences are determined, an analysis of planning, financing, and development barriers could be conducted in an attempt to find ways to mitigate and/or circumvent such barriers. Research to identify the specific business and financial models for achieving the desired housing types is also needed as the private sector (both nonprofit and for-profit entities) plays an important role in creating housing for an aging population.

Fourth, additional research is needed with respect to affordability and sustainability. This includes, but is not limited to the following: further exploring how green building or sustainable features enable savings to residents based on reductions in utilities and/or operating costs passed along from building operations; improving understanding of the "bandwidth" of affordability, which includes housing for the lowest income groups (e.g., public housing programs, those below 30\% of MFI), the range of housing available to those who fall between affordable housing programs and market-rate housing options, and what constitutes the upper range of affordability (e.g., $80 \%$ to $120 \%$ of MFI, market-rate housing); exploring how various levels of affordability affect a project's sustainability; and determining how green building policies that require affordable housing to adhere to specific practices affect the sustainability and health of such housing. 
Fifth, more research is needed in exploring housing that is considered sustainable and affordable and the services that are needed to facilitate quality of life and well-being. One area of future inquiry is the services that community development corporations and nonprofit housing developers provide. Respondents identified those services as being vital to the well-being of the older residents in such housing as they provide support to highly vulnerable residents. As health care policy continues to shift at the state and federal levels, research is needed to understand how the delivery of home- and community-based services will support an aging population. Also, as the aging demographic continues to change, it is critically important to understand how the public, nonprofit, and for-profit sectors will contribute, independently and collaboratively, to the growing need for housing with supportive services.

Sixth, Portland, like other cities, continues to be planned for and developed in intentional (as well as unintentional) ways. New development opportunities on undeveloped lands are becoming less available as redevelopment (e.g., infill) opportunities are growing in importance. Several important questions emerge from this phenomenon. How can infill development best meet the needs of an aging population? How can automobile-oriented areas (e.g., suburbs) be retrofitted for an aging population? How should priorities be set for urban development to account for the needs of older adults? How should affordable housing developments be approached, especially when trying to advance social equity as a main planning goal?

Seventh, the new proposed set of guiding principles of sustainable development for an aging society proposed here can and should be explored further. In particular, how 
do these guiding principles align with current sustainable development principles that are applied in various communities? How can the proposed principles guide planning and development in the public and private sectors? Also, what are the opportunities and barriers to operationalizing the principles in research and practice?

Finally, the research questions that were asked in the present study can be expanded upon quantitatively, geographically, and longitudinally. As was described in the limitations section, this research cannot be generalized to other population or locations. However, based on the findings from this research, additional quantitative approaches could be developed (e.g., a survey instrument distributed to a representative sample of those in the planning and development fields). Additionally, the findings from this case study of housing for older adults in Portland can be compared with those from other cities to determine the effects of similar or different policies and practices in other locations. Finally, it is important to note that the meaning of sustainable development may continue to shift over time, as it has to date, and thus, so may the practices, processes, and policies that explain how and why sustainable, affordable housing for older adults is planned for and developed. Longitudinal studies would allow researchers to examine those changes over time.

\section{Conclusion}

The growing number and proportion of older adults in Portland will be accompanied by many challenges. One pressing need is the provision of appropriate housing that supports the well-being of the changing age structure. As the WHO (2007a, p.4) detailed, to be sustainable, cities must provide "supportive and enabling living 
environments to compensate for physical and social changes associated with ageing." If we are to be stewards for future generations we must plan for and develop housing that is appropriate for the burgeoning number of older adults. This housing must be appropriate in its physical characteristics, but also in its affordability and social settings. Furthermore, it is critical that older adults are viewed beyond their needs. They must also be viewed as having assets that can serve society; leaders and policymakers will do well by considering opportunities that accompany the aging of Portland and should attempt to foster engaged, connected, healthy, and thriving neighborhoods and communities through proactive strategies that integrate those of all ages and abilities.

The approaches, policies, and programs associated with sustainable development are still relatively new and evolving. To date, sustainable development has focused more on the environmental and economic components of sustainability, but it lags in addressing issues of social equity. In particular, little to no attention has been paid to the fact that our population is aging, and that to meet the needs of future generations-a key principle of sustainable development-public, nonprofit, and for-profit organizations must focus on planning, designing, and building housing and environments in a manner that enables active aging across the life course. The proposed 10 guiding principles of sustainable development for an aging society offer one direction for framing future research and translating evidence into polices, programs, and practices that serve cities and communities in a positive manner.

This study revealed that the factors that affect the planning and development of sustainable, affordable housing for older adults are complicated. Those factors include an 
evolving understanding of the relationship between sustainability, aging, and affordable housing, as well as the myriad people, processes, and policies that contribute to the creation of the housing itself. It also showed that it is possible to achieve the desired outcome of addressing the housing needs of lower-income older adults in a sustainable way, evidenced by the six housing developments that exist in Portland. However, additional attention is needed if we are to meet the needs of future generations in a sustainable manner. By understanding the factors that influence the development of sustainable, affordable housing for older adults in Portland, researchers and practitioners are better positioned to create such housing in Portland and beyond. 


\section{References}

AARP. (2000). Fixing to stay: A national survey on housing and home modification issues. Retrieved from http://assets.aarp.org/rgcenter/il/home_mod.pdf

AARP. (2003). These four walls: Americans 45+ talk about home and community. Retrieved from http://assets.aarp.org/rgcenter/il/four_walls.pdf

AARP. (2005a). Livable Communities: An evaluation guide. Retrieved from http://assets.aarp.org/rgcenter/il/d18311_communities.pdf

AARP. (2005b). Beyond 50.05: A Report to the Nation on Livable Communities: Creating Environments for Successful Aging. Retrieved from http://assets.aarp.org/rgcenter/il/beyond_50_communities.pdf

AARP. (2008). Increasing home access: Designing for visitability. Retrieved from http://assets.aarp.org/rgcenter/il/inb163_access.pdf

AARP. (2011). Aging in place: A state survey of livability policies and practices. Retrieved from http://assets.aarp.org/rgcenter/ppi/liv-com/aging-in-place-2011full.pdf

Abbott, C. (1983). Portland: Planning politics, and growth in a twentieth century city. Lincoln, NE: University of Nebraska Press.

Abbott, C. (2011). Metro regional government. The Oregon Encyclopedia, Oregon History and Culture. Retrieved from http://www.oregonencyclopedia.org/ entry/view/metro/

Administration on Aging. (2005). A profile of older Americans: 2005. U.S. Department of Health and Human Services. Retrieved from http://www.aoa.gov/AoAroot /Aging_Statistics/Profile/2005/index.aspx

Administration on Aging. (2010). A profile of older Americans: 2010. Retrieved from U.S. Department of Health and Human Services website: http://www.aoa.gov/ aoaroot /aging_statistics/Profile/2010/docs/2010profile.pdf

Aguirre, B. E. (2002). "Sustainable development" as collective surge. Social Science Quarterly, 83(1), 101-118.

Altman, I. (1975). The environment and social behavior: Privacy, personal space, territory, crowding. Monterey, CA: Brooks/Cole Publishing. 
American Planning Association (2004). Housing Choice in the Oregon-Washington Region Scoping Session Summary. Retrieved from http://www.planning.org/ research /housing/pdf/orewashsummary.pdf

Andrews Architects (n.d.). Rosemont Commons, Portland, Oregon. Retrieved from http://www.andrews-architects.com/aaFrameSet1.html

Armstrong, M. (n.d.). Portland's Proposed Green Building Policy. City of Portland, Office of Sustainable Development. Retrieved from City of Portland website: www.portlandonline.com /bds /index.cfm? $\mathrm{a}=202128 \& \mathrm{c}=49007$

Atlanta Regional Commission. (n.d.). Lifelong communities handbook: Creating opportunities for lifelong living. Retrieved from http://atlantaregional.com/ File\%20Library /Aging/ag_llc_designhandbook.pdf

Atlanta Regional Commission. (2009). Lifelong communities: A regional guide to growth and longevity. Retrieved from AARP website: http://www.aarp.org/content/ dam/aarp/livable-communities/learn/planning/Lifelong-Communities-ARegional-Guide-to-Growth-and-Longevity-AARP.pdf

Bachelder, J.M., \& Hilton, C.L. (1994). Implications of the Americans with Disabilities Act of 1990 for elderly persons. The American Journal of Occupational Therapy 48(1), 73-81.

Barringer, H. P. (2003). A life cycle cost summary. Paper presented at the International Conference of Maintenance Societies in Perth, Western Australia. Retrieved from http://www.barringer1.com/pdf/LifeCycleCostSummary.pdf

Bender, R. (1985). Affordable housing: Livable communities. Places, 2(1), 1-6. Retrieved from http://placesobserver.net/media/pdf/Affordable_Hou_123.pdf

Bengtson, V.L., Gans, D., Putney, N.M., \& Silverstein, M. (2009). Theories About Age and Aging. In V.L. Bengtson, M. Silverstein, N.M. Putney, \& D. Gans (Eds.) Handbook of Theories of Aging ( $2^{\text {nd }}$ ed., pp. 3-23). New York: Springer Publishing Company.

Bengtson, V.L., \& Putney, N.M. (2006). Future 'conflicts' across generations and cohorts?. In J.A. Vincent, C.R. Phillipson, \& M. Downs (eds.), The futures of old age (pp. 20-29). Thousand Oaks, CA: Sage.

Berke, P. (2002). Does sustainable development offer a new direction for planning? Challenges for the Twenty-First Century. Journal of Planning Literature, 17(1), 21-36. 
Berke, P., \& Manta Conroy, M. (2000). Are we planning for sustainable development? An evaluation of 30 comprehensive plans. Journal of the American Planning Association, 66(1), 21-33.

Bicket, M.C., \& Mitra, A. (2009). Demographics and living arrangements of the minority elderly in the United States. Applied Economic Letters, 16(10), 1053-1057. doi:10.1080/13504850701335293

Binstock, R.H. (2010). From compassionate ageism to intergenerational conflict. The Gerontologist, 50(5), 574-858.

Bjork, N. (2010, July 7). Inspection delays costing contractors [sic] money. Daily Journal of Commerce. Retrieved from Daily Journal of Commerce website: http://djcoregon.com/news /2010/07/07/portland-inspection-delays-costingcontractors-money/

Bloom, C. (2011). LeadingAge Works to Modify Unwelcome Policy Changes Announced in HUD Memo. Retrieved from Leading Age Senior Housing Report website: http://www.leadingage.org/Newsletter.aspx?id=4150\&pv=t

Blum, A. (2008). Portland, Oregon: Headwaters at Tryon Creek. Real Estate \& Construction Review: Washington/Oregon Edition, 4, 44-45. Retrieved from Winkler Development Corporation website: http://www.winklerdevcorp.com/ pdfs/Real\%20Estate\%20and\%20Construction\%20Review.pdf

Bratt, R.G. (1989). Rebuilding a low-income housing policy. Philadelphia, PA: Temple University Press.

Bronfenbrenner, U. (1979). The ecology of human development: Experiments by nature and design. Cambridge, MA: Harvard University Press.

Brown, L., \& Tremoulet, A. (2006). The process and partners in affordable housing development. Poster presentation for the School of Urban Studies and Planning, Portland State University, adapted from the Community Real Estate Development Chart (1998) by the Development Training Institute, Inc. Portland, OR: Portland State University.

Building Codes Division. (n.d.). About us: Mission. Retrieved from State of Oregon, Building Codes Division website: http://www.cbs.state.or.us/bcd/aboutus.html

Carder, P.C., Weinstein, J., \& Kohon, J. (2012). Home Forward's Aging-in-Place Initiative: Planning for the aging in place of current and future resident. Retrieved from Portland State University website: www.pdx.edu/ioa/ sites/www.pdx.edu.ioa /files/HFFR2012.pdf 
Carp, F.M. (1987). Environment and aging. In D. Stokols, \& I. Altman (Eds.) Handbook of environmental psychology (pp.329-360). New York: Wiley

Cascadia Region Green Building Council. (2007). In depth case studies: Trenton Terrace. Retrieved from http://casestudies.cascadiagbc.org/ overview.cfm?ProjectID=1002

Centers for Disease Control and Prevention and The Merck Company Foundation. (2007). The state of aging and health in America 2007. Whitehouse Station, NJ: The Merck Company Foundation.

Chodzo-Zajko, Wojtek J. (Ed.) (2001) National blueprint for increasing physical activity among adults 50 and older: Creating a strategic framework and enhancing organizational capacity for change. Journal of Aging and Physical Activity, 9, Supplement.

Choguill. (1999). Sustainable human settlements: Some second thoughts. In A.F. Foo, \& B. Yuen (Eds.), Sustainable cities in the $21^{\text {st }}$ century (pp. 131-144). Singapore: Singapore University Press.

Choguill. (2007). The search for policies to support sustainable housing. Habitat International, 31(1), 143-149.

Christians, C.G. (2003). Ethics and politics in qualitative research. In N.K. Denzin, \& Y.S. Lincoln (Eds.), The landscape of qualitative research: Theories and issues ( $2^{\text {nd }}$ ed., pp. 208-243). Thousand Oaks, CA: Sage.

Cities of Portland and Gresham, and Multnomah County. (2005). 2005-2011 Consolidated Plan. Retrieved from City of Portland website: http://www.portlandonline.com/phb /index.cfm?c=52523

Cities of Portland and Gresham, and Multnomah County (2011). Consolidated Plan: 2011-2016. Retrieved from City of Portland website: http://www.portlandonline.com/phb /index.cfm?c=54087

City of Portland. (2001a). Land use changes for City-zoned Multnomah County properties. Retrieved from http://web.multco.us/sites/default/files/land-useplanning /documents/multnomah_county_city_of_portland_2040_project.pdf

City of Portland. (2001b). Green building policy (Binding City Policy BCP-ENB-9.01). Retrieved from City of Portland, Office of the City Auditor website: http://www.portlandonline.com/auditor/index.cfm?a $=54355 \& \mathrm{c}=34835$ 
City of Portland. (2002). Greening Portland's affordable housing: A resource guide to improving environmental performance, tenant health and long term durability in affordable housing. Retrieved from http://www.portlandonline.com/shared/cfm/ image.cfm?id=122094

City of Portland. (2005a). Portland green building policy strengthens environmental development practice: City council adopts standards and incentives to stimulate sustainable economic development. Retrieved from City of Portland, Office of the City Auditor website: http://www.portlandonline.com/shared/cfm/ image.cfm?id=87378

City of Portland. (2005b). Green building resolution. Retrieved from http://www.portlandonline.com/osd/index.cfm?c=41701\&a=112681

City of Portland. (2008a). Portland 2030: A vision for the future. Retrieved from http://www.visionpdx.com/downloads/final\%20vision\%20document_Feb.pdf

City of Portland. (2008b). Expanding sustainable development practices in Portland, Oregon: Development Review Advisory Committee (DRAC) report and recommendations. Retrieved from http://www.portlandonline.com/bds/ index.cfm? $\mathrm{a}=184671 \& \mathrm{c}=46633$

City of Portland (2008c). Portland Development Commission: Developers comply with disposition and development agreements, but PDC does not monitor adequately. Retrieved from www.portlandonline.com/auditor/index.cfm?a=210294\&c=46297

City of Portland (2009a). State of infusion. Retrieved from http://www.portlandonline.com/mayor/index.cfm?c=51352\&a=276648

City of Portland. (2009b). Exhibit A: City of Portland Green Building Policy (Resolution No. 36700). Retrieved from City of Portland, Office of the City Auditor website: http://www.portlandonline.com/auditor /index.cfm? \&a=250416\&c=34835

City of Portland. (2010). Suspend system development charges until June 30, 2013 (Resolution Number 36766). Retrieved from www.portlandonline.com/bds/ index.cfm?a $=295305$

City of Portland. (2011a). Comprehensive plan goals and policies. Retrieved from http://www.portlandonline.com/bps/Comp_Plan_Nov2011.pdf

City of Portland. (2011b). Our mission. Retrieved from http://www.portlandonline.com /phb/index.cfm?c=32315 
City of Portland. (2011c). Bureau of Planning and Sustainability. Retrieved from http://www.portlandonline.com/bps/index.cfm

City of Portland. (2011d). Design reviews. Retrieved from http://www.portlandonline.com /bds/index.cfm?a $=74223 \& \mathrm{c}=37424$

City of Portland. (2011, June). Portland's ecoroof program. Retrieved from http://www.portlandoregon.gov/bes/article/261074

City of Portland. (2012a). Affordable Housing Preservation (Title 30.01). Retrieved from http://www.portlandonline.com/auditor/index.cfm?c=28481\#cid_15373

City of Portland. (2012b). The Portland plan. Retrieved from http://www.portlandonline.com /portlandplan/index.cfm?c=56527\&

City of Portland. (2012c). Green Investment Fund (GIF) Grant. Retrieved from http://www.portlandoregon.gov/bps/42134

City of Portland. (2012d). Green Building Policy (Binding City Policy BCP-ENB-9.01). Retrieved from http://www.portlandonline.com/auditor/ index.cfm?c $=34835 \& a=54355$

City of Portland (2012e). System development charges. Retrieved from http://www.portlandonline.com/bds/index.cfm?\&c=34186

City of Portland and Multnomah County. (2009). Climate Action Plan. Retrieved from City of Portland website: http://www.portlandonline.com/bps/ index.cfm? $=49989 \& a=268612$

Commission on Affordable Housing and Health Facility Needs for Seniors in the $21^{\text {st }}$ Century. (2002). A quiet crisis in America. A report to the United States Congress. Retrieved from University of North Texas website: http://govinfo.library.unt.edu/seniorscommission/pages/final_report/ finalreport.pdf

Community Partners for Affordable Housing, (2011). Community Partners for Affordable Housing. Retrieved from http://www.cpahinc.org

Concrete Change. (2008). Visit-ability (inclusive home design). Retrieved from http://concretechange.org/

Congress for New Urbanism. (2005). Malls into mainstreets: An in-depth guide to transforming dead malls into communities. Retrieved from http://www.mrsc.org/artdocmisc /CNUmallsmainstreets.pdf 
Congressional Budget Office. (2005). Global Population Aging in the $21^{\text {st }}$ Century and its economic implications. Retrieved from http://www.cbo.gov/sites/default/files/ cbofiles/ftpdocs/69xx/doc6952/12-12-global.pdf

Creswell, J. W. (1998). Qualitative inquiry and research design: Choosing among five traditions. Thousand Oaks, CA: Sage.

Crowley, S. (2012, June 7). Testimony of Sheila Crowley, Ph.D., MSW, President of the National Low Income Housing Coalition presented to the Subcommittee on Insurance, Housing, and Community Opportunity Financial Services Committee, United States House of Representatives, June 7, 2012. Retrieved from National Low Income Housing Coalition website: http://financialservices.house.gov/ uploadedfiles/hhrg-112-ba04-wstate-scrowley-20120607.pdf

Cummings, J. L., \& DiPasquale, D. (1998). Building affordable rental housing: An analysis of the low-income housing tax credit. Retrieved from City Research website: http://www.cityresearch.com/lihtc/cr_lihtc.pdf

Cunningham G. O., \& Michael, Y. L. (2004). Concepts guiding the study of the impact of the built environment on physical activity for older adults: A review of the literature. American Journal of Health Promotion, 18(6), 435-443.

DeNavas-Walt, C., Proctor, B.D., \& Smith, J.C. (2011). Income, Poverty, and health Insurance Coverage in the United States: 2010. Retrieved from U.S. Census Bureau website: http://www.census.gov/prod/2011pubs/p60-239.pdf

Denzin, N. K., \& Lincoln, Y. S. (2003). The landscape of qualitative research: Theories and issues $\left(2^{\text {nd }}\right.$ ed.). Thousand Oaks, CA: Sage.

Department of Land Conservation and Development. (2010a). Goal 10: Housing (OAR 660-015-0000(10)). Retrieved from State of Oregon website: http://www.oregon.gov/LCD /docs/goals/goal10.pdf

Department of Land Conservation and Development. (2010b). Goal 2: Land use planning (OAR 660-015-0000(2)). Retrieved from State of Oregon website: http://www.oregon.gov/LCD /docs/goals/goal2.pdf

Department of Land Conservation and Development. (2010c). Goal 1: Citizen involvement (OAR 660-015-0000(1)). Retrieved from State of Oregon website: http://www.oregon.gov/LCD/docs/goals/goal01.pdf

Department of Land Conservation and Development. (2012). Oregon Department of Land Conservation and Development. State of Oregon. Retrieved from State of Oregon website: http://www.oregon.gov/LCD/Pages/about_us.aspx 
Dill, J., Neal, M., Shandas, V., Luhr, G., Adkins, A., \& Lund, D. (2010). Demonstrating the benefits of green streets for active aging: Final report to EPA. Retrieved from U.S. Environmental Protection Agency website: http://www.epa.gov/agingepa/ grants/winners /psu_green_streets_active_aging_report.pdf

Dillard, J. F., Dujon, V., \& King, M. C. (2009). Introduction. In J. F. Dillard, V. Dujon, \& M. C. King. (Eds.). Understanding the social dimension of sustainability (pp. 1-14). New York: Routledge.

Earth Advantage Institute. (2012). Sustainable building and climate solutions. Retrieved from http://www.earthadvantage.org/programs/homes/earth-advantage-newhomes/

Ekstrom, C. D., \& Ingman, S. R. (1999). Gerontology/environmental links in aging education: Toward an intergenerational view of sustainability. Educational Gerontology, 25(6), 613-621.

Ekstrom, C. D., \& Pei, X. (1995). A connection: The elderly and sustainable futures. In S. R. Ingman, X. Pei, C. D. Ekstrom, H. J. Friedsam, \& K. R. Bartlett (Eds.), An aging population, an aging planet, and a sustainable future (pp. 23-31). Denton, TX: University of North Texas Press.

Elkington, J. (2004). Enter the triple bottom line. In A. Henriques, J. Richardson (Eds.), The triple bottom line, does it all add up?: Assessing the sustainability of business and CSR.(pp. 1-16). Sterling, VA: Earthscan.

Enterprise Community Investment, Inc. (2011). Low-Income Housing Tax Credits. Retrieved from http://www.enterprisecommunity.com/products_and_services/ lihtc.asp

Farber, N., Shinkle, D., Lynott, J., Fox-Grage, W., \& Harrell, R. (2011). Aging in place: A state survey of livability policies and practices. Retrieved from AARP website: http://assets.aarp.org/rgcenter/ppi/liv-com/aging-in-place-2011-full.pdf

Federal Interagency Forum on Aging-Related Statistics. (2009). Data sources on the impact of the 2008 financial crisis on the economic well-being of older Americans (Aging Forum Report: Issue No. 1). Retrieved from http://www.agingstats.gov/ agingstatsdotnet/main_site/docs/DSOA_Aging_Brief.pdf

Federal Interagency Forum on Aging-Related Statistics. (2010). Older Americans 2010: Key indicators of well-being. Retrieved from http://www.agingstats.gov/ agingstatsdotnet /Main_Site/Data/Data_2010.aspx 
Federal Interagency Forum on Aging-Related Statistics. (2012). Older Americans 2012: Key indicators of well-being. Retrieved from http://www.agingstats.gov/ agingstatsdotnet/Main_Site/Data/2012_Documents/Docs/EntireChartbook.pdf

Federal Transit Administration (2004). TCRP Report 102. Retrieved from http://onlinepubs.trb.org/onlinepubs/tcrp/tcrp_rpt_102.pdf

Feldman, P.H., \& Oberlink, M. (2003). The AdvantAge Initiative: Developing community indicators to promote the health and well-being of older people. Families \& Community Health, 26(4), 268-274.

Fetsch, M. (2012). TriMet changes fares and service beginning Sept. 1-2. Retrieved from TriMet website: http://media.trimet.org/trimet-changes-fares-and-servicebeginning-sept-1-2/

Fischer, D. (2010, June 7). Do green buildings minimize human health concerns? Retrieved from Scientific American website: http://www.scientificamerican.com/ article.cfm?id=do-green-building-standards-minimize-health-cooncerns

Flick, U. (2002). An introduction to qualitative research ( $2^{\text {nd }}$ ed.). Thousand Oaks, CA: Sage.

Folts, W.E., \& Muir, K.B. (2002). Housing for older adults: New Lessons from the past. Research on Aging, 24(1), 10-28.

Foo, A.F., \& Yuen, B. (1999). Sustainable cities in the $21^{\text {st }}$ century. Singapore University Press: Singapore.

Fry, R., Cohn, D., Livingston, G., \& Taylor, P. (2011). The Old Prosper Relative to the Young: The Rising Gap in Economic Well-being. Retrieved from Pew Research Center website: http://www.pewsocialtrends.org/files/2011/11/ WealthReportFINAL.pdf

Garcia, R.M. (2011). Sustainable Communities Partnership: A New Role for Federal Agencies. National Civic Review, 100(1), 54-56.

Gerontological Society of America. (2011). The Gerontological Society of America: Leading the way for 65 years: Since 1945. Retrieved from The Gerontological Society of America website: http://www.geron.org/commemorativebook65th.pdf

Giegerich, A. (2008, April 27). World class sustainability. Portland Business Journal. Retrieved from http://www.bizjournals.com/portland/stories/2008/04/28/ story1.html 
Giger, J.N., \& Davidhizar, R.E. (1995). Transcultural Nursing Assessment and Intervention ( $2^{\text {nd }}$ ed.). St. Louis, MO: Mosby.

Girardet, H. (2003). Creating sustainable cities. Devon, UK: Green Books.

Giuliano, G. (2004). Land use and travel patterns among the elderly. In Transportation Research Board (Ed.), Transportation in an aging society: A decade of experience: Conference proceedings 27 (pp. 192-212). Retrieved from Transportation Research Board website: http://onlinepubs.trb.org/onlinepubs/ conf/reports/cp_27.pdf

Glaser, B. G., \& Strauss, A. L. (1967/2009). The discovery of grounded theory: Strategies for qualitative research. Piscataway, NY: Transaction.

Glass, T. A., \& Balfour, J. L. (2003). Neighborhoods, aging, and functional limitations. In I. Kawachi \& L. F. Berkman (Eds.), Neighborhoods and health (pp. 303-334). New York: Oxford University Press.

Glass, T.A., De Leon, C.F., Bassuk, S.S., \& Berkman, L.F. (2006). Social engagement and depressive symptoms in late life: Longitudinal findings. Journal of Ageing and Health, 18(4), 604-628.

Golant, S.M. (1987). In defense of age-segregated housing. In J.A. Hancock (ed.), Housing the elderly. New Brunswick, NJ: Center for Urban Policy Research.

Golant, S.M. (1992). Housing America's elderly: Many possibilities/few choices. Newbury Park, NJ: Sage Publications.

Golant, S.M. (2009). Aging in place solutions for older Americans: Groupthink responses not always in their best interests. Public Policy \& Aging Report, 19(1), 1, 33-39.

Gordon, P. (1998). Seniors' housing and care facilities: Development, business, and operations $\left(3^{\text {rd }}\right.$ ed., Vol. $\left.1 \& 2\right)$. Washington, DC: Urban Land Institute.

Greater Portland Council of Governments. (2008). Portland traffic calming report. Retrieved from www.stopchickenlittle.com/Documents/TcalmingReport20May08.pdf

Greater Portland Pulse. (2011). Age-friendly region. Retrieved from http://www.portlandpulse.org/age-friendly_region

Green Communities. (2007). Trenton Terrace: Portland, Ore. Retrieved from Enterprise Community Partners Inc. website: http://www.greencommunitiesonline.org /projects/profiles/trenton_terrace.pdf 
Green Communities. (2008). The Watershed. Projects: Ore. Retrieved from Enterprise Community Partners Inc. website: http://www.greencommunitiesonline.org /projects/profiles/watershed.pdf

Green Communities. (2010). Village at the Headwaters: Portland, Ore. Retrieved from Enterprise Community Partners Inc. website: http://www.greencommunitiesonline.org/projects/profiles/village_headwaters.pdf

Greenfield, E.A. (2012). Using ecological frameworks to advance a field of research, practice, and policy on aging-in-place initiatives. The Gerontologist, 52(1), 1-12.

Guest, G., Bunce, A., \& Johnson, L. (2006). How many interviews are enough? An experiment with data saturation and variability. Field Methods, 18(1), 59-82.

Haley, W.E., \& Zelinski, E. (2008). Progress and challenges in graduate education in gerontology. Gerontology \& Geriatrics Education, 27(3), 11-26.

Hancock, J.A. (1987). Housing the elderly. New Brunswick, NJ: Center for Urban Policy Research.

Handy, S.L., Boarnet, M.G., Ewing, R., \& Killingsworth, R.E. (2002). How the built environment affects physical activity: Views from urban planning. American Journal of Preventive Medicine, 23(2), Supplement 1, 64-73.

He, W., \& Muenchrath, M.N. (2011). 90+ in the United States: 2006-2008 (American Community Survey Reports: ACS-17). Retrieved from U.S. Census Bureau website: www.census.gov/prod/2011pubs/acs-17.pdf

He, W., Sengupta, M., Velkoff, V. A., \& DeBarros, K. A. (2005). 65+ in the United States: 2005 (Current Populations Reports: Special Studies: P23-209). Retrieved from U.S. Census Bureau website: http://www.census.gov/prod/2006pubs/p23209.pdf

Herremans, I. M., \& Reid, R. E. (2002). Developing awareness of the sustainability concept. The Journal of Environmental Education. 34(1), 16-20.

Hickey, R. (2013, February). After the downturn: New challenges and opportunities for inclusionary housing. Retrieved from Center for Housing Policy website: http://www.nhc.org/media/files/InclusionaryReport201302.pdf

The Home Depot Foundation. (n.d.). REACH's Station Place Tower. The Home Depot Foundation: Awards of Excellence for Affordable Housing. Retrieved from http://www.homedepotfoundation.org/pdfs/reach_3.pdf 
Home Forward (2011). An overview of our programs. Retrieved from http://www.homeforward.org/home-forward/overview-of-programs

Hooyman, N.R., \& Kiyak, H.A. (2011). Social gerontology: A multidisciplinary effort $\left(9^{\text {th }}\right.$ ed.). Boston, MA: Allyn \& Bacon.

House of Representatives Bill 2441, $112^{\text {th }}$ Congress. (2011). Housing Trust Fund Elimination Act of 2011. Retrieved from GovTrack.us website: http://www.govtrack.us/ congress/billtext.xpd?bill=h112-2441

The Housing Alliance. (2011). Document recording fess for housing opportunity (2009 session, HB 2436). Retrieved from http://www.oregonhousingalliance.org/ Document_Recording_Fee_Update_March_11.pdf

Housing Authority of Portland. (n.d.). Green building at New Columbia: Healthy, resource-wise housing and site design at Portland's largest urban development. Retrieved from Home Forward website: http://homeforward.org/sites/default/ files/docs/new-columbia-green.pdf

Housing Authority of Portland. (2007). New Columbia: Report on development goals. Retrieved from Home Forward website: http://homeforward.org/sites/default/ files/docs/NCreport-view.pdf

Housing Authority of Portland. (2009). Public Housing Preservation Initiative: A multiyear, interdepartmental initiative. Retrieved from Home Forward website: http://www.homeforward.org/system/files/docs/factsheet-PHPI.pdf

Housing Authority of Portland. (2010). Framing the future: Strategic directions and next steps. Retrieved from Home Forward website: http://www.homeforward.org /system/files/docs/StrategicDirection9-3-10.pdf

Howe, D. (2001). Aging and smart growth: Building aging sensitive communities (Translation Paper Number Seven). Funders' Network for Smart Growth and Livable Communities. Retrieved from Public Health Grand Rounds website: http://www.publichealthgrandrounds.unc.edu/urban/agingpaper.pdf

Howe, D. (2004). The reality of Portland's housing market. In C.P. Ozawa (Ed.), The Portland Edge (pp. 184-205). Washington, DC: Island Press.

Howe, D. A., Chapman, N. J., \& Baggett, S. A. (1994). Planning for an aging society (Planning Advisory Service Report No. 451). Chicago, Il: American Planning Association. 
Hsieh, H.F., \& Shannon, S.E. (2005). Three approaches to qualitative analysis. Qualitative Health Research, 15(9), 1277-1288.

Hunt, M.E., \& Ross, L.E. (1990). Naturally occurring retirement communities: A multiattribute examination of desirability factors. The Gerontologist, 30(5), 667674.

Ingman, S. R., Pei, X., Ekstrom, C. D., Friedsam, H. J., \& Bartlett, K. (2005). An aging population, an aging planet and a sustainable future conference. Denton, TX: University of North Texas Press.

International City/County Management Association (2003). Active living for older adults: Management strategies for healthy and livable communities (Item number 43000). Retrieved from http://bookstore.icma.org/freedocs/Active_Living.pdf

Jordan, J. (2012, February 14). HUD budget: Funding for CDBG, Sustainable Communities, Choice Neighborhoods. Retrieved from American Planning Association website: http://blogs.planning.org/policy/tag/sustainablecommunities/

Kahana, E. (1982). A congruence model of person-environment interaction. In M.P. Lawton, P.G. Windley, \& T.O. Byerts (Eds.), Aging and the environment: Theoretical approaches (pp. 97-121). New York: Springer Publishing Company.

Katz, B., Turner, M.A., Brown, K.D., Cunningham, M., \& Sawyer, N. (2003). Rethinking local affordable housing strategies: Lessons from 70 years of policy and practice. Retrieved from The Brookings Institution Center on Urban and Metropolitan Policy and the Urban Institute website: http://www.brookings.edu/reports/2003 /12metropolitanpolicy_katz.aspx

Kaufman, J.L. (1961). Planning and an aging population (Planning Advisory Service, Information Report No. 148). Retrieved from American Planning Association website: https://www.planning.org/pas/at60/report148.htm

King, A., Bauman, A., \& Calfas, K. (Eds.) (2002). Innovative approaches understanding and influencing physical activity. American Journal of Preventive Medicine, 23(2), Supplement 1, 1-108.

Kinsella, K., \& He, W. (2009). An Aging world: 2008. Retrieved from U.S. Census Bureau website: http://www.census.gov/prod/2009pubs/p95-09-1.pdf 
Kochera, A. (2002). Serving the affordable housing needs of older low-income renters: A survey of low-income housing tax-credit properties. Retrieved from AARP website: http://www.aarp.org/home-garden/housing/info-2002/aresearch-import747-2002-07.html

Kochera, A., \& Bright, K. (2006). Livable communities for older people. Generations, 29(4), 32-36.

Koff, T.H., \& Park, R.W. (1993). Aging public policy: Bonding the generations. Amityville, NY: Baywood Publishing Company, Inc.

Krueger, R., \& Gibbs, D. (2007). Problematizing the politics of sustainability. In eds. R. Krueger, \& D. Gibbs (Eds.), The sustainable development paradox: Urban political economy in the United State and Europe (pp. 1-11). New York: The Guilford Press.

L’Abate, L., Cusinato, M., Maino, E., Clesso, W., \& Scilletta, C. (2010). Relational competence theory. New York: Springer.

Larsson, N. (2004). The integrated design process. Retrieved from International Initiative for a Sustainable Built Environment website: http://iisbe.org/down/gbc2005/ Other_presentations/IDP_overview.pdf

Laws, G. (1995). Elderly people and the environment. In S. R. Ingman, X. Pei, C. D. Ekstrom, H. J. Friedsam, \& K. R. Bartlett (Eds.), An aging population, an aging planet, and a sustainable future (pp. 1-21). Denton, TX: University of North Texas Press.

Lawton, M.P. (1986). Environment and aging. Albany, NY: The Center for the Study of Aging.

Lawton, M. P., \& Nahemow, L. (1973). Ecology and the aging process. In C. Eisdorfer, \& M. P. Lawton (Eds.), The psychology of adult development and aging (pp. 619674). Washington, DC: American Psychological Association.

Lawton, M.P., \& Simon, B. (1968). The ecology of social relationships in housing for the elderly. The Gerontologist, 8(2), 108-115.

Leach, M., Mearns, R., \& Scoones, I. (1997). Challenges to community-based sustainable development. Institute of Development Studies, 28(4), 4-15.

Lehman, C. (2010, June 23). Oregon Project Independence targeted in budget cuts. Oregon Public Broadcasting. Retrieved from http://www.opb.org/news/article/ oregon-project-independence-repeated-target-budget-cuts/ 
Lehning, A.J. (2011). City governments and aging in place: Community design, transportation and housing innovation adoption. The Gerontologist, 52(3), 345356. doi:10.1093/geront/gnr089

Li, F., Fisher, K.J., Harmer, P., \& McAuley, E. (2002). Delineating the impact of Tai Chi training on physical function among the elderly. American Journal of Preventive Medicine, 23(2), Supplement 1, 64-73.

Libby, B. (2005, January 12). Green building does Portland. Architecture Week. Retrieved from http://www.architectureweek.com/2005/0112/environment_11.html

Madrecki, T. (2012, February 14). Obama Administration's support for Partnership for Sustainable Communities, revitalization programs in FY 2013 budget helps create great communities nationwide. Smart Growth America. Retrieved from http://www.smartgrowthamerica.org/2012/02/14/obama-administrations-supportfor-partnership-for-sustainable-communities-revitalization-programs-in-fy-2013budget-helps-create-great-communities-nationwide/

Mallach, A. (2009). A decent home: Planning, building, and preserving affordable housing. Chicago: American Planning Association, Planners Press.

Manzi, T., Lucas, K., Lloyd-Jones, T., \& Allen, J. (2010). Understanding social sustainability: Key concepts and developments in theory and practice. In T. Manzi, K. Lucas, T. Lloyd-Jones, \& J. Allen (Eds.), Social sustainability in urban areas: communities, connectivity and the urban fabric (pp. 1-34). Washington, DC: Earthscan.

Mayer, J. (2008, December 16). VisionPDX wins award for public outreach. The Oregonian. Retrieved from http://blog.oregonlive.com/portlandcityhall/2008/12 /visionpdx_wins_award_for_publi.html

Mazmanian, D.A., \& Sabatier, P.A. (1989). Implementation and public policy. New York: University of America Press.

McMahon, K. (2010). Ballot Measure 5 turns 20. Oregon Public Broadcasting. Retrieved from http://www.opb.org/thinkoutloud/shows/ballot-measure-5-turns-20/

Meadowcroft, J. (2000). Sustainable development: A new(ish) idea for a new century? Political Studies, 48, 370-397.

Metro. (2000). The nature of 2040: the region's 50-year strategy for managing growth. Retrieved from http://www.oregonmetro.gov/index.cfm/go/by.web/id=29882 
Metro. (2009). 20 and 50 year regional population and employment range forecasts. Retrieved from http://library.oregonmetro.gov/files/20302060_forecast_april_09.pdf

Metro. (2011a). Regional vision: The 2040 growth concept. Retrieved from http://www.oregonmetro.gov/index.cfm/go/by.web/id=29882

Metro. (2011b). Center Commons. Retrieved from http://www.oregonmetro.gov/ index.cfm/go/by.web/id=27185

Metro. (2011c). The Watershed. Retrieved from http://www.oregonmetro.gov/ index.cfm/go/by.web/id=26431

Metro. (2011d). Regional and town center maps. Retrieved from http:// www.oregonmetro.gov/index.cfm/go/by.web/id=15467\&do=map\&locID=14

MGH Associates. (n.d.). The Headwaters at Tryon Creek: Portland, Oregon. Retrieved from http://www.mghassociates.com/documents/HeadwatersatTryonCreek0408.pdf

Michael, Y.L., Green, M., \& Kellogg, H. (2003). Senior walking environmental assessment tool: Preliminary report. Unpublished manuscript, Oregon Health and Science University, Portland, Oregon.

Michael, Y.L., Keast, E.M., Chaudhury, H., Day, K., Mahmood, A., \& Sarte, A.F.I. (2008). Revising the senior walking environmental assessment tool. Preventive Medicine, 48(3), 247-249.

Miller, T. (2010). Green affordable housing policy toolkit. Enterprise Green Communities. Retrieved from Enterprise Community Partners, Inc. website: http://www.practitionerresources.org/cache/documents/673/67398.pdf

Morgan, D. L. (1999). Qualitative Research Methods Series 16: Focus groups as qualitative research $\left(2^{\text {nd }}\right.$ ed.). Thousand Oaks, CA: Sage.

Mrsnik, M. (2010). Global aging 2010: An irreversible truth. Standard \& Poor's. Retrieved from Council on Foreign Relations website: http://www.cfr.org/ economics/standard-poors-global-aging-2010-irreversible-truth/p23299

Multnomah County. (2012). Weatherization program. Retrieved from http://web.multco.us/dchs-community-services/weatherization 
Multnomah County Aging and Disability Services. (2011). Older American's Act Area Plan: For the period of January 1, 2008 to December 31, 2012. Retrieved from Multnomah County website: http://web.multco.us/sites/default/files/ads/ documents/2011_update_mcads_1.pdf

Multnomah County Aging and Disability Services. (2012). Older American's Act Area Plan: For the period of January 1, 2013 to December 31, 2016. Retrieved from Multnomah County website: http://web.multco.us/sites/default/files/ads/ documents/mcads_2013-2016_area_plan_-_final.pdf

Mumford, L. (1987). For older people-Not segregation but integration. In J.A. Hancock (Ed.), Housing the elderly (pp. 39-47). New Brunswick, NJ: Center for Urban Policy Research.

Municipal Research and Services Center of Washington. (2010). Developer agreement in plain English. Retrieved from http://www.mrsc.org/subjects/planning/lu /developagreements.aspx

National Institutes of Health. (2005). Theory at a glance: A guide for health promotion practice (NIH Publication No. 05-3896). U.S. Department of Health \& Human Services. $\left(2^{\text {nd }}\right.$ ed.). Retrieved from National Cancer Institute website: http://www.cancer.gov/cancertopics /cancerlibrary/theory.pdf

National Low Income Housing Coalition. (2009). 2009 advocates guide to housing \& community development policy. Retrieved from http://www.nlihc.org/doc/ AdvocacyGuide2009-web.pdf

National Safety Council. (2009). Sick building syndrome. Retrieved from http://www. nsc.org/news_resources/Resources/Documents/Sick_Building_Syndrome.pdf

Neal, M. B., Chapman, N., Dill, J., Sharkova, I., DeLaTorre, A., Sullivan, K., Kanai, T., \& Martin, S. (2006). Age-related shifts in housing and transportation demand: A multidisciplinary study conducted for Metro by Portland State University's College of Urban and Public Affairs. Portland State University. Retrieved from http://www.pdx.edu/sites/www.pdx.edu.ioa/ files/media_assets/cupa_age_ related_shifts.pdf

Neal, M. B., \& DeLaTorre, A. (2007a). The World Health Organization's Age-Friendly Cities project in Portland, Oregon: Final report. Portland State University. Retrieved from http://www.pdx.edu/sites/www.pdx.edu.ioa/files/media_assets/ ioa_age_friendly_cities.pdf 
Neal, M. B., \& DeLaTorre, A. (2007b). The World Health Organization's Age-Friendly Cities project in Portland, Oregon: Summary of findings. Portland State University and AARP. Retrieved from Portland State University website: http://www.pdx.edu/sites/www.pdx.edu.ioa/files/media_assets/ioa_who_summary offindings.pdf

Neal, M. B., \& DeLaTorre, A. (2010). The WHO Age-Friendly Cities project: A global effort to understand what works locally. Generations: Journal of the American Society on Aging, 33(2), 74-75.

Network for Oregon Affordable Housing. (2010). Rosemont Court. Retrieved from http://www.noah-housing.org/noah_property_pdfs/noah_rosemont\%20court.pdf

New Columbia. (2009). Community speaks initiative. Retrieved from New Columbia website: http://www.newcolumbia.org/wp-content/uploads/CSI-Final-ReportJune-20093.pdf

Newcomer, R.J., \& Weeden, J.P. (1986). Perspectives of housing needs and the continuum of care. In R.J. Newcomer, M.P. Lawton, \& T.O. Byerts (Eds.) Housing and aging society: Issues, Alternatives, and Policy (pp. 3-9). New York, NY: Van Nostrand Reinhold Company.

Norris, M. (2011). Pynoos discusses senior housing. National Public Radio. Retrieved from http://www.npr.org/2011/09/29/140932807/pynoos-discusses-seniorhousing

North Carolina State University Center for Universal Design. (2006). Universal design in housing. Retrieved from North Carolina State University website: http://designdev.ncsu.edu/openjournal/index.php/redlab/article/viewFile/97/51

Northwest Pilot Project. (2011). Community partners. Retrieved from http://www.nwpilotproject.org/about-us/community-partners.php

O’Brien, E., Wu, K.B., \& Baer, D. (2010, April). Older Americans in Poverty: A Snapshot. Retrieved from AARP Public Policy Institute website: http://assets.aarp.org/rgcenter/ppi/econ-sec/2010-03-poverty.pdf

Office of Economic Analysis. (2011, November). Oregon's Demographic Trends. Retrieved from State of Oregon website: http://www.oregon.gov/DAS/OEA/docs /demographic/OR_pop_trend2011.pdf

Oregon Housing and Community Services. (2010). OHCS programs. Retrieved from State of Oregon website: http://www.oregon.gov/ohcs/Pages/ COM_OHCSProgramsOverview .aspx 
Oregon Housing and Community Services. (2011). Consolidated funding cycle application. Retrieved from State of Oregon website: http://www.oregon.gov/ ohcs/pages/hrs_cfc_overview.aspx

Partnership for Sustainable Communities. (2009, June). HUD, DOT and EPA Partnership: Sustainable Communities. U.S. Department of Housing and Urban Development, U.S. Department of Transportation, and U.S. Environmental Protection Agency. Retrieved from Partnership for Sustainable Communities website: http://www.sustainablecommunities.gov/pdf/DOT-HUD-EPAPartnershipAgreement.pdf

Patton, M.Q. (1999). Enhancing the quality and credibility of qualitative analysis. Health Services Research, 34(5), 1189-1208. Retrieved from National Center for Biotechnology Information website: http://www.ncbi.nlm.nih.gov/pmc/ articles/PMC1089059/pdf/hsresearch00022-0112.pdf

Perl, L. (2010). Section 202 and other HUD rental housing programs for low-income elderly residents (Congressional Research Service Report for Congress 7-7806). Retrieved from Congressional Research Service website: http://aging.senate.gov/ crs/aging13.pdf

Pine, P.P., \& Pine, V.R. (2002). Naturally occurring retirement community-supportive service program: An example of devolution. Journal of Aging \& Social Policy, 14(3/4), 181-193.

Policy Link. (2003). Inclusionary zoning. Retrieved from http://www.policylink.org/site /c.lkIXLbMNJrE/b.5137027/k.FF49/Inclusionary_Zoning.htm

Pollack, P.B. (2000). Livable communities: An evaluation guide. Retrieved from AARP website: http://assets.aarp.org/rgcenter/il/d18311_communities.pdf

Porter, D. R., Brecht, S. B., Cory, L. E., Faigin, R. A., Gamzon, M., \& Taber, S. (1995). Housing for seniors: Developing successful projects. Washington, DC: Urban Land Institute.

Portland Development Commission. (n.d.). How we're funded. Retrieved from http://www.pdc.us/about_pdc/pdcfunding.asp

Portland Development Commission. (2001). Rosemont Court: News Release. Retrieved from http://www.pdc.us/pdf/ura/interstate/bulletins/200109.pdf 
Portland Development Commission (2004). Headwaters apartment project (Board Report No. 04-82). Retrieved from OregonLive.com website: http://media.oregonlive.com/portland_impact/other/Report\%2004-82.pdf

Portland Development Commission. (2005). Green building policy program guidelines (Resolution No. 6262). Retrieved from City of Portland website: http://www.portlandonline.com/shared/cfm/image.cfm?id=112680

Portland Development Commission. (2007). A green building primer and the business case for constructing LEED certified buildings. Retrieved from http://www.pdc.us/pdf/sustainability/2007-business-case-to-building-green.pdf

Portland Development Commission (2010). Authorizing Intergovernmental agreements between the Portland Development Commission and the City of Portland to transfer housing programs and employees and to provide support services to the Portland Housing Bureau (Resolution No. 6803). Retrieved from http://vmw.pdc.us/commission-archive/2010/Adopted-Resolutions/ResolutionNo-6803-Intergovernmental-Agreement-Operatoins-PDC-PHB.PDF

Portland Housing Bureau (2012). 2013 HUD median family income. Retrieved from City of Portland website: http://www.portlandonline.com/phb/index.cfm?c= $50010 \& a=425966$

Proscio, T. (2007). Affordable housing's green future: Building a movement for durable, healthier and more efficient housing: Lessons from Minnesota and beyond. Retrieved from Enterprise Community Partners, Inc. website: http://www.practitionerresources.org /cache/documents/649/64911.pdf

Provo, J. (2009). Risk-averse regionalism: The cautionary tale of Portland, Oregon, and affordable housing. Journal of Planning Education and Research, 29(3), 368-381.

Pynoos, J. (1987). Housing the aged: Public policy at the crossroads. In V. Regnier, \& J. Pynoos (Eds.) Housing the aged: Design directives and policy considerations (pp. 25-40). New York: Elsevier.

Pynoos, J., \& Cicero, C. (2009). New approaches to housing and aging in place. Public Policy \& Aging Report, 19(1), 1, 3-8.

Pynoos, J., Nishita, C., Cicero, C., \& Caraviello, R. (2008). Aging in place, housing, and the law. The Elder Law Journal 16(1), 77-106.

Quadagno, J. (2002). Aging and the life course: An introduction to social gerontology ( $2^{\text {nd }}$ ed.). Boston, MA: McGraw Hill. 
Raco, M. (2007). Spatial policy, sustainability and state restructuring: A reassessment of sustainable community building in England. In R. Krueger, \& D. Gibbs (Eds.). The sustainable development paradox: Urban political economy in the United States and Europe (pp. 214-237). New York: The Guilford Press.

Random House Webster's College Dictionary. (1992). New York: Random House.

REACH Community Development Inc. (2004). REACH development profile: State Place Tower. Retrieved from http://reachcdc.org/main/docs/housing_development /temp_file_Station_Place_Tower_fact_sheet1.pdf

REACH Community Development Inc. (n.d.). Practicing green building at Station Place Tower. Retrieved from http://reachcdc.org/main/docs/housing_development /Practicing_Green_Building_at_Station_Place_Tower1.pdf

Richard, L., Gauvin, L., \& Raine, K. (2011). Ecological models revisited: Their uses and evolution in health promotion over two decades. Annual Review of Public Health, 32, 307-326.

The Robert Wood Johnson Foundation (2001). National blueprint: Increasing physical activity among adults aged 50 and older. Princeton, NJ: The Robert Wood Johnson Foundation.

Rosenbloom, S. (2001). Sustainability and automobility among the elderly: An international assessment. Transportation, 28, 375-408.

Rosnik, D., \& Baker, D. (2009). The wealth of the baby boom cohorts after the collapse of the housing bubble. Retrieved from Center for Economic and Policy Research website: http://www.cepr.net/documents/publications/baby-boomer-wealth-200902.pdf

Rosow, I. (1961). Retirement housing and social integration. The Gerontologist, 1(2), 8591.

Rouse, D., \& Zobl, N. (2004). Form-based development codes: Practice form-based zoning. Zoning Practice, (5). Retrieved from American Planning Association website: www.planning.org/zoningpractice/2004/pdf/may.pdf

Ryff, C.D., \& Singer, B. (2009). Understanding health aging: Key components and their integration. In V.L. Bengtson, M. Silverstein, N.M. Putney, \& D. Gans (Eds.), Handbook of Theories of Aging ( $2^{\text {nd }}$ ed., pp. 117-144). New York: Springer Publishing Company. 
Sallis, J. F. (2003). New thinking on older adults' physical activity. American Journal of Preventive Medicine, 25(3), 110-111[Supplement 2].

Satariano, W. A. (2006). Epidemiology of aging: An ecological approach. Boston, MA: Jones and Bartlett.

Satariano, W. A. \& McAuley, E. (2003). Promoting physical activity among older adults: From ecology to the individual. American Journal of Preventive Medicine, 25(3) 184-192 [Supplement 2].

Schafer, R. (1999). America's elderly population and their need for supportive services (Special Report No. W99-3). Retrieved from Joint Center for Housing Studies, Harvard University website: http://www.jchs.harvard.edu/publications/seniors/ schafer_W99-3.pdf

Scharlach, A., Grahm, C., \& Lehning, A. (2011). The "Village" model: A consumerdriven approach for aging in place. The Gerontologist, 52(3), 418-427. doi:10.1093/geront/gnr083.

Schulz, J.H. (2001). The Economics of Aging ( $7^{\text {th }}$ Ed.). Westport, CN: Auburn House.

Schwartz, A.F. (2006). Housing policy in the United States: An introduction. New York: Routledge.

Segal, E.A. (2010). Social welfare policy \& social programs: A values perspective $\left(2^{\text {nd }}\right.$ ed.). Belmont, CA: Cengage Learning.

Seltzer, E. (2004). It's not an experiment: Regional planning at Metro, 1990 to the present. In C. P. Ozawa (Ed.), The Portland edge (pp. 184-205). Washington, DC: Island Press.

Seventh Generation Fund for Indian Development. (2011). Organizational history. Retrieved from http://7genfund.org/our-mission

Shactman, D.I., \& Altman, S.A. (2002). Overview: Issues and option for an aging population. In S.H. Altman, \& D.I. Shactman. (Eds.), Policies for an aging society (pp. 3-33). Baltimore, MD: The Johns Hopkins University Press.

Shrestha, L.B., \& Heisler, E.J. (2011). The changing demographic profile of the United States (Congressional Research Service Report for Congress RL 32701). Retrieved from Federation of American Scientists website: http://www.fas.org/sgp/crs/misc/RL32701.pdf 
Smith, J.L. (2006). Public housing transformation: Evolving national policy. In L. Bennett, J.L. Smith, P.A. Wright. (Eds.), Where are poor people to live? Transforming public housing communities (pp. 19-40). Armonk, NY: M.E. Sharpe.

Smith, K. (2007, July 3). S.W. Portland not quite ready for mixed use development. Daily Journal of Commerce. Retrieved from http://findarticles.com/p/articles/ mi_qn4184/is_20070703/ai_n19360764

Sofaer, S. (1999). Qualitative methods: What are they and why use them? Health Services Research, 34(5), 1101-1118.

Spector, R.E. (2004). Cultural diversity in health and illness $\left(6^{\text {th }}\right.$ ed.). Upper Saddle River, NJ: Pearson Prentice Hall.

Stake, R. E. (1995). The art of case study research. Thousand Oaks, CA: Sage.

State of Oregon. (2001). Oregon Sustainability Act (Oregon Revised Statute 184.421). Retrieved from http://www.leg.state.or.us/ors/184.html

State of Oregon. (2009). House bill 2436. $75^{\text {th }}$ Oregon Legislative Assemble: 2009 Regular Session. Retrieved from http://www.leg.state.or.us/09reg/ measpdf/hb2400.dir/hb2436.intro.pdf

State of Oregon. (2011a). Oregon Revised Statute 456.510: Visitability requirements. 2009 Oregon Revised Statutes. Retrieved from https://www.oregonlaws.org/ ors $/ 456.510$

State of Oregon. (2011b). Oregon Revised Statute 456.513: Exemption from visitability requirements. 2009 Oregon Revised Statutes. Retrieved from http://www.oregonlaws.org/ors/456.513

State of Oregon (2011c). Oregon Housing Bill 3531. $76^{\text {th }}$ Oregon Legislative Assembly 2011 Regular Session. Retrieved from www.leg.state.or.us/11reg/measpdf /hb3500.dir/hb3531.intro.pdf

Strauss, A. (1987). Qualitative analysis for social scientists. New York: Cambridge University Press.

Strauss, A., \& Corbin, J. (1990). Basics of qualitative research: Grounded theory procedures and techniques. Newbury Park, CA: Sage.

Stokols, D. (1992). Establishing and maintaining healthy environments: Toward a social ecology of health promotion. American Psychologist, 47(1), 6-22. 
Street, D.A. (2007). Sociological approaches to understanding age and aging. In J.A. Blackburn, \& C.N. Dulmus (eds.), Handbook of gerontology: Evidence-Based Approaches to Theory, practice, and Policy (143-168). Hoboken, NJ: John Wiley \& Sons, Inc.

Torres-Gil, F., \& Lam, D. (2012). The evolving nexus of policy, longevity and diversity: Agenda setting for Latino health and aging. In J.L. Angel, F. Torres-Gil, \& K. Markides (Eds.), Aging, health, and longevity in the Mexican-origin population (pp. 327-336). New York: Springer.

Turner, L. (1986). Public policies and individual housing choices. In R.J. Newcomer, M.P. Lawton, and T.O. Byerts (Eds.), Housing and aging society: Issues, alternatives, and policy (pp. 42-52). New York, NY: Van Nostrand Reinhold Company.

U.S. Census Bureau. (2003). American Housing Survey for the Portland Metropolitan Area: 2002 (Current Housing Reports, Series H170/02-34). Retrieved from http://www.census.gov/prod/2003pubs/h170-02-34.pdf

U.S. Census Bureau. (2005). Interim state population projects: 2005. Retrieved from www.census.gov

U.S. Census Bureau. (2008). National population projections: Summary Tables. Retrieved from http://www.census.gov/population/projections/data/national/ 2008/summarytables.html

U.S. Census Bureau. (2010). Older Americans month: May 2010. Retrieved from http://www.census.gov/newsroom/releases/pdf/cb10-ff06.pdf

U.S. Census Bureau. (2012a). The 2012 statistical abstract: The national data book. Retrieved from http://www.census.gov/compendia/statab/cats/population.html

U.S. Department of Health and Human Services. (2012). 2012 HHS poverty guidelines. Retrieved from http://aspe.hhs.gov/poverty/12poverty.shtml

U.S. Department of Housing and Urban Development. (1998). Fair Housing Act design manual: A manual to assist designers and builders in meeting the accessibility requirements of the Fair Housing Act. Retrieved from http://www.huduser.org/ portal/publications/PDF/FAIRHOUSING/fairfull.pdf 
U.S. Department of Housing and Urban Development. (2004, September 13). HUD recognizes 14 local communities for outstanding achievement in community development: Community development excellence awards mark $30^{\text {th }}$ anniversary of CDBG. Retrieved from http://archives.hud.gov/ news/2004/pr04-088.cfm

U.S. Department of Housing and Urban Development. (2007). Title VIII: Fair Housing and Equal Opportunity. Retrieved from http://portal.hud.gov/hudportal/ HUD?src=/program_offices/fair_housing_equal_opp/progdesc/title8

U.S. Department of Housing and Urban Development. (2010a). Strategy of the month: Green affordable housing policy toolkit. Retrieved from http://www.huduser.org /portal/rbc/strategy/vol7.html

U.S. Department of Housing and Urban Development. (2010b). How do housing tax credits work? Retrieved from http://www.hud.gov/offices/cpd/affordablehousing /training/web/lihtc/basics/work.cfm

U.S. Department of Housing and Urban Development. (2011a). FY 2012: HUD income limits briefing material. Retrieved from http://www.huduser.org/portal/datasets/ il/il12/IncomeLimitsBriefingMaterial_FY12_v2.pdf

U.S. Department of Housing and Urban Development. (2011b). HUD's Public Housing Program. Retrieved from http://portal.hud.gov/hudportal/HUD?src=/topics /rental_assistance/phprog

U.S. Department of Housing and Urban Development. (2011c). Resident characteristic report. Retrieved from http://portal.hud.gov/hudportal/HUD?src=/ program_offices/public_indian_housing/systems/pic/50058/rcr

U.S. Department of Housing and Urban Development. (2011d). Housing Choice Vouchers fact sheet. Retrieved from http://portal.hud.gov/hudportal/ HUD?src=/topics/housing_choice_voucher_program_section_8

U.S. Department of Housing and Urban Development. (2011e). Section 202 Supportive Housing for the Elderly Program. Retrieved from http://portal.hud.gov/hudportal /HUD?src=/program_offices/housing/mfh/progdesc/eld202

U.S. Department of Housing and Urban Development. (2011f). Office of Affordable Housing Preservation. Retrieved from http://portal.hud.gov/hudportal/HUD?src= /program_offices/housing/mfh/mfbroch/mfbroc7

U.S. Department of Housing and Urban Development. (2011g). Community Development Block Grant Program - CDBG. Retrieved from http://portal.hud.gov/hudportal/ HUD?src=/program_offices/comm_planning/communitydevelopment/programs 
U.S. Department of Housing and Urban Development. (2011h). Home Investment Partnership Program. Retrieved from http://www.hud.gov/offices/cpd/ affordablehousing/programs/home/

U.S. Department of Housing and Urban Development. (2011i). Housing Trust Fund. Retrieved from http://www.hud.gov/offices/cpd/affordablehousing/ programs/home/htf.cfm

U.S. Department of Housing and Urban Development. (2011j). Senior housing: What you should know... Retrieved from http://portal.hud.gov/hudportal/ HUD?src=/program_offices/fair_housing_equal_opp/seniors

U.S. Department of Housing and Urban Development. (2011k). Title VIII: fair housing and equal opportunity. Retrieved from http://portal.hud.gov/hudportal/HUD?src= /program_offices/fair_housing_equal_opp/progdesc/title8

U.S. Department of Housing and Urban Development. (2011m). Section 504 of the Rehabilitation Act of 1973. Retrieved from http://portal.hud.gov/hudportal/ HUD?src=/programdescription/sec504

U.S. Department of Housing and Urban Development. (2011n). Notice of Public Interest for Fiscal Year 2010: Transformation Initiative: Sustainable Communities Research grant (Docket No. FR-5415-N-24A). Retrieved from http://hud.gov/ offices/adm/grants/nofa10/nopiscrg24a.pdf

U.S. Department of Housing and Urban Development. (2011p). Neighborhood Stabilization Program Grants. Retrieved from http://portal.hud.gov/ hudportal/HUD?src=/program_offices/comm_planning/communitydevelopment/p rograms/neighborhoodspg

U.S. Department of Housing and Urban Development. (2011q). About HOPE VI. Retrieved from http://portal.hud.gov/hudportal/HUD?src=/program_offices /public_indian_housing/programs/ph/hope6/about

U.S. Department of Housing and Urban Development. (2012a). Affordable housing. Retrieved from http://portal.hud.gov/hudportal/HUD?src=/program_offices /comm_planning/affordablehousing

U.S. Department of Housing and Urban Development. (2012c). FY 2012 income limits. Data Sets. Retrieved from http://www.huduser.org/portal/datasets/il/ il12/index.html 
U.S. Department of Justice. (2009). Americans with Disabilities Act of 1990, as amended. Retrieved from http://www.ada.gov/pubs/ada.htm

U.S. Department of Justice. (2010). 2010 ADA Standards for Accessible Design. Retrieved from http://www.ada.gov/regs2010/2010ADAStandards/ 2010ADAStandards_prt.pdf

U.S. Department of Labor. (n.d.). Architectural Barriers Act (ABA). Retrieved from U.S. Department of Labor's Office of Disability Employment Policy website: https://www.disability.gov/home/i_want_to/disability_laws/architectural_barriers _act_\%28aba\%29

U.S. Department of Transportation, Federal Transit Administration, and the U.S. Department of Housing and Urban Development. (2008). Better coordination of transportation and housing programs to promote affordable housing near transit. Retrieved from U.S. Department of Housing and Urban Development website: http://www.huduser.org/Publications/pdf/better_coordination.pdf

U.S. Department of Veterans Affairs. (2011). The Department of Housing and Urban Development and VA's Supportive Housing (HUD-VASH) Program. Retrieved from http://www.va.gov/HOMELESS/HUD-VASH.asp

U.S. Environmental Protection Agency. (n.d., March). Sustainability. Retrieved from http://www.epa.gov/sustainability/basicinfo.htm

U.S. Environmental Protection Agency. (2010, April). Leveraging the Partnership: DOT, HUD, and EPA Programs for Sustainable Communities. Retrieved from http://www.epa.gov/smartgrowth/pdf/2010_0506_leveraging_partnership.pdf

U.S. Environmental Protection Agency. (2012). Brownfields and land revitalization. Retrieved from http://www.epa.gov/brownfields/

U.S. Government Accountability Office. (2009). Metropolitan planning organizations: Options to enhance transportation planning capacity and federal oversight. Retrieved from http://www.gao.gov/assets/300/294812.pdf

U.S. Government Printing Office. (2012, November). Notice of neighborhood stabilization program; Closeout requirements and recapture (Federal Register, 7(228), 70799-70805). Retrieved from http://www.gpo.gov/fdsys/pkg/FR-201211-27/pdf/2012-28642.pdf

U.S. Green Building Council. (2008). LEED 2009 for new construction and major renovations. Retrieved from http://www.usgbc.org/ShowFile.aspx?

DocumentID $=8868$ 
U.S. Green Building Council. (2011). What LEED is? Retrieved from http://www.usgbc.org/DisplayPage.aspx?CMSPageID=1988

United Nations. (1987). Report of the World Commission on Environment and Development. United Nations General Assembly. Retrieved from http://www.worldinbalance.net/pdf/1987-brundtland.pdf

United Nations Educational, Scientific and Cultural Organization. (2001). UNESCO universal declaration on human diversity. Adopted by the $31^{\text {st }}$ session of the general conference of UNESCO, Paris, 2 November 2001. Retrieved from http://unesdoc.unesco.org/images/0012/001271/127160m.pdf

Urban Works Real Estate. (2009). The Watershed @ Hillsdale. Retrieved from http://www.urbanworksrealestate.com/documents/TheWatershedHillsdale.pdf

The Village at the Headwaters. (2006). The Headwaters at Tryon Creek: The Village. Retrieved from http://www.villageattheheadwaters.com/village_features.htm

Vincent, G.K., \& Velkoff, V.A. (2010). The next four decades: The older population in the United States, 2010 to 2050 (P25-1138). Retrieved from U.S. Census Bureau website: http://www.census.gov/prod/2010pubs/p25-1138.pdf

Vining, A.R., \& Weimer, D.L. (2009). Assessing the costs and benefits of social policies. In D.L. Weimer and A.R. Vining (Eds.), Investing in the disadvantaged (pp. 116). Washington D.C.: Georgetown University Press.

Wahl, H. W., \& Weisman, G. D. (2003). Environmental gerontology at the beginning of the new millennium: Reflections on its historical, empirical, and theoretical development. Gerontologist, 43(5), 616-27.

Walk Score. (2012). Walk Score ${ }^{\circledR}$. Retrieved from http://www.walkscore.com/

Walker, A. (1990). The economic 'burden' of ageing and the prospect of intergenerational conflict. Ageing and Society, 10(4), 377-396).

Weisman, G.D., Chaudhury, H., \& Diaz Moore, K. (2000). Theory and practice of place: Toward an integrative model. In R.L. Rubenstein, M. Moss, and M. Kleban (Eds.), The many dimensions of aging. Essays in honor of M. Powell Lawton, (pp. 3-21). New York: Springer.

Wells, W. (2007). Blueprint for greening affordable housing. Washington, D.C.: Global Green/Island Press.

Wheeler, S. (2000). Planning sustainable and livable cities. In R. T. LeGates \& F. Stout (Eds.), The city reader, ( $2^{\text {nd }}$ ed., pp. 434-445). New York: Routledge. 
Williams, C. C., \& Millington, A. C. (2004). The diverse and contested meanings of sustainable development. The Geographic Journal, 170(2), 99-104.

Wilson, A. (2009, June). Dirty dozen list of POPs expanded. Environmental building news, 18(6). Retrieved from http://www.buildinggreen.com/auth/article.cfm/ 2009/5/29/Dirty-Dozen-List-of-POPs-Expanded/

Wise, R. N., Fiore, E., Brockman, C., \& Brukman, E. (2007, October). Economic development opportunities for Portland's green building industry. Retrieved from City of Portland website: http://www.portlandonline.com/shared/cfm/ image.cfm?id=170933

World Health Organization. (2002). Active ageing: A policy framework. Retrieved from http://whqlibdoc.who.int/hq/2002/who_nmh_nph_02.8.pdf

World Health Organization. (2007a). Global age-friendly cities: A guide. Geneva, Switzerland. Retrieved from http://www.who.int/ageing/publications/ Global_age_friendly_cities_Guide_English.pdf

World Health Organization. (2007b). WHO Age-Friendly Cities project methodology: Vancouver protocol. Retrieved from http://www.who.int/ageing/publications /Microsoft\%20Word\%20-\%20AFC_Vancouver_protocol.pdf

World Health Organization. (2010). Urban planning essential for public health. Retrieved from http://www.who.int/mediacentre/news/releases/2010/ urban_health_20100407/en /index.html

World Health Organization. (2012). WHO Global Network of Age-Friendly Cities and Communities. Retrieved from http://www.who.int/ageing/ age_friendly_cities_network/en/index.html

Wright, S. D., \& Lund, D. A. (2000). Gray and green? Stewardship in an aging society. Journal of Aging Studies, 14(3), 229-249.

Wuest, J. J. (January, 2009). The St. Louis Equity Fund and LIHTCs: Past and future. In Board of Governors of the Federal Reserve System and Federal Reserve Bank of St. Louis (Eds.), Innovative ideas for revitalizing the LIHTC market (Report No. CA0925). Retrieved from http://www.macdc.org/resources/LIHTCreport_ final.pdf

Yin, R. K. (2003). Case study research: Design and methods ( $3^{\text {rd }}$ ed.). Applied Social Research Methods Series, Volume 5. Thousand Oaks, CA: Sage. 


\section{Appendix A ${ }^{46}$}

\section{Regional Sustainable Development Initiative Timeline}

The City of Portland has already adopted guidelines, established programs, and endorsed policies to promote and expand sustainable and Green Building practices. The City continues to show leadership in addressing the environmental health and economic well being. The City has developed policies regarding natural resource consumption, the acceleration of climate change, and pollution prevention.

\section{3}

Urban Growth Boundaries - Senate Bill 100 passed by Oregon Legislature, requiring Portland to establish urban growth boundaries.

\section{4}

Replacement of Harbor Drive with Waterfront Park - Harbor Drive, a six-lane road running along the west bank of the Willamette River, is removed and replaced with a City park.

$\underline{1977}$

Downtown Transit Mall - The Transit Mall helps revitalize downtown Portland by improving bus access and connections and catalyzing investment in the central City.

\section{9}

Energy Policy - Portland's first energy policy emphasizes energy efficiency and renewable energy.

$\underline{1980}$

Comprehensive Plan - Portland's comprehensive land-use plan addresses 14 goals established by the State of Oregon, including transportation, economic development, neighborhoods, housing, water quality, air quality, energy, and citizen involvement. The resulting land-use policies provide a written framework for future program and funding decisions related to urban development, as well as addressing a broad range of urban issues.

$\underline{1986}$

First Light-Rail Line - The initial light-rail line, the first element of what is now a 44- mile system, connects Gresham, 15 miles east of downtown Portland, to the Portland central City

${ }^{46}$ From: City of Portland. (2008b). Expanding sustainable development practices in Portland, Oregon: Development Review Advisory Committee (DRAC) report and recommendations. 
Recycling Plan - Curbside-recycling service is provided to all residences.

1993

Carbon Dioxide Reduction Strategy-Portland becomes the first local government in the U.S. to adopt a plan to address global climate change.

BEST Awards - City of Portland makes inaugural BEST (Businesses for an Environmentally Sustainable Tomorrow) Awards to businesses with significant and unique achievements in sustainability. The intent of the BEST Awards is to showcase innovation and commitment to sustainability.

Recycle at Work (formerly BlueWorks) - The City team of Recycling Specialists provides recycling, waste prevention, and sustainable purchasing assistance to Portland businesses.

Downspout Disconnection Program - Bureau of Environmental Services (BES) provides outreach and incentives for residents of selected neighborhoods to disconnect downspouts from the combined sewer system and to redirect roof water to gardens and lawns.

$\underline{1994}$

Sustainable City Principles - City Council formally establishes its intention promote a sustainable future that meets today's needs without compromising the ability of future generations to meet their needs. Specifically, it commits to:

- Support a stable, diverse and equitable economy

- Protect the quality of the air, water, land and other natural resources

- Conserve native vegetation, fish, wildlife habitat and other ecosystems

- Minimize human impacts on local and worldwide ecosystems

$\underline{1996}$

Commercial Recycling Requirement -All businesses in Portland are required to recycle at least 50 percent of their solid waste

Bicycle Master Plan - Created by Portland residents and City of Portland Bicycle Program staff, the Bicycle Master Plan seeks to ensure that Portland is a bicycle friendly city, and includes a recommended bikeway network, end-of-trip facilities, links to transit, and educational efforts.

$\underline{2000}$

Office of Sustainable Development (OSD) - The office was created in September 2000 by merging the Solid Waste \& Recycling Division, previously part of the Bureau of Environmental Services, with the Energy Office, which housed the City's energy and Green Building programs and staffed the Sustainable Development Commission. 
Green Building Policy - Portland's initial Green Building policy required all new City construction and major renovation projects to meet the U.S. Green Building Council's LEED Silver standard. In 2005, the requirement was raised to LEED Gold. In addition, private-sector projects that receive public funding must meet LEED Silver.

Green Investment Fund - Since 2000, the Green Investment Fund has provided financial support to more than 80 innovative building projects in Portland that exemplify comprehensive Green Building practices.

$\underline{2001}$

Local Action Plan on Global Warming (major revision to CO2 Reduction Strategy) -With a goal of reducing greenhouse gas emissions to 10 percent below 1990 levels by 2010, Portland's updated climate-protection plan identifies 150 actions to reduce carbon emissions while supporting livability and economic growth. As of 2005, local greenhouse gas emissions were 1 percent below 1990 levels.

Portland Streetcar - Portland Streetcar becomes the first new streetcar in the U.S. in 50 years. More than $\$ 1$ billion in development has followed the streetcar line.

Green Building Policy - Portland Development Commission approves the Green Building Policy Guidelines that required LEED Certified for most commercial/retail construction and three other tiered standards for tenant improvement, smaller multifamily residential, and affordable housing projects.

Rainwater Harvesting Guide - Bureau of Development Services (BDS) created prescriptive technical assistance guide for rainwater harvesting systems to be used in single-family homes.

Sustainable Stormwater Management Program - BES program promotes the integration of vegetated stormwater management approaches through demonstration projects, monitoring, policy development and education and outreach.

$\underline{2003}$

"ReThink Green Building” Training Series - The City of Portland launches a Green Building training series for commercial and residential building design and construction professionals.

2004

Rainwater Harvesting Included in Portland Plumbing Regulations - The City of Portland Council decides to unanimously include rainwater harvesting into the City plumbing regulations.

Clean and Healthy River Strategy - A BES comprehensive effort to create healthy watersheds and a livable, sustainable community. It encourages environmentally friendly building techniques and designs to use resources efficiently and minimize adverse impacts. 
Watershed Management Plan - BES plan sets criteria and recommends actions to improve watershed health. It helps set targets and strategies for sustainable stormwater management project implementation.

Sustainable Development Commission - The Sustainable Development Commission will provide expertise and technical assistance, community connections and visibility to further the City and County's internal sustainability efforts. The Commission advises the City and County, including elected officials, on priorities for making a real difference in operating sustainably.

Processed Permitting for Innovative Building - The BDS partners with the OSD to provide process management assistance to all Green Investment Fund grantees.

Green Building Policy - The City raises the requirement for municipal buildings to LEED Gold and Portland Development Commission (PDC) raises its commercial Green Building standard to LEED Silver.

$\underline{2006}$

Major Projects Group \& LEED Silver Minimum Requirement - The Major Projects Group program is an innovative multi-bureau, fee-based program intended to serve the largest and most complex development projects through the permitting and inspection process. Selection criteria for acceptance into the program include a project goal of LEED Silver certification or above.

Clean River Rewards Program - provides technical assistance, educational materials and offers workshops tailored to Portland residential and commercial ratepayers interested in managing their stormwater runoff on-site. In partnership with BDS, they developed a simple check list of permit requirements for stormwater facility retrofits.

Renewable Fuel Standard - Beginning in August 2007, all diesel sold in Portland is required to be 5 percent biodiesel; beginning in November 2007, all gasoline must contain 10 percent ethanol.

$\underline{2007}$

Peak Oil Task Force Report - A City-appointed citizen commission, the Peak Oil Task Force developed recommendations for how Portland should respond to the rising costs and eventual decline in supply of oil and natural gas. The Peak Oil Task Force Report is adopted by City Council and the City sets the goal of reducing fossil fuel use by 50 percent in 25 years.

Green Streets Policy - City of Portland Bureau of Environmental Services policy to promote and incorporate the use of vegetated green street facilities in public and private development. Creates standards for stormwater management and treatment of runoff.

Western Climate Initiative - The Governors of Oregon, Washington, Arizona, and New Mexico signed The Western Climate Initiative. The purpose is to reduce, on the average, regional greenhouse gas emissions by 15 percent by the year 2020 . 


\section{Appendix B}

\section{Human Subjects Research Review Committee Application ${ }^{47}$}

\section{Project Title and Prospectus:}

"A Case Study of Factors Influencing the Development of Sustainable, Affordable Housing for Older Adults in Portland, Oregon"

Empirical data focusing on the planning and development of affordable housing that is considered to be sustainable for older adults are limited. For the purposes of this research, the terms "sustainable development" and "sustainable" will be used to describe "livable" and "age-friendly" housing and environments (e.g., sidewalks, nearby social spaces and parks, transportation options, etc.) for older adults and will be defined as follows: "Sustainable development seeks to balance human development, growth, and equity with ecological stewardship." ${ }^{48}$ In addition, the World Health Organization's (WHO) definition of an "age-friendly city" will be modified throughout the remainder of this research by replacing "age-friendly city" with "sustainable housing and environments" as follows, "[sustainable housing and environments] for older adults encourage active aging by optimizing opportunities for health, participation, and security in order to enhance quality of life as people age."49

Although myriad studies have focused on housing for older adults, sustainable housing in general, and/or affordable housing, there is no research that looks at the convergence of these three topics, especially the pre-occupancy stages of project planning and development. Additionally, because sustainable, affordable housing for older adults is rare (only six developments in the city of Portland over the past 10 years meet the criteria), examining how and why this type of development came about and whether it has applicability beyond the Portland region will contribute to knowledge and, hopefully, facilitate future development here and elsewhere.

Previous research in conjunction with the WHO on age-friendly cities in Portland (Neal $\&$ DeLaTorre, 2007) ${ }^{50}$ has shown that there is a pressing need for affordable housing for

\footnotetext{
${ }^{47}$ This application reflects the final approved application which reflects the changes that have been approved by Portland State University's Human Subject Research Review Committee (HSRRC), including the valid extension that was granted that applies to the research through March 5, 2013 (HSRRC Proposal \# 09843).

${ }^{48}$ City of Portland (2001). Green building policy. (Binding City Policy BCP-ENB-9.01).

${ }^{49}$ World Health Organization, (2007). Global age-friendly cities: A guide. "An age-friendly city encourages active ageing by optimizing opportunities for health, participation and security in order to enhance quality of life as people age"

${ }^{50}$ Neal, M.B., \& DeLaTorre, A. (2007). The World Health Organization's Age-Friendly Cities project in Portland, Oregon: Summary of findings. Portland, OR: Portland State University and AARP.
} 
older adults in Portland, as well as housing that incorporates elements that could be considered sustainable (e.g., green and/or natural features, accessible design, proximity/access to services, participatory planning processes, well designed social spaces).

The WHO research focused on residents' day-to-day experiences in housing and the surrounding environment. There is, however, a dearth of empirical data on urban planning practices related to senior housing development (Giuliano, 2004 ${ }^{51}$ ) and little is known regarding the pre-occupancy stages of project planning and development that lead to sustainable/livable/age-friendly housing and nearby infrastructure (e.g., sidewalks, nearby services); thus, further research is needed.

\section{Research Methods}

The proposed research will analyze primary data to be gathered from individuals who were participants in the planning and development of six sustainable, affordable housing projects for older adults, as well as from other housing and development experts. In addition, secondary data will be analyzed to enhance understanding of the projects within this case study. Interviews will be semi-structured; due to expected emerging insights, changes to the script are expected.

\section{Data to be Collected}

\section{Key informant interviews}

Aim: Develop an understanding of the planning and development processes of housing for older adults that are considered to be sustainable and affordable; develop an understanding of the contributions of key actors in the planning and development process, the diffusion of innovative practices (e.g., sustainable/green development), and future policy considerations; inform focus group protocols that will be completed later in the research.

Description of sample: In-depth, personal interviews with experts who are experienced with affordable housing, urban planning, housing development, or housing for older adults.

Expected number: At least eight. At least four initial interviews will be conducted with: (a) a member of the Housing Authority of Portland's Board of Directors; (b) a contractor involved with the development of housing for older adults; (c) the director of a non-profit affordable housing development agency in Portland who has experience in housing development for older adults; and (d) an architect involved with the development of

${ }^{51}$ Giuliano, G. (2004). Land use and travel patterns among the elderly. Transportation in an Aging Society: A decade of Experience. Transportation Research Board, Washington, D.C. 
housing for older adults. At least four additional interviews will be conducted after completion of the focus group interviews (see Data Collection Strategy 3, below) and are expected to include: (e) the instructor of a course on affordable housing development at Portland State University (this person also directs a non-profit organization focused on affordable housing); (f) the instructor of a course on green building development at Portland State University (this person also is an architect and planner with a local planning and development firm); (g) a real estate developer at a regionally-based development firm who focuses on sustainable development; and (h) the Director of Portland's Bureau of Planning and Sustainability.

Additional interviews may be conducted as needed to acquire additional expert insight; a snowball sampling technique will be used in order to reach a point of "saturation" when new information is no longer being collected.

\section{Secondary analysis of archival data}

Aim: Identify which urban planning and development policies affect, both positively and negatively, the planning and development of sustainable, affordable housing for older adults; develop recommendations for future policy changes that would facilitate future housing developments.

Description of sample: Review of planning, zoning, and development documents.

Expected scope: Several archived documents for each case.

\section{Data Analysis Plan}

All primary data collected will be transcribed and entered in Atlas TI for content analysis. Selected secondary data will also be entered into Atlas TI for analysis.

\section{Expedited Review}

This research study is socio-cultural in nature - it focuses on individuals' beliefs and practices related to the planning and development of sustainable, affordable housing for older adults. The research methods are qualitative, including surveys, interviews, focus groups, and analysis of secondary data. This research poses minimal risk to all participants involved with the research and fits under the Expedited Review category \#7 of Portland State University's Application Guidelines for Research Involving Human Subjects.

\section{Subject Recruitment}

Subject recruitment involves the identification of key informants for in-depth interviews who understand aspects of the planning and development of sustainable, affordable housing. 


\section{Identifying key informants}

The principal investigator (PI) has established relationships with several key informants, including two professors from Portland State University (PSU), the executive directors of two Portland-based non-profit organizations, and a current board member of the Housing Authority of Portland (formerly a City Commissioner for Portland and State Representative for Oregon.) Additional key informants have been recommended or will be identified during the initial interviews and subsequent focus groups. In-depth interviews will be conducted until the researcher considers the desired level of information to have reached a "saturation" point. Contact with key informants will be made by phone (see attached phone script).

\section{Informed Consent}

Informed consent will be acquired from all participants. However, the return of the survey to be completed by project sponsors/owners (see Appendix B) will be taken as implied consent, rather than having each sponsor/owner complete an informed consent document. All participants will be aged 18 or older. See Appendixes A-C for informed consent documents (including survey instrument).

\section{First-Person Scenario}

\section{Interviews}

"This week I received a call from Alan DeLaTorre, a student at Portland State University, asking if I would be willing to participate in his dissertation research on sustainable, affordable housing for older adults. His interest was in understanding the factors that influenced the planning and development of several housing projects, especially the processes associated with pre-occupancy, rather than those occurring after people moved into a building. I felt that I would have some useful knowledge to contribute, so I agreed to participate in the research, and we set up a time for Mr. DeLaTorre to come to my office to conduct an interview.

After our initial conversation, Alan sent me an overview of the questions that he was going to cover during our meeting, and he asked me to review them and think about my answers ahead of time. After reading the questions I made some notes on the paper so that I could remember my thoughts when we met. When Mr. DeLaTorre arrived at my office he then reiterated the purpose of the research and explained that the data would be kept confidential and not identifiable to anyone, although he would record the conversation for his purposes only. I then read and signed a form that said I understood and agreed to participate, and he gave me a copy to keep for my records.

We proceeded to discuss aspects of sustainable and affordable housing for older adults. The questions ranged from my assessment of the current state of the art of sustainable 
development in Portland, to explaining how certain processes worked. Most of the questions flowed from one to the next, and Alan kept me on track by bringing up a new topic when he felt like it was time to move on. Overall, the interview lasted a little over an hour, which was perfect, as I had scheduled 90 minutes for the meeting at his request. I felt as though I was able to contribute some good insight to his research, including giving him the contact information of someone whom I thought would be a great person to include in his research. When the interview was over, Mr. DeLaTorre thanked me and told me that my contribution to the research project was invaluable. He also said that I call him if I had any questions, concerns, or additional thoughts to add following this meeting. I'm interested to see what he finds out about the factors influencing the planning and development of housing for older adults."

\section{Potential Risks and Safeguards}

The potential risks of the study are minimal. The two possible risks are: (a) emotional upset or fatigue on the part of the participant; and (b) loss of privacy/confidentiality. The PI proposes to mitigate potential harms by attempting to maximize convenience for research participants and by ensuring confidentiality to the maximum extent possible.

In order to reduce participant fatigue, interviews and focus groups will be held at a location that maximizes accessibility for research participants, taking into account participants' office locations and available transportation options (e.g., parking, light rail, bus, streetcar); additionally, important materials (e.g., consent forms and interview questions) will be distributed in a timely fashion in order to give participants ample time to review and prepare responses at their convenience. Time allocated for interviews or focus groups will be strictly adhered to as it is understood that participants are professionals who will expect a well-prepared and efficient interview, survey, or focus group.

Regarding subject matter and the potential for emotional upset, some questions concerning past projects may be sensitive (e.g., issues pertaining to finances or interpersonal conflicts that may have occurred); participants will not be required to answer any questions they would prefer not to answer. Interview participants will also be free to terminate the interview at any time, to take a break whenever they would like, and/or reschedule. Focus group participants will be free to not answer questions they prefer not to answer, to stop their participation in the group at any time, and/or to take a break if they need or want to.

To minimize loss of privacy and confidentiality, the PI will not share the names of participants with anyone, including the other research participants involved in the research. However, focus groups interviews do create problems with confidentiality due to the group setting; participants will be informed of this before participating, they will be given name tags with their first names only, and they will be asked to maintain the confidentiality of what is said in the group. 
The PI will ask for permission to record, via audio recording device, the participant interviews and focus groups. After the completion of each survey, interview, or focus group, each participant will be assigned a unique code (alphanumeric or pseudonym) that will be used on all study materials outside of the original records to be held only by the researcher; at no time will the individual's name be recorded, either by hand or on audio record, apart from the original records of the PI. All electronic project files with identifiers will be password protected. Tapes, transcripts, and notes will be stored in a locked file cabinet in the PI's office at Portland State University for three years. Participants will not be identified by name in any written or oral reports; pseudonyms will be used.

\section{Potential Benefits}

This research is intended to identify best practices that may be used in the development of new housing designed to enhance the quality of life and independence of older adults, as well as minimize the footprint that these projects have on the environment. The knowledge acquired from this research will provide new information to support the creation of housing and development-related policy in Portland and beyond. For participants in the interviews, there may be no direct benefit other than knowing they are contributing to knowledge. For those who participate in the focus groups, there may be the added opportunity to interact with and learn from other experts and professionals in the fields planning and development of housing and related fields.

VIII. Records and Distribution

All data will be under the control of the PI. All interviews and focus groups will be recorded using an audiotape or digital voice recorder. The digital data will later be transcribed by the PI or a trained transcriptionist. The written and audio data will be stored in a locked office and locked file cabinet in the Institute on Aging; the transcribed data and other computer records (e.g., contact lists) will be stored on a passwordprotected computer file designated for use by the PI only; the computer will be password protected to further ensure confidentiality. The data will be kept on file for at least three years after completion of the research, at which point it will be destroyed.

Pseudonyms will be used in all publications and presentations.

IX. Additional appendices:

B.1 Key informant interview informed consent document

B.2 Key informant initial phone script

B.3 Key informant interview protocol

B.4 Human Subjects Research Review Committee extension to March 5, 2013 


\section{Appendix B.1: Key informant Interview: Informed Consent}

\section{A Case Study of Factors Influencing the Development of Sustainable, Affordable Housing for Older Adults in Portland, Oregon}

You are invited to participate in a research study conducted by Alan DeLaTorre, a doctoral candidate from Portland State University. The purpose of this research is to understand the factors that influence the planning and development of sustainable, affordable housing for older adults. You were selected as a possible participant in this study because you have knowledge and experience in housing, aging, and/or sustainable development.

If you decide to participate, you will be asked to participate in a face-to-face interview. The researcher will ask you questions on the topic of planning and/or development of housing projects, in particular projects that are considered sustainable and affordable for older adults. With your permission, the interview will be audio recorded. The entire process should take about an hour of your time and will be scheduled at your convenience.

While taking part in this study, it is possible that you will become upset or tired; if so, you may stop the interview to take a break, stop it entirely, or reschedule it to be completed at another time. You may not receive any direct benefit from taking part in this study, but the study may help to increase knowledge which may help others in the future.

Any information that is obtained from you in connection with this study will be kept confidential. That means that your name or the name of your business will not be used in any papers, presentations, or publications resulting from this study. An alpha-numeric code or pseudonym will be used where necessary. No information about you will be shared with your business associates, your family, or any other person or organization. All information will be kept confidential.

Your participation is voluntary. You do not have to take part in this study, and whether or not you participate will not affect your relationship with Portland State University. You may also withdraw from this study at any time without affecting your relationship with the university.

If you have concerns about your participation in this study or your rights as a research subject, please contact the Human Subjects Research Review Committee, Office of Research and Sponsored Projects, 600 Unitus Bldg., Portland State University, 503-725-4288 or toll-free at 1877-480-4400. If you have questions about the study itself, please contact Alan DeLaTorre at the Institute on Aging, Portland State University, Portland, OR, 97207, 503-725-5168, aland@pdx.edu.

Your signature indicates that you have read and understand the above information and agree to take part in this study. Please understand that you may withdraw your consent at any time without penalty, and that, by signing, you are not waiving any legal claims, rights or remedies. The researcher will provide you with a copy of this form for your own records. 


\section{Appendix B.2: Key-informant interview: Initial phone scripts}

\section{Phone script for those with knowledge of project:}

Hello ___ [insert name]. This is Alan DeLaTorre from Portland State University. I'm calling to let you know a little more about my dissertation research on sustainable and affordable housing for older adults and to try and schedule a time when we could meet up and conduct an interview. It should take approximately one hour and I would like to have it at a place and time that is most convenience for you.

When would be the best time to set up an appointment to talk with me? [Allow respondent time to answer]

Do you have any questions about the project or anything else? [Allow respondent time to answer]

I will send you a copy of the interview questions and a copy of the informed consent form for you review. Thank you and I look forward to speaking with you soon.

\section{Phone script for those identified in snowball sampling:}

"Hello [insert name], my name is Alan DeLaTorre and I recently received your name from a participant in a research study that I am conducting. I am a doctoral candidate at Portland State University in the Urban Studies program. My dissertation research focuses on factors that influence the planning and development of sustainable and affordable housing for older adults.

I am calling you because you have been identified as someone with unique knowledge and experience in the field of (choose appropriate category/categories: affordable housing, urban planning, housing development, sustainable development, or housing for older adults). I would like to ask you to allow me to interview you as your contributions may be important in completing my research. The interview should take approximately one hour and I would like to have it at a place and time that is most convenience for you.

Overall, the interview is intended for me to learn about your assessment of the state of sustainable development in Portland, as well as how certain professional roles contribute to housing developments for older adults.

Would you be willing to set up an appointment to talk with me?"

[If respondent answers "yes," read the statement marked (yes); if the respondent answers "no," skip to the statement marked (no)]

(Yes) I will send you a copy of the interview questions and a copy of the informed consent form for you review. Do you have any questions about the project or anything else? [Allow respondent time to answer] Thank you and I look forward to speaking with you soon.

(No) Thank you for your time. Goodbye. 


\section{Appendix B.3: Key-informant interview: Interview protocol}

\section{Opening comment:}

"Hello, as you know, I'm Alan DeLaTorre. I am a doctoral candidate at Portland State University in the Urban Studies program. I am conducting research regarding the factors that influence sustainable and affordable housing for older adults.

I would like to talk with you, in particular, because of your expertise in (choose appropriate category/categories: affordable housing, urban planning, housing development, sustainable development, or housing for older adults). The purpose of this interview is to discuss, in general, the following topics: first, your understanding of the meaning of sustainable housing for older adults; second, the key positions and roles of those who are involved in the planning and development of sustainable and affordable housing for older adults; and finally, how sustainable and affordable housing developments for older adults can be accomplished and improved upon in the future.

I have identified six housing development projects within the City of Portland that are unique and offer examples that can be learned from and possibly used to guide future developments. All of the projects meet the following criteria: first, housing that was developed specifically for older adults, in particular those aged 55 and older; second, housing developments that were considered sustainable, green, or had elements of ecological stewardship; and finally, housing which is considered affordable for its residents.

\section{[Review informed consent form.]}

Do you have any questions or need any clarification before we begin?" [Allow respondent time to ask questions]

Please sign the form. I will give you a copy for your records. [Hand participant an unsigned copy of the informed consent form]

\section{Beginning of interview:}

"I am going to begin recording the interview now, ok?"

\section{- Warm up: Sustainable housing and environments for older adults}

- [Read the following statement and then hand the participant a card with the description of sustainable development for older adults. ${ }^{52}$ ] "For the purpose

\footnotetext{
${ }^{52}$ From the City of Portland's Green Building Policy: "Sustainable development seeks to balance human development, growth, and equity with ecological stewardship." From the World Health Organization's Global Age-Friendly Cities: A Guide: "[Sustainable housing and environments for older adults] encourage active aging by optimizing opportunities for health, participation, and security in order to enhance quality of life as people age."
} 
of this interview, I am going to use the term 'sustainable' instead of 'livable' or 'age-friendly' when describing the quality of housing and the surrounding environments for older adults. This includes the housing itself but also the sidewalks, nearby services, parks, transportation options, etc. To begin this interview, I would like to get your thoughts on two descriptions of sustainable development, one from the City or Portland, and the other from the World Health Organization.

Here is a card with the two descriptions (hand card to participant). I will read both descriptions and then ask you two questions as a warm up to the interview.

According to the City of Portland's Green Building Policy, 'sustainable development seeks to balance human development, growth, and equity with ecological stewardship.'

According to the World Health Organization, '[sustainable housing and environments for older adults] encourage active aging by optimizing opportunities for health, participation, and security in order to enhance quality of life as people age."”

- I am interested in gaining an understanding of what these descriptions mean to you. Please take a moment to review the card. When you are ready, please share whatever thoughts you may have regarding these descriptions.

- In general, what would you consider to be some of the most important elements of sustainable housing and environments for older adults?

\section{- Topic: The state of sustainable and affordable housing for older adults in Portland}

- Please respond to the following statement: "sustainable development is a buzz word that will eventually be replaced by the next trend in planning and real estate development."

- Please respond to the following statement: "a development cannot be sustainable unless it addresses the issue of affordability."

- Please describe, in general, any current efforts that you feel are being made to create sustainable housing for older adults in Portland. Do you feel that Portland is making any specific efforts as compared to other cities?

- Do you feel that sustainable housing development for older adults is being "championed" by a particular individual, group, or entity in Portland, and if so, by whom? Why do you feel that is occurring? 
- Thinking broadly about the real estate development industry - such as developers, architects, contractors, and others - please describe, in general, changes in practice that are occurring in response to our aging society.

- In your opinion, what are the major differences in the ways in which the private, public, and non-profit sectors are contributing to the creation of sustainable housing and environments for older adults?

- How do you feel the current economic climate is affecting the development of sustainable and/or affordable housing for older adults?

- Please add any additional thoughts that you have regarding the state of sustainable and/or affordable housing for older adults in Portland.

\section{- Topic: Professional roles in the housing development process}

- In your opinion, what do you feel are the most important professional roles in the planning and development of sustainable and affordable housing for older adults and how do they contribute?

- Collaborative and participatory processes such as design charrettes, design review, integrated design, etc., are being used more commonly in building design and development. In your opinion, how do you feel these processes affect the development of housing for older adults?

- How are consultants and/or subcontractors important to the development of sustainable and/or affordable housing for older adults?

- What additional thoughts do you have regarding the various professional roles in the planning and development of housing for older adults?

\section{- Topic: Future development}

- In general, what do you see as the major barriers to creating housing developments for older adults that are sustainable and affordable?

- Are there any policies that are particular to Portland that limit or enable the amount and/or quality of sustainable and affordable housing for older adults? Could you please describe these?

- Looking forward over the next 20 years, what do you expect to occur with respect to the development of housing and environments for older adults?

- What additional thoughts do you have regarding the future development of sustainable and/or affordable housing for older adults? 


\title{
Appendix B.4: Human Subjects Research Review Committee Final Extension (to 3/5/2013)
}

\section{Portland State University HSRRC Memorandum}

\section{Date: February 24,2012}

\author{
To: $\quad$ Alan DeLaTorre \\ From: Mary Oschwald, Chair, HSRRC 2012 \\ Re: HSRRC renewal of approval for your project entitled, "A Case Study of Factors \\ Influencing the Development of Sustainable, Affordable Housing for Older Adults in Portland, \\ Oregon" (HSRRC Proposal \#09843)
}

As part of the Committee's continuing review, the Human Subjects Research Review Committee has reviewed your above referenced project for compliance with Department of Health and Human Services policies and regulations on the protection of human subjects.

The Committee is satisfied that your provisions for protecting the rights and welfare of all subjects participating in the research are adequate. Your project is renewed and this approval will expire on 3/5/13. Please note the following policies:

1. If the project continues beyond the expiration date, the investigator needs to submit a Continuing Review Report form (available in the Office of Research \& Strategic Partnerships) two months before the expiration date.

2. To add this project's continuing review to the HSRRC/IRB meeting agenda, please refer to the HSRRC/Institutional Review Board (IRB) meeting schedule. Submit the report, and the required number of copies, by the submission deadline that is approximately two months before the project's expiration date. The HSRRC/IRB needs two months to do a continuing review of the project, so it is extremely important that you meet the committee's submission deadline.

3. If this project finishes before the expiration date, please contact the HSRRC administrator so that the file can be closed and records updated. It is the investigator's responsibility to keep the approval status current. If the project's approval expires while the project is active, the investigator must complete new application and submit it for a new HSRRC review. In addition, any data collected after the expiration date cannot be used in the research. Please don't let this happen!

If you have questions or concerns, please contact the HSRRC in Research and Strategic Partnerships (RSP), (503) 725-4288. 